\title{
Atmospheric Fluidized Bed Combustion Advanced Concept System
}

Final Report

Work Performed Under Contract No.: DE-AC21-87MC24216

\author{
For \\ U.S. Department of Energy \\ Office of Fossil Energy \\ Morgantown Energy Technology Center \\ P.O. Box 880 \\ Morgantown, West Virginia 26507-0880
}

By

DONLEE Technologies Inc.

693 North Hills Road

York, Pennsylvania 17402

May 1992 


\section{EXECUTIVE SUMMARY}

DONLEE Technologies Inc. is developing with support of the U.S. Department of Energy an advanced circulating fluidized bed technology known as the Vortex ${ }^{\mathrm{TM}}$ Fluidized Bed Combustor (VFBC). The unique feature of the VFBC is the injection of a significant portion of the combustion air into the cyclone. Since as much as one-half of the total combustion air is injected into the cyclone, the cross-sectional area of the circulating fluidized bed is considerably smaller than typical circulating fluidized beds.

The technology is being developed for two applications:

- Industrial-scale boilers ranging from 20,000 to 100,000 pounds per hour steam generating capacity; and

- Two-stage combustion in which a substoichiometric Vortex Fluidized Bed Combustor (2VFBC) or precombustor is used to generate a ccmbustible gas for use primarily in boiler retrofit applications.

This Level $I I$ analysis of these two applications indicate that both have merit. An industrial-scale VFBC boiler $(60,000 \mathrm{lb} / \mathrm{hr}$ of steam) is projected to be economically attractive with coal prices as high as $\$ 40$ per ton and gas prices between $\$ 4$ and $\$ 5$ per thousand cubic feet. The payback time is between 3 and 4 years. The 2VFBC system was evaluated at three capacities of application: 20,$000 ; 60,000$ and $1.00,000 \mathrm{lb} / \mathrm{hr}$ of steam. The payback times for these three capacities are 4.5, 2.1 and 1.55 years, respectively.

The 2VFBC has potential applications for retrofit of existing pulverized coal-fired boilers or as a new large (utility) boiler. Pressurized operation of the 2VFBC has considerable potential for combined cycle power generation applications.

Experimental development of both applications is presented here to demonstrate the potential of these two technologies. 


\section{ACKNOWLEDGEMENT}

The work on this project was supported by the U. S. Department of Energy, Morgantown Energy Technology Center (DOE/METC) under Contract Number DE-AC21-87MC24216.

The authors wish to thank Peter Botros of DOE/METC for his support and encouragement, and for help in the writing of this report. Technical staff members of DOE/METC are gratefully acknowledged for their suggestions and comments during this project. 


\section{TABLE OF CONTENTS}

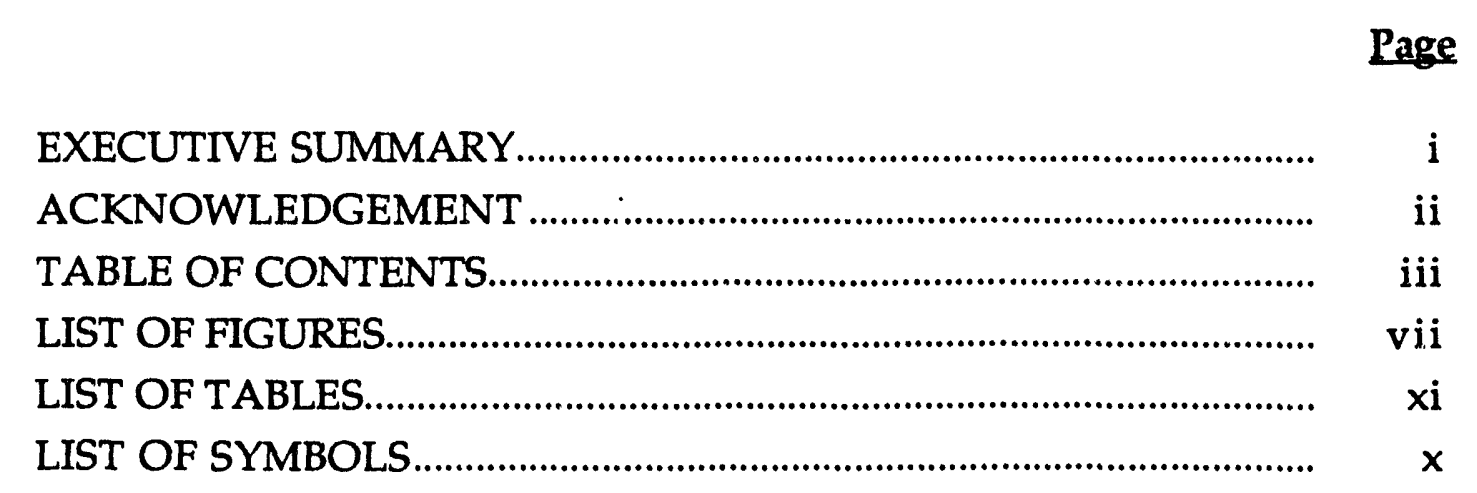

\section{SECTION 1}

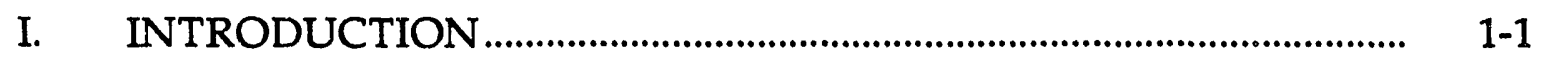
A. LEVEL I
$1-1$
B. LEVEL II
1-1
C. LEVEL III

II. TECHNICAL BACKGROUND.

A. THE VORTEXTM FLUIDIZED BED CONCEPT ............................ 1-. 1-5

B. CONCEPT EVALUATION ....................................................... 1-8

III. FACILITY DESIGN AND CONSTRUCTION .......................................... 1-9

A. FREEBOARD ...................................................................... 1-12

B. MAIN BED .................................................................... $1-12$

C. COOIING BED .................................................................... 1-13

D. LIFT CHANNEL ........................................................................ 1-13

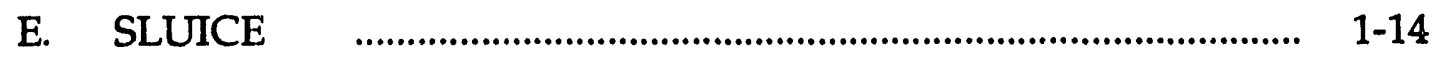

F. CYCLONE ……............................................................... $1-15$

G. MATERIALS OF CONSTRUCTION ………............................. 1-17

H. BALANCE OF FACILITY ...................................................... 1-17

I. FANS ……................................................................ 1-17

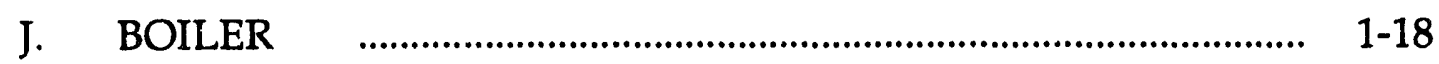

K. BAGHOUSE ................................................................... $1-18$

L. EQUIPMENT CHANGES FROM 1990 TESTING ........................ 1-18 
IV. VFBC LAB-SCALE TESTING..................................................... 1-20

A. TEST PLAN/OBJECTIVES....................................................... 1-23

B. ADIABATIC TESTS …...................................................... 1-24

1. 1989 Adiabatic Tests.............................................................. 1-24

2. 1991 Adiabatic Tests................................................................ 1-26

C. 1990 SHORT TERM TESTS........................................................ 1-28

1. Objectives and Procedures ..................................................... 1-28

2. Results ............................................................................... 1-29

3. Nozzle Location and Velocity ................................................. 1-29

4. Coal Size Distribution............................................................... 1-31

D. 1990 LONG TERM TESTS......................................................... 1-32

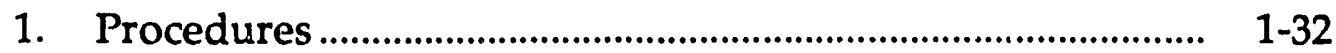

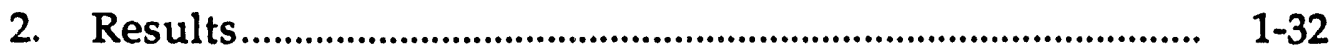

E. 1990 CONCLUSIONS/DISCUSSIONS ....................................... 1-33

F. 1991 SHORT TERM TESTS................................................... 1-34

1. Procedures and Objectives .................................................. 1-34

2. Results................................................................................ 1-34

G. 1991 LONG TERM TESTS........................................................... 1-35

1. Procedures .......................................................................... $1-35$

2. Results ............................................................................. 1-36

3. Coal and Limestone Chemical/Physical Properties ............ 1-37

4. VFBC Testing........................................................................... 1-38

H. DISCUSSION/CONCLUSIONS................................................. $1-41$

\section{SECTION 2}

ACKNOWLEDGEMENT …...................................................... i

TABLE OF CONTENTS...................................................................... ii

LIST OF FIGURES.

LIST OF TABLES............................................................................. vi

LIST OF SYMBOLS................................................................................ vii

I. INTRODUCTION ..................................................................

A. LEVEL I _.......................................................................

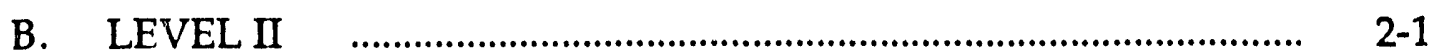

C. LEVEL III ............................................................................. 2-2 
II. TECHNICAL BACKGROUND …….................................................... 2-3

A. THE VFBC CONCEPT.............................................................. 2-3

B. THE 2VFBC CONCEPT ...............................................................

III. FACILITY DESIGN AND CONSTRUCTION ……................................ 2-7

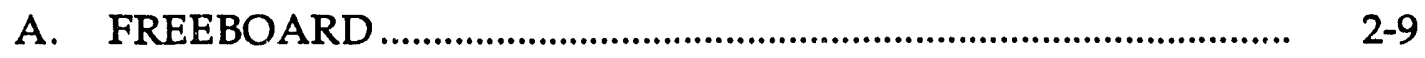

B. MAIN BED ............................................................................... $2-9$

C. SLUICE ……................................................................ 2-9

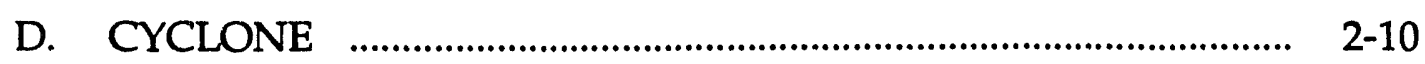

E. MATERIALS OF CONSTRUCTION ………................................... 2-11

F. BALANCE OF FACILITY ......................................................... 2-11

G. FANS _............................................................... $2-12$

H. CWF FEED SYSTEM ………..................................................... 2-12

I. BOILER …................................................................ 2

J. BAGHOUSE ............................................................................... 2-13

K. INSTRUMENTATION ............................................................. 2-14

IV. 2VFBC LAB-SCALE TESTING................................................... 2-15

A. TEST PLAN/OBJECTIVES...................................................... 2-15

B. NON-VORTEX TESTS.......................................................... 2-17

Objectives and Procedures ..................................................... 2-17

C. VORTEX TESTS............................................................................. 2-18

Objectives and Procedures ......................................................... 2-18

D. RESULTS ........................................................................... 2-18

Calcium-to-Sulfur Molar Ratio and Sulfur Capture........... 2-20

Coal and Limestone Feedstocks................................................. 2-23

2VFBC Residence Time........................................................... 2-27

Freeboard Velocity ................................................................... 2-28

Nozzle Location, Air Rate and Nozzle Velocity.................. 2-2-30

Optimum Temperature Level for Sulfur Capture and Carbon Conversion ............................................................. 2-31

Vortex-to-Primary Air Ratio...................................................... 2-33

Cyclone Inlet and Exit Velocities............................................. 2-34

Stoichiometric Air Ratio.......................................................... 2-34

Higher Heating Value of the Flue Gas................................... 2-37

Chemical Equilibria Analysis.................................................. 2-39

Ash Composition......................................................................... 2-43

E. CONCLUSIONS AND DISCUSSIONS ……................................. 2-45 
V. FULL SCALE DESIGN AND ECONOMIC ANALYSIS ........................ 2-46

A. DESIGN PARAMETERS........................................................... 2-4

Retrofit Boiler .................................................................... 2-46

Coal Analysis (CWF) ......................................................... 2-46

Limestone Analysis................................................................. 2-46

Vortex Gasifier Conditions....................................................... 2-46

B. SPECIFIC MASS BALANCE................................................... 2-47

C. BOILER EFFICIENCY ................................................................. 2-48

D. MASS AND HEAT BALANCES.............................................. 2, 2-48

System Mass Balance.................................................................. 2-48

Vortex Gasifier Mass Balance................................................... 2-49

Vortex Gasifier Heat Balance.................................................... 2-... 2-49

E. EQUIPMENT ARRANGEMENT ............................................. 2-50

F. PROJECT CAPITAL COSTS....................................................... 2-53

G. PROJECT OPERATING COSTS ……............................................ 2-54

H. ECONOMIC ANALYSIS AND "PAYBACK" ................................ 2-55

I. DISCUSSION AND CONCLUSIONS.......................................... 2-56

APPENDIX A: Vortex ${ }^{\mathrm{TM}}$ (VFBC) Pilot Plant Facility Drawings

APPENDIX B: $\quad$ VFBC Testing Trends

APPENDIX C: Economic Evaluation of the Vortex ${ }^{\mathrm{TM}}$ (VFBC)

Proof-of-Concept Facility

APPENDIX D: Penn State 2VFBC Gasifier - Nen-Vortex Raw Operating Data

APPENDIX E: Penn State 2VFBC Gasifier - Vortex Raw Operating Data

APPENDIX F: $\quad$ 2VFBC Gas Chromatography Data from Outside Laboratory

APPENDIX G: $\quad$ 2VFBC Gas Chromatography Analyses and Analysis of Accuracies

APPENDIX H: $\quad$ 2VFBC Solid Analyses of Sluice Drain and Baghouse Drain 


\section{LIST OF FIGURES}

Page

Figure 1.1. Sectional View of the Vortex ${ }^{\mathrm{TM}}$ Fluidized

Bed Combustor (VFBC) .................................................................. 1-5

Figure 1.2. $\quad 60,000 \mathrm{Lb} / \mathrm{hr}$ of Steam VFBC Design Material Balance.............. 1-11

Figure 1.3. Cyclone Separator Proportions ........................................................ 1-15

Figure 1.4. Long Term Tests (Based on Gas Data) .......................................... 1-21

Figure 1.5. Vortex Air Nozzle Location ....................................................... 1-30

Figure 2.1. Vortex ${ }^{\mathrm{TM}}$ Fluidized Bed Combustor (VFBC)

Sectional Views.................................................................................. $2-4$

Figure 2.2. Vortex ${ }^{\mathrm{TM}}$ Fluidized Bed Combustor (VFBC) Isometric View.. $\quad$ 2-4

Figure 2.3. Two Stage Coal Fired Adiabatic Vertical VFB Combustor....... 2-5

Figure 2.4. 2VFBC Experimental Facility ………............................................. 2-8

Figure 2.5. Cyclone Separator Proportions ........................................................ 2-10

Figure 2.6a. Schematic of the CWF Feed System ............................................ 2-12

Figure 2.6b. Plan Section - PSU Research Boiler .............................................. 2-13

Figure 2.7. Gas Analysis System at PSU .......................................................... 2-14

Figure 2.8. Sulfur Capture Versus Temperature $\left({ }^{\circ} \mathrm{F}\right)$ - First Order............. 2-22

Figure 2.9. Sulfur Capture Versus Temperature $\left({ }^{\circ} \mathrm{F}\right)$ - Second Order........ 2-22

Figure 2.10. Residence Time Versus Carbon Conversion................................ 2-27

Figure 2.11. Residence Time Versus Sulfur Capture ........................................ 2-28

Figure 2.12a. Sulfur Capture Versus Freeboard Velocity ................................... 2-29

Figure 2.12b. Carbon Conversion Versus Freeboard Velocity.......................... 2-29

Figure 2.13. Sulfur Capture and Carbon Conversion

Versus Nozzle Velocity................................................................. 2-2-30

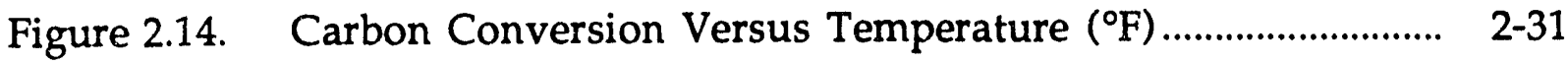

Figure 2.15. Sulfur Capture Versus Carbon Conversion.................................. 2-32 
Figure 2.16. Sulfuir Capture and Carbon Conversion Versus Vortex-to-Primary Air Ratio............................................. 2-33

Figure 2.17. Stoichiometry Versus Temperature - All Data .......................... 2-34

Figure 2.18. Stoichiometry Versus Carbon Conversion................................... 2-35

Figure 2.19a. Stoichiometry Versus Sulfur Capture - All Data........................ 2-36

Figure 2.19b. Stoichiometry Versus Sulfur Capture Constant Ca-to-S for Non-Vortex Data ........................................ 2-36

Figure 2.19c. Stoichiometry Versus Sulfur Capture Constant Ca-to-S for Vortex Data .................................................. 2-37

Figure 2.20. HHV Versus Stoichiometry .......................................................... 2-37

Figure 2.21. HHV (Dry) Versus Carbon Conversion........................................ 2-38

Figure 2.22. CO Versus Time - Vortex Versus Non-Vortex........................... 2-42

Figure 2.23. Equipment Arrangement - End View.......................................... 2-50

Figure 2.24. Equipment Arrangement - Side View .......................................... 2-51

Figure 2.25. Equipment Arrangement - Plan View.......................................... 2-52

Figure 2.26. Economic Analysis for Retrofit Steam Outputs.......................... 2-55

Figure 2.27. Payback Time ............................................................................. 2-56 


\section{LIST OF TABLES}

Page

Table 1.1. Vortex Testing Schedule....................................................................... 1-20

Table 1.2. Effect of Vortex Nozzle Location and Air Velocity........................... 1-30

Table 1.3. Coal Sizes and Composition for 1990 Preliminary and Long Term Testing....................................................................... 1-31

Table 1.4. Limestone Composition for 1990 Preliminary and Long Term Testing......................................................................... 1-31

Table 1.5. VFBC Operating Conditions ................................................................. 1-39

Table 1.6. Combustion Efficiency and Sulfur Capture Based on Gas Analysis Versus Ash Analysis...................................................... 1-40

Table 2.1. Penn State 2VFBC - Planned Test Matrix ............................................ 2-17

Table 2.2a. 2VFBC Precombustor Operating Conditions..................................... 2-19

Table 2.2b. 2VFBC Precombustor Operating Conditions..................................... 2-19

Table 2.3. Input Gas Chromatography Data for the 2VFBC Precombustor HMB $(1,2,3)$............................................... 2-20

Table 2.4. 2VFBC Precombustor Test Results....................................................... 2-21

Table 2.5. Bradford No. 44 Coal Chemical Analyses Non-Vortex Test Coal...................................................................... 2-24

Table 2.6. Bradford No. 44 Coal Chemical Analyses Vortex Test Coal........................................................................... 2-24

Table 2.7. Meckley Limestone Chemical Analyses ............................................ 2-25

Table 2.8. Initial Bradford No. 44 Coal Chemical Analyses............................. 2-26

Table 2.9. Initial Meckley Limestone Chemical Analyses................................. 2-26

Table 2.10. Cyclone Outlet Fuel Gas Composition............................................... 2-41

Table 2.11. Gasification and Water Shift Reactions' Equilibrium Constants............................................................................ 2-41

Table 2.12a. Analyses of Sluice Drain Ash........................................................ 2-43

Table 2.12b. Analyses of Baghouse Ash Drain................................................. 2-43 


\section{LIST OF SYMBOLS}

\section{ABBREVIATIONS}

ACFM

CFB

CFBC

CWF

FD

GC

$\mathrm{HHV}$

ID

IWC

IWG

$\mathrm{MM}$

$\mathrm{MM} \mathrm{BTU/hr}$

MW

$P$

PC

PPH

PSIG

RA85H

RA330

SCFM

316SS

$\mathrm{T}$

VFBC

2VFBC
Actual Cubic Feet per Minute

(at actual test conditions of temperature and pressure)

Circulating Fluid Bed

Circulating Fluid Bed Combustor

Coal Water Fuel

Forced Draft (fan)

Gas Chromatograph or gas chromatography

Higher Heating Value, BTU/lb for solids or BTU/SCF for gases

Induced Draft (fan)

Inches of Water Column (Pressure). Equivalent to IWG.

Inches of Water Gauge (Pressure). Equivalent to IWC.

Million

Million BTU's per Hour

Megawatt (Electrical)

Pressure

Pulverized Coal

Pounds per Hour or $\mathrm{Lb} / \mathrm{Hr}$

Pound per Square Inch Gauge (Units of Pressure)

Rolled Alloys 85H (Stainless Steel)

Rolled Alloys 330 (Stainless Steel)

Standard Cubic Feet per Minute

316 Stainless Steel

Temperature $\left({ }^{\circ} \mathrm{C}\right.$ or $\left.{ }^{\circ} \mathrm{F}\right)$

Vortex ${ }^{\mathrm{TM}}$ Fluid Bed Combustor

Two-Stage Vortex ${ }^{\mathrm{TM}}$ Fluid Bed Combustor or Precombustor 


\section{SECTION 1}

\begin{tabular}{|c|}
\hline DEVELOPMENT OF THE \\
VORTEX \\
COMB FLUIDIZED BED \\
COMTOR (VFBC) \\
\hline
\end{tabular}




\section{SECTION 1}

\section{INTRODUCTION}

In October 1987, the U.S. Department of Energy awarded DONLEE Technologies Inc. a contract to continue development of an advanced fluidized bed combustor known as the Vortex ${ }^{\mathrm{TM}}$ Fluidized Bed Combustor (VFBC). This contract was subsequently modified to include evaluation of a two-stage Vortex ${ }^{\mathrm{TM}}$ Fluidized Bed Combustor (2VFBC).

The VFBC development program includes three levels as described below:

A. LEVEL I - featured investigations to establish the feasibility of the advanced VFBC package boiler concept. The major results of this work level (1) verified and updated the VFBC design concept and (2) established that the concept can be reasonably priced.

B. LEVEL II - is characterized by laboratory-scale experimentation with an integrated "hot" VFBC system to establish the operational and performance boundaries of the total system and identify any remaining issues to be resolved prior to building the proof-of-concept facility. The four technical tasks that were performed during this level were:

1. Laboratory-scale VFBC design,

2. Laboratory-scale VFBC system construction,

3. Laboratory-scale VFBC system testing, and

4. Technical and economic evaluation.

C LEVEL III - features the design, construction, installation, and operation of a full-scale proof-of-concept VFBC system. The operability, reliability, and cost of the VFBC system will be established and compared to conventional technologies. The successful completion of this Level III effort should provide the commercial/institutional/industrial market with a technically, environmentally, and economically acceptable coal-fired VFBC system. 
Section I of this report summarizes the Level II activities associated with the VFBC concept; Level II activities associated with the 2VFBC are summarized in Section II of this report.

This report is organized according to the four technical tasks described above for the Level II effort. An introductory description of the VFBC concept along with a brief summary of its performance projected in the Level I effort is presented to acquaint the reader with the concept and to permit this report to be used independently. 


\section{TECHNICAL BACKGROUND}

Circulating Fluidized Bed Combustion has become popular as an effective technology for medium to large scale coal-fired boilers due to its ability to handle a wide range of fuel and its ability to control sulfur emissions. Small scale industrial boiler applications have not been adequately addressed by the technology due to, in part, the relatively high capital cost of the tall water-wall boilers used in most current CFBC designs. Donlee Technologies is developing a new type of circulating fluidized-bed system that will address small to medium sized industrial applications with steam generation capacities ranging from 10,000 to 50,000 kilograms of steam per hour and higher capacities as well.

This advanced circulating fluidized bed is known as the Vortex ${ }^{\mathrm{TM}}$ Fluidized Bed. Its unique feature is the injection of a significant portion of the combustion air into the cyclone; as much as $\mathbf{5 0}$ percent of the combustion air is injected as secondary air into the cyclone. The cross-sectional area of the Vortex ${ }^{\mathrm{TM}}$ Circulating Fluidized Bed is therefore $50 \%$ of the size of a conventional CFB for the same freeboard velocity. However, the Vortex ${ }^{\mathrm{TM}}$ combustor operates at a freeboard velocity about twice that of a conventional CFB, the velocities being 38 to $40 \mathrm{ft} / \mathrm{sec}$ versus $15-20 \mathrm{ft} / \mathrm{sec}$, respectively. Thus, the cross-sectional area of the Vortex ${ }^{\mathrm{TM}}$ freeboard is about $25 \%$ or less than that of a conventional CFB due to the much higher freeboard velocities of the Vortex ${ }^{\mathrm{TM}}$ combustor. The required combustor/boiler height is minimized because the cyclone combustor requires ' $s$ ss residence time and no waterwall tubes are used: heat is extracted in an adjacent bubbling cooling bed.

Conventional circulating fluidized bed combustors typically employ heat transfer surface installed on the wall of the freeboard. Although combustor cross-sectional area is relatively small for a circulating fluidized bed (relative to a bubbling fluidized becl combustor), the vessel must be very tall in order to accommodate sufficient heat transfer surface. It is well known that heat transfer coefficients to surfaces in the freeboard of a circulating fluidized bed are considerably lower than those exhibited in bubbling fluidized beds. In addition, all the surface of heat transfer tubes immersed in bubbling beds are active; only half of the surface area of waterwall tubes in the freeboard of a circulating fluidized bed are effective. Combining this effect with the differences in heat transfer coefficients, heat transfer surfaces immersed in a bubbling bed can be up to five times more effective than those installed in the freeboard of a circulating fluidized bed. 
The use of an adjacent cooling bed for heat extraction results in a substantial reduction in heat transfer surface required and permits a sizable reduction in combustor height, resulting in a reduction in front-end costs. Tube surface erosion is essentially eliminated because the surfaces are immersed in a low-velocity, fine particle bubbling bed. Furthermore, tube surface corrosion is minimized because the environment in the cooling bed is oxidizing or mildly reducing. Boiler tube failure will be much less common; system reliability will increase and maintenance costs will decrease. Combustor performance is also enhanced by using an adjacent cooling bed because conditions for combustion and heat extraction can be controlled separately; start-up and load following should be improved in the Vortex ${ }^{\mathrm{TM}}$ Fluidized Bed due to the use of an adjacent cooling bed.

Since the use of an adjacent cooling bed permits a reduction in combustor height, residence time within the combustor is reduced. In order to maintain adequate combustion efficiency, combustion intensity must be increased. This is accomplished in the Vortex ${ }^{\mathrm{TM}}$ Fluidized Bed by using the cyclone as a combustor as well as a particle capture device. Sufficient air to complete combustion is injected tangentially into the barrel of the cyclone. The turbulence and high particle-gas slip velocity within the cyclone combustor (vortex) result in very high mass transfer rates and therefore combustion intensity. The high heat capacity of solids circulating between the fluidized bed and the vortex moderates the temperature differential between these two components. The temperature differential depends upon the rate of solids circulation and the heat released within the vortex. As much as $50 \%$ of the total combustor heat release can occur within the vortex whise maintaining a temperature differential of only $55^{\circ} \mathrm{C}\left(100^{\circ} \mathrm{F}\right)$ with a solids suspension density of 80 kilograms per cubic meter ( 5 lbs per cubic foot) in the freeboard of the circulating fluidized bed. 


\section{A. THE VORTEXTM FLUIDIZED BED CONCEPT}

A schematic of the Vortex ${ }^{\mathrm{TM}}$ Fluidized Bed Combustor is shown in Figure 1.1. The easiest way to understand its operation is first to consider the circulating fluidized bed portion only (no air injected into the vortex). This mode of operation is used at reduced load condition, about $50 \%$ or less of capacity.

Coal and limestone are fed into the circulating fluidized bed and air enters the bed through an air distributor. Combustion and sulfur capture reactions occur in the relatively dense portion of the circulating fluidized bed (the bottom) and in the freeboard. A portion of the primary air is injected into the freeboard by first passing through the adjacent cooling bed. Solids are entrained through the freeboard, captured $i_{11}$ the cyclone, and returned to the circulating fluidized bed. The high relative mass of solids circulating in this way tends to minimize temperature differences between the bottom, freeboard, and cyclone.

At this part load condition, the VFBC differs from most circulating fluidized bed combustors only in the manner in which heat is extracted. Hot

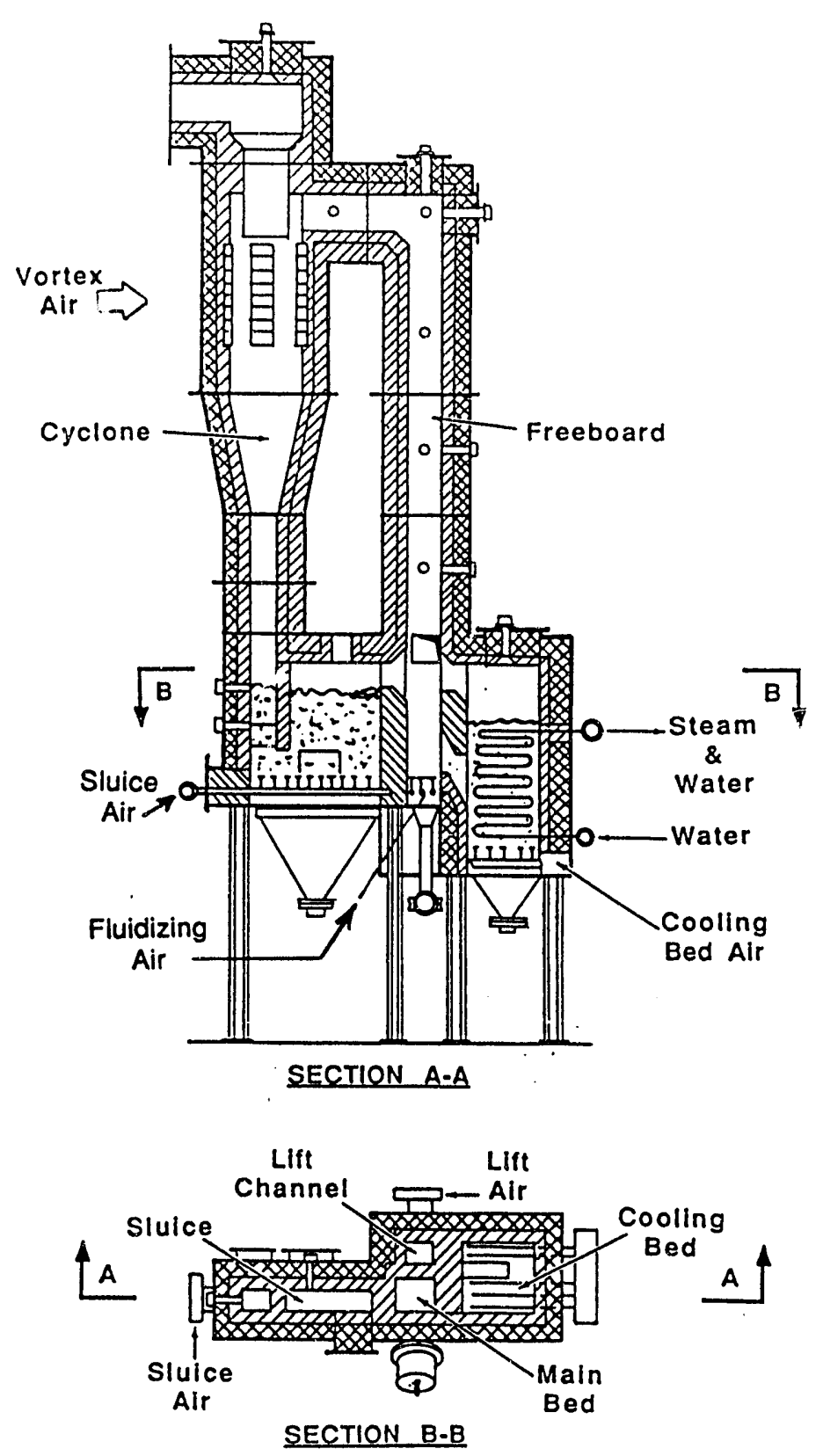

Figure 1.1. Sectional Views of the Vortex ${ }^{\mathrm{TM}}$ Fluidized Bed Combustor (VFBC) 
solids from the main bed (the bottom of the circulating bed) enter the adjacent cooling bed. Heat is transferred to a fluid through tubes immersed in the cooling bed and the temperature of the solids drops. The cooled solids are then returned to the circulating bed where they are reheated. The rate of heat extraction and, therefore, the combustion temperature are controlled by the rate of solids circulating between the main bed and cooling bed.

The solids circulate between the main bed and cooling bed in the following manner (See Figure 1.1, Cross Section A-A):

1. Solids pass from the main bed into the cooling bed through an opening in the wall separating the two beds. The relative fluid head of the main bed and cooling bed is the driving force for moving solids through the opening.

2. The solids leave the cooling bed by passing through an opening in the wall separating the cooling bed and the reinjection channel. The relative fluid head between the cooling bed and the reinjection channel is the driving force for moving solids through this opening.

3. Once in the reinjection channel, the solids are lifted in a gas stream and returned to the circulating fluidized bed. The point of reinjection of solids is at the base of the freeboard. The rate of solids circulation through the reinjection channel, and therefore through the cooling bed, is controlled by the air velocity in the reinjection channel.

At part load operation, the amount of solids recirculating between the main bed and cooling bed is relatively low because the amount of heat that needs to be extracted to maintain combustor temperature to the desired value is relatively low. However, the rate of solids circulating through the main bed, freeboard, and vortex does not change appreciably with load changes. This circulation rate is a function of freeboard gas velocity for a given particle size, and the freeboard gas velocity at low load is essentially the same as that for full load operation.

As load increases above the nominal 50 percent of capacity operation, coal and limestone feed rates are increased and secondary air injection into the vortex is initiated. At operating conditions above 50 percent of capacity, the total amount of 
air admitted to the circulating fluidized bed is less than that required for combustion. Sufficient air to complete combustion is injected into the cyclone.

Several changes occur within the system with increasing load. More of the heat is released in the cyclone, up to a maximum of about 50 percent of the total at full load. As a result, the temperature difference between the main bed and the cyclone will increase; however, this difference is maintained to within about $55^{\circ} \mathrm{C}$ by the high rate of circulating solids as previously described. Likewise, to maintain the combustion system temperature, the solids circulation rate between the main bed and the cooling bed will be increased which will, in turn, increase the amount of heat extracted in the cooling bed.

The primary advantage of the VFBC compared with circulating fluidized beds is reduced cost due to reduction in combustor size. The circulating fluidized bed and cyclone cross-sectional areas in the VFBC are approximately 25 and 50\%, respectively, of the cross-sectional areas of a typical circulating fluidized bed system of the same capacity due to the higher Vortex ${ }^{\mathrm{TM}}$ freeboard velocity. Furthermore, elimination of freeboard heat transfer surface results in a dramatic reduction in combustor height; the VFBC combustor height can be as small as one-fourth the height of a typical circulating fluidized bed of similar capacity. These dramatic reductions in combustor size result in lower capital costs for the whole installation and should permit shop fabrication for the small capacity systems (steam generating capacity of 30,000 kilograms per hour and less). This should make the system even more attractive for small industrial applications, but it does not preclude the possibility of system scale-up to larger, field-erected installations. In fact, the boiler size has no practical limitations. Thus, units as large as 2 , or 200 , megawatts electrical are possible.

The use of an adjacent cooling bed for heat extraction has two primary benefits. First, tube surface erosion/corrosion is essentially eliminated because the surfaces are immersed in a low-velocity, fine particle bubbling bed in an oxidizing or mild reducing environment. Boiler tube failures will be much less common; system reliability will increase and maintenance cost will decrease. The second favorable impact of using an adjacent cooling bed is the fact that turndown capabilities are improved by separating combustion and heat extraction. Start-up and load following should be improved in the VFBC. 


\section{B. CONCEPT EVALUATION}

Commercial, institutional and industrial boilers with steam generating capacities of about $20,000 \mathrm{lb} / \mathrm{hr}$ to about $100,000 \mathrm{lb} / \mathrm{hr}$ are believed to be excellent candidates for applying the VFBC concept. The prototype was sized at $60,000 \mathrm{lb} / \mathrm{hr}$ of saturated 200 psig steam generating capacity due to the capacity at a potential site.

Performance criteria, for which the prototype was designed, included maintaining emissions to within regulated limits, providing automated solids handling systems capable of dust free operation, and providing a turndown capability of at least 4:1. 


\section{FACILITY DESIGN AṆD CONSTRUCTION}

The laboratory VFBC unit was designed and constructed to experimentally determine performance of the concept at sufficient scale to provide meaningful data. It was felt that the minimum size for a circulating fluidized bed to provide such data would have a diameter of one foot. Therefore, the size of the lab unit was based on providing a freeboard cross-sectional area equivalent to a one-foot diameter circulating fluidized bed.

Once the size of the freeboard was established, the balance of the lab unit could be readily specified following general guidelines consistent with the anticipated performance described earlier in this report. The primary operating parameters were:

$\begin{array}{ll}\text { Freeboard Velocity } & 33 \mathrm{ft} / \mathrm{sec} \\ \text { Freeboard Temperature } & 1500^{\circ} \mathrm{F} \\ \text { Cyclone/Freeboard Air Flow } & 3: 1 \\ \text { Cyclone Inlet Velocity } & 70 \mathrm{ft} / \mathrm{sec} \\ \text { Cyclone Outlet Temperature } & 1600^{\circ} \mathrm{F} \\ \text { Percent Excess Air } & 20 \\ \text { Cooling Bed Temperature } & 1450^{\circ} \mathrm{F} \\ \text { Coal Heat Input } & 6.5 \mathrm{MMBTU} / \mathrm{hr}\end{array}$

The composition of the design coal used was:

Component

Carbon

Hydrogen

Sulfur

Oxygen

Nitrogen

Moisture

Ash

\section{Weight Percent}

63.23

4.7

2.7

8.43

1.24

9.7

10.0 
The limestone design composition used was:

Component
Calcium Carbonate
Magnesium Carbonate
Silica
Inerts
Moisture

\begin{tabular}{c} 
Weight Percent \\
\hline 94.1 \\
3.3 \\
0.6 \\
1.8 \\
0.2
\end{tabular}

The overall design material balance for a $60,000 \mathrm{lb} / \mathrm{hr}$ of steam VFBC unit is depicted in Figure 1.2.

Several alternate designs of the lab unit were developed and evaluated for feasibility of construction and flexibility of operation. The major dimensions and design considerations for the combustor, on a section-by-section basis, are presented below. Complete drawings of the facility are included in Appendix A of this report. 


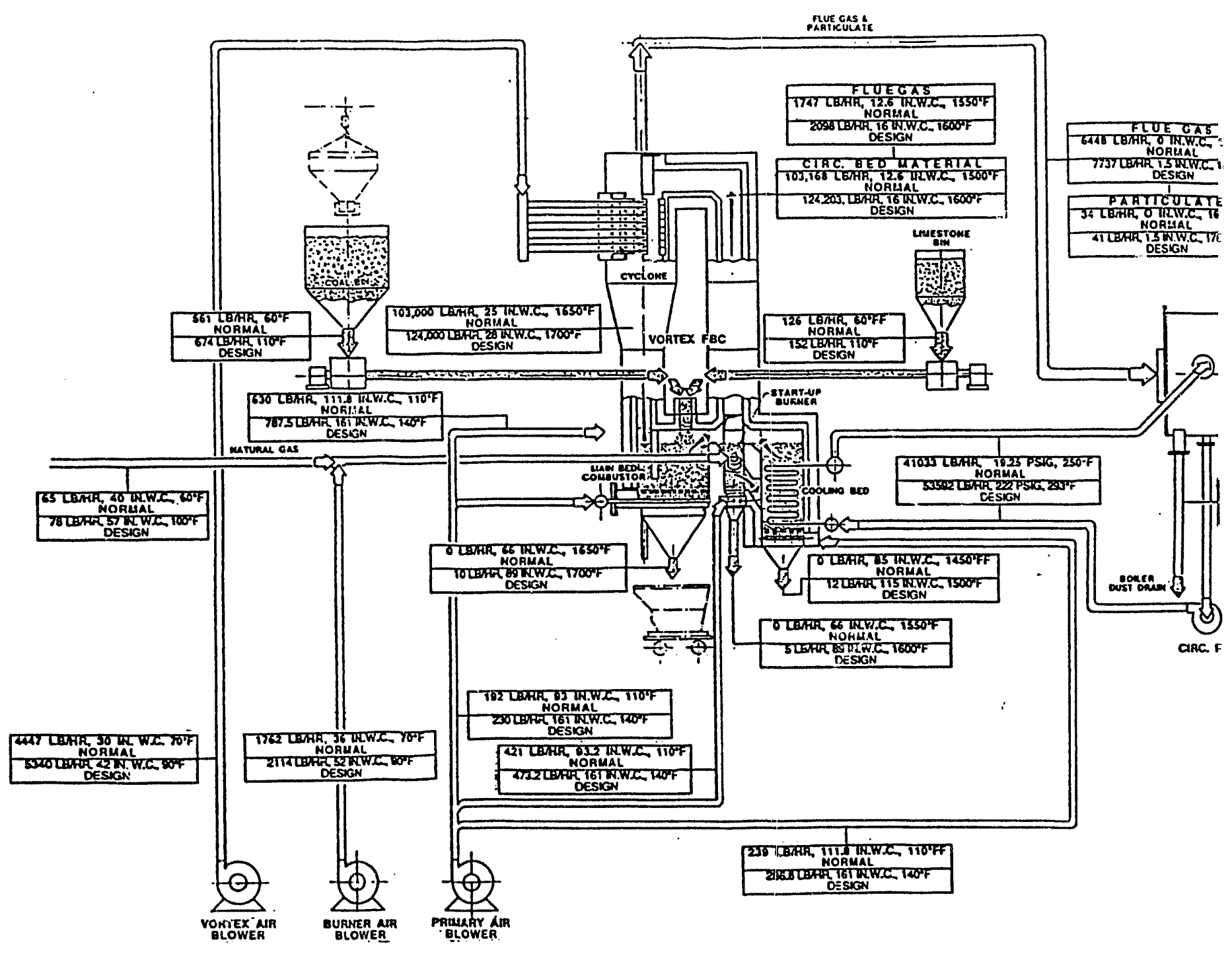



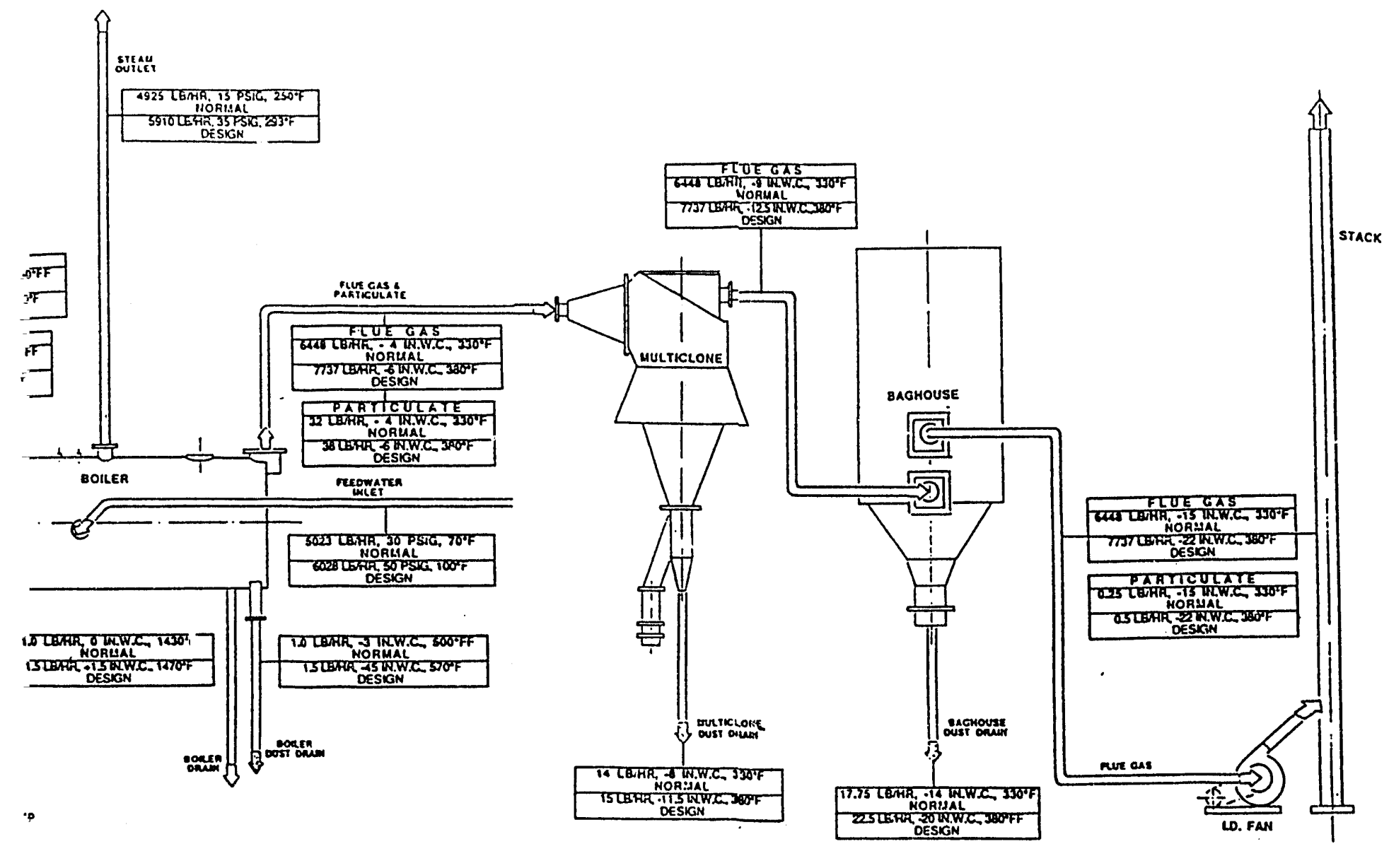

VORTEX FBC PROJECT
FLOW DIAGRAM

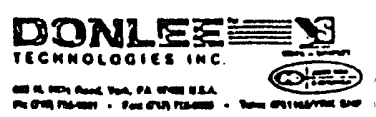

Figure 1.2. $6 \mathrm{l}, 000 \mathrm{lb} / \mathrm{hr}$ of Steam VFBC Design Material Balance 


\section{A. FREEBOARD}

As previously described, the cross-sectional area of this section was selected to be equivalent to a one-foot diameter circulating fluidized bed. In order to facilitate transfer of solids between the various sections that comprise the bottom of the unit, i.e., the main bed, cooling bed, lift channel, and sluice, a rectangular freeboard was used. In order to provide the desired cross-sectional area, the inside dimensions of the freeboard are 10-5/8 inches by 10-5/8 inches. The height of the freeboard, 141 inches, was determined by the height of the cyclone and solids return line.

\section{B. MAIN BED}

The main bed is located directly under the freeboard, in fact, it could be considered to be the lower portion of the freeboard. The main bed height, measured from the bottom steel shell to the top steel shell, is $\mathbf{5 2}$ inches. The fluidized bed height was expected to be 36 inches.

At least one opening in each of the four walls of the main bed was provided for solids transfer and to accommodate the start-up burner. Originally, an 8 inch high by 7 inch wide hole in the wall separating the sluice from the main bed was located at the top of the main fluidized bed. After operating the unit, the 36 inch high wall separating the sluice from the main bed was removed to facilitate solids flow into the main bed from the sluice. The wall directly opposite the sluice connected the main bed with the cooling bed. Two openings were provided in this wall. An 8 inch high by 10-5/8 inch wide opening was provided directly opposite the opening from the sluice to permit the air used to fluidize the cooling bed to enter the main bed/freeboard. Near the bottom of the main bed, a 7 irich by 6 inch opening was provided to permit solids flow from the main bed to the cooling bed. One of the walls contained a 4 inch diameter opening for the start-up burner. The wall opposite the start-up burner contained an 6 inch by 10-5/8 inch opening for solids flow from the lift channel into the main bed/freeboard. This opening was located at the top of the main bed above the points where all other gas used to fluidize the various sections would enter the main bed/freeboard.

The main bed was fluidized with air that passed through a distributor that contained four standpipes, each containing four holes. A bubble cap was located on the top of each standpipe to prevent solids back sifting into the distributor. 


\section{COOLING BED}

The cooling bed was sized based on an energy balance on the unit at design flow conditions. The design feed rate of coal was approximately $561 \mathrm{lb} / \mathrm{hr}$, a firing rate of almost 6.5 million Btu/hr. The energy balance indicated that 3.4 million Btu/hr would need to be extracted from the cooling bed in order to maintain the temperature of the gas leaving the cyclone at $1600^{\circ} \mathrm{F}$. Since the cooling bed was selected to operate at a temperature of $1450^{\circ} \mathrm{F}$, and steam was to be generated at a maximum temperature of $220^{\circ} \mathrm{F}$, the available temperature differential for heat transfer was $1230^{\circ} \mathrm{F}$. Using an overall heat transfer coefficient of $50 \mathrm{Btu} / \mathrm{hr} \mathrm{ft}{ }^{\circ} \mathrm{F}$, the surface required was calculated to be $55 \mathrm{ft}^{2}$. We slightly oversized the cooling surface by providing $60 \mathrm{ft}^{2}$. The dimensions of the cooling bed were then determined to accommodate the calculated cooling surface. A 22 inch by 22 inch bed was selected. Five cooling coils made of 1-1/2 inch carbon steel pipe were installed. A dividing wall in the middile of the cooling bed was constructed to force solids to flow in a semicircular path through the cooling bed from the main bed into the lift channel. Operating experience during 1990 indicated that only three coils were needed. The other two coils were subsequently removed to operate the unit at lower heat inputs. Preliminary testing determined the upper limit of the firing rate to be approximately 4.7 million BTU/hr. The 1991 test program was designed around this firing rate. Repairs to the dividing wall have made the cooling bed work significantly more efficiently. As a result, all tests after October 10, 1991 only had two coils in the cooling bed (since the third coil had been removed). The higher efficiency of the cooling bed required less suface area (or coils) to perform the required heat transfer.

\section{LIFT CHANNEL}

Solids flow into the lift channel from the cooling bed and are conveyed by a densephase lift to their return to the main bed. Solids enter the lift channel through a 9 inch by 7 inch opening. The lift channel dimensions are 7 inch by 10-5/8 inch, and its height is 73 inches. The opening for solids return to the main bed/freeboard is located at the top of the lift channel. 


\section{E. SLUICE}

Solids flow through the sluice from the cyclone discharge to the main bed. It is 7 inches wide, 48 inches long, and 52 inches high. The solids are maintained as a fluidized bed in the sluice. The sluice does not provide solids circulation rate control. Its pirpose is simply to provide a seal to prevent gas back-flow through the cyclone, which would seriously disrupt particle capture, and to provide a means of solids transfer. The design included a wall separating the sluice from the main bed as previously described. The purpose of this wall was to assure that the sluice fluidized bed level did not drop below a critical value that would permit the solids seal to be blown out. Operating experience indicated that the wall should be removed to permit operation of the sluice at lower gas velocities and also to obtain good solid circulation from the sluice to the main bed.

In order to minimize coal feed chute plugging, normal practice is to design the coal feed chute as close to vertical as possible. Since the sluice provided a horizontal surface of sufficient size, we opted for a vertical coal feed chute into the sluice. We believed that coal fed into the sluice would be conveyed quickly into the main bed since the solids circulation rate through the sluice was expecied to be much greater than the coal feed rate, nearly 200 po'nds of circulating solids per pound of coal fed. However, the sluice plugged during initial operation of the unit. We felt that this was due to coal settling to the bottom of the sluice where it would agglomerate in the low velocity, oxygen-deficient fluidized bed. Removal of the wall helped to provide more flow into the main bed and kept the bottom of the sluice from becoming a point of accumulation of large coal particles. Operating experience also demonstrated that the wall was not required. Solids inventory, and therefore seal height, was not generally a problem. Later the limestone and coal feeder discharges were re-located so that the limestone discharge was on top, and fed into the coal discharge beneath it. 


\section{F. CYCLONE}

The cyclone in the VFBC lab unit is, of course, the unique component. This cyclone has two purposes - one is to separate recirculating solids from the gas stream; the other is to be a combustor. The cyclone was designed following generally applied design methods with a few modifications.

The inlet "dirty" gas velocity was selected to be $70 \mathrm{ft} / \mathrm{sec}$, within the normally accepted range for cyclones in similar service. This velocity was used to determine the gas inlet area of $0.37 \mathrm{ft}^{2}$. Using the typical cyclone dimensions shown in Figure 3, the dimensions would be:

$\begin{array}{lr}\text { Inlet Height } & 10.32 \\ \text { Inlet Width } & 5.16 \\ \text { Barrel Diameter } & 20.65 \\ \text { Barrel Height } & 41.29 \\ \text { Gas Outlet Diameter } & 10.32 \\ \text { Cone Height } & 41.29 \\ \text { Solids Discharge Diameter } & 5.16\end{array}$

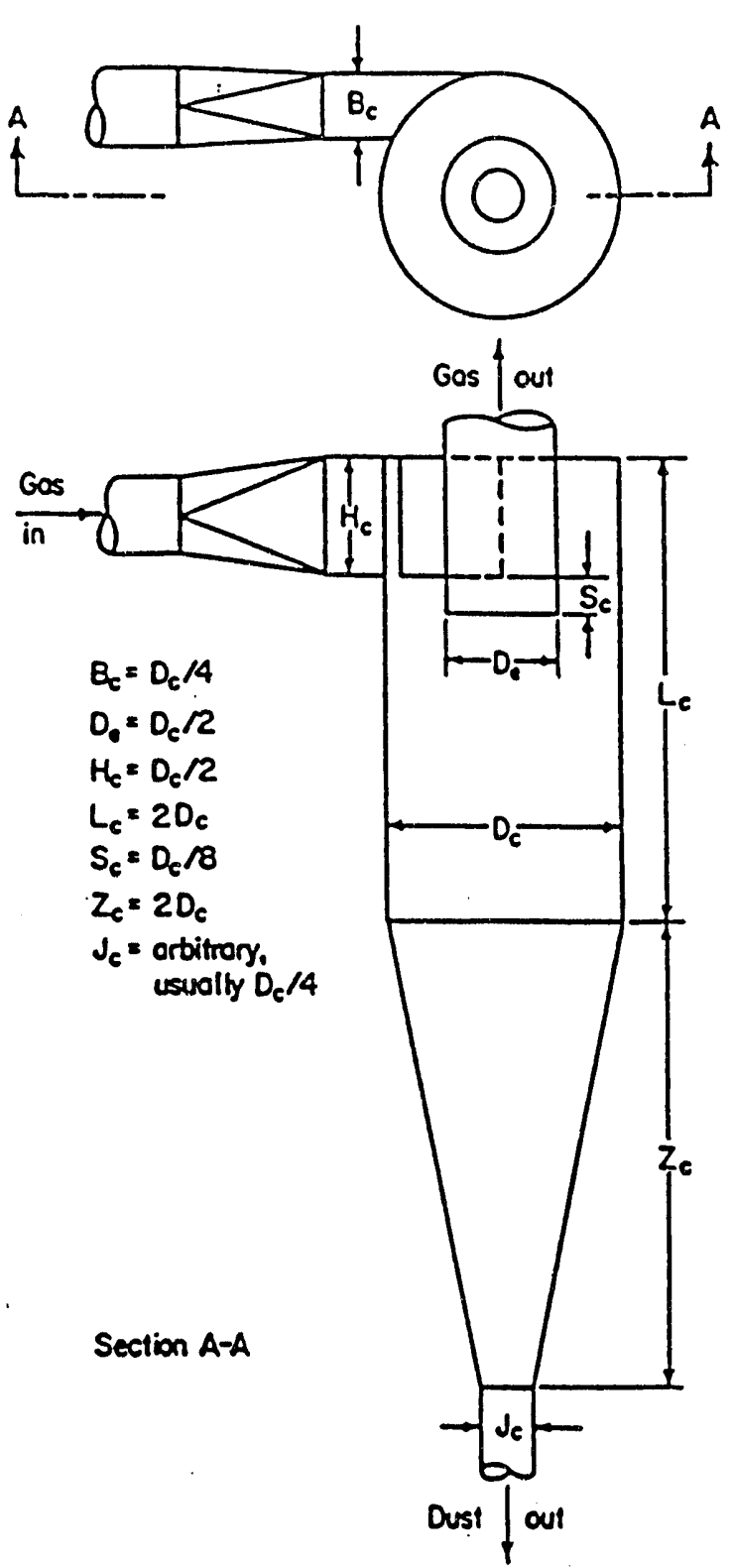

Figure 1.3. Cyclone Separator Proportions

A typical cyclone operating with an inlet velocity of $70 \mathrm{ft} / \mathrm{sec}$ would have a gas outlet velocity of about $45 \mathrm{ft} / \mathrm{sec}$. Since combustion air is injected into the barrel of the Vortex ${ }^{\mathrm{TM}}$ cyclone, the amount of gas leaving the cyclone is substantially larger than the quantity of "dirty" gas entering. In designing such a cyclone, if typical cyclone dimensions were used, and three-fourths of the combustion air was admitted to the cyclone, the outlet velocity would be $150 \mathrm{ft} / \mathrm{sec}$. We were concerned that such an outlet velocity would result in a significant pressure drop, therefore, we enlarged the diameter of the gas outlet to provide a gas outlet velocity at design operating 
conditions of $100 \mathrm{ft} / \mathrm{sec}$. The testwork velocity was later (during the 1991 testing) revised downward such that roughly one-half of the combustion air was admitted through the cylcone barrel, and resulted in a somewhat lower gas outlet velocity.

Once we enlarged the gas outlet diameter, the dimensions of the gas inlet and the cyclone barrel had to be modified in order to prevent solids in the "dirty" gas from impinging directly on the gas outlet pipe. Furthermore, the barrel length was extended somewhat to accommodate the tangential air nozzles and relatively elongated dirty gas inlet height, and the solids discharge opening was enlarged to accommodate the anticipated large solids recirculation rate. The resulting dirnensions of the Vortex ${ }^{\mathrm{TM}}$ cyclone used during the 1990 testing are:

\section{(Inches)}

$\begin{array}{lr}\text { Inlet Height } & 11.375 \\ \text { Inlet Width } & 4.625 \\ \text { Barrel Diameter } & 22.750 \\ \text { Barrel Height } & 61.750 \\ \text { Gas Outlet Diameter } & 12.750 \\ \text { Cone Height } & 36.000 \\ \text { Solids Discharge Diameter } & 8.000\end{array}$

The tangential air nozzles are located in four vertical rows. Each row contains eight nozzles, each with approximate dimensions of 2 inches by 4 inches. A windbox supplies air to each row of nozzles, and each nozzle within a row can be closed by inserting a plug. This configuration was selected to permit evaluation of alternate nozzle locations and nozzle air inlet velocities. Prior to starting the current 1991 test program, repairs were made to the cyclone. The entrance was changed to 12 inches high by 4 inches wide to give added clearance to the gas outlet tube (or vortex finder) which is now 12-11/16 inches inside diameter or 13-3/16 inches outside diameter. 


\section{G. MATERIALS OF CONSTRUCTION}

All sections of the VFBC combustor were lined with a double layer of refractory, each 4 inches thick. The hot face refractory used was Hymor 3000 and the insulation layer was Airlite 2100 , both products of Plibrico. The shell was fabricated from $1 / 4$ inch carbon steel plate. All air distributors and the cooling coil were also made of carbon steel. The only high temperature alloy used in the system was the cyclone gas outlet pipe, which was made of Rolled Alloys (RA 330) stainless steel.

\section{H. BALANCE OF FACILITY}

The facility included fans, a waste heat boiler with a water circulation pump, and a baghouse in addition to instrumentation required to assess performance. Each are described below.

\section{FANS}

The facility has five fans: the primary air fan which provides air to the main bed, cooling bed, lift channel, and sluice; the Vortex air fan; the start-up burner fan; the induced draft fan; and the sand reinjection fan. Note that the startup burner fan is also used to reinject flyash into the cooling bed.

The primary air fan is a positive displacement blower with a capacity of 560 SCFM at $7.4 \mathrm{psig}$. The discharge header pressure was regulated with a back-pressure regulator to maintain a constant supply pressure to the bottom air supply lines of 6 psig. Air flow from the header to each section was measured by an orifice and regulated by an electrically operated valve.

The Vortex air fan has a capacity of 1200 SCFM with a delivery pressure of 40 IWG. Air flow was measured by an orifice and regulated by an electrically operated valve. Following the regulating valve, the supply line feeds one or more of the four windboxes depending upon the position of the manual valves in the lines to each windbox. 
A fan for the start-up burner was provided because the primary air fan did not have sufficient air flow capacity to maintain fluidization in all sections while supplying the air required by the start-up burner. The start-up burner was typically fired at about 1.5 million Btu/hr. Air was supplied at 100 IWG.

The induced draft fan was shared by another circulating fluidized bed combustor facility. The fan was specified to satisfy the requirements of the other larger facility.

\section{J. BOILER}

The waste heat recovery boiler was also shared with the larger circulating fluidized bed facility. It is a $175 \mathrm{HP}$ firetube boiler, and contains $875 \mathrm{ft}^{2}$ of surface. Ash drains/ hoppers are located at the ends of the first and second passes of this three-pass boiler. The first pass drain was equipped with a sand reinjection system that reinjects sand into the cooling bed to maintain bed inventory.

\section{K. BAGHOUSE}

The baghouse was also shared with the larger facility. It contains twenty-eight (28) 6inch diameter bags. Each bag is $10 \mathrm{ft}$ long. The total area for particle capture, then, is $440 \mathrm{ft}^{2}$ providing an air-to-cloth ratio at design conditions of about $4.9 \mathrm{ACFM} / \mathrm{ft}^{2}$.

\section{EQUIPMENT CHANGES FROM 1990 TESTING}

Before testing was started in 1991, several changes were made to the facility. The coal feed hopper was redesigned and constructed to aid the coal feeding. The barrel was made of stainless steel and the cone was made of 316 stainless steel (SS), to help the coal flow out of the hopper.

In addition, air nozzles, angled downward, were added to the four sides of the cone to help break up any coal plugs, as needed. 
As in all Vortex ${ }^{\mathrm{TM}}$ tests, the sand reinjection system from the first pass drain of the boiler reinjects sand into the cooling bed via a cyclone that separates the transporting air from the sand. The dip leg of this cyclone was lengthened to ensure a good seal.

A flyash reinjection system was added to the baghouse to increase the combustion efficiency and sulfur capture. This system includes a conveying screw in the cone of the baghouse, a rotary valve, an eductor and piping to the cyclone on the cooling bed. Note that there are two entrances to the cyclone -- one for the sand (on top) and one for the flyash (on bottom). The cyclone inside diameter was increased from 8 inches to 12 inches to accommodate both solids and air flows to the cyclone.

The dimensions of the openings connecting the various portions of the Vortex ${ }^{\mathrm{TM}}$ unit presented in the Facility Design and Construction Section represent the current facility. These unit openings have the same dimensions as the original design for the Vortex ${ }^{\mathrm{TM}}$ system. During the 1990 testing, some of these unit openings had slightly different dimensions due to the methods of casting the refractory.

One of the most significant changes to the operation and stability of the unit was the conversion of the lift channel air damper to automatically control the upper freeboard temperature around a set point. This change eliminates the larger swings that resulted from manual control and increased the quality of performance of the unit. 


\section{VFBC LAB-SCALE TESTING}

A summary of the types of tests performed in the VFBC lab units is given in Table 1.1.

Table 1.1. Vortex Testing Schedule

Test Unit

Old 1 Ft Unit

New 1 Ft Unit

New $1 \mathrm{Ft}$ Unit

New $1 \mathrm{Ft}$ Modified

New 1 Ft Modified

New $1 \mathrm{Ft}$ Modified
Type of Test

Adiabatic; Short Tests

Non-adiabatic; Short Tests

Non-adiabatic; Long Tests

Adiabatic; Short Tests

Non-adiabatic; Short Tests

Non-adiabatic; Long Tests
Test Period

Spring of 1989

Apr. thru Mid-Aug. 1990

Mid-Aug. thru Mid-Sept. 1990

Aug. thru Sept. 1991

Sept. thru Oct. 1991

Nov. 1991

Testing was conducted in the VFBC lab unit during several time periods of 1990 and 1991. Short and long term tests were performed during April through the middle of September, 1990. During this time, the unit was in operation for approximately $\mathbf{5 0 0}$ hours and over 70 tons of high sulfur bituminous coal were burned. Although some operational problems were encountered, the mechanical integrity of the VFBC design was well demonstrated. One of the major concerns going into the test program - erosion of the cyclone refractory - was satisfied. No problems with this refractory were encountered. Furthermore, the cyclone particle capture efficiency appeared to be insensitive to admission of Vortex air; capture efficiencies of about 98.5\% we achiev: : An extended operation of nearly 100 continuous hours was achieved thout $t \mathrm{l}$ need to add supplemental \& make-up material.

Analysis of the ash produced during extended operation indicated that carbon conversions of 96 percent or greater could be achieved. The equivalent coal combustion efficiency based on coal heating value is about 97 percent. A maximum sulfur capture efficiency of 86 percent was achieved during extended operation. This level of performance would be acceptable for many small industrial coal-fired applications using conventional technology (e.g., stokers), and shows considerable potential for improvement in scaled-up units. However, the general results from these tests were quite scattered and not consistent. Refer to Figure 1.4 for an example of the scatter of the data. Also, specifica , the sulfur capture during these tests was rather poor due to the relatively unreactive limestones that were used. 


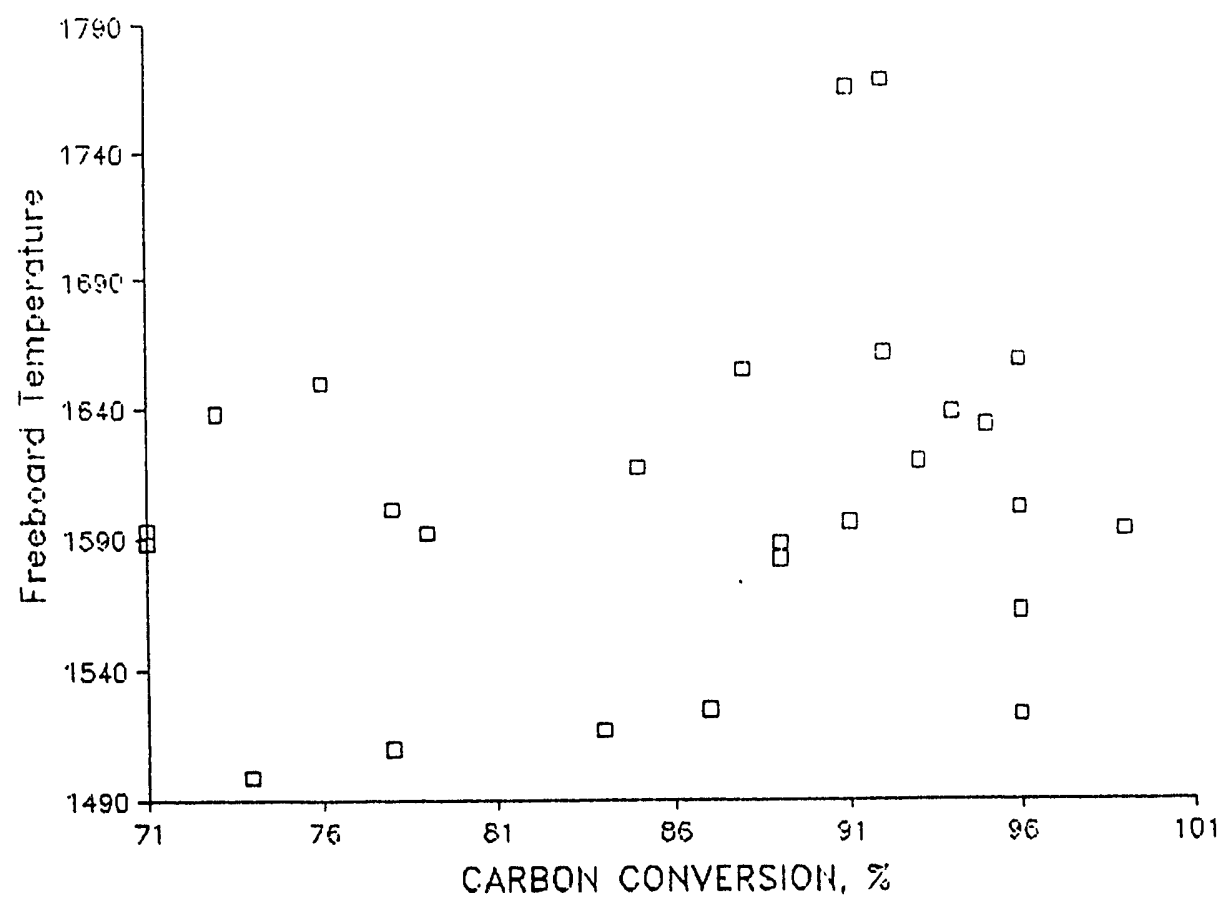

Figure 1.4. Long Term Tests (Based on Gas Data)

The Vortex ${ }^{\mathrm{TM}}$ unit was run for over 200 hours in 1991 while combusting about 20 tons of Illinois No. 6 coal. Short term tests were performed from September through the end of October, 1991. During early September preliminary tests were conducted adiabatically without the cooling bed heat excchanger being in place. The firing rates ranged between $1.2-2.3 \mathrm{MM} \mathrm{BTU} / \mathrm{hr}$ and the unit performed very well during these tests. Sulfur captures of about 75 to $90 \%$ were achieved using calciumto-sulfur molar ratios of 3.8 to 4.8 . Combustion efficiencies of approximately 86 to 98\% were achieved, with the higher efficiencies being achieved while the unit operated in the Vortex ${ }^{\mathrm{TM}}$ mode. The vortex-to-primary air ratio was approximately 1.0 in the vortex testing. The cooling coil was inserted on September 9, 1991. In tests from then through October 11, 1991, the cooling bed heat exchanger consisted of three (3) coils. With the repairs that had been made to the dividing wall prior to the 1991 testing, the coil worked more effectively, and so, one of the heat exchanger coils was removed. All remaining tests through mid-November were run with only two coils. The newly installed flyash reinjection system was used during most of these tests. 
The short term tests were run at the following range of conditions:

\begin{tabular}{|c|c|c|}
\hline Coal Heat Input & (MM BTU/hr) & $\begin{array}{l}1.6-2.4 \text { non-Vortex or CFB } \\
2.6-3.7 \text { Vortex }\end{array}$ \\
\hline Calcium-to-Sulfur & Molar Ratio & $1.4-4.8$ \\
\hline Carbon Efficiency & $(\%)$ & $80-100+($ Several @ 98+\%) \\
\hline Sulfur Capture & $(\%)$ & $56-85$ \\
\hline Flue Gas Oxygen & $(\%)$ & $>5-7$ \\
\hline Excess Air & $(\%)$ & $>31-50$ \\
\hline Vortex-to-Primary & Air Ratio & $0.5-0.7$ (Range for Vortex tests) \\
\hline
\end{tabular}

These results, while quite promising, were not always consistent since the unit had not been run long enough to be completely stable, especially in the tests which used flyash reinjection.

During November 1991, four (4) long term tests were performed. All of these tests used flyash reinjection. These tests all had start $\rightarrow$ and stabilization times that allowed the flyash being reinjected to be completel: burnt out prior to the start of the tests. The results from these tests were extremely promising with two of the four tests having coal combustion efficiencies in excess of $99 \%$. The highest sulfur capture obtained during these four tests was $88.5 \%$, with a range of 80.2 to $88.5 \%$. 


\section{A. TEST PLAN/OBJECTIVES}

The objectives of Level II testing were to establish the operational and performance boundaries of the total system and identify any remaining issues to be resolved prior to building the proof-of-concept facility. Since the Vortex ${ }^{\mathrm{TM}}$ Fluidized Bed Boiler is an improvement on conventional circulating fluidized bed technology, the operating variables that affect performance of circulating fluidized bed combustors were expected to have a similar impact on VFBC performance. Technical uncertainties that were identified in the test plan to be of particular interest for examination were:

1. the amount of excess air required to achieve satisfactory combustion performance,

2. sulfur capture efficiency as a function of limestone use (calcium-to-sulfur ratio),

3. residence time required to achieve adequate performance.

4. optimum freeboard superficial velocity to ensure stable operation and minimize temperature differentials, and

5. the operating temperature level to obtain the best combination of combustion efficiency and sulfur capture.

In addition, specific questions relating to cyclone performance and secondary air injection that needed to be addressed experimentally were identified to be:

1. How much air can be effectively injected into the cyclone as secondary combustion air without adversely affecting combustion and/or cyclone particle capture performance?

2. What is the optimum location of the air injection nozzles, i.e., should the air be injected along the axis (length) of the cyclone barrel or should it be injected along the circumference of the cyclone barrel near the "dirty gas" inlet?

3. What air injection velocity should be used, i.e., how many nozzles of what size should be used? Is there a minimum secondary air injection velocity as well as a maximum velocity that must be maintained in order to achieve adequate performance? 
The test plan indicated that the experimental program had to provide verification of:

1. adequate cyclone temperature control by circulating solids through the cyclone combustor;

2. adequate performance of the cooling bed and lift channel to control system temperature; and

3. operating ranges for gas velocity through the cooling bed, main bed, lift channel, and sluice.

Finally, miscellaneous design information such as performance of materials of construction and methods for coal and limestone feec $\mathrm{ng}$ were anticipated to be acquired.

In order to address as many of these system performance questions as possible, two types of tests were conducted. Preliminary tests of relatively short duration were conducted to screen the effect of operating variables. Long duration tests that permitted acquisition of representative ash samples for analysis were conducted to verify performance at steady state conditions and to demonstrate that the system could be operated for extended periods without developing unusual difficulties. The results of these tests are discussed in the following sections.

\section{B. ADIABATIC TESTS}

Adiabatic testing was conducted during two test periods: during the Spring of 1989 using the old one-foot unit and during August and September of 1991 using the new one-foot modified unit.

\section{1989 Adiabatic Tests}

The preliminary tests performed in the original one-foot diameter facility were very encouraging. A maximum firing rate of $2 \mathrm{MMBTU} / \mathrm{hr}$ was achieved with a combustion efficiency of $96.5 \%$. Cyclone-to-CFB air ratios from $1: 1$ to $2.5: 1$ were tested with no discernable change in performance. In order to permit increases in firing rate beyond about 530,000 $\mathrm{BTU} / \mathrm{hr}$ without using a tremendous amount of 
excess air or operating at excessive temperatures, water was injected into the main bed (bottom of the freeboard) as a heat load. The results of these tests are summarized as:

$\begin{array}{ll}\text { Cyclone-to-CFB Air Ratio } & 1: 1 \text { to } 2.5: 1 \\ \text { Firing Rate } & 1.0-2.0 \mathrm{MMBTU} / \mathrm{hr} \\ \text { Freeboard Velocity } & 33 \mathrm{ft} / \mathrm{sec} \\ \text { Specific Heat Release Rate } & 150,000 \mathrm{BTU} / \mathrm{ft}^{3} \mathrm{hr} \\ \text { Temperatures } & \\ \quad \text { Main Bed } & 1607^{\circ} \mathrm{F} \\ \text { Freeboard } & 1629^{\circ} \mathrm{F} \\ \text { Cyclone } & 1654^{\circ} \mathrm{F} \\ \text { Flue Gas Composition } & \\ \mathrm{O}_{2} & 5-7 \% \\ \mathrm{CO} & 80-120 \mathrm{ppm} \\ \mathrm{NO}_{\mathbf{x}} & 150-200 \mathrm{ppm} \\ \mathrm{SO}_{2} & 200-425 \mathrm{ppm}\end{array}$

The new facility was in shakedown testing at this time. These initial tests have indicated that sufficient solids circulation between the circulating fluidized bed and cyclone can be maintained to control the temperature difference between these two components. Most of these tests were at reduced load conditions (the unit was operated as a circulating fluidized bed). A few short duration tests with Cyclone-toCFB air ratios up to nearly $1: 1$ have been completed during which the temperature profile within the combustion system was nearly isothermal; the temperature difference was only $22^{\circ} \mathrm{F}$. Furthermore, combustion efficiency during Vortex ${ }^{\mathrm{TM}}$ operation (with tangential air injection) has been as high as that achieved during CFB operation. 


\section{1991 Adiabatic Tests}

Two separate adiabatic tests were performed. In the first test, either gas or coal was fired in the unit, and only non-vortex testing was performed. The results from this test are summarized as follows:

Firing Rate

Superficial Air Velocities:

Main Bed

Freeboard

Temperatures

Main Bed

Freeboard

Cyclone

Flue Gas Composition

$\mathrm{O}_{2}$

$\mathrm{CO}_{2}$

co

$\mathrm{SO}_{2}$
1.35 MMBTU/hr (on natural gas only) -2.0 MMBTU/hr (on coal only)

$10.0-12.4 \mathrm{ft} / \mathrm{sec}$

$29.0-42.6 \mathrm{ft} / \mathrm{sec}$

$1197-1672^{\circ} \mathrm{F}$

$1016-1703^{\circ} \mathrm{F}$

$970-1747^{\circ} \mathrm{F}$

$5.69-14.53 \%$

$3.77-12.9 \%$

64 - 339 ppm

0 - 1429 ppm

These test results demonstrate that the adiabatic vortex would be a good source for drying gases or for vitiated air required for further combustion or gasification.

During the second adiabatic test, the unit was run both as a CFB and a vortex unit. All testing was fired with coal and limestone. The averaged results from this test are as follows: 
CFB

Vortex-to-Primary Air Ratio Firing Rate

Superficial Air Velocities

Main Bed

Freeboard

Temperatures

Main Bed

Freeboard

Cyclone

Flue Gas Composition

$\mathrm{O}_{2}$

$\mathrm{CO}_{2}$

$\mathrm{CO}$

$\mathrm{SO}_{2}$

$\mathrm{NO}_{2}$

Calcium-to-Sulfur Molar Ratio

Sulfur Capture

Combustion Efficiency
0

1.88 MMBTU/hr

$17.7 \mathrm{ft} / \mathrm{sec}$

$46.1 \mathrm{ft} / \mathrm{sec}$

$1601^{\circ} \mathrm{F}$

$1631^{\circ} \mathrm{F}$

$1567^{\circ} \mathrm{F}$

$10.83 \%$

$8.90 \%$

164 ppm

307 ppm

212 ppm

3.75

$75.4 \%$

$85.9 \%$
VORTEX

1.0

2.23 MMBTU/hr

$16.6 \mathrm{ft} / \mathrm{sec}$

$46.1 \mathrm{ft} / \mathrm{sec}$

$1586^{\circ} \mathrm{F}$

$1641^{\circ} \mathrm{F}$

$1497^{\circ} \mathrm{F}$

$13.0 \%$

$7.39 \%$

195 ppm

149 ppm

189 ppm

4.77

$86.2 \%$

$97.8 \%$

These test results demonstrate good sulfur capture for both methods of firing and excellent combustion efficiency in the vortex case. These gases could also be used for vitiated air or as a source of drying gases. 


\section{1990 SHORT-TERM TESTS}

Most of the 1990 test program involved preliminary testing in which the unit was operated for a relatively short period; tests were typically conducted for about 12 hours including startup and shutdown.

\section{Objectives and Procedures}

It can be seen above that there is a relatively large number of operating variables that can potentially affect the overall performance of the unit. It was simply not practical to investigate every possible permutation, and a level of judgement had to be exercised. On the whole, this was successful but there are some areas where confirmation of apparent trends is desirable.

The controlled variables for the preliminary tests included: location of tangential air nozzles in the cyclone; nozzle velocity; Vortex/Primary. Air ratio; freeboard temperature; calcium-to-sulfur ratio; and coal size distribution.

The main advantages of the VFBC technology when applied to full scale units (i.e., the significant reduction in main bed, freeboard, and cyclone size), unfortunately had the effect of imposing some limits on the range of operability when applied to a small pilot plant. Since the sluice and cooling bed represent a substantial portion of the total cross-sectional area of the pilot plant unit, the amount of air used to fluidize these sections is a large portion of the total air fed to the bottom of the unit. Operation of the lab unit at freeboard velocities below about $35 \mathrm{ft} / \mathrm{sec}$ was not possible because this resulted in a main bed velocity of less than $19-20 \mathrm{ft} / \mathrm{sec}$. This severely limited our ability to examine Vortex/Primary Air ratio independent of coal feed rate and excess air.

Overall performance was also probably significantly affected by the relatively high heat losses from the pilot plant unit. This is a shortcoming with all scaled-down test units and, in our case, was exacerbated for the same reasons as described above. The cooling bed configuration was modified during the preliminary tests to reduce the amount of heat extracted from the system. Tests were conducted with one to three of the five cooling coils in place during the 1990 testing. 


\section{Results}

Perhaps not surprisingly, the data from these tests exhibit significant scatter. Some of the scatter is possibly due to instabilities resulting from process upsets such as coal feed blockage. Some may be due to the fact that the tests were of short duration steady state conditions may not have been achieved, particularly with regard to the heat losses mentioned above, and the relatively high mass of refractory that had to be employed in the unit.

\section{Nozzle Location and Velocity.}

The effect of air nozzle distribution and velocity was examined as part of the preliminary test program. Location of nozzles appears to have less impact on performance than some other variables; however, there is indication that locations closer to the top of the cyclone are more effective than those lower in the cyclone. Furthermore, higher air inlet velocities appear to be somewhat more effective than lower inlet velocities.

As previously described in the cyclone portion of the Facility Design and Construction section, a total of 32 nozzles were installed in the barrel of the cyclone. These nozzles were arranged in four vertical rows of eight nozzles. The nozzles were actually rectangular slots that were 2 inches wide and approximately 4 inches long. There were no spaces between slots in the vertical dimension, i.e., the eight nozzles occupied a total vertical height of 32 inches with 10 gauge (approximately $1 / 8$ inch) steel separating adjacent slots. Each nozzle was assigned an alphanumeric identification as follows: Each row, starting with the row that penetrated the barrel immediately after the dirty gas inlet, was assigned a letter designation of A, B, C, or $D$ as shown in Figure 1.5. Nozzles, or slots, were numbered within each row from 1 through 8, starting with the top nozzle as shown in Figure 1.5. Using this designation system, then, nozzle A1 is the top nozzle in row A, nozzle B8 is located at the bottom of row $\mathrm{B}, \mathrm{C} 1$ is located at the top of row $\mathrm{C}$ diametrically across the cyclone from $A 1$, etc.

Six different nozzle configurations were used in the preliminary tests as shown in Table 1.2. The best combustion performance was achieved with only the two uppermost nozzles in row A (A1 \& A2) open. The average carbon combustion achieved in eight tests using this configuration was 92 percent. Tests conducted with nozzles located lower in the barrel open (A4 \& A5) resulted in an average combustion efficiency of 84 percent. 
Only one test with the uppermost nozzle in each row open was conducted. This test resulted in the second best combustion efficiency, 91 percent. However, this test was conducted with a very high level of excess air, 88 percent, and had a high freeboard temperature.

During the long term tests of 1990 and all of the 1991 testing only nozzles A1 together with A2 were used.

Table 1.2. Effect of Vortex Nozzle Location and Air Velocity

\begin{tabular}{|l|c|c|c|c|c|c|}
\hline $\begin{array}{c}\text { Nozzle } \\
\text { Configuration }\end{array}$ & $\begin{array}{c}\text { Average } \\
\text { Air Ratio }\end{array}$ & $\begin{array}{c}\text { Average } \\
\text { Air Velocity } \\
(\mathrm{ft} / \mathbf{s e c})\end{array}$ & $\begin{array}{c}\text { Carbon } \\
\text { Conversion } \\
(\%)\end{array}$ & $\begin{array}{c}\text { Excess } \\
\text { Air } \\
(\%)\end{array}$ & $\begin{array}{c}\text { No. } \\
\text { Tests }\end{array}$ & $\begin{array}{c}\text { Average } \\
\text { Freeboard } \\
\text { Temp. }\left({ }^{\circ} \mathrm{F}\right)\end{array}$ \\
\hline $\mathrm{A} 1, \mathrm{~B} 1, \mathrm{C} 1, \mathrm{D} 1$ & 1.0 & 36 & 91 & 88 & 1 & 1765 \\
\hline $\mathrm{B} 2, \mathrm{~B} 3, \mathrm{~B} 4, \mathrm{~B} 5$ & 0.9 & 39 & 67 & 26 & 2 & 1574 \\
\hline $\mathrm{A} 4, \mathrm{~A} 5$ & 0.8 & 37 & 84 & 28 & 2 & 1624 \\
\hline $\mathrm{A} 1, \mathrm{~A} 2$ & 1.0 & 65 & 92 & 37 & 8 & 1589 \\
\hline $\mathrm{A} 2, \mathrm{~A} 3, \mathrm{~A} 4, \mathrm{~A} 5$ & 1.3 & 40 & 76 & 30 & 2 & 1505 \\
\hline $\mathrm{A} 1, \mathrm{~A} 2, \mathrm{~A} 3, \mathrm{~A} 4$ & 0.9 & 34 & 88 & 41 & 11 & 1623 \\
\hline
\end{tabular}
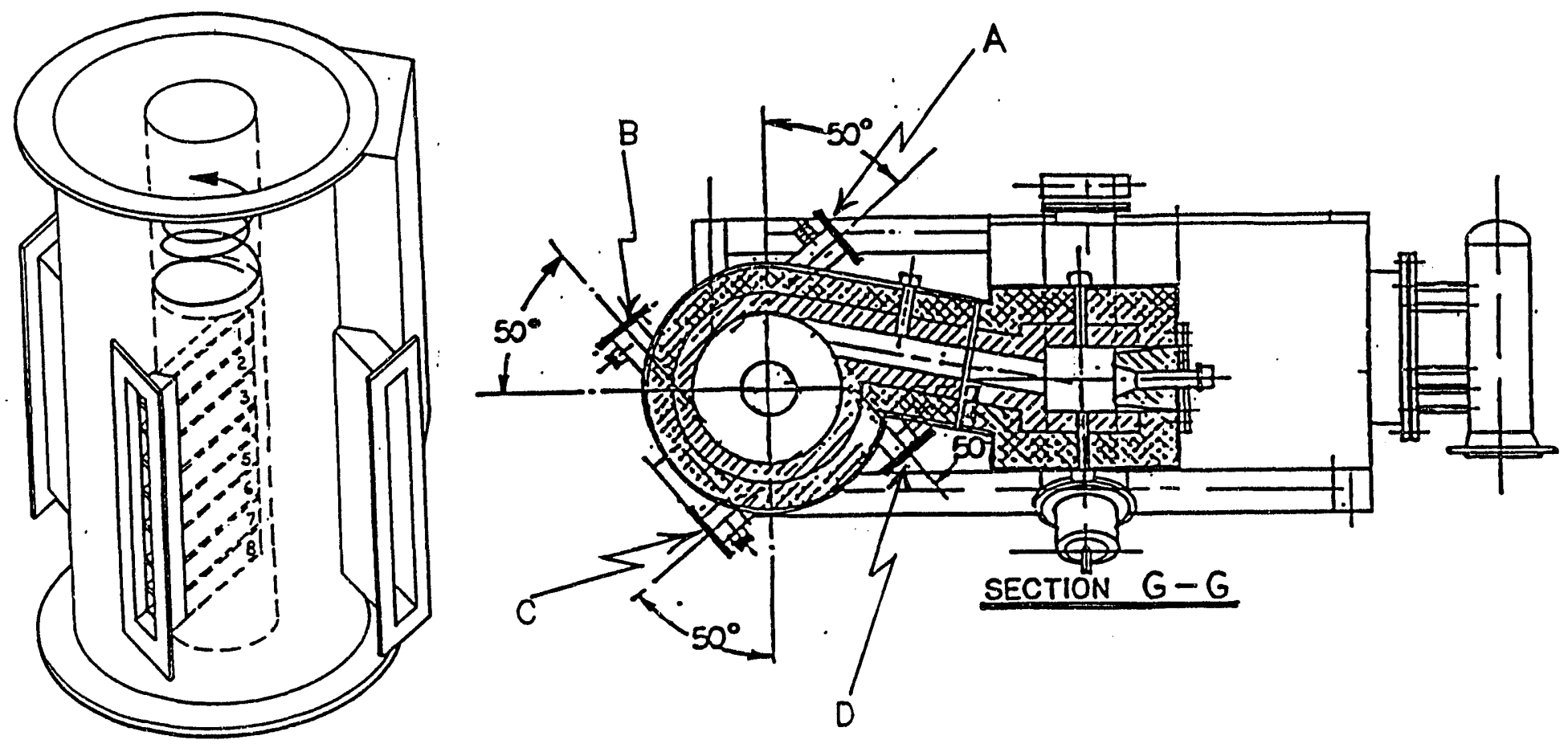

Figure 1.5. Vortex Air Nozzle Location 


\section{Coal and Limestone Feedstocks}

Coal sizes and composition are presented in Table 1.3 and the composition of the limestone is presented in Table 1.4. The source of the coal is Bradford Coal Company located in Clearfield County in Central Pennsylvania. Thomasville Limestone is located in South Central Pennsylvania near York, Pennsylvania. Meckley Limestone is in North Central Pennsylvania near Herndon, Pennsylvania.

Table 1.3. Coal Sizes and Composition for 1990 Preliminary and Long Term Testing

\begin{tabular}{|l|c|c|c|c|}
\hline Size & $3 / 8^{\prime \prime} \times 28$ mesh & $3 / 8^{\prime \prime} \times \mathbf{0}$ & $\mathbf{1 / 4} \times \mathbf{0}$ & $\mathbf{1} / \mathbf{8}^{\prime \prime} \times \mathbf{0}$ \\
\hline Carbon & $69.9 \%$ & $72.4 \%$ & $72.0 \%$ & $75.8 \%$ \\
\hline Hydrogen & $4.2 \%$ & $4.3 \%$ & $4.3 \%$ & $4.5 \%$ \\
\hline Oxygen & $4.1 \%$ & $1.4 \%$ & $3.1 \%$ & $1.4 \%$ \\
\hline Sulfur & $2.2 \%$ & $4.3 \%$ & $3.2 \%$ & $4.0 \%$ \\
\hline Nitrogen & $1.2 \%$ & $1.2 \%$ & $0.9 \%$ & $1.2 \%$ \\
\hline Ash & $12.8 \%$ & $12.6 \%$ & $9.7 \%$ & $10.1 \%$ \\
\hline Moisture & $5.6 \%$ & $3.8 \%$ & $7.0 \%$ & $3.0 \%$ \\
\hline
\end{tabular}

Table 1.4. Limestone Composition for 1990 Preliminary and Long Term Testing

\begin{tabular}{|l|c|c|}
\hline Source & Thomasville & Meckley \\
\hline Calcium carbonate & $\mathbf{8 2 . 4 \%}$ & $80.9 \%$ \\
\hline Magnesium carbonate & $\mathbf{8 . 1 \%}$ & $3.6 \%$ \\
\hline Inerts & $9.5 \%$ & $15.5 \%$ \\
\hline
\end{tabular}

Most of the preliminary tests were conducted with a 3/8" $\times 0$ coal feedstock. The coarser feedstock was used in an attempt to eliminate coal feeding problems. However, the coarser coal was just as problematic as the full range coal. During the long term tests $3 / 8^{\prime \prime} \times 0,1 / 4^{\prime \prime} \times 0$, and $1 / 8^{\prime \prime} \times 0$ coals were used. The latter two feedstocks were produced on site via dry screening.

Thomasville Limestone was used initially primarily because it is a local limestone. However, this stone proved to be relatively unreactive. So, Meckley Blend Limestone was used. This stone has widespread use in the commercial anthracite culm circulating fluidized bed combustors in the North-Central regions of Pennsylvania, and showed a much higher reactivity than the Thomasville stone.

There is a trend toward higher carbon efficiency as the stoichiometric ratio (or primary air divided by the theoretical air or the fraction of theoretical air in the circulating fluidized bed) in the circulating fluidized bed portion of the system is increased. 


\section{1990 LONG TERM TESTS}

A series of long term tests were conducted in an attempt to reduce the amount of data scatter by assuring that steady state conditions were achieved. In these tests, the lab unit was operated continuously for several days. Operation in this manner also permitted acquisition of a more representative ash sample for analysis to be used as the basis for performance assessment.

\section{Procedures}

Data were analyzed based on gas analysis and on ash analysis. The flue gas was sampled downstream of the waste heat boiler in order to have an acceptable sample probe life. Since the flue gas duct operates at negative pressure, air can leak into the flue gas stream prior to this sample point. An expendable, high-temperature probe was also used to check oxygen upstream of the boiler. Using this gas oxygen content relative to that measured downstream of the boiler, the extent of sample dilution was determined. The gas analysis was then adjusted to account for this dilution.

The ash analysis was used in two ways. The direct application of the ash data was to determine the amount of carbon lost in the ash by multiplying the measured ash collection rate by the weight fraction of organic carbon. This value was then subtracted from the total carbon content of the coal fed. Sulfur capture was determined from the ash data by multiplying the ash rate by the total percent sulfur in the ash and dividing this value by the total sulfur fed in the coal.

Checking the ash data for a calcium balance indicated some degree of error. Therefore, a second method of applying the ash data was also used. In this method, the ash rate was adjusted to provide a balance between the calcium discharged in the ash and the calcium fed in the limestone. The ash composition data was then applied to this revised ash rate as described above.

\section{Results}

As in the analysis of the short term tests, a positive trend was seen between carbon efficiency and the stoichiometric air ratio in the circulating bed portion of the system. The trend shows that combustion performance improves as the circulating fluidized bed approaches stoichiometric conditions. 


\section{E. $\quad 1990$ CONCLUSIONS/DISCUSSION}

The long term tests, as well as the short term tests, indicated that the only significant variables that had an effect on system performance were the related variables of excess air and stoichiometric ratio in the circulating bed portion of the system. Significant scatter of the data remained when performance was determined based on ash analysis, and the limited number of data points makes it difficult to quantify the relationships. When basing performance on gas analyses, data scatter remains, but the relationships are more easily determined since more points were available. 


\section{F. 1991 SHORT TERM TESTS}

\section{Procedures and Objectives}

Most of the 1991 tests were preliminary tests in which the unit was operated for a relatively short period. The unit was operated for various conditions that helped define the following variables for the later Long Term Tests:

- flyash reinjection rate,

- excess air,

- calcium-to-sulfur molar ratio,

- set point for the top freeboard temperature,

- firing rate in millions of BTU/hr,

- primary air rate required, and

- resulting velocities of the main bed, sluice, cooling bed, freeboard and lift channel (range of control).

\section{Results}

The following nominal conditions were determined for later testing:

- flyash reinjection rates roughly of $0,30,120,200$ and $380 \mathrm{lb} / \mathrm{hr}$;

- excess airs of $\mathbf{4 0}$ and 50 percent;

- calcium-to-sulfur molar ratios of 2.5, 3.0 and 3.5,

- set point of $1525^{\circ} \mathrm{F}$ in all but one test;

- firing rates of 2, 2.5, 3.0 and 3.5 MM BTU/hr;

- Nominal superficial gas velocities of:

$\begin{array}{lll}\text { - } & \text { main bed } 20 \text { to } 22 \mathrm{ft} / \mathrm{sec} \\ \text { - } & \text { sluice } & 2.2 \text { to } 2.4 \mathrm{ft} / \mathrm{sec} \\ \text { - } & \text { cooling bed } 0.6 \text { to } 0.8 \mathrm{ft} / \mathrm{sec} \\ \text { - } & \text { freeboard } 38 \text { to } 40 \mathrm{ft} / \mathrm{sec} \\ \text { - } & \text { lift channel } 6 \text { to } 10 \mathrm{ft} / \mathrm{sec} .\end{array}$

The results from these tests were promising but were not always consistent since the unit had not always been run long enough to become completely stable. 


\section{G. 1991 LONG TERM TESTS}

Four tests were run in the first half of November, 1991. The test conditions were determined in the short term testing. The unit was run until it had stabilized at the maximum flyash rate (roughly $380 \mathrm{lb} / \mathrm{hr}$ ).

\section{Procedures}

Data were based both on gas and ash analyses. The flue gas was sampled from three (3) locations:

- from the duct at the outlet of the vortex cyclone by using a high temperature probe;

- from the duct downstream of the waste heat boiler (to protect the sample probe and extend its life); and

- from the stack and near the annubar that measures the stack gas flow rate.

The oxygen gas analysis from the cyclone outlet is representative of the flue gas produced by the Vortex ${ }^{\mathrm{TM}}$ unit. The gas analysis from both the sample points at the boiler rear and at the stack can include a complete gas analysis of $\mathrm{O}_{2}, \mathrm{CO}_{2}, \mathrm{CO}, \mathrm{SO}_{2}$ and NOx via a common gas conditioning system. Normally only oxygen data were collected from the stack sample point while complete analyses were collected continuously from the boiler sample port. Since the flue gas duct operates at negative pressure, air can leak in prior to the sample point at the boiler rear. Also, since the sand reinjection, the flyash reinjection and the baghouse reverse pulse jet airs all pass through the baghouse, the flue gas at the stack is diluted by these airs in addition to the air in leakage through the ductwork, the waste heat boiler, etc.. Using the oxygen data at the cyclone, the complete gas analysis at the boiler rear was adjusted to the cyclone outlet flue gas analysis via dilution calculations. The vortex outlet flue gas flow rate was calculated using the stack gas oxygen reading, the stack temperature, the pressure drop reading from the annubar and the cyclone flue gas oxygen concentration.

The ash analysis was used to determine the amount of carbon lost in the ash by multiplying the measured ash collection rate by the weight fraction of organic carbon. This value was then subtracted from the total carbon content of the coal 
feed. This also can be used to check the combustion efficiency determined from the gas analysis. Sulfur capture was determined from the ash data by multiplying the ash rate by the total percent sulfur in the ash and dividing this value by the total sulfur feed in the coal.

\section{Results}

Referring to the Test Plan/Objectives for Level II testing, the following items were determined from the Vortex ${ }^{\mathrm{TM}}$ Test Program:

- Excess airs of 40 to $50 \%$ are sufficient to obtain satisfactory combustion performance;

- The sulfur capture efficiency is $80 \%$ or greater for a Ca-to-S molar ratio of $2.4-2.8$;

- The overall residence time for the pilot unit is 0.7 seconds $(0.2$ seconds in the cyclone) and adequate results were obtained;

- The freeboard superficial velocity range of 38 to $40 \mathrm{ft} / \mathrm{sec}$ gave stable operation and the temperature differentials were kept to less than the $100^{\circ} \mathrm{F}\left(55^{\circ} \mathrm{C}\right)$;

- The Vortex-to-Primary air ratio maximum is about 0.70 , without adversely affecting combustion and/or (possible) cyclone capture. This results in roughly 300 to $340 \mathrm{scfm}\left(70^{\circ} \mathrm{F}, 1 \mathrm{~atm}\right.$.) being fed into the vortex;

- The optimum location of the air injection nozzles are the two uppermost nozzles in row A (A1 and A2) near the dirty gas inlet. (Refer to Figure 5); and

- Two air injection nozzles (A1 and A2) worked best for the 1990 test program, so the same nozzles were used exclusively in the 1991 testing. The air injection velocity ranged from 45 to $50 \mathrm{ft} / \mathrm{sec}$ in the November 1991 testing.

During the testing the cyclone outlet temperature was controlled secondarily by varying the lift channel air to increase or decrease the solids flow into the combustor to primarily control the top freeboard temperature. The control of the top freeboard temperature to the $1525^{\circ} \mathrm{F}$ set point was good, nearly always within 20 to $30^{\circ} \mathrm{F}$ of the desired set point. The operating ranges of superficial gas velocity for the cooling bed, main bed, lift channel, sluice and freeboard were:

Gas Velocity, $\mathrm{ft} / \mathrm{sec}$ (typical)

$\begin{array}{ll}\text { Main bed } & 20 \text { to } 2 . \\ \text { Sluice } & 2.2 \text { to } 2.4 \\ \text { Cooling bed } & 0.6 \text { to } 0.8 \\ \text { Freeboard } & 38-40\end{array}$

The lift channel velocity was allowed to float in contrulling the freeboard top temperature around the set point. This velocity was 6-10 fps (typical). 


\section{Coal and Limestone Chemical/Physical Properties}

The coal used during the 1991 testing was an Illinois No. 6 coal from Sahara Mine. The ultimate and proximate analyses are as follows:

\begin{tabular}{lc} 
Proximate & As Received, \% \\
\cline { 2 - 2 } Ash & 7.24 \\
$\mathrm{H}_{2} 0$ & 8.41 \\
Volatile Matter & 35.32 \\
Fixed Carbon & $\underline{49.03}$ \\
Total & 100.00 \\
& \\
Ultimate & As Received, \% \\
\hline Carbon & 67.40 \\
Hydrogen & 4.41 \\
Oxygen & 8.63 \\
Nitrogen & 1.44 \\
Sulfur & 2.47 \\
Ash & 7.24 \\
H 20 & 8.41 \\
Total & 100.00 \\
& \\
HHV (measured) $=12,280$ BTU $/ \mathrm{lb}$
\end{tabular}

The bulk density of the coal ranged from about 45 to $51 \mathrm{lb} / \mathrm{ft}^{3}$. The size of the $\mathrm{c}$ al was $1 / 2 " \times 0$, with an average Rosin Rammler diameter of $2000 \mu \mathrm{m}$ (or $0.079 \mathrm{inch}$ ). The chemical analysis of the Meckley -20 mesh limestone used during the 1991 test program is:

$\begin{array}{lr}\mathrm{CaCO}_{3} & 81.92 \% \\ \mathrm{MgCO}_{3} & 3.12 \% \\ \text { Inerts } & 14.96 \% \\ \text { Total } & 100.00 \%\end{array}$

The bulk density of the limestone ranged from 90 to $100 \mathrm{lb} / \mathrm{ft}^{3}$ during the testing. The Meckley limestone was 20 mesh $\times 0$ with an average Rosin Rammler diameter of $122 \mu \mathrm{m}$. 


\section{VFBC Testing}

The operating conditions for the Vortex ${ }^{\mathrm{TM}}$ unit for the November 1991 tests are presented in Table 1.5. Carbon and combustion efficiencies and sulfur capture in this table are based on gas analysis.

During the tests performed on the pilot VFBC unit, the combustion efficiencies, based on the coal heating value, ranged from 97.0 to $99.6 \%$. The sulfur captures ranged from 80.2 to $88.5 \%$ for calcium-to-sulfur ratios from 2.4 to 2.8 . Note that these results are based only on the gas analysis and feed rates, but ashes gathered during these tests were also analyzed to confirm these results. The results appear to be extremely encouraging. 
Table 1.5. VFBC Operating Conditions

\begin{tabular}{|c|c|c|c|c|}
\hline $\begin{array}{r}\text { TEST NUMBER } \\
\text { DATE } \\
\end{array}$ & $\begin{array}{c}1 \\
11 / 7 / 91 \\
\end{array}$ & $\begin{array}{c}2 \\
11 / 8 / 91 \\
\end{array}$ & $\begin{array}{c}3 \\
11 / 8 / 91 \\
\end{array}$ & $\begin{array}{c}4 \\
11 / 15 / 91 \\
\end{array}$ \\
\hline Freeboard Temperature, ${ }^{\circ} \mathrm{F}$ & 1520 & 1518 & 1522 & 1523 \\
\hline Main Bed Temperature, ${ }^{\circ} \mathrm{F}$ & 1475 & 1501 & 1457 & 1473 \\
\hline Coal Rate, lb/hr & 278 & 173 & 274 & 270 \\
\hline Limestone Rate, $\mathrm{lb} / \mathrm{h}$ & 69 & 45.7 & 66.4 & 60.1 \\
\hline Ca-to-S Molar Ratio & 2.6 & 2.8 & 2.6 & 2.4 \\
\hline Carbon Efficiency, \% & 98.2 & 96.2 & 99.2 & 99.5 \\
\hline Combustion Efficiency, \% & 98.6 & 97 & 99.3 & 99.6 \\
\hline $\begin{array}{l}\text { Sulfur Capture, } \% \\
\text { SO2 Emissions. } 1 \mathrm{~b} / 10^{\wedge} 6 \text { BTU }\end{array}$ & 80.2 & 81.4 & 81.6 & $\frac{88.5}{0.46}$ \\
\hline SO2 Emissions, $1 \mathrm{~b} / 10^{\wedge} 6 \mathrm{BTU}$ & 0.8 & 0.75 & 0.74 & 0.46 \\
\hline Heat Input, 10^6 BTUh & 3.41 & 2.12 & 3.36 & 3.32 \\
\hline \multicolumn{5}{|c|}{ CYCLONE OUTLET GAS EMISSIONS } \\
\hline $\mathrm{O} 2, \%$ & 7.14 & 5.67 & 5.86 & 7.03 \\
\hline $\mathrm{CO} 2, \%$ & 12.04 & 13.25 & 12.7 & 12.53 \\
\hline $\mathrm{CO}, \mathrm{ppm}$ & 194 & 207 & 132 & 193 \\
\hline $\mathrm{SO} 2, \mathrm{ppm}$ & 340 & 355 & 345 & 199 \\
\hline NOx, ppm & 198 & 155 & 197 & 185 \\
\hline \multicolumn{5}{|c|}{ AIR RATES, SCFM $\quad$ (Note 1) } \\
\hline Main Bed & 266.2 & 250.2 & 251.3 & 270.2 \\
\hline $\begin{array}{l}\text { Sluice } \\
\end{array}$ & 40.8 & 40.8 & 40.8 & 40.8 \\
\hline $\begin{array}{l}\text { Adjacent Cooling Bed } \\
\end{array}$ & 53.1 & 54.4 & 53.1 & 54.9 \\
\hline \begin{tabular}{|l|} 
Lift Channel \\
\end{tabular} & 93.2 & 93.2 & 94.2 & 60.3 \\
\hline Total Primary, scfm (Note 2) & $467.8 / 464.0$ & $453.1 / 446.6$ & $453.9 / 447.1$ & $440.7 / 436.4$ \\
\hline Vortex-to-Primary Ratio & 0.72 & 0 & $0.66-0.67$ & $0.72-0.73$ \\
\hline Flvash Reinjection Ratio & 3.5 & 5.6 & 3.5 & 3.5 \\
\hline
\end{tabular}

NOTE:

(1) Standard conditions are $32^{\circ} \mathrm{F}$ and 1 atm

(2) ----- equals the sum of primary airs/primary air from an orifice; plus the purge air and air at the bottom of the circulating bed cyclone added to both sets of the primary airs. 
Combustion efficiencies and sulfur captures based on gas analysis and ash analysis are compared in Table 1.6.

Table 1.6. Combustion Efficiency and Sulfur Capture Based on Gas Analysis Versus Ash Analysis

\begin{tabular}{|c|c|c|c|c|c|c|c|c|}
\hline \multirow{3}{*}{$\begin{array}{l}\text { TEST NUMBER } \\
\text { DATE }\end{array}$} & \multirow{2}{*}{\multicolumn{2}{|c|}{$\frac{1}{11 / 7 / 91}$}} & & & & & \multirow{2}{*}{\multicolumn{2}{|c|}{$\frac{4}{11 / 15 / 91}$}} \\
\hline & & & \multicolumn{2}{|c|}{$11 / 8 / 91$} & \multicolumn{2}{|c|}{$11 / 8 / 91$} & & \\
\hline & GAS & ASH & GAS & ASH & GAS & ASH & GAS & ASH \\
\hline $\begin{array}{l}\text { Combustion } \\
\text { Efficiency (\%) }\end{array}$ & 98.6 & 99.1 & 97.0 & 98.6 & 99.3 & 98.3 & 99.6 & 99.1 \\
\hline Sulfur Capture (\% & 80.2 & 86.6 & 81.4 & 95.1 & 81.6 & 95.2 & 88.5 & 85.1 \\
\hline
\end{tabular}

Note: although fairly good agreement can be seen between the gas and ash values, especially for combustion efficiency, the accuracy of the gas values is much higher because of the limitations in determining ash rates and the accuracy of the ash chemical analyses.

During the testing a trend was noticed between $\mathrm{SO}_{2}$ emissions and the cyclone outlet temperature. As the temperature increased to and above $1800^{\circ} \mathrm{F}$ (at roughly constant coal and limestone feeding) the $\mathrm{SO}_{2}$ emissions increased. And as the temperature fell (from high temperatures toward $1700^{\circ} \mathrm{F}$ ), the $\mathrm{SO}_{2}$ emissions also fell. This trend logically could be expected. The trends of the gas emissions at the boiler outlet during these tests are presented in Appendix B - Figures B-1 through B-6. The trends for the main bed, freeboard, and cyclone outlet temperatures during these tests are given in Appendix B - Figures B-7 through B-10. From these trends the operation of the unit can be seen to be very stable.

Note: In Figures B-8 and B-9 (Appendix B) the main bed temperature trend of the Vortex $^{\mathrm{TM}}$ test (Test No. 3 ) is lower than that in the non-Vortex test (Test No. 2) since the primary area only received about $80 \%$ of theoretical air, i.e., combustion is substoichiometric and not complete. 


\section{H. DISCUSSION/CONCLUSIONS}

Good indications were noticed during these tests and earlier tests performed during the summer and fall of 1991 . Flyash reinjection appears to have increased both combustion efficiency and sulfur capture. The automatic temperature control of the freeboard temperature has resulted in good stable operation requiring much less attention compared to the 1990 testing.

Scale-up of the unit to a $20,000 \mathrm{lb} / \mathrm{hr}$ steam, proof-of-concept boiler system, for example, focuses clearly on the overall gas residence times of the units and, more specifically, the cyclone gas residence times. The assumption of a Vortex-to-Primary air ratio of $1: 1$,results in overall residence times of 0.7 and 1.4 seconds for the pilot unit and the proof-of-concept unit, respectively. Primarily, the combustion takes place, or is completed, in the cyclone, and thus its residence time is more critical. These residence times are 0.2 seconds for the pilot unit and would be about 0.7 seconds for the proof-of-concept unit. The overall gas residence time of the proofof-concept unit would be more than twice that of the pilot unit. Even more important, the cyclone gas residence time of the proof-of-concept unit would be over 3 times that of the pilot plant. More than likely the combustion efficiency and sulfur capture in the proof-of-concept unit will be as good or better than the pilot unit. Further comparison of the two units' cyclones shows some differences. There is only one secondary air injection port for the proof-of-concept unit which would result in a much smoother cyclone barrel as opposed to the pilot unit cyclone with 4 sets of 8 rows of metal-framed air openings. Thus, the capture efficiency of the proof-of-concept cyclone may be even higher than the pilot unit cyclone even though the proof-of-concept cyclone diameter is about 2-3/4 times larger.

During this testing we achieved a cyclone/freeboard combustion air ratio of 0.7:1. This would allow a turndown ratio of about $4.25: 1$ and exceeds the objective of the Vortex technology of a ratio of at least $4: 1$. When loads lower than about $60 \%$ are required, the unit operates as a conventional CFB. Typically, the best turndown achievable by a conventional CFB is 3:1. Due to the relatively high heat losses associated with a small but intensive unit, the amount of air (or oxygen) flow through the bottom was higher than if the unit had been designed for a freeboard gas velocity of 38 to $40 \mathrm{ft} / \mathrm{sec}$ instead of the designed velocity of $30 \mathrm{ft} / \mathrm{sec}$. It is also 
contemplated that at the same or lower freeboard gas velocity a higher, up to 5:1, turndown ratio can be achieved in the scaled-up proof-of-concept VFBC unit.

An Economic Evaluation updated from the Level I evaluation is presented in Appendix $C$. 
SECTION 2

\begin{tabular}{|c|}
\hline THE TWO-STAGE \\
VORTEX $^{\mathrm{TM}}$ FLUIDIZED BED \\
COMBUSTOR (2VFBC) $^{-}$ \\
\hline
\end{tabular}




\section{ACKNOWLEDGEMENT}

The authors would like to acknowledge Penn State's Combustion Laboratory engineers, technicians, students and staff who were involved in the construction of the facility, in the test preparations, and in the test operations associated with the 2VFBC gasifier testwork.

The authors wish to thank Peter Botros of the U.S. Department of Energy, Morgantown Energy Technology Center (DOE/METC ), for his support and encouragement, and for help in the writing of this report. Technical staff members of DOE/METC are gratefully acknowledged for their suggestions and comments during this project.

The work on this project was supported by DOE/METC under Contract Number DE-AC21-87MC24216. 


\section{TABLE OF CONTENTS}

Page

\section{SECTION 2}

ACKNOWLEDGEMENT ........................................................................ i

TABLE OF CONTENTS............................................................................ ii

LIST OF FIGURES.......................................................................... iv

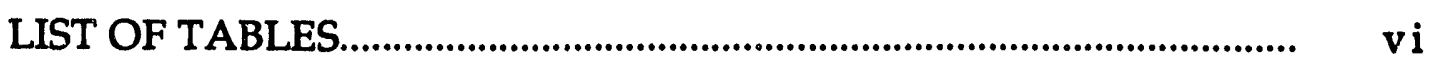

LIST OF SYMBOLS................................................................................. vii

I. INTRODUCTION ............................................................................ 2-1

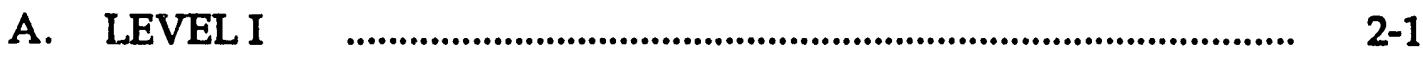

B. LEVEL II …….................................................................. 2-1

C. LEVEL III .................................................................................

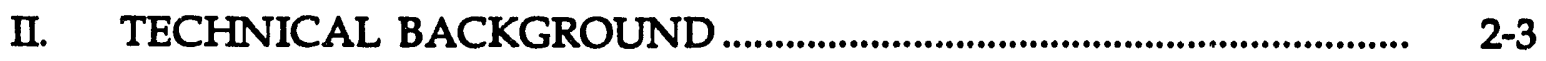

A. THE VFBC CONCEPT........................................................... 2-3

B. THE 2VFBC CONCEPT............................................................. 2-4

III. FACILITY DESIGN AND CONSTRUCTION......................................... 2-7

A. FREEBOARD .................................................................................. 2-9

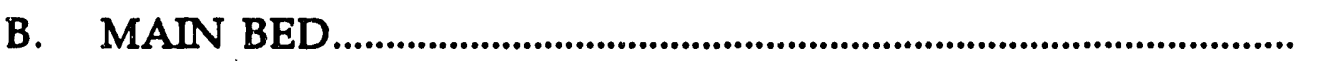

2-9

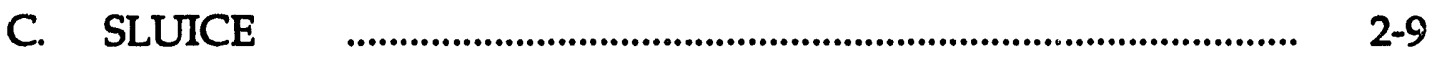

D. CYCLONE ...................................................................................... 2-10

E. MATERIALS OF CONSTRUCTION .............................................. 2-11

F. BALANCE OF FACILITY ...................................................... 2-11

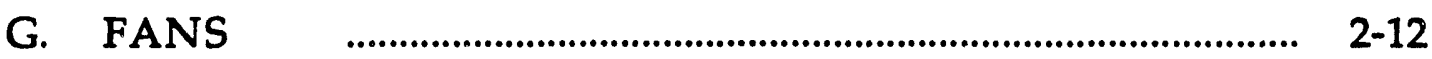

H. CWF FEED SYSTEM ............................................................... $\quad 2-12$

I. BOILER …......................................................................... $\quad 2-12$

J. BAGHOUSE.................................................................................... 2-13

K. INSTRUMENTATION ...................................................................... 2-14

IV. 2VFBC LAB-SCALE TESTING.................................................... 2-15 
A. TEST PLAN/OBJECTIVES...................................................... 2-15

B. NON-VORTEX TESTS .................................................................. 2-17

Objectives and Procedures .................................................. 2-17

C. VORTEX TESTS...................................................................... 2-18

Objectives and Procedures ........................................................... 2-18

D. RESULTS …....................................................................... $2-18$

Calcium-to-Sulfur Molar Ratio and Sulfur Capture........... 2-20

Coal and Limestone Feedstocks................................................ 2-23

2VFBC Residence Time............................................................. 2-27

Freeboard Velocity............................................................... 2-28

Nozzle Location, Air Rate and Nozzle Velocity ................... 2-2-30

Optimum Temperature Level for Sulfur Capture and Carbon Conversion ......................................................... 2-31

Vortex-to-Primary Air Ratio ...................................................... 2-33

Cyclone Inlet and Exit Velocities......................................... 2-34

Stoichiometric Air Ratio....................................................... 2-34

Higher Heating Value of the Flue Gas..................................... 2-37

Chemical Equilibria Analysis................................................... 2-39

Ash Composition........................................................................... 2-43

E. CONCLUSIONS AND DISCUSSIONS .......................................... 2-45

V. FULL SCALE DESIGN AND ECONOMIC ANALYSIS ......................... 2-46

A. DESIGN PARAMETERS.......................................................... 2-46

Retrofit Boiler ............................................................................ 2-46

Coal Analysis (CWF) ........................................................ 2-46

Limestone Analysis............................................................... 2-46

Vortex Gasifier Conditions....................................................... 2-46

B. SPECIFIC MASS BALANCE................................................. 2-47

C. BOILER EFFICIENCY ........................................................... 2-48

D. MASS AND HEAT BALANCES............................................... 2-48

System Mass Balance..................................................................... 2-48

Vortex Gasifier Mass Balance.................................................... 2-49

Vortex Gasifier Heat Balance.................................................. 2-49

E. EQUIPMENT ARRANGEMENT .................................................... 2-50

F. PROJECT CAPITAL COSTS...................................................... 2-53

G. PROJECT OPERATING COSTS ............................................. 2-54

H. ECONOMIC ANALYSIS AND "PAYBACK" .............................. 2- 2-55

I. DISCUSSION AND CONCLUSIONS......................................... 2-56 


\section{LIST OF FIGURES}

Page

Figure 2.1. Vortex $\quad$ TM Fluidized Bed Combustor (VFBC)

Sectional Views

Figure 2.2. Vortex ${ }^{\mathrm{TM}}$ Fluidized Bed Combustor (VFBC) Isometric View.. 2-4

Figure 2.3. Two Stage Coal Fired Adiabatic Vertical VFB Combustor....... 2-5

Figure 2.4. 2VFBC Experimental Facility ...................................................... 2-8

Figure 2.5. Cyclone Separator Proportions .................................................. 2-10

Figure 2.6a. Schematic of the CWF Feed System .......................................... 2-12

Figure 2.6b. Plan Section - PSU Research Boiler ........................................... 2-13

Figure 2.7. Gas Analysis System at PSU ......................................................... 2-14

Figure 2.8. Sulfur Capture Versus Temperature $\left({ }^{\circ} \mathrm{F}\right)$ - First Order............ 2-22

Figure 2.9. Sulfur Capture Versus Temperature ( $\left.{ }^{\circ} \mathrm{F}\right)$ - Second Order........ 2-22

Figure 2.10. Residence Time Versus Carbon Conversion.............................. 2-27

Figure 2.11. Residence Time Versus Sulfur Capture ................................... 2-28

Figure 2.12a. Sulfur Capture Versus Freeboard Velocity ................................. 2-29

Figure 2.12b. Carbon Conversion Versus Freeboard Velocity........................ 2-29

Figure 2.13. Sulfur Capture and Carbon Conversion

Versus Nozzle Velocity ........................................................... 2-30

Figure 2.14. Carbon Conversion Versus Temperature $\left({ }^{\circ} \mathrm{F}\right)$........................... 2-31

Figure 2.15. Sulfur Capture Versus Carbon Conversion............................. 2-32

Figure 2.16. Sulfur Capture and Carbon Conversion

Versus Vortex-to-Primary Air Ratio.......................................... 2-33

Figure 2.17. Stoichiometry Versus Temperature - All Data ....................... 2-34

Figure 2.18. Stoichiometry Versus Carbon Conversion............................... 2-35

Figure 2.19a. Stoichiometry Versus Sulfur Capture - All Data...................... 2-36

Figure 2.19b. Stoichiometry Versus Sulfur Capture -

Constant Ca-to-S for Non-Vortex Data ..................................... 2-36 
Figure 2.19c. Stoichiometry Versus Sulfur Capture -

Constant Ca-to-S for Vortex Data ................................................ 2-37

Figure 2.20. HHV Versus Stoichiometry .................................................... 2-37

Figure 2.21. HHV (Dry) Versus Carbon Conversion......................................... 2-38

Figure 2.22. CO Versus Time - Vortex Versus Non-Vortex............................ 2-42

Figure 2.23. Equipment Arrangement - End View......................................... 2-50

Figure 2.24. Equipment Arrangement - Side View ........................................ 2-51

Figure 2.25. Equipment Arrangement - Plan View....................................... 2-52

Figure 2.26. Economic Analysis for Retrofit Steam Outputs.......................... 2-55

Figure 2.27. Payback Time ................................................................................. 2-56 


\section{LIST OF TABLES}

Page

Table 2.1. Penn State 2VFBC - Planned Test Matrix .......................................... 2-17

Table 2.2a. 2VFBC Precombustor Operating Conditions................................... 2-19

Table 2.2b. 2VFBC Precombustor Operating Conditions..................................... 2-19

Table 2.3. Input Gas Chromatography Data for the

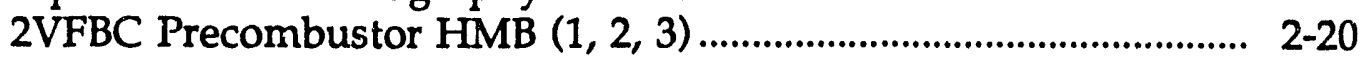

Table 2.4. 2VFBC Precombustor Test Results................................................... 2-21

Table 2.5. Bradford No. 44 Coal Chemical Analyses Non-Vortex Test Coal...................................................................... 2-24

Table 2.6. Bradford No. 44 Coal Chemical Analyses Vortex Test Coal........................................................................... 2-24

Table 2.7. Meckley Limestone Chemical Analyses .............................................. 2-25

Table 2.8. Initial Bradford No. 44 Coal Chemical Analyses.............................. 2-26

Table 2.9. Initial Meckley Limestone Chemical Analyses.................................. 2-26

Table 2.10. Cyclone Outlet Fuel Gas Composition ................................................ 2-41

Table 2.11. Gasification and Water Shift Reactions' Equilibrium Constants...................................................................... 2-41

Table 2.12a. Analyses of Sluice Drain Ash.................................................... 2-43

Table 2.12b. Analyses of Baghouse Ash Drain.................................................. 2-43 


\section{LIST OF SYMBOLS}

\section{ABBREVIATIONS}

ACFM Actual Cubic Feet per Minute

(at actual test conditions of temperature and pressure)

CFB

Circulating Fluid Bed

CFBC

Circulating Fluid Bed Combustor

CWF

Coal Water Fuel

FD

Forced Draft (fan)

GC

Gas Chromatograph or gas chromatography

HHV

Higher Heating Value, BTU/lb for solids or BTU/SCF for gases

ID

Induced Draft (fan)

IWC

Inches of Water Column (Pressure). Equivalent to IWG.

IWG

Inches of Water Gauge (Pressure). Equivalent to IWC.

$\mathrm{MM}$

Million

$\mathrm{MM} \mathrm{BTU} / \mathrm{hr}$

Million BTU's per Hour

MW

$P$

Megawatt (Electrical)

Pressure

PC

Pulverized Coal

PPH

Pounds per Hour or $\mathrm{Lb} / \mathrm{Hr}$

PSIG

Pound per Square Inch Gauge (Units of Pressure)

RA85H

Rolled Alloys $85 \mathrm{H}$ (Stainless Steel)

RA330

Rolled Alloys 330 (Stainless Steel)

SCFM

Standard Cubic Feet per Minute

$316 \mathrm{SS}$

316 Stainless Steel

$\mathrm{T}$

Temperature $\left({ }^{\circ} \mathrm{C}\right.$ or $\left.{ }^{\circ} \mathrm{F}\right)$

VFBC

Vortex ${ }^{\mathrm{TM}}$ Fluid Bed Combustor

2VFBC

Two-Stage Vortex ${ }^{\mathrm{TM}}$ Fluid Bed Combustor or Precombustor 


\section{INTRODUCTION}

In October 1987, the U.S. Department of Energy awarded DONLEE Technologies Inc. a contract to continue development of an advanced fluidized bed combustor known as the Vortex ${ }^{\mathrm{TM}}$ Fluidized Bed Combustor (VFBC). This contract was subsequently modified to include the evaluation of a two stage Vortex ${ }^{\mathrm{TM}}$ Fluidized Bed combustor (2VFBC). The 2VFBC development program includes three levels that are described below:

A. LEVEL I - featured theoretical investigations to establish the feasibility, both technically and economically, of 2VFBC technology for new equipment and for the retrofit of existing boilers. Theoretical investigations include:

1. Technical analysis that encompassed a comprehensive technical review of the 2VFBC concept and establishing performance and emission requirements for the system,

2. Chemical analyses for a theoretical investigation of the substoichiometric combustion chemistry in the 2VFBC. Characterization of the off-gas constituents, sulfur capture and sorbent utilization, and heat and material balance predictions were investigated to determine a basis for designing the laboratory-scale test unit.

3. Fine particle capture efficiency studies for cold and heated cyclones were performed with and without tangential vortex air injection to obtain design recommendations for the laboratory-scale precombustor hot test unit.

B. LEVEL II - is characterized by laboratory-scale experimentation with an integrated "hot" 2VFBC system to establish the operational and performance boundaries of the total system and identify any remaining issues to be resolved prior to building the proof-of-concept facility. The four technical tasks that were performed during this level were:

1. Laboratory-scale precombustor (2VFBC) design,

2. Laboratory-scale precombustor system construction,

3. Laboratory-scale precombustor testing, and

4. Technical and economic evaluation was also done. Additional testing at this level is suggested prior to considering the Level III proof-ofconcept work. 
C. LEVEL III - features the design, construction, installation and operation of a full-scale proof-of-concept 2VFBC system. The operability, reliability, and cost of the 2VFBC system will be established and compared to oil-, gas- and coalfired package boilers. The successful completion of the Level III effort should provide the commercial/industrial market with a technically, environmentally and economically acceptable coal-fired precombustor (2VFBC) system.

Section II of this report summarizes the Level II activities associated with the precombustor (2VFBC) concept; Level II activities associated with the VFBC concept are summarized in Section I of this report.

Section II is organized according to the four technical tasks described above for the Level II effort. An introductory description of the VFBC concept and the 2VFBC concept along with a brief summary of the 2VFBC performance projected in the Level I effort is presented to acquaint the reader with the concept and to permit this report to be used independently of previous or other reports. 


\section{TECHNICAL BACKGROUND}

\section{A. THE VFBC CONCEPT}

Donlee Technologies is developing a new type of circulating fluidized-bed system that will address small to medium sized industrial applications with steam generation capacities ranging from 20,000 to 100,000 pounds of steam per hour and higher. This advanced circulating fluidized bed is known as the Vortex ${ }^{\mathrm{TM}}$ Fluidized Bed. Its unique feature is the injection of a significant portion of the combustion air into the cyclone; as much as 50 percent of the combustion air is injected as secondary air into the cyclone. The cross-sectional area of the circulating fluidized bed is therefore 50 percent of the size of a conventional CFB operating at the same velocity. The cross-sectional area of the VFBC fluidized bed is only 25 percent of the size of a conventional CFB if the VFBC freeboard velocity is twice that of the CFB. The required combustor/boiler height is minimized because the cyclone combustor requires less residence time and no water-wall tubes are used: heat is extracted in an adjacent bubbling cooling bed.

The use of an adjacent cooling bed for heat extraction results in a substantial reduction in heat transfer surface required and permits a substantial reduction in combustor height, resulting in a reduction in front-end costs. Tube surface erosion is essentially eliminated because the surfaces are immersed in a low-velocity, fine particle bubbling bed. Furthermore, tube surface corrosion is minimized because the environment in the cooling bed is oxidizing or mildly reducing. Boiler tube failure will be much less common; system reliability will increase and maintenance costs will decrease. Combustor performance is also enhanced by using an adjacent cooling bed because conditions for combustion and heat extraction can be controlled separately; start-up and load following should be improved in the Vortex ${ }^{\mathrm{TM}}$ Fluidized Bed due to the use of an adjacent cooling bed.

Sectional views of the Vortex ${ }^{\mathrm{TM}}$ Fluidized Bed Combustor (VFBC) are shown in Figure 2.1 and an isometric view is shown in Figure 2.2. 


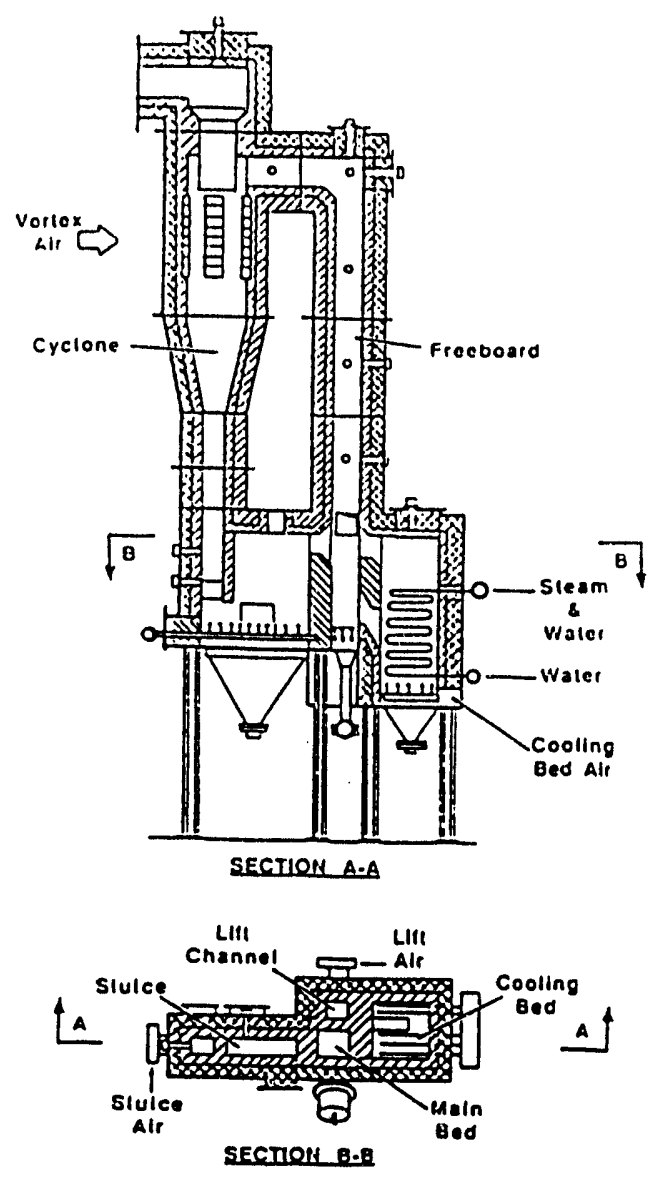

Figure 2.1. Vortex ${ }^{\mathrm{TM}}$ Fluidized Bed Combustor (VFBC) Sectional Views

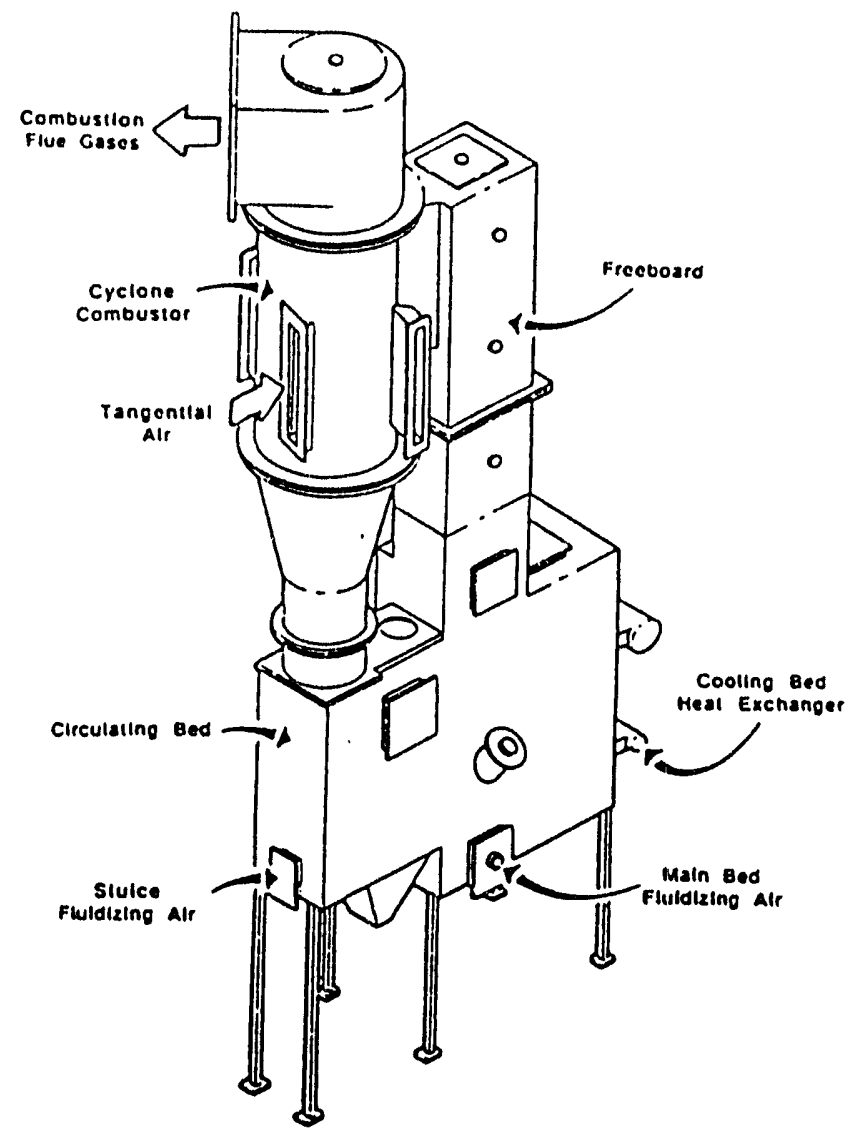

Figure 2.2. Vortex ${ }^{\mathrm{TM}}$ Fluidized Bed Combustor (VFBC) Isometric View

\section{B. THE 2VFBC CONCEPT}

The VFBC combustion technology described above is also readily adaptable for operation as a gasifier. In fact the equipment is simplified by the removal of the cooling bed. Operating temperature in a gasification mode is determined by the respective fuel and air flow rates. As a gasifier, the Vortex ${ }^{\mathrm{TM}}$ technology provides the first stage in a two stage combustion process. It operates substoichiometrically and provides a combustible gas and char. Combustion would normally be completed in a second stage. This could be a gas burner in a conventional boiler operating at atmospheric pressure, or a topping combustor in an integrated gasification comrined cycle (IGCC) operating at high pressure (150 to $300 \mathrm{psig}$ ). 
This two stage approach, using Vortex Fluidized Bed technology to minimize the first stage combustor size is called 2VFBC combustion (Korenberg, 1987). A diagram of the concept is shown in Figure 2.3. Coal or CWF (Coal-WaterFuel) is fed into the fluidizing bed, operating in a circulating fluidized bed regime, where coal devolatilizes and is partially oxidized (gasified).

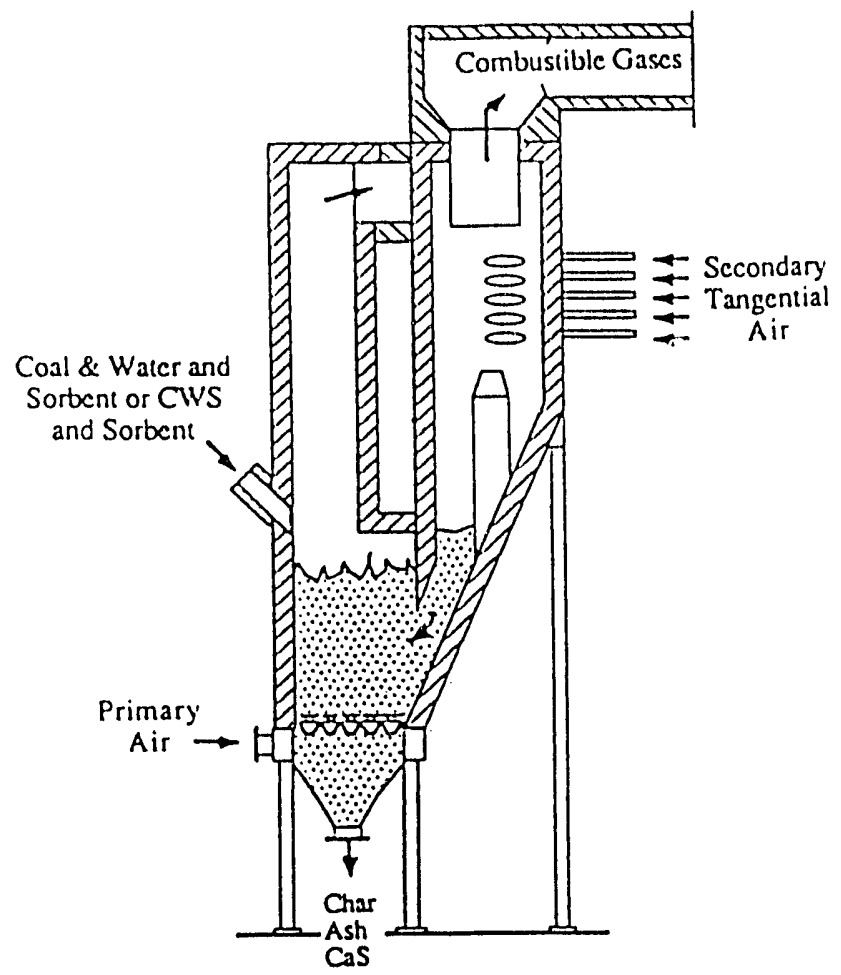

Figure 2.3. Two Stage Coal Fired Adiabatic Vertical VFB Combustor

About $50 \%$ of the total air (approximately $25 \%$ of the stoichiometric air) is used in this portion of the 2VFBC. Limestone is injected dry, or with the CWF, into the bed where it reacts with sulfur volatilized from the coal. Since the atmosphere is reducing, calcium sulfide is the probable product of the sulfur capturing reactions. The balance of the first stage air is injected into the hot cyclone of the unit. This air is injected tangentially into the cyclone barrel to complete conversion of carbon and possibly convert $\mathrm{CaS}$ to $\mathrm{CaSO} 4$.

The first task of this project involved theoretical investigation to verify the technical and economic feasibility of the 2VFBC concept for both new equipment and for retrofit of existing boilers. The objectives of these investigations were to:

- develop the 2VFBC design concept,

- examine the range of applications for this concept, and

- establish whether the concept can be reasonably priced.

Based upon heat and material balances and design parameters, the 2VFBC concept seems technically feasible for industrial and larger sized systems. In new applications, the 2VFBC system appears least expensive when compared to 
pulverized coal (PC) and CFB systems. The retrofit of an industrial size PC system with a 2VFBC unit also seems feasible. Final justification will be dictated by an indepth economic analysis.

The second task of this project includes laboratory-scale experimentation to define the operational and performance parmeters of the 2VFBC concept. Also, this work will identify remaining areas which need to be investigated to scale the concept up to an industrial size. Specific goals for the laboratory test program include optimizing performance in terms of minimizing emissions, maximizing combustor efficiency, characterization of combustion products, and development of empirical correlations for scale-up purposes.

Based upon the results of this test program, design recommendations for a proof-ofconcept facility will be established. The capital installed cost and annual operating cost for the 2 VFBC precombustor concept was projected during this task. 


\section{FACILITY DESIGN AND CONSTRUCTION}

A drawing of the 2VFBC experimental unit is shown in Figure 2.4. This unit was constructed and delivered to the Penn State University Combustion Laboratory in July, 1989. Auxiliary systems to feed slurry and burn the 2VFBC fuel gas are available at the site, as are the analytical instruments to monitor unit performance.

The 2VFBC combustor includes a 1 foot inside diameter freeboard section and a 1 foot inside diameter cyclone. Operation with a superficial gas velocity in the riser freeboard of $15 \mathrm{ft} / \mathrm{sec}$ and a cyclone/circulating bed air ratio of about 0.5:1 provides a thermal output from the unit of about $2 \mathrm{MM} \mathrm{Btu} / \mathrm{hr}$.

The experimental unit was designed for flexibility; it can accept CWF or dry coal feed. The cyclone barrel can be replaced with one having an 18 inch inside diameter and the cyclone gas outlet can be reduced by inserting a different diameter sleeve if necessary. Numerous ports (16) for temperature and pressure measurements and refractory access plugs to facilitate internal repair or modification were provided.

The nominal design values for the primary operating parameters were as follows:

$\begin{array}{ll}\text { Freeboard Velocity } & 15 \mathrm{ft} / \mathrm{sec} \\ \text { Freeboard (or Unit) Temperature } & 1650,1750,1850^{\circ} \mathrm{F} \\ \text { Main Bed Velocity } & 8 \mathrm{ft} / \mathrm{sec} \\ \text { Sluice Velocity } & 6 \mathrm{ft} / \mathrm{sec} \\ \text { Cyclone Tangential Velocity } & 70 \mathrm{ft} / \mathrm{sec} \\ \text { Percent of Stoichiometric Air } & 30-50\end{array}$



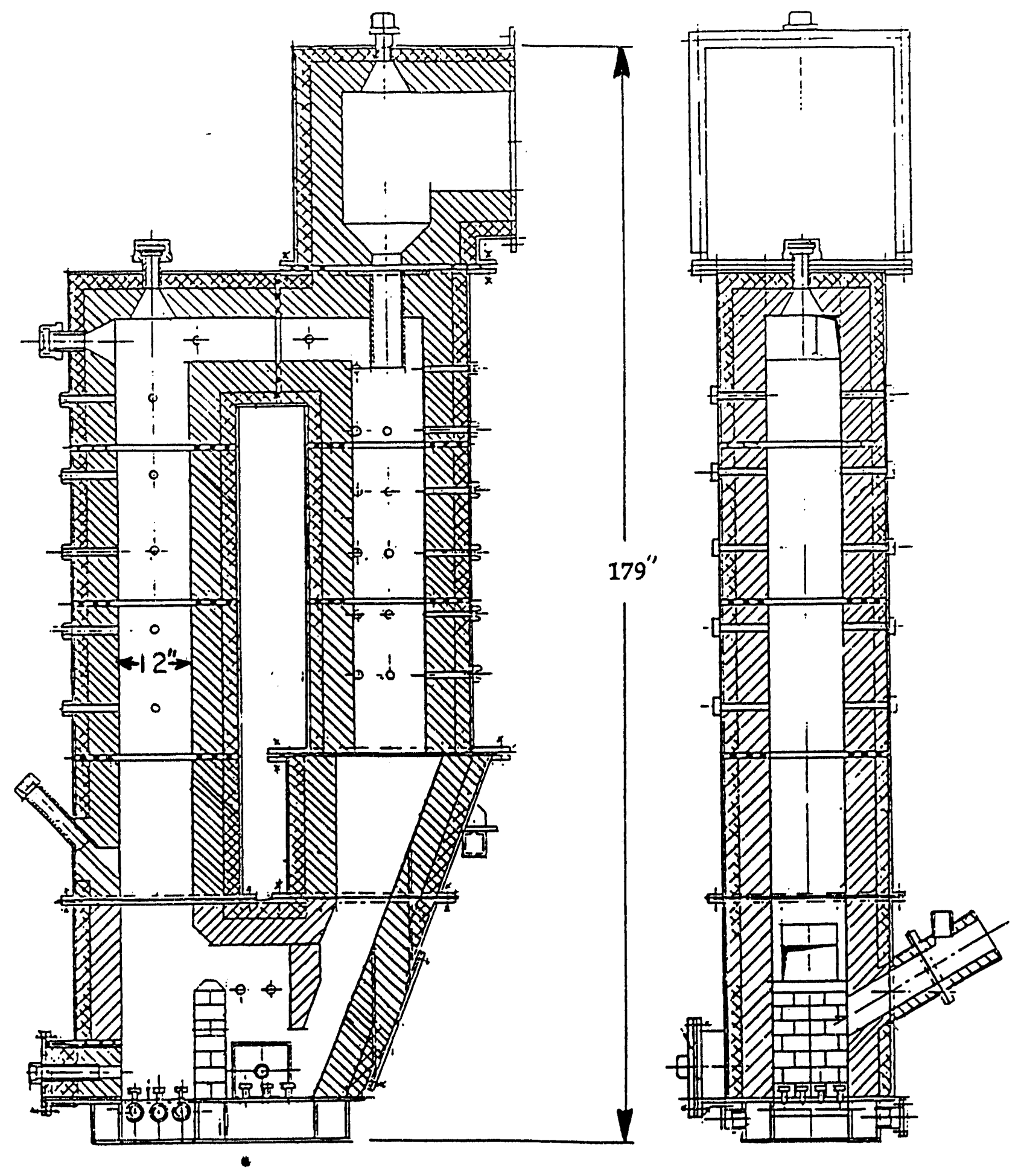

Figure 2.4. 2VFBC Experimental Facility 


\section{A. FREEBOARD}

The inside diameter of the freeboard is one foot. The freeboard height from the top of the opening separating the sluice from the main bed to the top steel shell is 100 $1 / 2$ inches. Superficial gas velocities during testing ranged from 12.4 to $17.3 \mathrm{ft} / \mathrm{sec}$.

\section{B. MAIN BED}

The main bed is located directly under the freeboard, in fact, it could be considered to be the lower portion of the freeboard. Thus, its inside diameter is also one feet. The height of the main bed is $25-1 / 2$ inches. The main bed was fluidized by bubblecaps located on four standpipes. During operation the main bed superficial gas velocity ranged from 5.7 to $10.3 \mathrm{ft} / \mathrm{sec}$. The coal water fuel (CWF) was pumped into the main bed during all of the tests that were performed at Penn State. However, the unit was designed for flexibility; it can accept either CWF or dry coal feed.

\section{SLUICE}

Solids flow through the sluice from the cyclone solids discharge to the main bed. It is 9 inches wide by 15 inches long by 25-1/2 inches high. The solids are maintained as a fluidized bed in the sluice. $A$ wall 19 inches tall by 9 inches wide separates the sluice from the main bed. An opening 6-1/2 inches high by 9 inches wide above this wall connects these two beds together. The sluice does not provide solids circulation rate control. Its purpose is simply to provide a seal to prevent gas backflow through the cyclone, which would seriously disrupt particle capture and to provide a means of solids transfer. The wall between the main bed and sluice ensures that the sluice bed level would not drop below a critical height that would allow the solids seal to be broken. During the testing the sluice superficial gas velocity remained between 4.7 and $6.3 \mathrm{ft} / \mathrm{sec}$ with the bed being fluidized by the air through the 6 bubblecaps. 


\section{CYCLONE}

The cyclone in the 2VFBC lab unit is the unique component of the unit. The cyclone has two purposes -- one is to separate recirculating solids form the gas stream and the other is to be a gasifier. The cyclone was designed using general design methods with several changes. Typical relative cyclone dimensions are shown in Figure 2.5. The 2VFBC cyclone was designed to accommodate either a 12 inch or an 18 inch inside diameter barrel in the cyclone design, as needed.

The inlet and outlet dimensions of the cyclone are a composite of those that would be determined for 12 inch diameter and an 18 inch diameter cyclone barrel. The cyclone dimensions are as follows:

Inlet Height .7 inches

Inlet Width 3-1/2 inches

Barrel Diameter ............ 12 or 18 inches

Barrel Height.......................79 inches

Gas Outlet Diameter................6 inches (changed later to 4.72 inches)
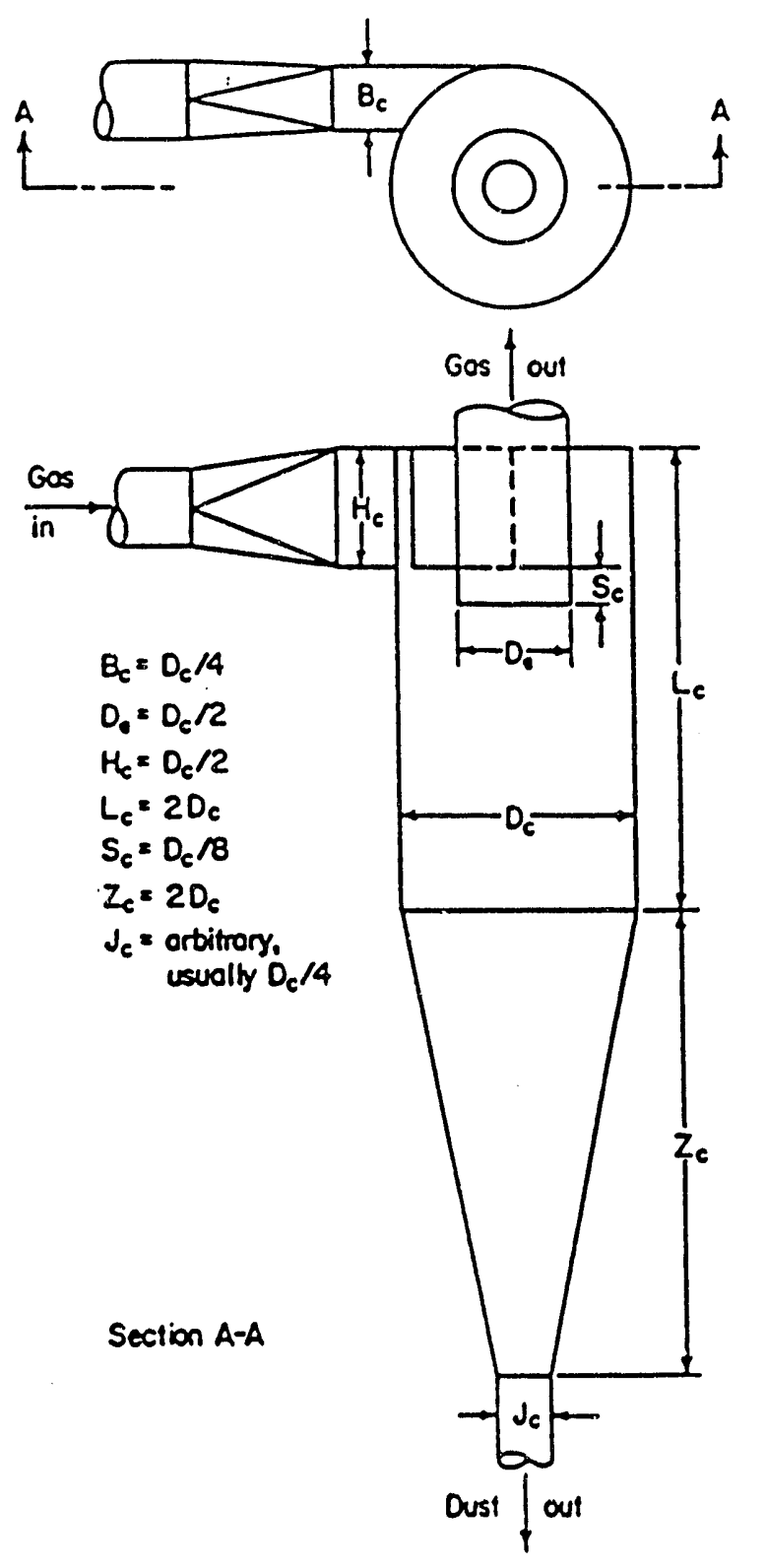

Cone Height .23 inches

Solids Discharge Diameter ......9 inches

Figure 2.5. Cyclone Separator Proportions

The cyclone outlet tube diameter can be reduced by inserting a different diameter sleeve if necessary. Neither of these options were used during the testing. The cyclone barrel inside diameter remained at one foot for all of the tests. However, 
one problem did occur. The gas outlet in the original design was 6 inches inside diameter with a 6-5/8 inches outside diameter. During preliminary testing (prior to the test matrix tests) the entering solids eroded through the cyclone exit tube wall (304 Stainless Steel) causing the cyclone to short-circuit. The repair to this situation was to decrease the diameter of the outle tube to 4.72 inches inside diameter (5.22 inches outside diameter) to protect the cyclone exit tube from the entering solids. The cyclone exit tube was first replaced prior to the start of the test matrix. After running 8 tests the cyclone exit tube was replaced a second time. The replacement tube in each case was made of $1 / 8$ inch thick (or 10 gauge) Rolled Alloys $85 \mathrm{H}$ (RA85H) stainless steel.

The cyclone has a total of twelve vortex $3 / 4$ inch pipe nozzles for injecting air during vortex testing. The nozzles are vertically spaced across the cyclone barrel in two columns of 6 nozzles diametrically opposite each other. These nozzles enter the cyclone inside barrel tangent to the inside barrel surface.

\section{E. MATERIALS OF CONSTRUCTION}

All sections of the 2VFBC gasifier were lined with a double layer refractory. A section of the insulation block layer near the burner required replat ement during the testing. Holes were cut into the outside shell of the unit, and Cease Fire insulating foam was pumped in to replace the insulation layer. The hot face refractory made of Plibrico Hymor 3000 did not require replacement. The shell was fabricated from $1 / 4$ inch carbon steel. All air distributors were also made of carbon steel. The Inconel sleeve used in the burner extension and the RA85H material used in the cyclone gas outlet pipe were the only high temperature alloys used in the system.

\section{F. BALANCE OF FACILITY}

The facility also included fans, a CWF feed system, a waste heat boiler with a burner to combust the gases generated by the 2VFBC unit, the duct to the boiler from the cyclone outlet, a baghouse, and instrumentation required to assess the unit's performance. 


\section{G. FANS}

The facility has two fans. The FD fan is a six-stage centrifugal Hoffman blower that delivered up to $220 \mathrm{ACFM}$ at a maximum pressure of $125 \mathrm{I}$.W.C. and $158^{\circ} \mathrm{F}$ to the main bed, sluice, or vortex nozzles. The facility also included a Chicago Blower ID fan that maintained the balance point at the outlet of the cyclone.

\section{H. CWF FEED SYSTEM}

At Penn State University, a relatively simple CWF feed system was developed. This system was designed to utilize a coarse grind of coal without pumping or settling problems. A roughly equivalent mixture of fine coal pulverized coal and coarse coal (nominally $1 / 8^{\prime \prime} \times 0$, with 0.143 " maximum or top size) is added to a 100 or 500 gallon/day tank. A sufficient amount of water is then mixed with the coal in the tank in order to achieve the desired solids loading. A solids loading of $70 \%$ was planned.

The CWF feed to the 2 VFBC is supplied by a progressing cavity 3-stage pump (Model 3P3 Moyno) downstream of the transfer pump. The flow rate through the pump to the 2 VFBC was controlled by varying the pump speed. Refer to Figure 2.6a.

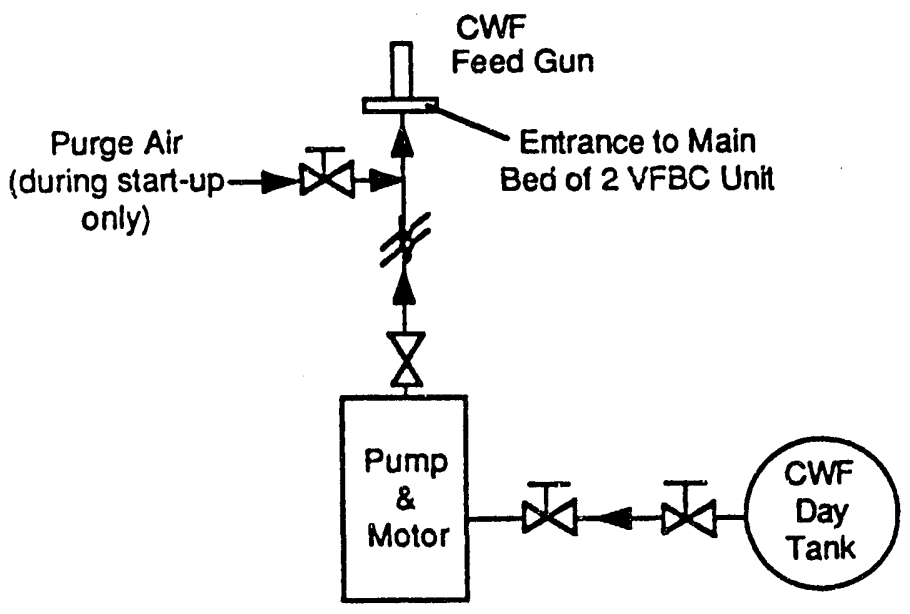

Figure 2.6a. Schematic of the CWF Feed System 


\section{BOILER}

The 2VFBC laboratory unit has been integrated with a $2 \mathrm{MM} \mathrm{Btu/hr}$ watertube boiler (see Figure 2.6b) in order to combust the fuel gas and entrained particulates exiting the cyclone. The fuel gas is carried to the watertube boiler in an 8" I.D. stainless steel pipe. An Inconel burner pipe enters through the rear door of the watertube boiler. The fuel gas enters the boiler axially through this 6 inch pipe which extends 48 inches into the boiler; the combustion air enters the boiler through access ports on each side of the front of the boiler. In order to assure complete combustion of the fuel gas and unburned carbon, the natural gas burner at the front of the boiler was maintained at low fire during testing. The gases exiting the boiler then pass through a baghouse to remove particulates. A negative pressure is maintained in the boiler by adjusting the I.D. fan damper in order to avoid gas/particulate leakage.

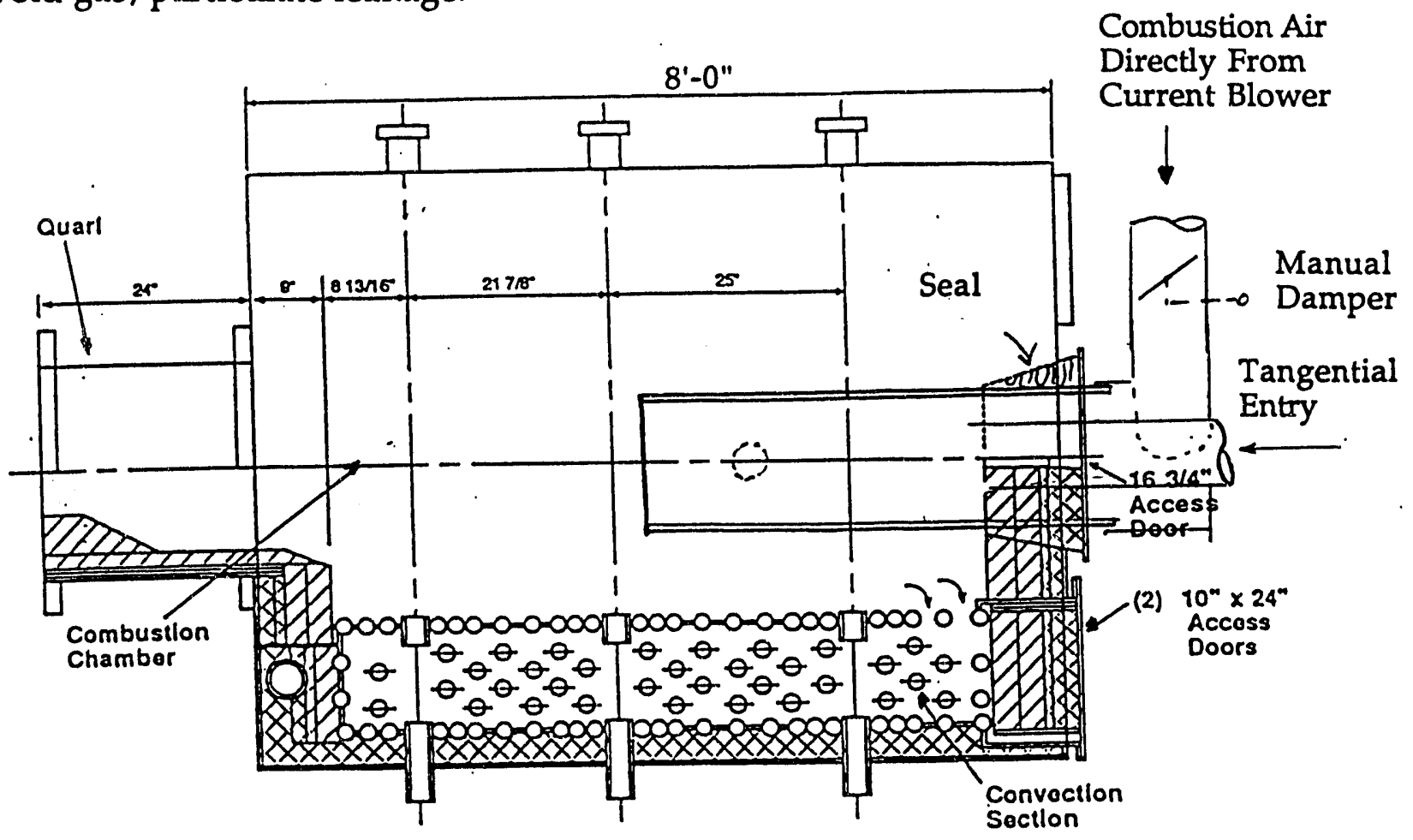

Figure 2.6b. Plan Section - PSU Research Boiler

\section{J. BAGHOUSE}

The baghouse contains 16 Fiberglas $@$ felt bags, each 8 feet long and 6 inches in diameter. Thus, the surface of the bags provides $201 \mathrm{ft}^{2}$ of area. The bags provided an air-to-cloth ratio of about 4.5 to 6.0 during the tests sufficient for good operation. However, if a vortex-to-primary air ratio of 1:1 or higher had been possible with respect to the fans, the air-to-cloth ratic would then be about 9.25, and the baghouse would have started to become a limiting factor in the testing. 


\section{K. INSTRUMENTATION}

A gas chromatograph was utilized to yield on-line gas analysis and monitor 2VFBC performance. The gas sample was obtained at the cyclone outlet about one foot upstream of the water quench spray. The gas chromatograph (GC) analysis can quantify the following components in the fuel gas stream: $\mathrm{CH}_{4}, \mathrm{CO}, \mathrm{CO}_{2}, \mathrm{H}_{2}, \mathrm{H}_{2} \mathrm{~S}$, $\mathrm{N}_{2}, \mathrm{C}_{2} \mathrm{H}_{4}, \mathrm{SO}_{2}$ and $\mathrm{O}_{2}$. Water $\left(\mathrm{H}_{2} \mathrm{O}\right)$ analysis was determined via the dry gas analysis plus nitrogen and hydrogen balance based on the input compositions.

The flue gas was also analyzed for the following:

- Oxygen via a paramagnetic analyzer; and

- Carbon Monoxide and Carbon Dioxide via a non-dispersive infrared analyzer.

No $\mathrm{NO} / \mathrm{NO}_{\mathrm{x}}$ analysis was provided for in these tests. In addition, the detection limits for $\mathrm{SO}_{2}$ and $\mathrm{H}_{2} \mathrm{~S}$ for the Penn State $\mathrm{GC}$ were too high to be used in the gas analyses for the 2VFBC gasifier. An outside laboratory was hired to perform gas chromatographic analyses for each test to provide sulfur compound $\left(\mathrm{SO}_{2}\right.$ and $\mathrm{H}_{2} \mathrm{~S}$ ) analyses and complete analysis to check Penn State University's GC analysis.

The gas analysis system at Penn State is presented in Figure 2.7.

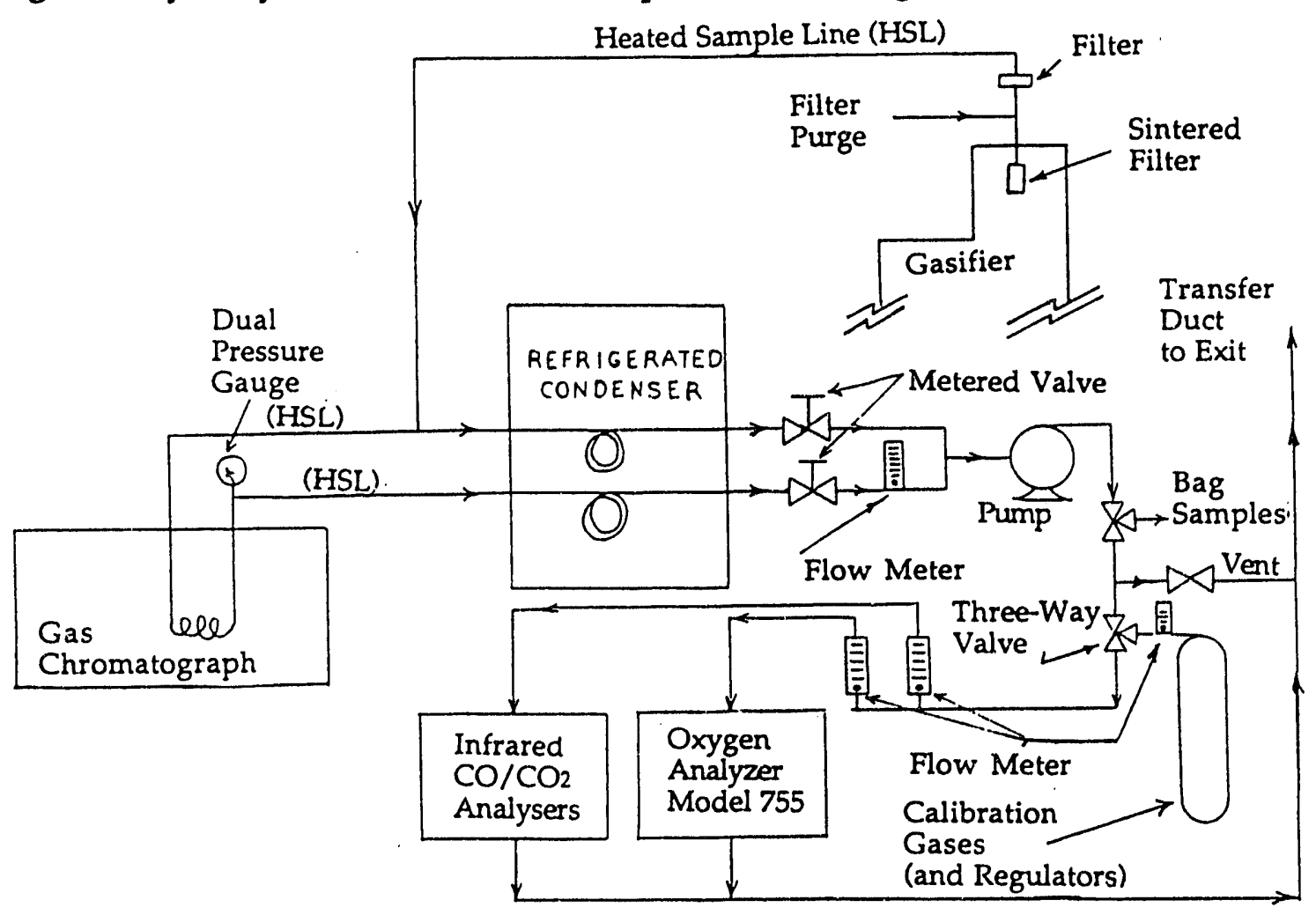

Figure 2.7. Gas Analysis System at PSU 


\section{2VFBC LAB-SCALE TESTING}

Formal testing was conducted in the 2VFBC lab unit at the Penn State Combustion Laboratory from March through July of 1991. During that period 10 formal tests were obtained, along with a number of shakedown tests. Some operational problems were encountered especially with the initial feed system. Most of these problems were eliminated by making changes to the Moyno pump, eliminating the Sandpiper diaphragm transfer pump between the storage day tank and the Moyno pump, and by adding an air injection line in the feed.line to keep the CWF nozzle open prior to CWF being injected into the main bed. One problem occurred with the refractory. The insulating block material near the gas burner and several feet higher needed to be replaced due to burner gases getting behind the hot face material. A pumpable material, Cease Fire insulating foam, was pumped through holes cut in the outer shell to replace the insulating refractory. These holes were later welded shut after being sealed with Kaowool. The Inconel burner tube was extended further toward the main bed to avoid gases getting behind the hot face refractory in the future.

\section{A. TEST PLAN/OBJECTIVES}

The objectives of Level II testing were to establish the operational and performance boundaries of the total system and identify any remaining issues to be resolved prior to building the proof-of-concept facility. Technical uncertainties that were identified in the test plan to be of particular interest for examination were:

1. the amount of theoretical air required to achieve satisfactory gasification performance,

2. sulfur capture efficiency as a function of limestone use (calcium-to-sulfur molar ratio),

3. residence time required to achieve adequate performance.

4. optimum freeboard superficial velocity to ensure stable operation and minimize temperature differentials, and

5. The operating temperature level to obtain the best combination of carbon conversion and sulfur capture. 
In addition, specific questions relating to cyclone performance and secondary air injection that needed to be addressed experimentally were identified to be:

1. How much air can be effectively injected into the cyclone as secondary gasification air without adversely affecting gasification and/or cyclone particle capture performance?

2. What is the optimum location of the air injection nozzles, i.e., should the air be injected along the axis (length) of the cyclone barrel or should it be injected along the circumference of the cyclone barrel near the "dirty gas" inlet?

3. What air injection velocity should be used, i.e., how many nozzles of what size should be used? Is there a minimum secondary air injection velocity as well as a maximum velocity that must be maintained in order to achieve adequate performance?

The test plan indicated that the experimental program had to provide verification of:

1. adequate cyclone temperature control by circulating solids through the cyclone combustor; and

2. operating ranges for gas velocity through the main bed, slui and freeboard.

Finally, miscellaneous design information such as performance of materials of construction and methods for coal and limestone feeding were inticipated to be acquired.

In order to address as many of these system performance questions as possible, two types of tests were conducted. Preliminary tests of shorter duration were conducted to screen the effect of rerating variables and to determine operating conditions without vortex seconda. .1 . Longer duration tests were run with vortex secondary air to determine the am int of air and its velocity (number and size of nozzles) that can be used to obtain adequate performance. Ash samples were collected at the end of all but the first test. Chemical analyses of these samples were used to verify material balances. The results of these tests are discussed in the following sections.

The test matrix used as a guide for the Level II testing is presented in Table 2.1.

This test $\mathrm{m}$ trix varies operating freeboard temperature, heat input, $\mathrm{Ca} / \mathrm{S}$ ratio, air rates, air ratios, the number of vortex nozzles and nozzle velocity. From the tests given here, the effects of these changes can be evaluated. 
Table 2.1. Penn State 2VFBC - Planned Test Matrix

\begin{tabular}{|c|c|c|c|c|c|c|c|c|}
\hline $\begin{array}{l}\text { TEST } \\
\text { RUN } \\
\text { NO. }\end{array}$ & $\begin{array}{c}\text { REEBOARD } \\
\text { TEMP. } \\
{ }^{\circ} \mathrm{F}\end{array}$ & \begin{tabular}{|l|} 
HEAT \\
INPUT \\
$10^{6} \mathrm{BTU} / \mathrm{h}$ \\
\end{tabular} & \begin{tabular}{|l|} 
CA/S \\
RATIO
\end{tabular} & $\begin{array}{c}\text { VORTEX } \\
\text { AIR } \\
\text { RATIO }\end{array}$ & \begin{tabular}{|c|} 
FREEBOARD \\
AIR \\
SCFM \\
\end{tabular} & $\begin{array}{c}\text { VORTEX } \\
\text { AIR } \\
\text { SCFM }\end{array}$ & $\begin{array}{c}\text { NUMBER } \\
\text { OF } \\
\text { NOZZLES }\end{array}$ & $\begin{array}{c}\text { NOZZLE } \\
\text { VELOCITY } \\
\text { FT/S } \\
\end{array}$ \\
\hline \multicolumn{9}{|c|}{ BASE } \\
\hline 1 & 1650 & 2 & 0 & $\mathbf{0}$ & A (CHECK) & 0 & 0 & 0 \\
\hline \multicolumn{9}{|c|}{ TEMP.RANGE } \\
\hline 2 & 1550 & 2 & 2.5 & $\mathbf{0}$ & A- & 0 & 0 & 0 \\
\hline 3 & 1650 & 2 & $\overline{2.5}$ & 0 & $\bar{A}$ & $\overline{0}$ & 0 & 0 \\
\hline 4 & 1750 & 2 & 2.5 & 0 & At & 0 & 0 & 0 \\
\hline \multicolumn{9}{|c|}{ CA/S CHANGE } \\
\hline 5 & 1650 & 2 & 1.5 & $\begin{array}{l}0 \\
0\end{array}$ & $\bar{A}$ & 0 & 0 & 0 \\
\hline 6 & 1650 & 2 & 2.5 & 0 & $\mathrm{~A}$ & 0 & 0 & 0 \\
\hline 7 & 1650 & 2 & 3.5 & 0 & $\mathrm{~A}$ & 0 & 0 & 0 \\
\hline \multicolumn{9}{|c|}{ VORTEX AIR } \\
\hline 8 & 1650 & 3.0 & 2.5 & 0.5 & $\bar{A}$ & $0.5 . \mathrm{A}$ & $\mathrm{N}_{1}$ (CHECK) & $\mathrm{V}_{1}$ (CHECK) \\
\hline 9 & 1650 & 3.5 & 2.5 & 0.75 & $\bar{A}$ & $0.75 \mathrm{~A}$ & $\mathrm{~N}_{1}$ & $1.5 . \mathrm{V}_{1}$ \\
\hline 10 & 1650 & 4.0 & 2.5 & 1.0 & $\bar{A}$ & $1.0 . \mathrm{A}$ & $\overline{N_{1}}$ & $2 . \mathrm{V}_{1}$ \\
\hline \multicolumn{9}{|c|}{ NOZZLE CHANGE } \\
\hline 11 & 1650 & 3.0 & 2.5 & 0.5 & $\mathrm{~A}$ & $0.5 . \mathrm{A}$ & $\mathrm{N}_{2}$ & $\mathrm{~V}_{2}$ \\
\hline 12 & 1650 & 3.5 & 2.5 & 0.75 & $\bar{A}$ & $\overline{0.75 . A}$ & $\mathrm{~N}_{2}$ & $1.5 . \mathrm{V}_{2}$ \\
\hline$\overline{13}$ & 1650 & 4.0 & 2.5 & 1.0 & $\bar{A}$ & $1.0 . \mathrm{A}$ & $\mathrm{N}_{2}$ & $2 . V_{2}$ \\
\hline
\end{tabular}

INOTES: 1. A: Baseline air rate

2. N: Number of vortex nozzles

3. V: Nozzle Velocity

4. At: Air rate higher than $A$

5. A-: Air rate less than $A$

6. $N_{i}$ and $V_{i}:(N)$ nozzles corresponding to a nozzle velocity $(V)$

for a corresponding vortex air rate.

\section{B. NON-VORTEX TESTS}

The non-vortex tests were run with only air entering the main bed and sluice, and without any air entering the cyclonic gasifier.

\section{Objectives and Procedures:}

The objectives of those non-vortex tests are as follows:

- Determine the theoretical air needed to obtain satisfactory gasification performance;

- Determine the sulfur capture efficiency as a functions of calcium-to-sulfur molar ratio;

- Optimize the freeboard superficial gas velocity to ensure stable operation and minimize temperature differentials; and

- Determine the operating temperature level to obtain the best combustion of carbon conversions and sulfur capture. 
Heat and material balances were performed for each set of data: Coal and limestone compositions and feedrates, flue gas composition via gas chromatograph, the air rates to the sluice and main bed, and the composition of the ash drained at the end of each test except for the first test.

During all testing the unit was heated up via the natural gas burner as a combustor. The CWF was brought on and stabilized at a high excess air. The burner vas then turned off and the CWF pump flowrate was increased to bring the air-to-fuel rate into the substoichiometric or gasifier regime at the desired theoretical air. After the operating conditions were stable for a time period, the gas chromatography data, gas bag samples, and operating data were collected. At the end of a test, a sluice ash sample was collected as an aid to the heat and material balance.

\section{VORTEX TESTS}

The testing included a total of 10 successful tests. Seven were non-vortex tests and 3 were vortex tests.

\section{Objectives and Procedures:}

These tests helped determine the amount of air that can be effectively injected into the cyclone as secondary air without adversely affecting gasification and/or cyclone particle capture efficiency. Also, these tests were to determine the optimum location of the air injection nozzles and the air injection velocity (or number of nozzles).

\section{RESULTS}

The operating data for the non-vortex and vortex tests are in Appendices $G$ and $H$, respectively. The data included are the following items:

- Unit temperatures;

- Test dates and times;

- Bed pressures;

- Air rates (uncorrected for bed temperature and pressure);

- Velocities (uncorrected for bed temperature and pressure);

- Coal feed rate;

- Firing Rate:

- Gas analysis via analyzers for $\mathrm{O}_{2} \mathrm{CO}_{2}$ and $\mathrm{CO}$;

- Times when GC analysis, gas bag samples and sluice samples were taken; and

- Plots of CO versus time. 
The temperature used for these discussions is the average bed temperature. The temperatures of the unit were fairly constant across the height. The average bed temperature was calculated as the average of the main bed (T2) and sluice (T15) temperatures. Throughout all the discussions in this report, the average bed temperature is used and is referred to as the average temperature throughout the rest of the report. The reduced operating conditions are presented in Tables $2.2 \mathrm{a}$ and $2.2 \mathrm{~b}$. These operating conditions will be discussed in the following sections along with the other test results. The input data from the gas chromatograph used for the heat-and-material balances are in Table 2.3. Corrections for in leakage of air eliminate $\mathrm{O}_{2}$ from these analyses since the atmosphere is substoichiometric and change $\mathrm{N}_{2}$ values, correspondingly.

Table 2.2a. 2VFBC Precombustor Operating Conditions

\begin{tabular}{|c|l|c|c|c|c|c|c|c|}
\hline $\begin{array}{c}\text { TEST } \\
\text { NO. }\end{array}$ & $\begin{array}{l}\text { TEST } \\
\text { DATE }\end{array}$ & $\begin{array}{c}\text { COAL } \\
\text { RATE } \\
(\text { LB/HR) }\end{array}$ & $\begin{array}{c}\text { LIMESTONE } \\
\text { RATE } \\
(\text { LB/HR) }\end{array}$ & $\begin{array}{c}\text { CWF } \\
\text { SLURRY } \\
\text { WATER } \\
(\%)\end{array}$ & $\begin{array}{c}\text { HEAT } \\
\text { INPUT } \\
\text { X 10-6 } \\
\text { (B TU/HR) }\end{array}$ & $\begin{array}{c}\text { 2VFBC } \\
\text { AVERAGE } \\
\text { TEMP. } \\
\left({ }^{\circ} \text { F) }\right.\end{array}$ & $\begin{array}{c}\text { STOICHIO- } \\
\text { METRIC } \\
\text { AIR RATIO } \\
(\%)\end{array}$ & $\begin{array}{c}\text { Ca/S } \\
\text { MOLAR } \\
\text { RATIO }\end{array}$ \\
\hline \hline 1 & $3-28-91$ & 148.2 & 0 & 30.9 & 2.006 & 1688 & 43.6 & 0 \\
2 & $5-8-91$ & 148.2 & 66.1 & 30.9 & 2.006 & 1859 & 53.3 & 2.98 \\
3 & $4-11-91$ & 148.2 & 66.1 & 30.9 & 2.006 & 1684 & 43.3 & 2.98 \\
4 & $4-5-91$ & 148.2 & 66.1 & 30.9 & 2.006 & 1788 & 53.8 & 3.98 \\
5 & $5-14-91$ & 148.2 & 33.6 & 31.1 & 2.006 & 1682 & 41.1 & 1.52 \\
6 & $5-9-91$ & 148.2 & 66.1 & 30.9 & 2.006 & 1714 & 41.6 & 2.98 \\
7 & $5-16-91$ & 148.2 & 112.6 & 30.8 & 2.006 & 1682 & 49.3 & 5.08 \\
8 & $6-5-91$ & 192.7 & 85.9 & 30.8 & 2.479 & 1776 & 50.7 & 2.91 \\
9 & $6-18-91$ & 170.4 & 76.0 & 30.8 & 2.193 & 1748 & 49.8 & 2.91 \\
10 & $6-25-91$ & 192.7 & 85.9 & 30.8 & 2.479 & 1774 & 53.8 & 2.91 \\
\hline
\end{tabular}

* The coal rate includes some moisture: $1.82 \%$ for Test Numbers 1-7 and 1.99\% for Test Numbers 8-10.

Table 2.2b. 2VFBC Precombustor Operating Conditions

\begin{tabular}{|c|c|c|c|c|c|c|c|c|c|c|c|c|}
\hline \multirow[b]{2}{*}{$\begin{array}{l}\text { TEST } \\
\text { NO. }\end{array}$} & \multirow[b]{2}{*}{$\begin{array}{l}\text { TEST } \\
\text { DATE }\end{array}$} & \multirow[b]{2}{*}{ Main Bed } & \multirow{2}{*}{$\begin{array}{l}\text { R RATE } \\
\text { Sluidoe }\end{array}$} & \multirow{2}{*}{$\begin{array}{l}\text { SCFM (1 } \\
\text { Freeboand } \\
(2,3)\end{array}$} & \multirow[b]{2}{*}{$\begin{array}{c}\text { Vontex } \\
\text { (3) }\end{array}$} & \multirow{2}{*}{\begin{tabular}{|c|} 
VORTEX \\
TO \\
PRIMARY \\
RATIO
\end{tabular}} & \multirow[b]{2}{*}{ Main Bed } & \multirow[b]{2}{*}{ Shuice } & \multirow{2}{*}{$\begin{array}{l}\text { LOCITIES, } \\
\text { Freebound }\end{array}$} & \multirow{2}{*}{$\begin{array}{c}\text { FT/SEC } \\
\text { Vortex } \\
\text { Nozzle } \\
\end{array}$} & \\
\hline & & & & & & & & & & & ${ }_{\text {Inlet }}^{C}$ & One- \\
\hline 1 & 3-28-91 & 87.1 & 65.8 & 152.9 & 0 & 0 & 7.5 & 4.7 & 13.1 & 0 & 60.7 & 84.9 \\
\hline 2 & $5-8-91$ & 109.9 & 76.9 & 186.8 & 0 & 0 & 10.2 & 6.0 & 17.3 & 0 & 80.1 & 112.1 \\
\hline 3 & $4-11-91$ & 83.5 & 68.5 & 152.0 & 0 & 0 & 7.2 & 4.9 & 13.0 & 0 & 60.2 & 84.3 \\
\hline 4 & $4-5-91$ & 114.9 & 73.8 & 188.7 & 0 & 0 & 10.3 & 5.6 & 17.0 & 0 & 78.4 & 109.8 \\
\hline 5 & 5-14-91 & 66.3 & 78.0 & 144.3 & 0 & 0 & 5.7 & 5.6 & 12.4 & 0 & 57.2 & 80.0 \\
\hline 6 & $5-9-91$ & 69.0 & 76.9 & 146.0 & 0 & 0 & 6.0 & 5.6 & 12.7 & 0 & 58.7 & 82.2 \\
\hline 7 & $5-16-91$ & 85.6 & 87.5 & 173.1 & 0 & 0 & 7.3 & 6.3 & 14.8 & 0 & 68.5 & 96.0 \\
\hline 8 & $6-5-91$ & 92.7 & 76.6 & 169.3 & 51.6 & 0.30 & 8.3 & 5.7 & 15.2 & 67.6 & 70.0 & 127.8 \\
\hline 9 & $6-18-91$ & 85.3 & 75.7 & 160.8 & 31.5 & 0.20 & 7.5 & 5.6 & 14.2 & 41.3 & 65.6 & 109.8 \\
\hline 10 & $6-25-91$ & 89.8 & 81.7 & 171.5 & 62.6 & 0.37 & 8.0 & 6.1 & 15.3 & 82.1 & 70.8 & 135.3 \\
\hline
\end{tabular}

Notes: (1) Standard conditions are 1 atm and $70^{\circ} \mathrm{F}$.

(2) Total primary air equals main bed air plus sluice air, i.e., the freeboard air.

(3) Total air equals total primary air plus vortex air.

(4) Differences in freeboard air from main bed air plus sluice air are due to roundoff. 
Table 2.3. Input Gas Chromatography Data for the 2VFBC Precombustor HMB $(1,2,3)$

\begin{tabular}{|c|c|c|c|c|c|c|c|c|c|c|}
\hline TEST NO. & 1 & 2 & 3 & 4 & 5 & 6 & 7 & 8 & 9 & 10 \\
\hline DATE & 3-28-91 & $5-8-91$ & $4-11-91$ & $4-5-91$ & 5-14-91 & $5-9-91$ & $5-16-91$ & $6-5-91$ & $6-18-91$ & $6-25-91$ \\
\hline \multicolumn{11}{|c|}{ GAS COMPONENT } \\
\hline $\mathrm{N}_{2}(\%)$ & 70.54 & 60.3 & 56.1 & 61.25 & 65.04 & 62.02 & 54.17 & 61.6 & 58.22 & 64.5 \\
\hline$\overline{\mathrm{CO}_{2}(\%)}$ & 14.78 & 14.7 & 9.5 & 12.2 & 15.8 & 14.93 & 12.19 & 12.6 & 13.19 & 6.01 \\
\hline $\mathrm{CO}(\%)$ & 3.92 & 6.44 & 4.5 & 3.71 & 5.06 & 5.17 & 6.95 & $\overline{14.4}$ & 11.46 & 2.39 \\
\hline $\mathrm{H}_{2} \mathrm{~S}(4)(\mathrm{ppm})$ & 611 & 992 & 569 & 452 & 12 & 673 & 247 & 409 & 614 & 359 \\
\hline $\mathrm{O}_{2}(\%)$ & 1.06 & 0.8 & 0.8 & 0.84 & 1.01 & 0.93 & 0.71 & 1.2 & 0.86 & 10.39 \\
\hline $\mathrm{CH}_{4}(\%)$ & 1.37 & 0.76 & $\overline{1.3}$ & 0.69 & $\overline{1.47}$ & 1.56 & 0.96 & $\overline{0.6}$ & $\overline{0.46}$ & 0.26 \\
\hline $\mathrm{C}_{2} \mathrm{H}_{4}(\%)$ & 0.099 & 0.01 & 0.94 & 0.031 & 0.06 & 0.09 & 0.04 & 0.0182 & 0.0091 & 0.0019 \\
\hline $\mathrm{H}_{2}(\%)$ & 5.38 & 5.97 & 6.5 & 4.06 & 7.17 & 7.59 & 9.25 & 10.0 & 9.1 & 4.26 \\
\hline
\end{tabular}

Notes:

(1) All the data above are Penn State data, except the data in Test Number 8, which is from Texas Research Institute (TRI), and outside laboratory. These Test Number 8 data were substituted since they are clearly superior even to all other test results. No other test data showed this distinction. Penn State data were arbitrarily used elsewhere since these data were obtained on-line and the TRI data were from bag samples and probabiy not as good.

(2) No $\mathrm{SO}_{2}$ was detected in any analysis.

(3) The inilut gas chromatography data from the outside laboratory are in Appendix C. See Appendix D for a discussion of the gas chromatography analyses and the accuracies of these analyses.

(4) The $\mathrm{H}_{2} \mathrm{~S}$ for Penn State data were estimated from TRI data.

\section{Calcium-to-Sulfur Molar Ratio and Sulfur Capture:}

The sulfur captures for the 10 tests are presented in Table 2.4. Note that sulfur capture is very good with values ranging from 79 to $99+\%$. The highest sulfur capture occurred at the lowest temperature area at $1682^{\circ} \mathrm{F}$ and the lowest calcium-tosulfur molar ratio. Note that good sulfur capture in any fluid bed gasifier can be achieved with a calcium-to-sulfur molar ratio of only 1.2 to 1.5 . The sulfur capture decreases as the temperature increases with the lowest sulfur capture occurring at the highest temperature, $1859^{\circ} \mathrm{F}$. These data are plotted in Figures 2.8 and 2.9. The correlations in these figures are for the non-vortex data. The vortex data are plotted in the figures to show how they relate to the non-vortex data and the relationship. 
Table 2.4. 2VFBC Precombustor Test Results

\begin{tabular}{|c|c|c|c|c|c|c|c|c|c|c|}
\hline & $\begin{array}{l}\text { TEST } \\
\text { DATE }\end{array}$ & $\begin{array}{c}\text { 2VFBC } \\
\text { AVERAGE } \\
\text { TEMP. } \\
\text { (마) }\end{array}$ & $\begin{array}{l}\text { SULFUR } \\
\text { CAPIURE } \\
\text { (1) }(\%)\end{array}$ & $\begin{array}{l}\text { CARBON } \\
\text { CONVERSION } \\
\text { (2) }(\%)\end{array}$ & $\begin{array}{l}\text { HH } \\
\text { HBT } \\
\text { WET }\end{array}$ & $\begin{array}{l}\text { GAS } \\
\text { F)(3) } \\
\text { DRY }\end{array}$ & $\begin{array}{l}\text { GAS } \\
\text { MOISTURE } \\
\text { (\% BY } \\
\text { VOLUME) }\end{array}$ & $\begin{array}{c}\text { Ca/S } \\
\text { MOLAR } \\
\text { RATIO }\end{array}$ & $\begin{array}{l}\text { STOICHIO- } \\
\text { METRIC } \\
\text { AIR RATIO } \\
(\%)\end{array}$ & $\begin{array}{c}\text { TIME } \\
\text { UNIT } \\
\text { ON COAL } \\
\text { (HOURS) }\end{array}$ \\
\hline$\overline{1}$ & $3-28-91$ & 1688 & No Data & 59.9 & 39.5 & $\overline{50.0}$ & 21.0 & 0 & 43.6 & 3 \\
\hline 2 & $5-8-91$ & 1859 & 78.9 & 85.8 & 48.2 & 57.1 & 15.6 & 2.98 & 53.3 & $5-1 / 3$ \\
\hline 3 & $4-11-91$ & 1684 & 89.4 & 57.1 & $\overline{70.8}$ & 85.1 & 16.8 & 2.98 & 43.3 & $6-1 / 6$ \\
\hline 4 & $4-5-91$ & $\overline{1788}$ & 90.4 & 63.4 & 34.1 & $\overline{41.9}$ & $\overline{18.6}$ & 2.98 & 53.8 & 1.5 \\
\hline 5 & $5-14-91$ & 1682 & 99.8 & 65.0 & $\overline{50.6}$ & 61.2 & 17.3 & 1.52 & 41.1 & $4-1 / 3$ \\
\hline 6 & $5-9-91$ & 1714 & 89.1 & 63.9 & 55.1 & 67.2 & 18.0 & 2.98 & 41.6 & $5-11 / 30$ \\
\hline 7 & $5-16-91$ & 1682 & $\overline{94.6}$ & 76.7 & 66.4 & 77.9 & 14.8 & 5.08 & 49.3 & $5-1 / 2$ \\
\hline 8 & $6-5-91$ & 1776 & 92.3 & 104.4 & 76.5 & 90.3 & 15.3 & 2.91 & 50.7 & $5-1 / 2$ \\
\hline 9 & $6-18-91$ & 1748 & 88.1 & 96.5 & 67.1 & 80.5 & $\overline{16.6}$ & 2.91 & $\overline{49.8}$ & $6-1 / 30$ \\
\hline 10 & $6-25-91$ & 1774 & 83.8 & 76.3 & 53.7 & 63.7 & 15.7 & 2.91 & 53.8 & $4-3 / 4$ \\
\hline
\end{tabular}

Notes:

(1) Sulfur capture is in the solid form as calcium sulfide (CaS) or calcium sulfate (CaSO 4$)$.

Only $\mathrm{H}_{2} \mathrm{~S}$ (and no $\mathrm{SO}_{2}$ ) was detected during the testing.

(2) Carbon Conversion can be defined in two equivalent ways:

METHOD A CARBON CONVERSION =

$\frac{\text { (Total Carbon in - Carbon in the char - Carbon in limestone as } \mathrm{CO}_{2} \text { ) }}{\left.\text { (Carbon in - Carbon in limestone as } \mathrm{CO}_{2}\right)} \times 100$

METHOD B CARBON CONVERSION =

$\frac{\text { (Carbon in gases } \mathrm{CO}_{2}, \mathrm{CO}, \mathrm{CH}_{4} \text { and } \mathrm{C}_{2} \mathrm{H}_{4} \text { - Carbon in limestone as } \mathrm{CO}_{2} \text { ) }}{\text { Coal Rate } \times(\text { Carbon in coal/100) }} \times 100$

(3) Standard Conditions - $1 \mathrm{~atm}$ and $60^{\circ} \mathrm{F}$ as for all fuel gases. 


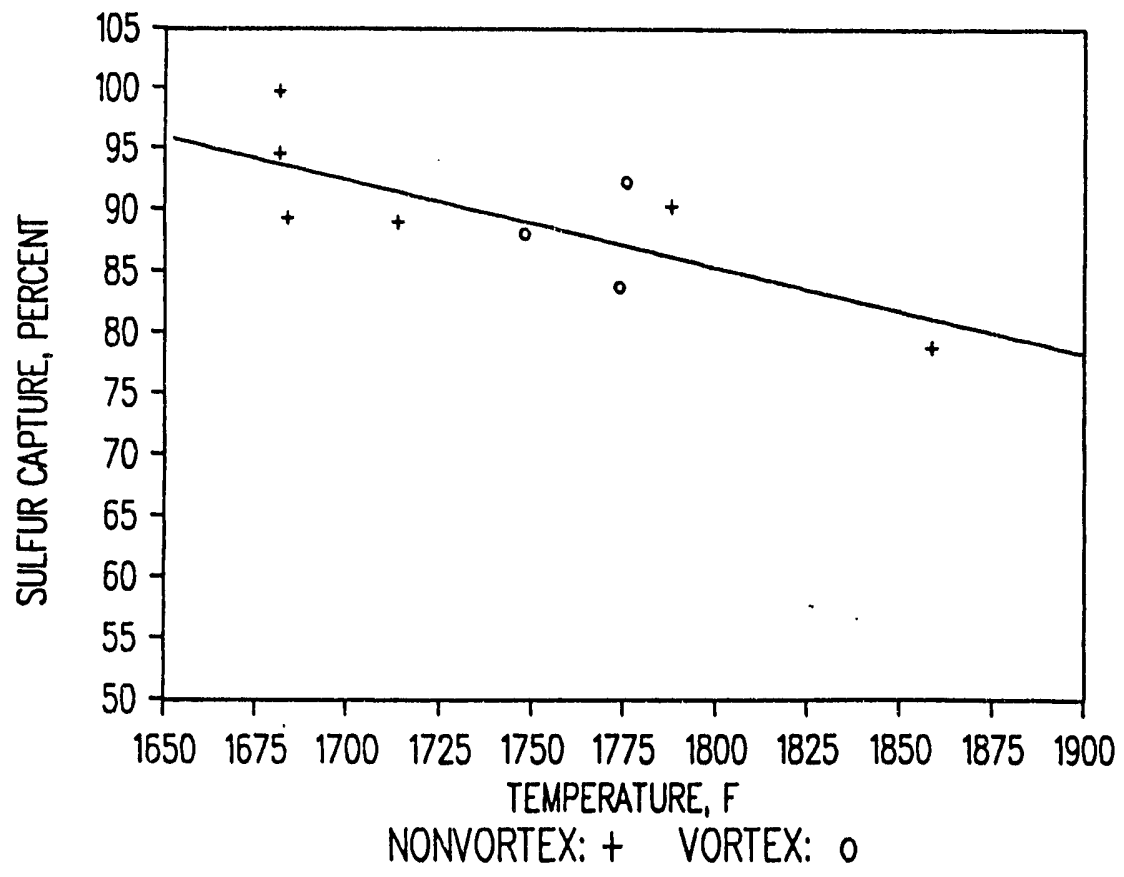

Figure 2.8. Sulfur Capture Versus Temperature $\left({ }^{\circ} \mathbf{F}\right)$ - First Order Figure 2.8 shows a linear equation representation where:

Sulfur Capture $=224.04-0.0771$ (Temperature)

Where Sulfur Capture, \%

Temperature is Bed Temperature, ${ }^{\circ} \mathrm{F}$

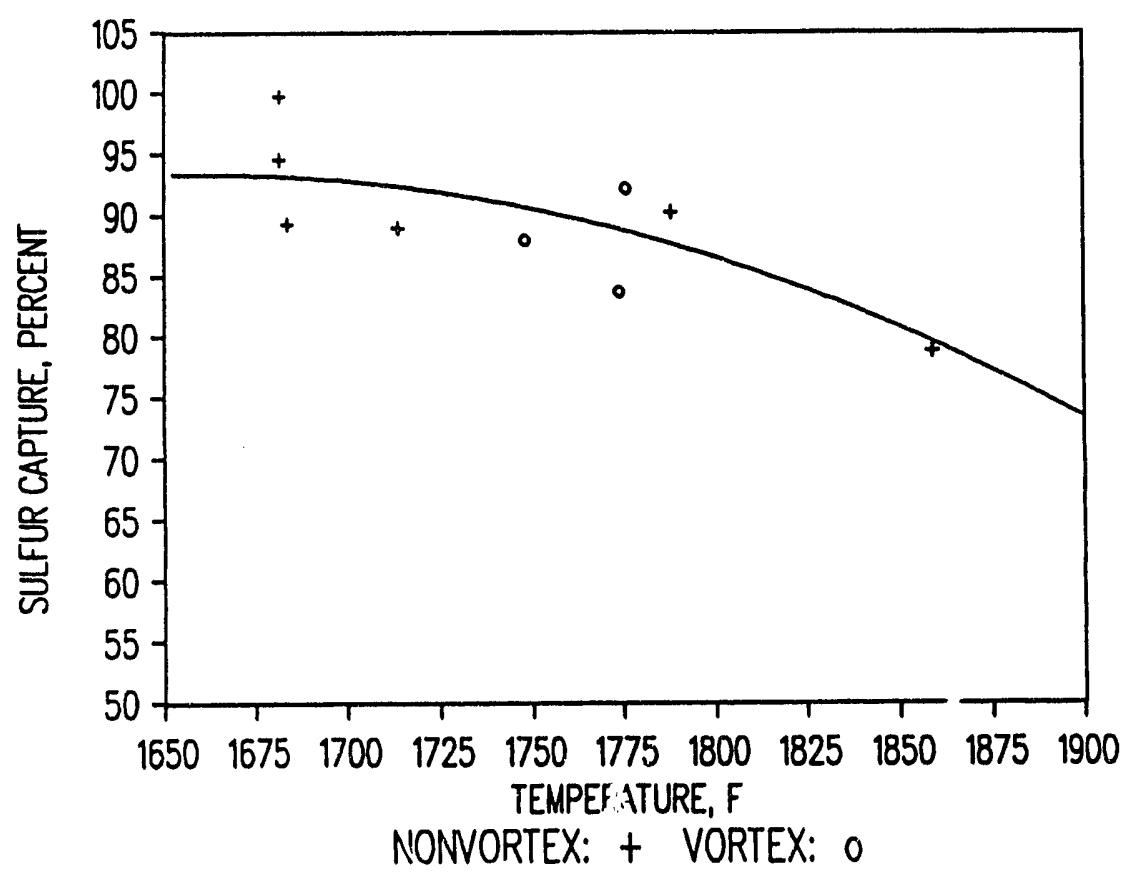

Figure 2.9. Sulfur Capture Versus Temperature $\left({ }^{\circ} F\right)$ - Second Order The second order equation in Figure 2.9 fits the data a little better:

Sulfur Capture $=-791.67+1.08$ (Temperature) $-.000327(\text { Temperature })^{2}$ Where Sulfur Capture, \%

Temperature is Bed Temperature, ${ }^{\circ} \mathrm{F}$ 
The second order correlation represents the data slightly better. The maximum sulfur capture for this equation occurs at $1661^{\circ} \mathrm{F}$.

A very weak correlation between the sulfur capture and the calcium-to-sulfur (Cato-S) molar ratio is not shown here since the correlation implies that as the Ca-to-S molar ratio increases, the sulfur capture decreases. This obviously is impossible. More data are needed to develop a stronger correlation.

\section{Coal and Limestone Feedstocks}

During the gasification testing at Penn State a total of 10 successful long-term tests were performed. Of these tests, 7 were non-vortex, i.e., no vortex air was introduced into the 2VFBC unit. The last 3 successful tests were vortex tests in which secondary air was introduced into the vortex cyclone to complete the gasification of the CWF fed into the main bed of the unit. More vortex tests were attempted during the last month of testing. However, none of these tests were successful due to operational problems. Additional tests could not be attempted since Penn State personnel were withdrawn from this project and placed on other contracts due to their time constraints. Two shipments of coal were obtained from the Bradford Coal Company during the test period. The first shipment was used during non-vortex testing. The second coal shipment was used during vortex testing. The coal obtained was all from Bradford's No. 44 Deep Mine in Clearfield County, PA. Each coal shipment was sampled and the analyses were composited. The physical and chemical properties of the coals from these two shipments are presented in Tables 5 and 6. The limestone (Fine limestone, -16 mesh) used in all of the testing was from Meckley Limestone near Herndon, PA. The limestone was stored in $50 \mathrm{lb}$ bags. Four of the bags were sampled and analyzed. The composite of the limestone analyses and other properties apply to all of the tests performed at Penn State and are presented in Table 2.7. These coal and limestone analyses were not available until after the testing was already completed. 
PROXIMATE ANALYSIS:

Moisture

Volatile Matter

Fixed Carbon

Ash

TOTAL

ULTIMATE ANALYSIS:

Carbon

Hydrogen

Nitrogen

Sulfur

Oxygen

Ash

Moisture

TOTAL

Higher Heating Value (Btu/lb)

Free Swelling Index

\section{Percent}

1.82

22.70

65.20

10.30

100.02 (due to roundoff)

75.84

4.66

1.25

4.00

2.13

10.30

1.82

100.00

13535 (13756 by Dulong Equation) $8.5-9$

NOTES:

1. These analyses are based on the representative composite sample resulting from combining two samples, each representative of one half of the pile. The above analyses are the average sample analyses representative of the entire coal pile.

2. The coal originally was $3 / 8 " \times 0$ in size.

Table 2.6. Bradford No. 44 Coal Chemical Analyses Vortex Test Coal

\begin{tabular}{lc} 
PROXIMATE ANALYSIS: & \\
Moisture & 1.99 \\
Volatile Matter & 22.74 \\
Fixed Carbon & 61.10 \\
Ash & 14.17 \\
TOTAL & 100.00 \\
ULTIMATE ANALYSIS: & \\
Carbon & 72.34 \\
Hydrogen & 4.55 \\
Nitrogen & 1.18 \\
Sulfur & 4.10 \\
Oxygen & 1.67 \\
Ash & 14.17 \\
Moisture & 1.99 \\
TOTAL & 100.00 \\
Higher Heating Value (Btu/lb) & $12868(13214$ by Dulong Equation) \\
Free Swelling Index & $8.5-9$ \\
\hline
\end{tabular}

NOTES:

1. The above analyses are based on two separate analyses. The first analysis was of the material larger than 8 mesh size and comprised 70\% (approximate) weight percent of the sample gathered. The undersized coal (-8 mesh), making up 30\% of the material, made up the second sample.

Therefore, the above sample analyses are the weighted sample analyses and are representative of the second coal pile.

2. The coal originally was $3 / 8$ " $\times 0$ in size. 


\section{Table 2.7. Meckley Limestone Chemical Analyses \\ Applied to All Test Results \\ (Average of 4 Sample Analyses)}

\begin{tabular}{|lrr|}
\hline Loss on Ignition at $900^{\circ} \mathrm{C}$ & $\frac{\text { Percent }}{38.59}$ & (included in $\mathrm{CO}_{2}$ evolution and moisture) \\
$\mathrm{CaO}$ & 46.79 & \\
$\mathrm{CaCO}_{3}$ & 83.51 & 83.51 \\
$\mathrm{MgO}_{\mathrm{MgCO}}$ & 2.00 & \\
Inerts & 4.18 & 4.18 \\
Moisture & 12.12 & 12.12 \\
TOTAL & 0.19 & $\underline{0.19}$ \\
\hline
\end{tabular}

NOTE: This material is -16 mesh.

The CWF feedstock consisted of coal, limestone (in all but the baseline case - Test Number 1) and water. The coal used was made up of $95 \% 1 / 8 " \times 0$ (actual maximum size was $0.143 ")$ and $5 \%$ fines $(<200$ mesh or $<74 \mu \mathrm{m})$. The nominal water content was $30 \%$. But since the coal contained roughly $2 \%$ water and the limestone contained a small fraction of water $(0.19 \%$ approx.,) the actual water content of the CWF was closer to $31 \%$ ( 30.8 to $31.1 \%$ ). Nominally the limestone rate was varied with respect to the coal rate to give calcium-to-sulfur molar ratios of $0 ., 1.5,2.5$ and 3.5 based on the initial coal and limestone analyses obtained before testing. However, since the actual coal and limestone compositions given above were very different (lower sulfur in the coal and higher calcium carbonate in the limestone), the calcium-to-sulfur molar ratios were much higher. These actual feed analyses were completed several months after the testing was completed. This resulted in the difference between the preliminary results presented in July of 1991 and the final results presented in this Topical Report. The coal and limestone analyses used in the preliminary analysis of the data are given in Tables 2.8 and 2.9, respectively. The data analysis presented here is based solely on the two coal shipment composites for non-vortex and vortex tests, correspondingly, and the composite limestone analysis for the entire test program. 
Table 2.8. Initial Bradford No. 44 Coal Chemical Analyses

(Preliminary Analyses)

Applied to All Test Results

PROXIMATE ANALYSIS:

Moisture (1)

Volatile Matter

0.00

Fixed Carbon

22.65

Ash

66.56

TOTAL

10.79

100.00

ULTIMATE ANALYSIS:

$\begin{array}{lr}\text { Carbon } & 77.29 \\ \text { Hydrogen } & 4.61 \\ \text { Nitrogen } & 1.43 \\ \text { Sulfur } & 4.62 \\ \text { Oxygen } & 1.26 \\ \text { Ash } & 10.79 \\ \text { Moisture (1) } & 0.00 \\ \text { TOTAL } & 100.00\end{array}$

Higher Heating Value (Btu/lb)

13500 (13990 by Dulong Equation) Free Swelling Index 8.5

NOTES:

1. This analysis is on a dry basis, i.e., the preliminary analysis ignored the coal moisture since the moisture was unknown (and considered to be small) during the test program.

Table 2.9. Initial Meckley Limestone Chemical Analyses (Preliminary Analysis)

Applied to All Test Results

\begin{tabular}{|lrr|}
\hline & Percent & \\
Loss on Ignition at $750^{\circ} \mathrm{C}$ & 35.75 & \\
$\mathrm{CaO}$ & 45.30 & \\
$\mathrm{CaCO}$ & 80.85 & 80.85 \\
$\mathrm{MgO}$ & 1.72 & \\
$\mathrm{MgCO} 3$ & 3.60 & 3.60 \\
Inerts & 15.36 & 15.36 \\
Moisture & 0.19 & 0.19 \\
& TOTAL & 100.00 \\
\hline
\end{tabular}

NOTE: This material is -16 mesh. 


\section{VFBC Residence Time}

The residence time for the unit includes the individual residence times of the main bed, freeboard, entrance to the cyclone, the cyclone barrel and the cyclone exit tube. For the range of velocities tested, the overall $2 \mathrm{VFBC}$ residence times lie in the range of 0.8 to 1.2 seconds, which is adequate, although it would help if it were somewhat longer, say 2 or more seconds. Refer to the section called Chemical Equilibria Analysis for further discussions. The plots of carbon conversion and sulfur capture versus residence time are presented in Figures 2.10 and 2.11. The correlations in these figures are for the non-vortex data. The vortex data are also plotted in the figures to show their relationship to the non-vortex data and relationship.

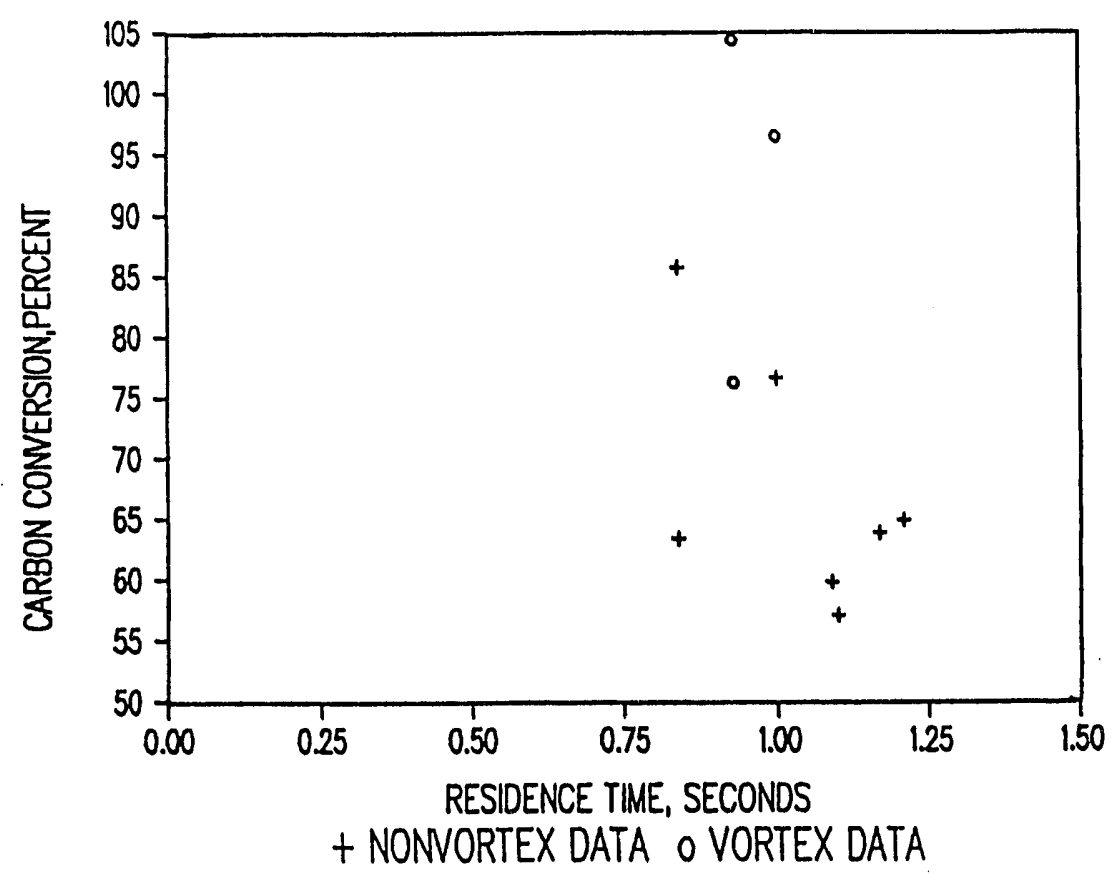

Figure 2.10. Residence Time Versus Carbon Conversion 


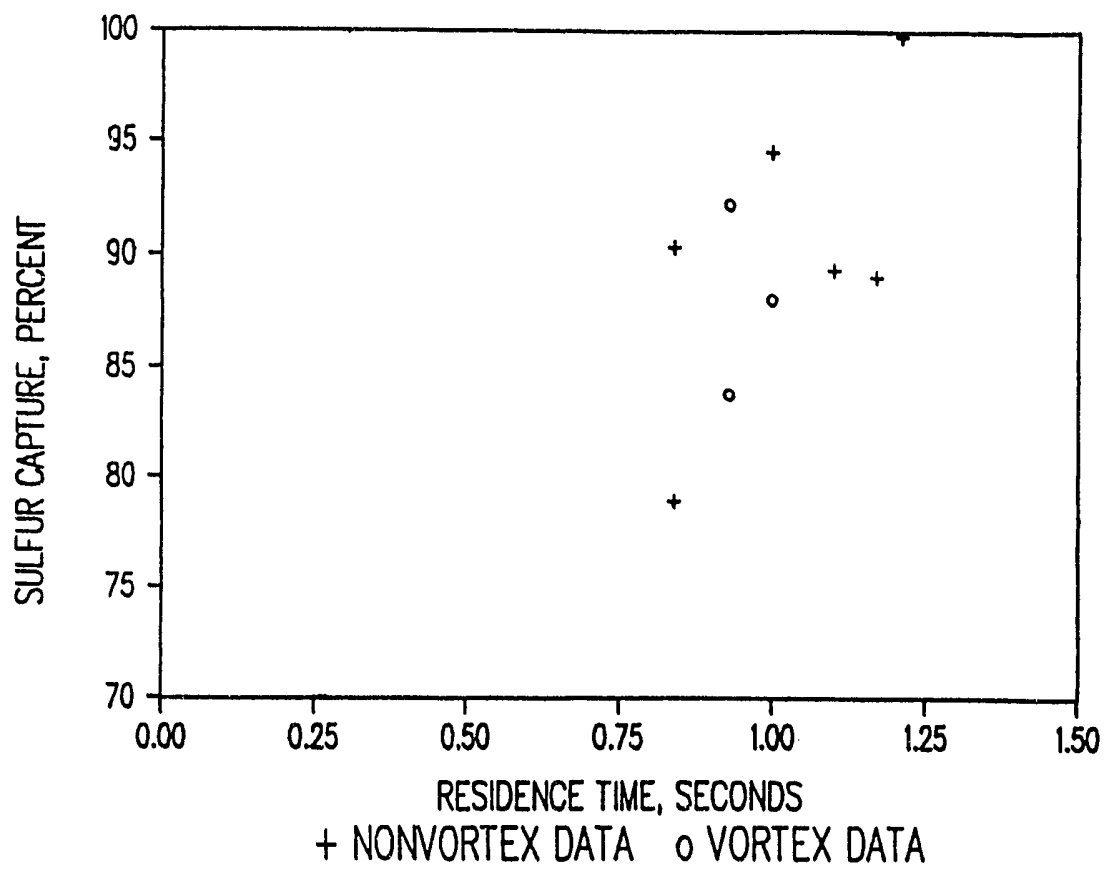

Figure 2.11. Residence Time Versus Sulfur Capture

\section{Freeboard Velocity}

Freeboard velocity can be estimated for a given sulfur capture or for a given carbon conversions by using Figures 2.12a and 2.12b. which plots sulfur capture and carbon conversions versus freeboard velocity. Note the predominant underlying variable is probably the stoichiometric air ratio. But since the freeboard velocity and stoichiometric air ratio are closely related to one another, their relationships to sulfur capture and carbon conversion are similar. Refer to the Stoichiometric Air Ratio section. If $90 \%$ sulfur capture is required, a freeboard velocity of 14-14.5 ft/sec would be required. A carbon conversion of 70-75 percent can be achieved for this sulfur capture. However, if $90 \%$ carbon conversion is required, the freeboard velocity must be 18-18.5 ft/sec. The sulfur capture achievable would then be $80-85$ percent. The correlations in these figures are for the non-vortex data. The vortex data are also plotted in the figures to show their relationship to the non-vortex data and relationship. The equations representing these curves are the following: 
Sulfur Capture $=118.64-1.945$ (Freeboard Velocity) where Sulfur Capture, \%

Freeboard Velocity, $\mathrm{ft} / \mathrm{sec}$ and

Carbon Conversion $=20.46+3.14$ (Freeboard Velocity)

where Carbon Conversion, \%

Freeboard Velocity, $\mathrm{ft} / \mathrm{sec}$.

The equations represent the non-vortex data. The vortex data are plotted in these figures to show how they relate to the non-vortex data and the equation.

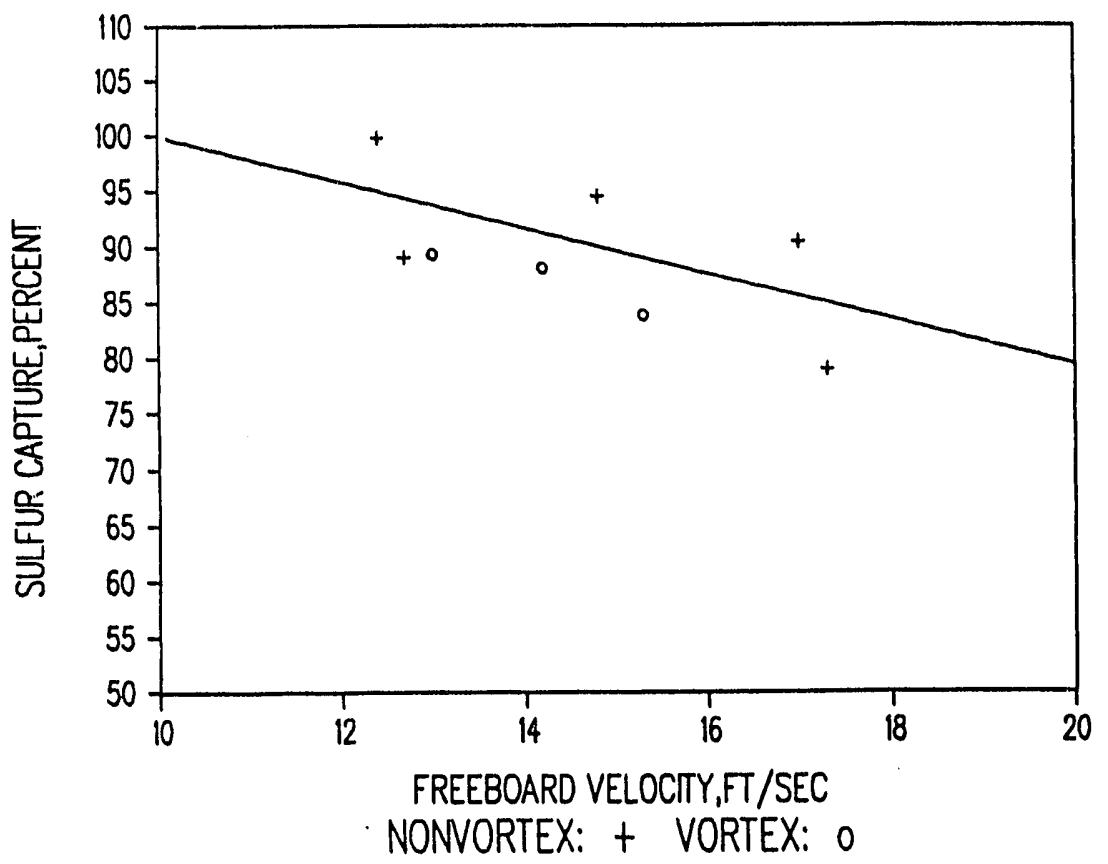

Figure 2.12a. Sulfur Capture Versus Freeboard Velocity

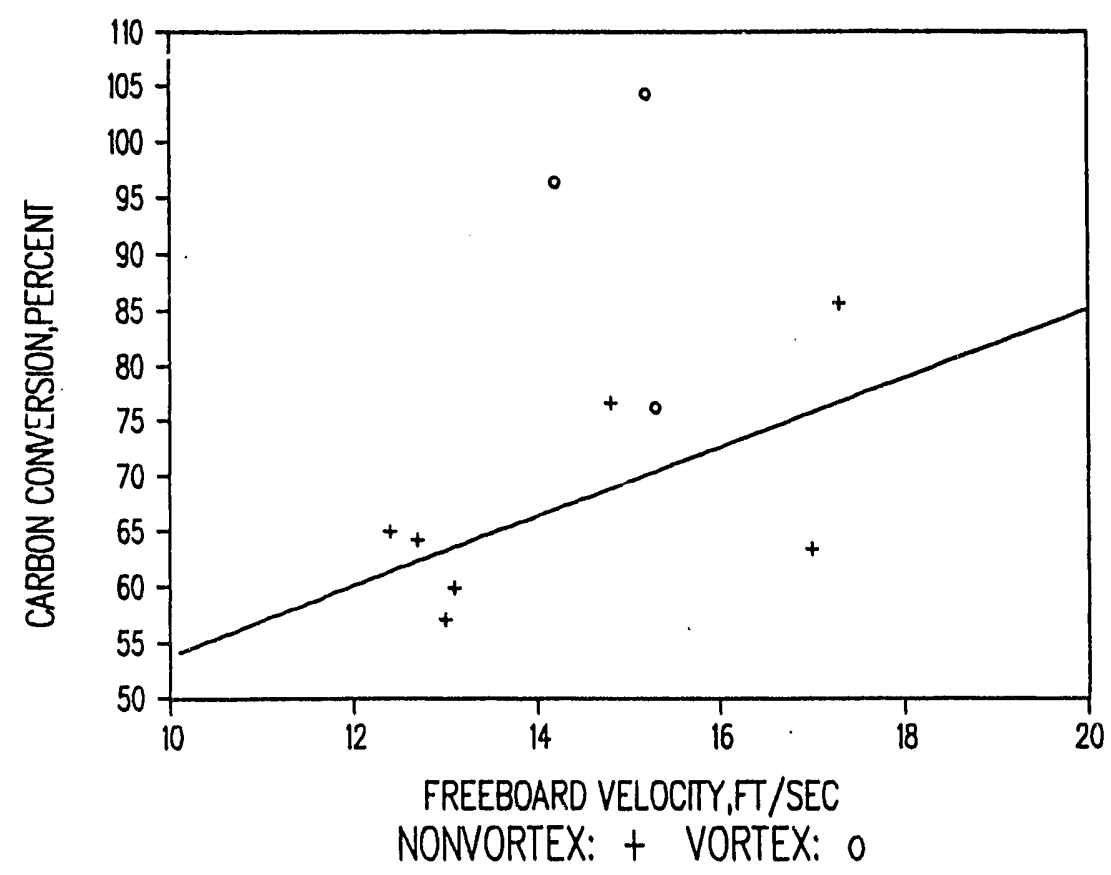

Figure 2.12b. Carbon Conversion Versus Freeboard Velocity 


\section{Nozzle Location, Air Rate, and Nozzle Velocity}

The 12 vortex nozzles were located in two vertical columns of size $3 / 4$ inch sch 40 nozzles diametrically opposite in .te barrel of the cyclone. Air rates of 31.5, 51.6 and $62.6 \mathrm{scfm}$ were achieved in the last three tests. These air rates resulted in nozzle velocities of $41.3,67.6$ and $82.1 \mathrm{ft} / \mathrm{sec}$, respectively. Referring to Figure 2.13, carbon conversion and sulfur capture are plotted against the nozzle velocity for these three vortex tests. Both carbon conversion and sulfur capture are roughly 90 percent near $70 \mathrm{ft} / \mathrm{sec}$.

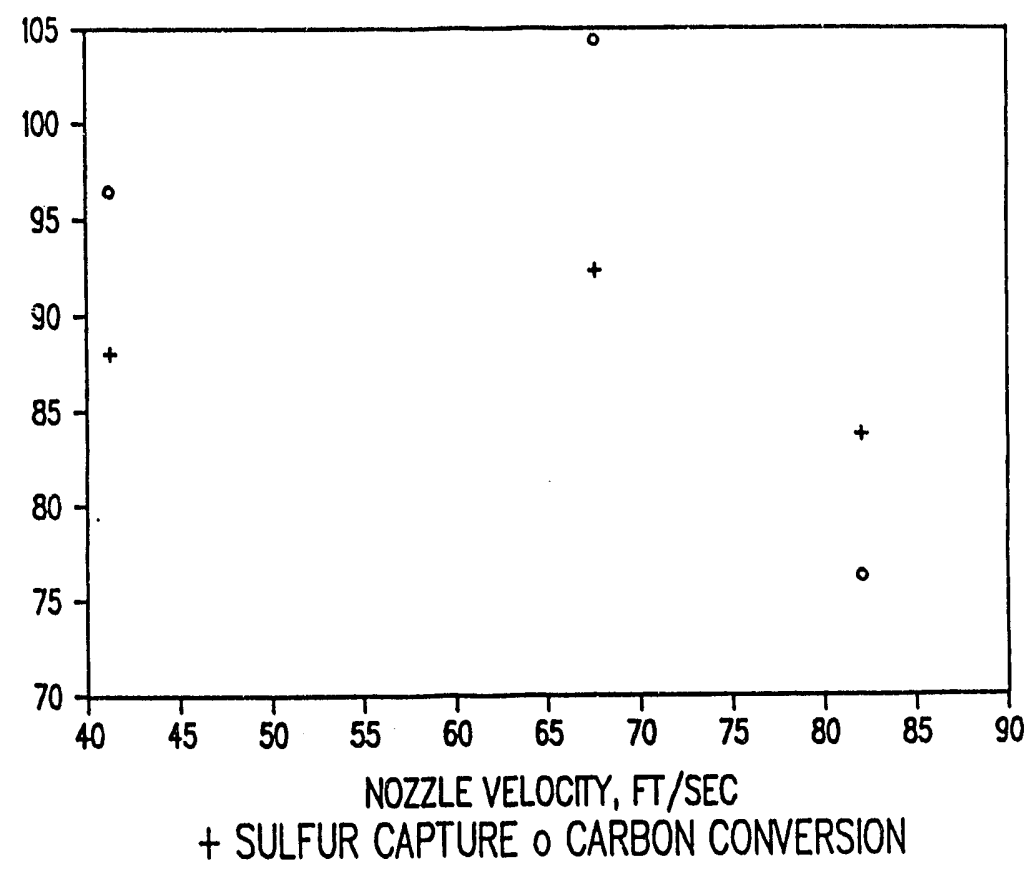

Figure 2.13. Sulfur Capture and Carbon Conversion Versus Nozzle Velocity 


\section{Optimum Temperature Level for Sulfur Capture and Carbon Conversion}

Carbon conversion is plotted versus average bed temperature in Figure 2.14. The second order correlation of sulfur capture and average bed temperature is presented in Figure 9. The correlations in these figures are for the non-vortex data. The vortex data are also plotted in the figures to show their relationship to the nonvortex data and relationship.

\section{Carbon Conversion $=-101.99+0.0984$ (Temperature) where Carbon Conversion, \% \\ Temperature is Bed Temperature, ${ }^{\circ} \mathrm{F}$}

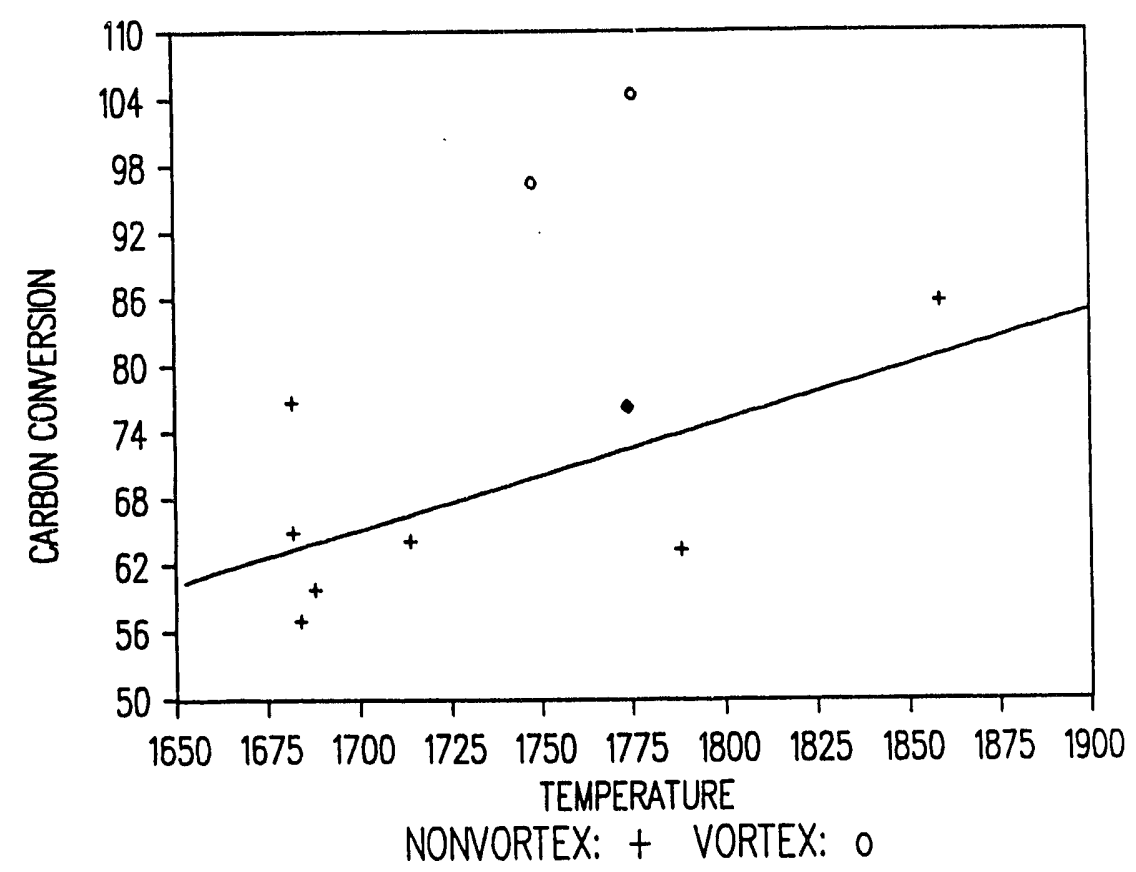

Figure 2.14. Carbon Conversion Versus Temperature, $\left({ }^{\circ} \mathrm{F}\right)$ 
Note the similarity to Figure $2.12 \mathrm{a}$ and $2.12 \mathrm{~b}$ due primarily to the relationship between the temperature and freeboard velocity. A $90 \%$ sulfur capture can be achieved at roughly $1725-1750^{\circ} \mathrm{F}$ where carbon conversion is $70-75 \%$. For a $90 \%$ carbon conversion a temperature range of approximately $1825-1850^{\circ} \mathrm{F}$ should be maintained, and the sulfur capture would be about $80-85 \%$. Figure 2.15 shows the relationship between sulfur capture and carbon conversion. The correlations in these figures are for the non-vortex data. The vortex data are also plotted in the figures to show their relationship to the non-vortex data and relationship.

$$
\begin{gathered}
\text { Carbon Conversion }=136.16-0.747 \text { (SC) } \\
\text { where Carbon Conversion, \% } \\
\text { Sulfur Capture, \% }
\end{gathered}
$$

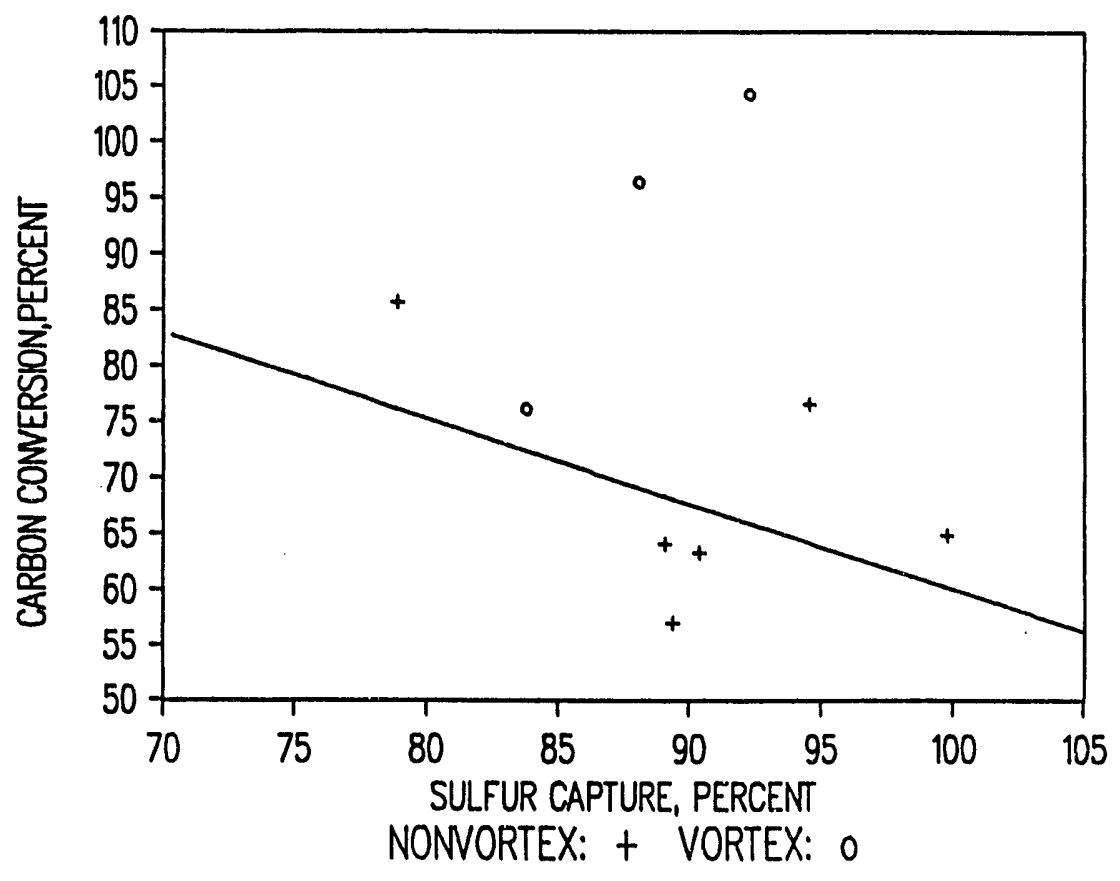

Figure 2.15. Sulfur Capture vs. Carbon Conversion 


\section{Vortex-to-Primary Air Ratio}

The relationship of the vortex-to-primary air ratio to the sulfur capture and the carbon conversion is the same as the relationship of the vortex air rate (or nozzle velocity) to the sulfur capture and the carbon conversion. This is due simply because of the direct relationship among the vortex-to-primary air ratio, the vortex air rate and the nozzle velocity. Thus, the carbon conversion and the sulfur capture are near $90 \%$ at a vortex-to-primary air ratio near 0.25 to 0.31 . See Figure 2.16 for the plot of the vortex test data.

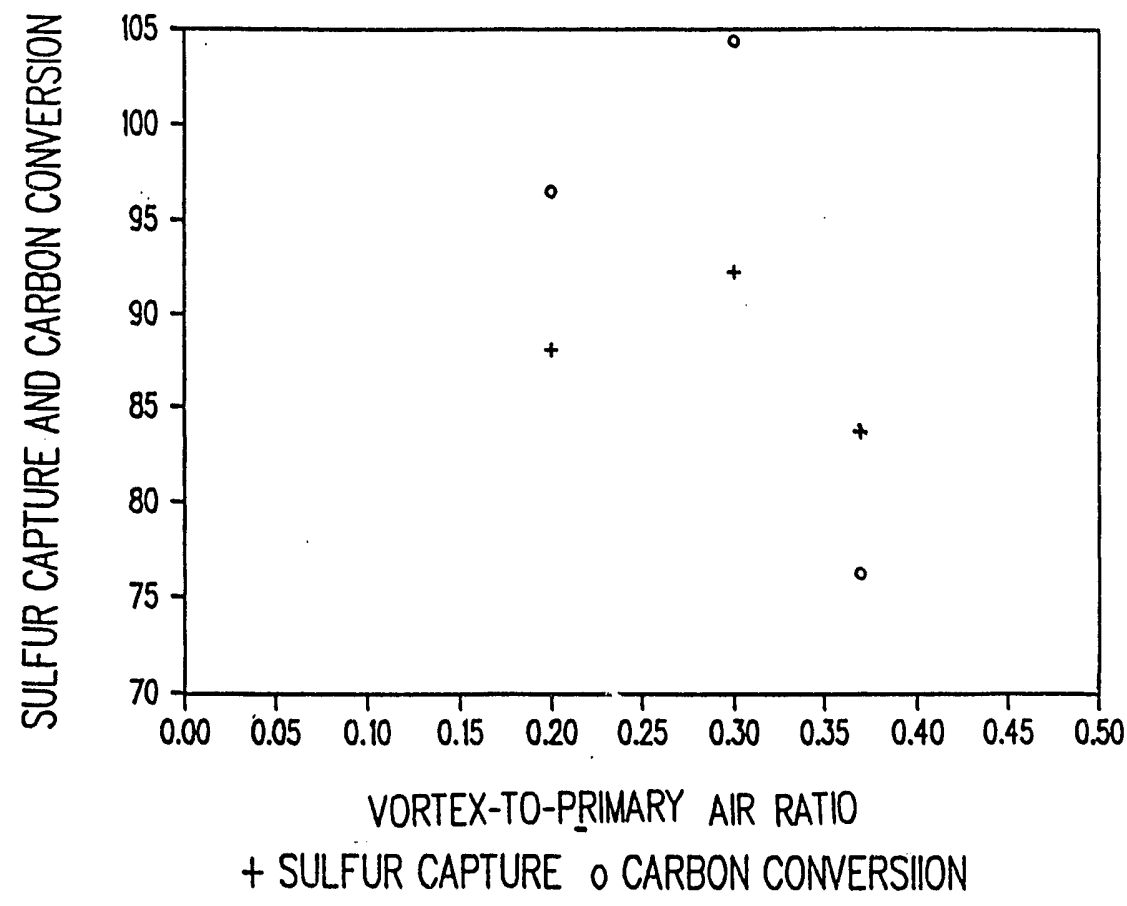

Figure 2.16. Sulfur Capture and Carbon Conversion Versus Vortex-to-Primary Air Ratio 


\section{Cyclone Inlet and Exit Velocities}

The cyclone inlet velocity ranged from 60 to $80 \mathrm{ft} / \mathrm{sec}$. However, the cyclone exit velocity ranged from $80 \mathrm{ft} / \mathrm{sec}$ to as high as $135 \mathrm{ft} / \mathrm{sec}$. Refer to Table 2.2b. The high outlet velocities are due to the smaller size of the cyclone exit tube (or vortex finder). The original inside diameter was 6 inches, but the tube diameter during testing was 4.72 inches. The vortex finder had to be reduced in diameter to partly eliminate the entering solids from impacting and eroding the cyclone exit tube. The tube diameter would have to have been even smaller to avoid all erosion completely. But this would not be possible without increasing the exit velocities to extremely high levels and to greatly increase the cyclone pressure drop.

\section{Stoichiometric Air Ratio}

The stoichiometric air ratio in the case of a gasifier, is the substoichiometric air. Thus, the stoichiometry fraction is always less than one (or the percent is always less than 100 percent). A plot of the stoichiometry versus the average bed temperature is shown in Figure 2.17. The correlations in these figures are for the non-vortex data. The vortex data are also plotted in the figures to show their relationship to the nonvortex data and relationship. The relationship can be represented by the following line whose equation is as follows:

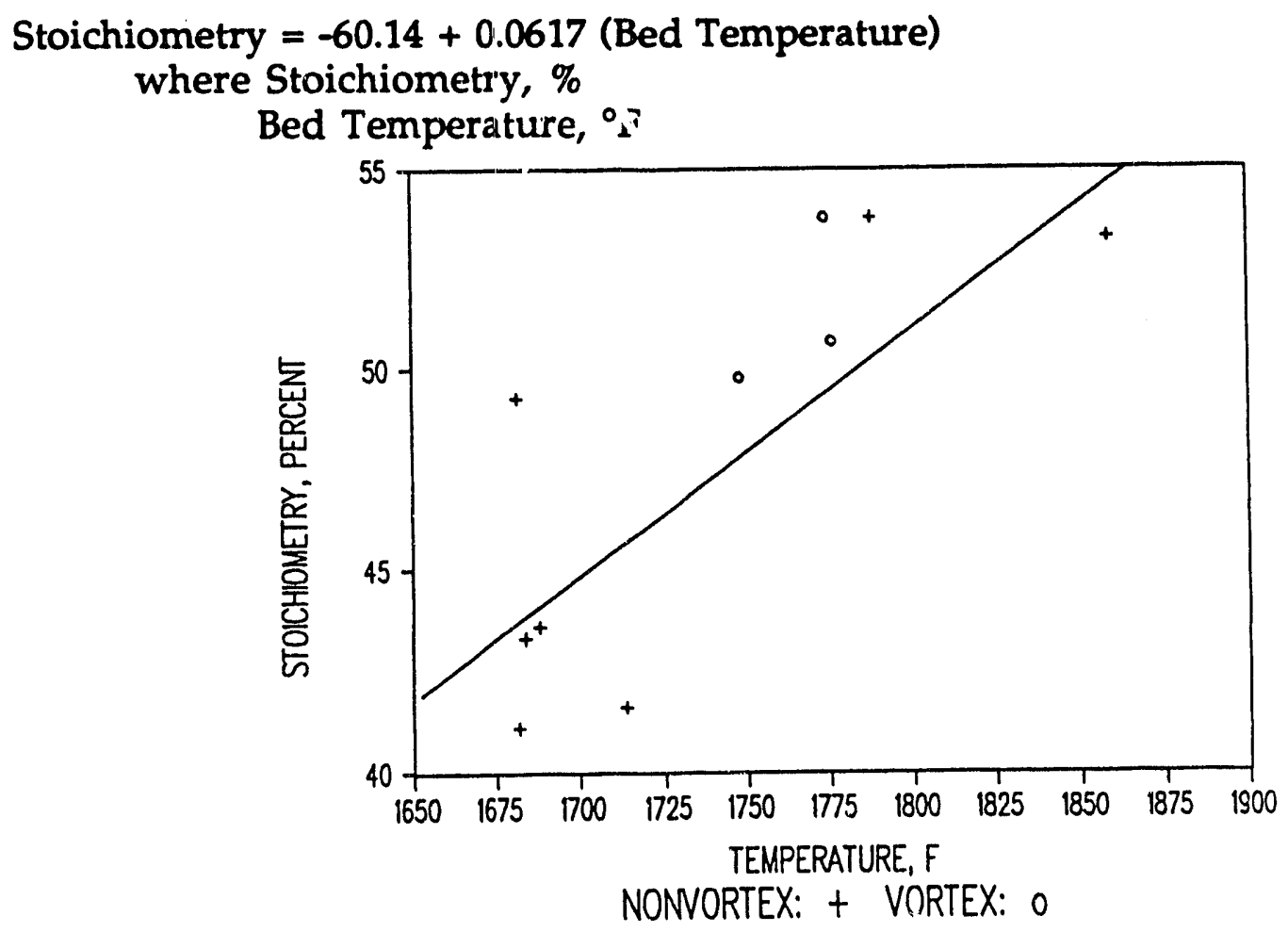

Figure 2.17. Stoichiometry vs. Temperature - All Data 
This correlation agrees with the adiabatic temperature versus theoretical air correlation which increases in temperature to a maximum where the air is equal to the theoretical air. These data correlate the best of all of the correlations presented in this report.

The correlation for the stoichiometric air ratio and carbon conversion is given in Figure 2.18. The correlations in these figures are for the non-vortex data. The vortex data are also plotted in the figures to show their relationship to the nonvortex data and relationship. The linear representation of this relation is:

Carbon Conversion $=14.078+1.146$ (Stoichiometry) where Carbon Conversion, \%

Stoichiometry, \%

The plots of the stoichiometric air ratio and sulfur capture data are given in Figure $2.19 \mathrm{a}-\mathrm{c}$, the linear representation of Figures 2.19a and 2.19b are:

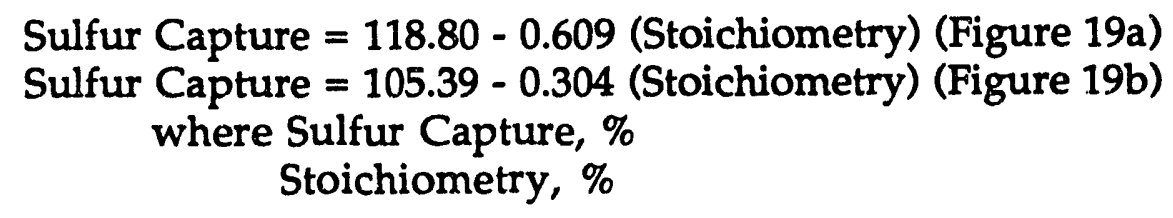

STOICHIOMETRY VS CARBON CONVERSION

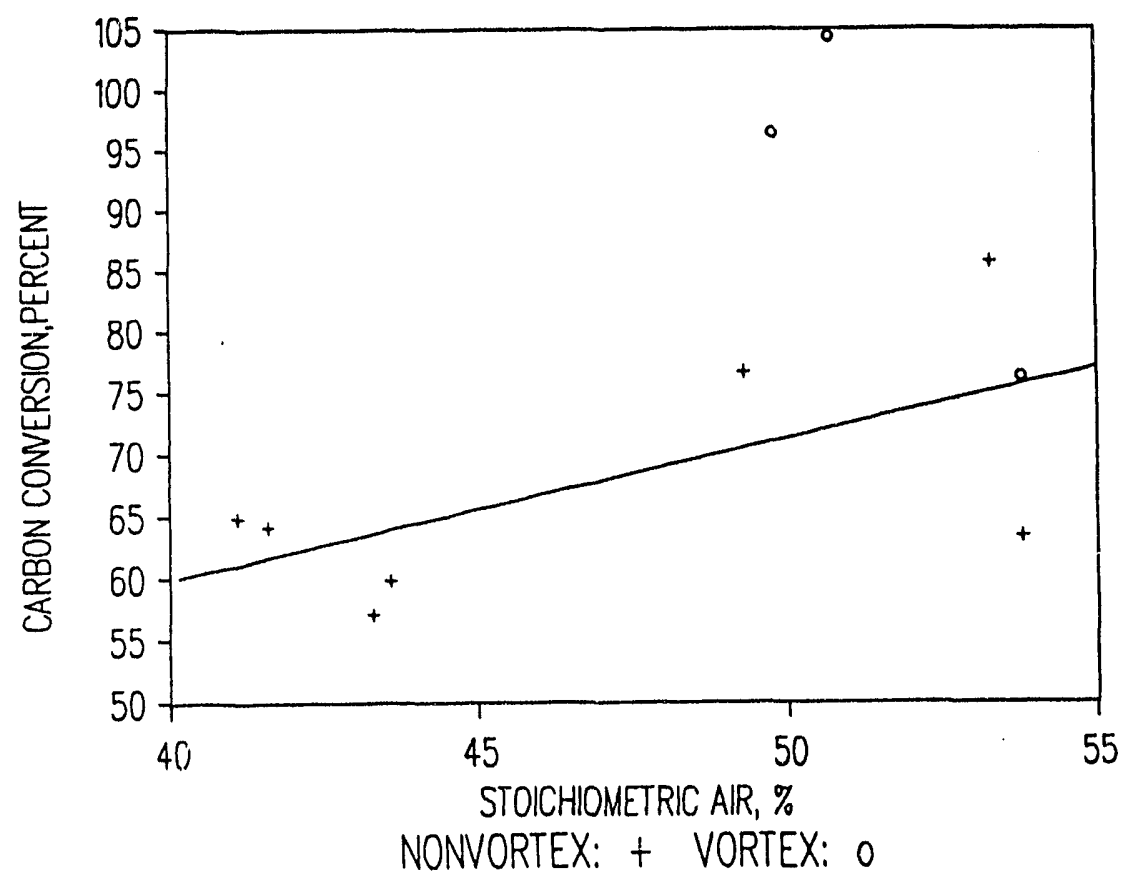

Figure 2.18. Stoichiometry Versus Carbon Conversion 


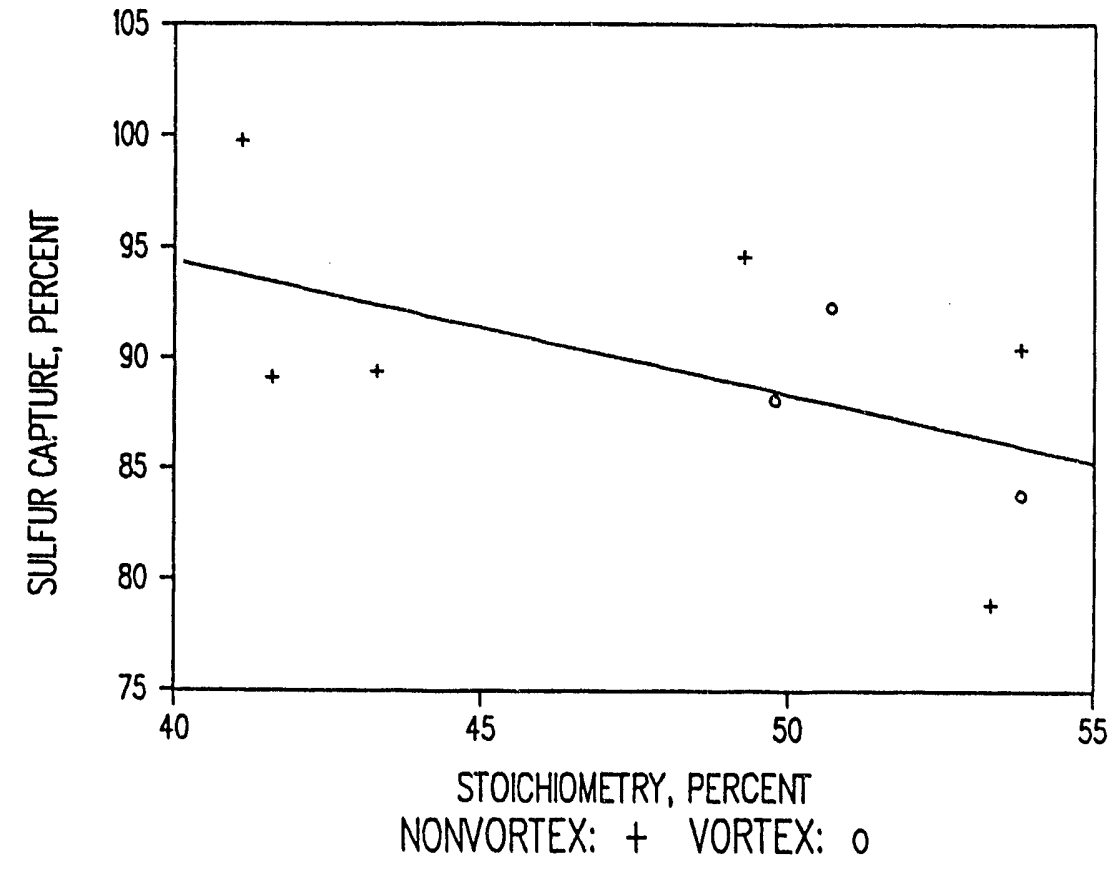

Figure 2.19a. Stoichiometry Versus Sulfur Capture - All Data

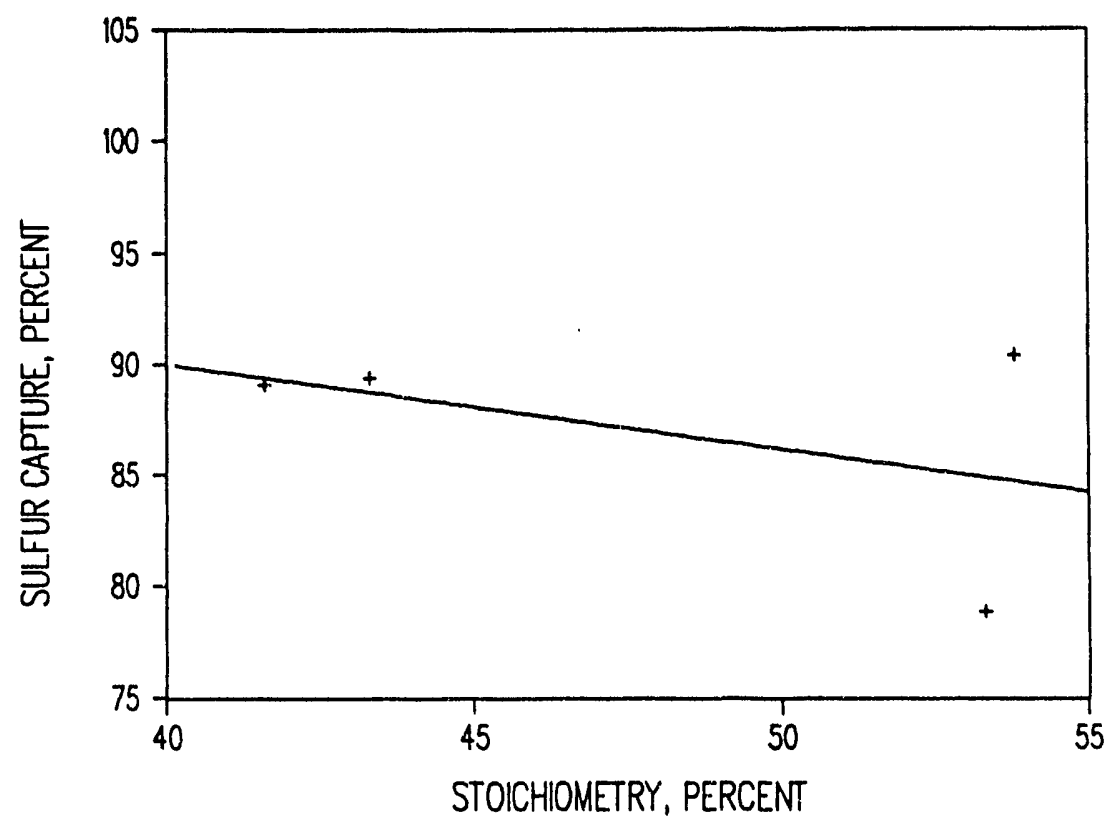

Figure 2.19b. Stoichiometry Versus Sulfur Capture Constant Ca-to-S for Non-Vortex Data 


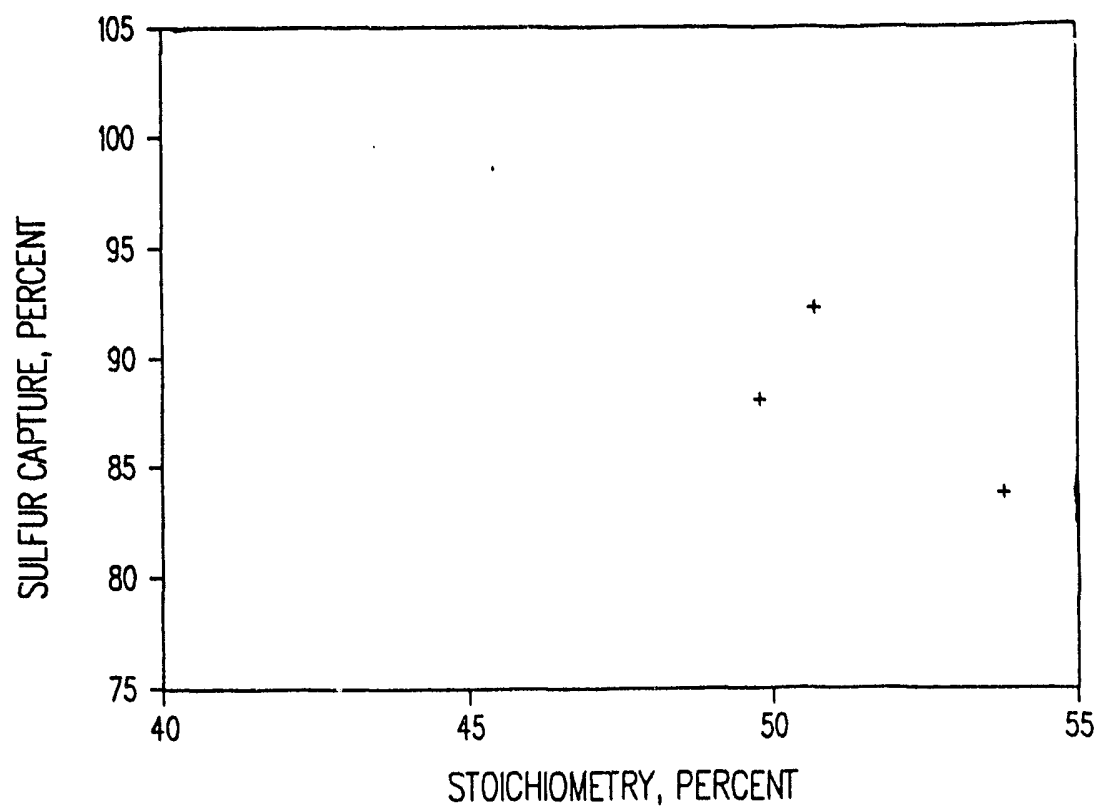

Figure 2.19c. Stoichiometry Versus Sulfur Capture Constant Ca-to-S for Vortex Data

Higher Heating Value of the Flue Gas

Several correlations were developed from the data relating various parameters to the Higher Heating Value (HHV) for the dry flue gas.

A weak correlation exists between the stoichiometry and the HHV. See Figure 2.20. The representative equation is:

Stoichiometry $=55.52-0.142$ (HHV) where Stoichiometry, \%

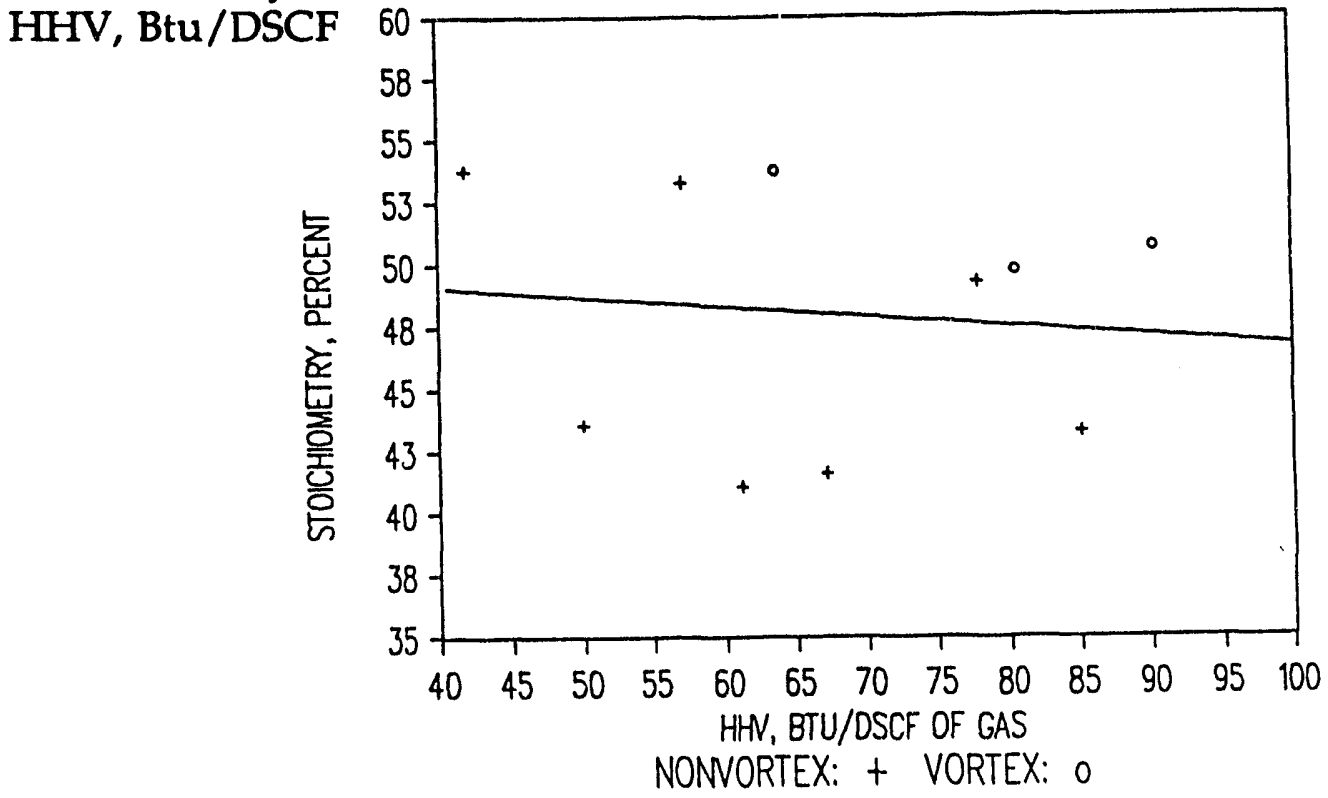

Figure 2.20. HHV Versus Stoichiometry 
This correlation weakly indicates that as the stoichiometric air ratio is decreased, the HHV of the flue gas increases. Future tests should be run at lower stoichiometric air ratios, say at $35 \%$ or $30 \%$, or even lower. A second correlation was developed between the HHV and the carbon conversion as shown in Figure 2.21. The correlations in these figures are for the non-vortex data. The vortex data are also plotted in the figures to show their relationship to the non-vortex data and relationship. The correlation is as follows:

Carbon Conversion $=68.57-0.0180$ (HHV)

where Carbon Conversion, \%

$\mathrm{HHV}, \mathrm{Btu} / \mathrm{DSCF}$

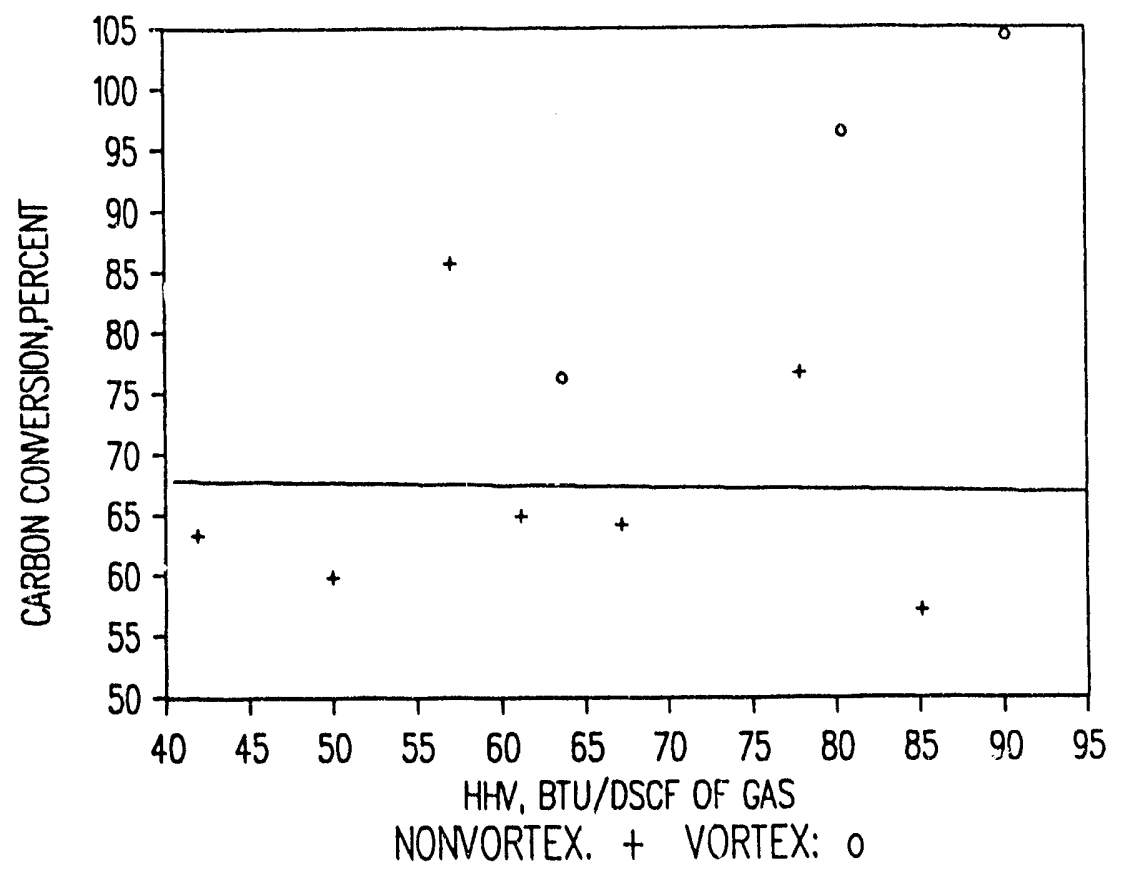

Figure 2.21. HHV (Dry) vs. Carbon Conversion 


\section{Chemical Equilibria Analysis}

Chemical analysis of coal gasification involves numerous individual reactions that

1 include many chemical components. Specific reactions involving coal gasification include the following:

$$
\begin{aligned}
& \text { Coal } \stackrel{\text { Pyrolysis }}{\longrightarrow} \text { Char }(C)+\text { Coal Volatiles (VM) } \\
& \mathrm{C}+\mathrm{H}_{2} \mathrm{O} \stackrel{\text { Gasification }}{\longrightarrow} \mathrm{CO}+\mathrm{H}_{2}+\Delta \mathrm{HR}_{2} \\
& \mathrm{C}+\mathrm{CO}_{2} \stackrel{\text { Gasification }}{\longrightarrow} 2 \mathrm{CO}+\Delta \mathrm{HR}_{3}
\end{aligned}
$$

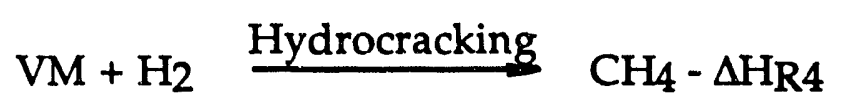

$$
\begin{aligned}
& \mathrm{VM}+\mathrm{H}_{2} \mathrm{O} \stackrel{\text { Gasification }}{\longrightarrow} \mathrm{CO}+\mathrm{H}_{2}+\Delta \mathrm{H}_{\mathrm{R}} \\
& \mathrm{C}+2 \mathrm{H}_{2} \stackrel{\text { Hydrogasification }}{\longrightarrow} \mathrm{CH}_{4}-\Delta \mathrm{H}_{\mathrm{R} 6} \\
& \mathrm{CO}+\mathrm{H}_{2} \mathrm{O} \stackrel{\text { Shift Reaction }}{\longrightarrow} \mathrm{CO}_{2}+\mathrm{H}_{2}-\Delta \mathrm{HR}_{7} \\
& \mathrm{C}+\mathrm{O}_{2} \stackrel{\text { Combustion }}{\longrightarrow} \mathrm{CO}_{2}-\Delta \mathrm{HR} 8 \\
& \text { Coal Minerals }+\mathrm{O}_{2} \stackrel{\text { Decomposition \& Oxidation }}{\longrightarrow} \text { Ash }
\end{aligned}
$$

where $+\Delta \mathrm{H}_{\mathrm{Ri}}$ indicates an endothermic reactions and $-\Delta \mathrm{H}_{\mathrm{Ri}}$ indicates an exothermic reactions.

The key reactions considered in this analysis of equilibria are equations (2) and (7), the water shift reaction. The other reactions are assumed to go to completion or near equilibrium. The equilibria of these two reactions are represented as the following: 


$$
\begin{aligned}
& \mathrm{C}(\mathrm{s})=\mathrm{H}_{2} \mathrm{O}(\mathrm{g}) \Longrightarrow \mathrm{CO}(\mathrm{g})+\mathrm{H}_{2}(\mathrm{~g}) \\
& \text { (Equilibrium Constant) } \mathrm{K}_{\mathrm{p} 2}=\frac{[\mathrm{CO}]\left[\mathrm{H}_{2}\right]}{1}=\frac{\mathrm{PCO}_{\mathrm{PH} 2}}{\left.\mathrm{PH} 2 \mathrm{H} \mathrm{H}_{2} \mathrm{O}\right]} \\
& \mathrm{CO}+\mathrm{H}_{2} \mathrm{O} \rightleftharpoons \mathrm{CO}_{2}+\mathrm{H}_{2} \\
& \mathrm{KP} 7=\frac{[\mathrm{CO}]\left[\mathrm{H}_{2}\right]}{[\mathrm{CO}]\left[\mathrm{H}_{2} \mathrm{O}\right]}=\frac{\mathrm{PCO}_{2} \mathrm{PH}_{2}}{\mathrm{PCO}_{\mathrm{P}} 2 \mathrm{O}} \\
& \quad \text { where [ ] = pressure fraction (or volume fraction) of any component }
\end{aligned}
$$

The two equations' equilibrium constants can be obtained from thermodynamic tables such as the Girdler Catalysts reference "Physical and Thermodynamic Properties of Elements and Compounds". Also, the equilibria constants can be calculated using the compositions of the fuel gases during testing. Refer to Table 2.10 for the fuel compositions. Using the Girdler Tables and the fuel gas compositions yields the results in Table 2.11 with the values for KP2 and KP7 from equilibira tables and fuel concentration values. The KP7 values from both methods are very close to each other, indicating near equilibrium. However, the KP2 values vary roughly 1 to 3 orders of magnitude from one another indicating that this reaction has not achieved equilibrium. This gasification reaction governs where the pressure is low and the temperatures are high, i.e., our case. Our test work was conducted at atmospheric pressure and at $1650-1900^{\circ} \mathrm{F}$ which fits these pressure and temperature conditions for this equation. Since equilibrium has not been nearly achieved, the test time should be increased to further approach equilibrium. Also, increasing the gas reside: $:$ time would help equilibrium to be achieved. 
Table 2.10. Cyclone Outlet Fuel Gas Composition

\begin{tabular}{|c|c|c|c|c|c|c|c|c|c|c|}
\hline EST NUMBER & 1 & 2 & 3 & 4 & 5 & 6 & 7 & 8 & 9 & 10 \\
\hline TEST DATE & 3-28-91 & 5-8-91 & $4-11-91$ & $4-5-91$ & 5-14-91 & 5-9-91 & 5-16-91 & 6-5-91 & 6-18-91 & 6-25-91 \\
\hline \multicolumn{11}{|l|}{ GAS COMPONENT } \\
\hline$(\%)$ & 57.06 & 56.69 & 58.20 & 60.01 & 55.77 & 54.60 & 54.20 & 51.01 & 51.40 & 55.81 \\
\hline$(\%)$ & 0.00 & 0.00 & 0.00 & 0.00 & 0.00 & 0.00 & 0.00 & 0.00 & 0.00 & 0.00 \\
\hline $\mathrm{CO}_{2}$ & 12.67 & 14.55 & 10.41 & 12.60 & 14.39 & 13.93 & 12.83 & 11.26 & 12.33 & 13.20 \\
\hline$(\%)$ & 3.36 & 6.37 & 4.93 & 3.83 & 4.61 & 4.82 & 7.31 & 12.87 & 10.71 & 5.25 \\
\hline (ppm) & 0 & 0 & 0 & 0 & 0 & 0 & 0 & 0 & 0 & 0 \\
\hline (ppm) & 523 & 982 & 623 & 467 & 10.5 & 628 & 260 & 365 & 574 & 788 \\
\hline $\mathrm{CH}_{4}$ & 1.17 & 0.75 & 1.43 & 0.71 & 1.34 & 1.46 & 1.01 & 0.54 & 0.43 & 0.57 \\
\hline (ppm) & 849 & 99 & 10,300 & 320 & 546 & 840 & 421 & 163 & 85.1 & 41.7 \\
\hline$(\%)$ & 4.61 & 5.91 & 7.13 & 4.19 & 6.53 & 7.08 & 9.74 & 8.94 & 8.51 & 9.36 \\
\hline $\mathrm{H}_{2} \mathrm{O}$ & 20.99 & 15.62 & 16.81 & 18.56 & 17.32 & 17.96 & 14.84 & 15.34 & 16.56 & 15.73 \\
\hline TOTAL (1) $\quad 100.00$ & 100.00 & 100.00 & 99.98 & 100.02 & 100.00 & 100.00 & 100.00 & 100.01 & 100.01 & 100.00 \\
\hline Molecular Weight & 26.61 & 27.20 & 25.98 & 27.00 & 26.73 & 26.44 & 25.93 & 25.90 & 26.07 & 26.06 \\
\hline $\mathrm{HHV}, \quad$ Btu/scf (2) & 39.5 & 48.2 & 70.8 & 34.1 & 50.6 & 55.1 & 66.4 & 76.5 & 67.1 & 53.7 \\
\hline
\end{tabular}
NOTES: (1) Values different from 100.00 are due to roundoff errors.

(2) Standard conditions for fuel gases are $60^{\circ} \mathrm{F}$ and $1 \mathrm{~atm}$. The HHV is on a wet basis.

Table 2.11. Gasification and Water Shift Reactions' Equilibrium Constants

\begin{tabular}{|c|c|c|c|c|c|c|c|c|c|c|}
\hline TEST NUMBER & 1 & 2 & 3 & 4 & 5 & 6 & 7 & 8 & 9 & 10 \\
\hline TEST DATE & 3-28-91 & $5-8-91$ & 4-11-91 & 4-5-91 & 5-14-91 & 5-9-91 & 5-16-91 & $6-5-91$ & 6-18-91 & 6-25-91 \\
\hline \multicolumn{11}{|c|}{ GASIFICATION REACTION (2) } \\
\hline KP2 Equilibria (1) & 37.12 & 100.9 & 36.22 & 69.1 & 36.22 & 40.00 & 34.66 & 63.43 & 53.08 & 72.49 \\
\hline $\begin{array}{rr}\text { Fuel } & \text { Concentration } \\
& \text { Method } \\
0.031 & \\
\end{array}$ & $\mathrm{Kp} 2$ & 1.35 & 0.024 & 0.48 & 1.15 & 0.017 & 0.019 & 0.048 & 0.075 & 0.055 \\
\hline \multicolumn{11}{|c|}{ WATER SHIFT REACTION (7) } \\
\hline KP7 Equilibria (1) & 0.71 & 0.56 & 0.71 & 0.61 & 0.71 & 0.70 & 0.72 & 0.61 & 0.64 & 0.60 \\
\hline $\begin{array}{l}\text { Fuel Concentration } \\
\text { Method } \quad \mathrm{Kp} 7 \\
\end{array}$ & 0.83 & 0.86 & 0.89 & 0.74 & 1.18 & 1.14 & 1.15 & 0.51 & 0.59 & 1.50 \\
\hline Bed Temperature $\left({ }^{\circ} \mathrm{F}\right)$ & 1688 & 1859 & 1684 & 1788 & 1682 & 1714 & 1682 & 1776 & 1748 & 1774 \\
\hline
\end{tabular}
NOTES:
(1) Determined from Girdler Catalysts Reference. 
One unfortunate aspect of the testing is that steady state conditions were certainly not reached on tests 1 to 7 (without vortex air) and it is doubtful whether true steady state was reached on tests 8 to 10 . This is illustrated by Figure 2.22 which shows plots of $\mathrm{CO}$ content in the product gas against a base of time. After a one hour start-up and up to 6 hours operation, the $\mathrm{CO}$ content was still increasing. Availability of personnel and safety concerns rendered it impractical to test for periods greater than about 7 hours per day.

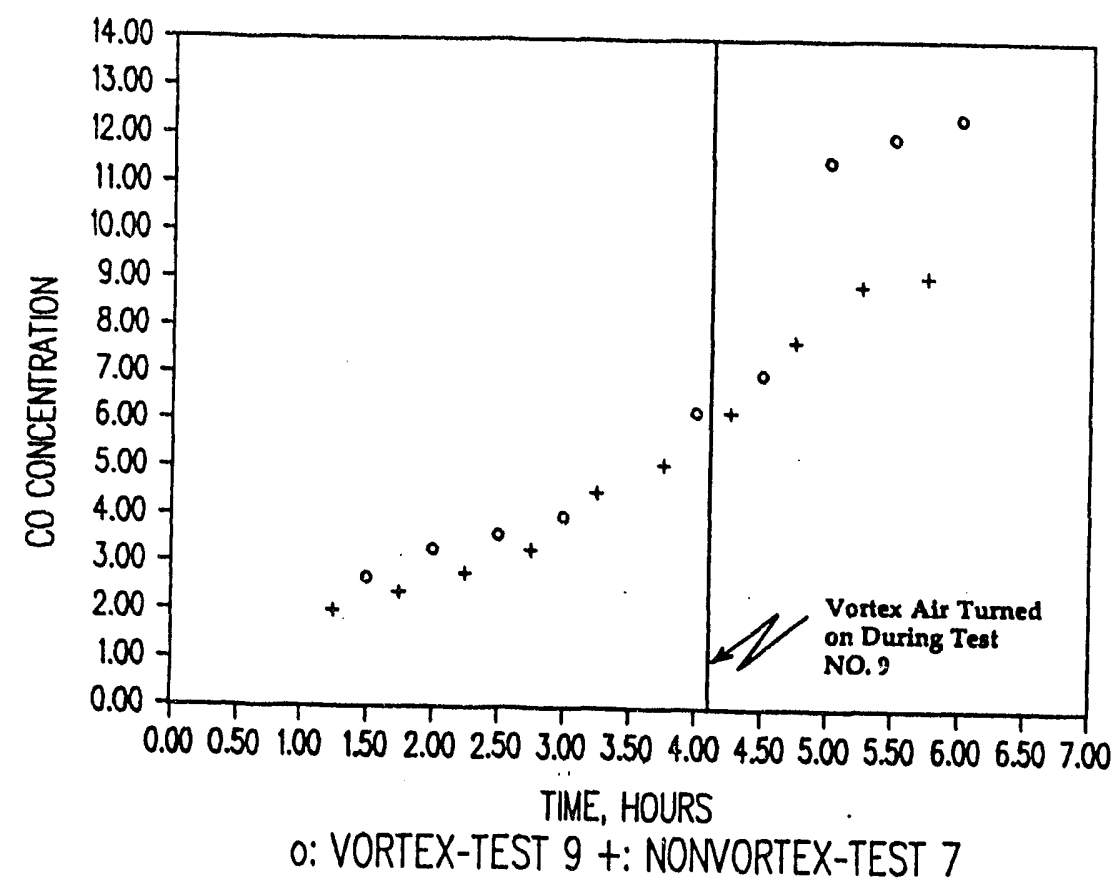

Figure 2.22. CO vs. Time - Vortex vs. Non-Vortex 


\section{Ash Composition}

The ash compositions for grab samples from the sluice drain and the baghouse are presented in Appendix $H$. Refer to Tables 2.12a and 2.12b for a summary of these ash analyses.

Table 2.12a. Analyses of Sluice Drain Ash

\begin{tabular}{|c|c|c|c|c|c|c|c|c|c|c|}
\hline $\begin{array}{l}\text { TEST } \\
\text { NO. }\end{array}$ & $\begin{array}{l}\text { TEST } \\
\text { DATE } \\
\end{array}$ & $\begin{array}{c}\text { TOTAL } \\
\text { SULFUR } \\
(\%)\end{array}$ & $\begin{array}{c}\text { SULFATE } \\
\text { SULFUR } \\
(\%)\end{array}$ & $\begin{array}{l}\text { SULFIDE } \\
\text { SLILFUR } \\
(\%)(1) \\
\end{array}$ & $\begin{array}{c}\text { ORGANIC } \\
\text { CARBON } \\
(\%)\end{array}$ & $\begin{array}{c}\text { TOTAL } \\
\text { CALCIUM } \\
(\%)\end{array}$ & $\begin{array}{c}\text { TOTAL } \\
\text { MAGNESIUN } \\
(\%)\end{array}$ & $\begin{array}{c}\text { ACID } \\
\text { INSOLUBLES } \\
(\%)\end{array}$ & PH & $\begin{array}{c}\text { TIME } \\
\text { UNITS } \\
\text { ON COAL } \\
\text { (HRS) } \\
\end{array}$ \\
\hline $1(2)$ & $3 / 28 / 91$ & -..-.- & -..-.- & -....- & --.-- & -...-. & -.... & --..-. & -..-. & -.... \\
\hline 2 & $5-8-91$ & 1.25 & 1.22 & 0.03 & 1.38 & 12.2 & $\overline{0.41}$ & $\overline{69.4}$ & 12.64 & $5-1 / 3$ \\
\hline 3 & $4-11-91$ & 0.65 & 0.65 & 0.00 & 4.54 & 6.75 & 0.24 & 79.0 & 12.81 & $4-5 / 6$ \\
\hline 3 & $4-11 / 91$ & 1.08 & 1.04 & 0.04 & 10.9 & $\overline{7.16}$ & $\overline{0.28}$ & $\overline{67.3}$ & 12.84 & $6-1 / 6$ \\
\hline$\overline{4}$ & $4-5-91$ & 0.14 & $\overline{0.14}$ & 0.00 & 1.05 & 2.10 & 0.09 & 83.2 & 12.50 & 1.5 \\
\hline 5 & $5-14-91$ & 2.14 & 1.78 & $\overline{0.36}$ & $\overline{20.0}$ & 4.09 & $\overline{0.19}$ & $\overline{67.0}$ & 12.49 & $4-1 / 3$ \\
\hline$\overline{6}$ & $5-9-91$ & 1.49 & 1.45 & 0.04 & 11.2 & 8.13 & 0.28 & 65.8 & 12.83 & $5-11 / 30$ \\
\hline 7 & 5-16-91 & 1.23 & 1.02 & 0.21 & 11.2 & 13.2 & 0.49 & 60.9 & 12.86 & $5-1 / 2$ \\
\hline 8 & $6-5-91$ & 0.94 & 6.91 & 0.03 & 10.3 & 9.13 & 0.32 & 67.8 & $\overline{12.6}$ & $5-1 / 2$ \\
\hline 9 & $6-18-91$ & 0.98 & 0.96 & 0.02 & 10.3 & 13.1 & $\overline{0.41}$ & 61.6 & 12.6 & $6-1 / 30$ \\
\hline 10 & $6-25-91$ & 1.18 & 1.11 & 0.07 & 9.99 & 8.66 & 0.36 & 65.9 & 12.8 & $4-3 / 4$ \\
\hline
\end{tabular}

\section{NOTES:}

(1) It is assumed that sulfide sulfur (not analyzed for) equals the total sulfur minus sulfate sulfur, i.e., the only forms of sulfur in the ash are sulfate sulfur and sulfide sulfur. This may not be completely true since by the fact that sulfate sulfur predominates, sulfite sulfur may also exist.

(2) No sample was collected from the 3-28-91 test.

Table 2.12b. Analyses of Baghouse Ash Drain

\begin{tabular}{|c|c|c|c|c|c|c|c|c|c|c|}
\hline $\begin{array}{l}\text { TEST } \\
\text { NO. } \\
\end{array}$ & $\begin{array}{l}\text { TEST } \\
\text { DATE } \\
\end{array}$ & $\begin{array}{c}\text { TOTAL } \\
\text { SULFUR } \\
(\%)\end{array}$ & $\begin{array}{c}\text { SUUFATE } \\
\text { SULFUR } \\
(\%) \\
\end{array}$ & $\begin{array}{l}\text { SUIFIDE } \\
\text { SULFUR } \\
(\%)(1) \\
\end{array}$ & $\begin{array}{c}\text { ORGANIC } \\
\text { CARBON } \\
(\%) \\
\end{array}$ & $\begin{array}{c}\text { TOTAL } \\
\text { CALCIUM } \\
(\%) \\
\end{array}$ & $\begin{array}{c}\text { TOTAL } \\
\text { MAGNESIUM } \\
(\%) \\
\end{array}$ & $\begin{array}{c}\text { ACID } \\
\text { INSOLUBLES } \\
(\%)\end{array}$ & FH & $\begin{array}{r}\text { TIME } \\
\text { UNTSS } \\
\text { ONCOAL } \\
\text { (HRS) } \\
\end{array}$ \\
\hline 7 & 5-16-91 & 4.13 & 3.29 & 0.84 & 34.1 & 18.5 & 1.56 & 10.5 & 11.92 & $5-1 / 2$ \\
\hline 8 & $6-5-91$ & 4.56 & 4.15 & 0.41 & 27.2 & 21.5 & 1.30 & 14.2 & 11.96 & $5-1 / 2$ \\
\hline
\end{tabular}

NOTES:

(1) It is assumed that sulfide sulfur (not analyzed for) equals the total sulfur minus sulfate sulfur, i.e., the only forms of sulfur in the ash are sulfate sulfur and sulfide sulfur. This may not be completely true since by the fact that sulfate sulfur predominates, sulfite sulfur may also exist. 
For the sluice samples, the largest component is the acid insolubles, i.e., basically the "starting bed of sand" component of the sluice ash. This shows that the beds have not been fully turned over. Sulfate sulfur predominates over sulfide sulfur as the major form of sulfur being about $80 \%$ or higher of the total sulfur. The ratio of total calcium to total magnesium in the sluice ash is much higher than in the limestone feed. This is countered by a much lower ratio in the baghouse ash. Organic carbon in the ash ranged from $1.05 \%$ to $20.0 \%$. The $\mathrm{pH}$ 's for the sluice samples ranged from 12.49 to 12.86 . Note that the acid insolubles (nearly $100 \%$ in fresh sand) decreased to less than $70 \%$ by the time roughly 4 hours of CWF had been fed into the unit. This time corresponds to roughly one bed turnover.

The baghouse ash is very different from the sluice ash with regard to the species concentrations. The concentrations of sulfur and magnesium in the baghouse ash are much higher than this (say 3 to 4 times) than their corresponding concentrations in the sluice ash. This is due to the fact that the sand carryover is much less than that of these components in this ash. Note the acid insolubles in the flyash is only 10 to $15 \%$. The carbon in the baghouse ash is not 3 to 4 times that in the sluice since some of the carbon combusts along with the flue gas in the boiler upstream of the baghouse. The calcium is higher in the flyash due to the lesser amount of sand, but lower than might be expected. This is due to calcium somewhat preferentially staying in the sluice bed.

The $\mathrm{pH}$ is somewhat lower for the flyash, ranging from 11.92 to 11.96 , the average $\mathrm{pH}$ of the sluice ash is 12.70. The average $\mathrm{pH}$ of the baghouse flyash is 11.94 . Therefore, the sluice ash is almost 6 times more caustic than the baghouse flyash. 


\section{E. CONCLUSIONS AND DISCUSSIONS}

Several conclusions are suggested by the test data:

- Sulfur capture is maximum approximately $95 \%$ at roughly 1600 to $1650^{\circ} \mathrm{F}$ and decreases as the bed temperature increases.

- A longer gas residence time, say about 2 seconds, may improve the performance of the 2VFBC gasifier, resulting in a fuel gas with a higher HHV.

- Roughly $85 \%$ sulfur capture and carbon conversion possibly can be achieved simultaneously at about $17 \mathrm{ft} / \mathrm{sec}$ freeboard velocity. A higher (say $90 \%$ ) value of one of these variables results in a lower value for the other, i.e., they vary inversely with on another.

- Sulfur capture and carbon conversion can possibly both achieve a $90 \%$ value at about a vortex nozzle velocity of $70 \mathrm{ft} / \mathrm{sec}$. This velocity seems reasonable for future testings.

- Sulfur capture can be $90 \%$ or greater if the bed temperature is about 1600 to $1725^{\circ} \mathrm{F}$. Carbon conversion of $90 \%$ or greater is possible if the temperature is greater than $1830^{\circ} \mathrm{F}$. Eighty-five percent might be achieved for both sulfur capture and carbon conversion at about $1810^{\circ} \mathrm{F}$.

- To achieve $90 \%$ sulfur capture and $90 \%$ carbon conversion, the vortex-toprimary air ratio may need to be less than 0.20 . Ninety percent carbon conversion can be achieved at a vortex-to-primary air ratio as high as 0.31 .

- The stoichiometric air ratio versus bed temperature correlation is the strongest of all the correlations. This correlation agrees with the correlation of the theoretical air versus adiabatic temperature.

- The estimated stoichiometry needed to achieve a HHV of $130 \mathrm{Btu} / \mathrm{DSCF}$ (at $60^{\circ} \mathrm{F}$ and $1 \mathrm{~atm}$ ) is $45.6 \%$ which is lower than most of the tests presented here.

- Equilibrium was not achieved during this test program. Longer tests need to be run. Since 3 to 4 hours are required to turnover the bed in the unit, at least ( 2 turnovers) 6 to 8 hours are required to approach equilibrium prior to the start of the test.

- Two forms of sulfur predominate in the ashes, for both bed material or baghouse flyash: sulfate sulfur and sulfide sulfur, with sulfate sulfur being at least $80 \%$ of the total sulfur in all cases. 


\section{FULL SCALE DESIGN AND ECONOMIC ANALYSIS}

In order to investigate the economics of a retrofit Vortex gasifier system, a preliminary design and pricing exercise has been completed. The results of this exercise, culminating with the economic analysis itself are presented below.

\section{A. DESIGN PARAMETERS}

The basic design parameters are as follows:

\section{Retrofit Boiler}

Fuel before Retrofit

Steam Output

Steam Pressure

Steam Temperature

Feedwater Temperature

Natural Gas

$100,000 \mathrm{PPH}$

250 PSIG

$406^{\circ} \mathrm{F}$ (Sat)

$220^{\circ} \mathrm{F}$

Stack Gas Temperature before Retrofit

$400^{\circ} \mathrm{F}$

\section{Coal Analysis (CWF)}

Carbon

Wt. \%)

Hydrogen

52.7

Oxygen

Nitrogen

Sulfur

Ash

3.1

Moisture

9.2

30.0

Higher Heating Value

\section{Limestone Analysis}

$9430 \mathrm{BTU} / \mathrm{lb}$

\section{Calcium Carbonate \\ Magnesium Carbonate \\ Inerts \\ Vortex Gasifier Conditions \\ Vortex Air Ratio \\ Carbon Conversion \\ Stoichiometric Ratio \\ Reaction Temperature \\ Freeboard Velocity \\ Calcium/Sulfur Molar Ratio \\ Total Sulfur Capture \\ Sulfur Capture as CaS \\ Sulfur Capture as $\mathrm{CaSO}_{4}$}

Wt. \%)

80

5

15

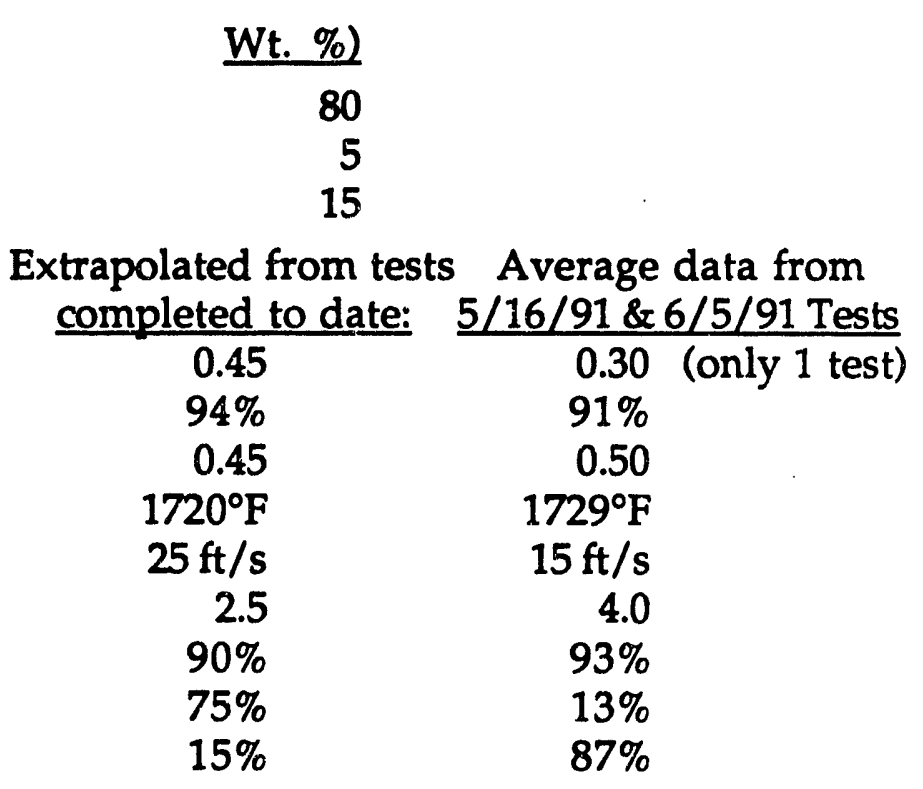




\section{B. SPECIFIC MASS BALANCE}

From an overall combustion standpoint, i.e., after second stage combustion in the boiler itself, it is assumed that the excess air level for retrofit coal firing is $25 \%$. Combustion and sorbent reaction calculations have been made comparing retrofit coal combustion and original natural gas firing as follows:

\section{EUEL}

Higher Heating Value BTU/lb

Overall Excess Air

Stoichiometric Dry Air

Dry Air Required

Moisture in Air

Wet Air Required

Limestone Required

Total Flue Gas Produced

Total Solids Produced

$\%$

$\mathrm{lb} / \mathrm{lb}$ fuel

$\mathrm{lb} / \mathrm{lb}$ fuel

$\mathrm{lb} / \mathrm{lb}$ fuel

$\mathrm{lb} / \mathrm{lb}$ fuel

$\mathrm{lb} / \mathrm{lb}$ fuel

$\mathrm{lb} / \mathrm{lb}$ fuel

$\mathrm{lb} / \mathrm{lb}$ fuel
COAL

9430

25

6.708

8.386

0.109

8.495

0.302

9.462

0.335

FLUE GAS ANALYSIS:

$\mathrm{H}_{2} \mathrm{O}$

$\mathrm{CO}_{2}$

$\mathrm{SO}_{2}$

$\mathrm{N}_{2}$

$\mathrm{O}_{2}$ wt. \%

wt. \%

wt. \%

wt. \%

wt. \%
7.25

20.38

0.07

68.21

4.10
NATURAL GAS

23,170

10

16.721

18.394

0.239

18.633

19.633

11.91

14.05

72.06

1.97

SOLIDS ANALYSIS:

Average Data from

5/16/91\&6/5/91 Tests

$\begin{array}{lrrll}\text { Ash } & \text { wt. \% } & 40.90 & - & - \\ \mathrm{MgO} & \text { wt. \% } & 2.09 & - & - \\ \mathrm{CaO} & \text { wt. \% } & 25.97 & - & - \\ \mathrm{CaSO} 4 & \text { wt. \% } & 5.97 & - & 9.05 \\ \mathrm{CaS} & \text { wt. \% } & 15.52 & - & 0.70 \\ \mathrm{C} & \text { wt. \% } & 9.55 & - & -\end{array}$




\section{BOILER EFFICIENCY}

Boiler efficiency calculations were made and again a comparison between coal and natural gis combustion is presented:

FUEL

Stack Temperature

Dry Flue Gas Loss

Fuel Moisture Loss

Air Moisture Loss

Calcination Loss

Solids Loss (Gasifier Drain)

Solids Loss (Flyash)

Unburned Carbon Loss

Radiation/Convection Loss

Sulfation Credit

Fan Power Credit

Total Losses/Credits

Fuel Efficiency
COAL

${ }^{\circ} \mathrm{F}$

$\%$

$\%$

$\%$

$\%$

$\%$

$\%$

$\%$

$\%$

$\%$

$\%$

$\%$

$\%$

0.19

2.05

1.27

0.06

4.94

0.60

$-0.33$

$-0.32$

$\underline{24.28}$

75.72
NATURAL GAS

400

5.78

10.82

0.15

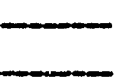

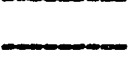

0.50

$-0.19$

17.06

82.94

\section{MASS AND HEAT BALANCES}

\section{System Mass Balance}

The overall system mass balance can now be calculated thus:

\section{FUEL}

Heat Output

Fuel Heat Input

Fuel Flow

Wet Air Flow

Limestone Flow

Flue Gas Flow

Solids Flow (Incl. Carbon)
$10^{6} \mathrm{BTU} / \mathrm{h}$

$10^{6} \mathrm{BTU} / \mathrm{h}$

$\mathrm{lb} / \mathrm{h}$

$\mathrm{lb} / \mathrm{h}$

$\mathrm{lb} / \mathrm{h}$

$\mathrm{lb} / \mathrm{h}$

$\mathrm{lb} / \mathrm{h}$
COAL

101.3

133.7

14,180

120,460

4,280

134,170

4,750

\section{NATURAL GAS}

101.3

122.1

5,270

98,190

103,460 
Vortex Gasifier Mass Balance

$\begin{array}{llr}\text { Fuel Input } & \mathrm{lb} / \mathrm{h} & 14,180 \\ \text { Limestone Input } & \mathrm{lb} / \mathrm{h} & 4,280 \\ \text { Dry Air Input } & \mathrm{lb} / \mathrm{h} & 42,810 \\ \text { Moisture in Air Input } & \mathrm{lb} / \mathrm{h} & 560 \\ \text { TOTAL } & \mathrm{lb} / \mathrm{h} & 61,830 \\ & & \\ \text { Unreacted Carbon Output } & \mathrm{lb} / \mathrm{h} & 450 \\ \text { Other Solids Output } & \mathrm{lb} / \mathrm{h} & 4,300 \\ \text { Moisture Output } & \mathrm{lb} / \mathrm{h} & 8,740 \\ \text { Dry Product Gas Output } & \mathrm{lb} / \mathrm{h} & 48,340\end{array}$

Main Bed (Primary) Air (Wet)

LB/H Stoichiometric Ratio

Sluice (Primary) Air (Wet)

27,800

0.289

Vortex (Cyclone) Air (Wet)

2,110

0.022

$\underline{13,460}$

$\underline{0.139}$

TOTAL GASIFIER AIR (WET)

43,370

0.450

Burner Primary Air (Wet)

\begin{tabular}{rr}
28,910 & 0.30 \\
48,180 & $\underline{050}$ \\
\hline 120,460 & 1.25
\end{tabular}

TOTAL COMBUSTION AIR (WET)

Note: The various air injection locations are shown on Figures $2.20,2.21$ and 2.22 .

Vortex Gasifier Heat Balance

Higher Heat Value in Coal

$\begin{array}{lr}10^{6} \mathrm{BTU} / \mathrm{h} & 133,717 \\ 10^{6} \mathrm{BTU} / \mathrm{h} & 0.444 \\ 10^{6} \mathrm{BTU} / \mathrm{h} & 0.250 \\ 10^{6} \mathrm{BTU} / \mathrm{h} & 134.411\end{array}$

Heat from Sorbent Sulfation

Fan Heat Credit

TOTAL HEAT INPUT

$10^{6} \mathrm{BTU} / \mathrm{h}$

8.578

Latent Heat of Vaporization

$10^{6} \mathrm{BTU} / \mathrm{h}$

6.545

Heat Value in Unreacted Carbon

$10^{6} \mathrm{BTU} / \mathrm{h}$

0.258

Sensible Heat of Unreacted Carbon

$10^{6} \mathrm{BTU} / \mathrm{h}$

1.925

Sensible Heat of Moisture in

$10^{6} \mathrm{BTU} / \mathrm{h}$

7.300

Sensible Heat of Dry Product Gas

$10^{6} \mathrm{BTU} / \mathrm{h}$

21.112

Heat Lost to Radiation/Convection

$10^{6} \mathrm{BTU} / \mathrm{h}$

0.134

Heat to Sorbent Calcination

$10^{6} \mathrm{BTU} / \mathrm{h}$

2.742

Heat Value in Product Gas

(by Difference)

$10^{6} \mathrm{BTU} / \mathrm{h}$

85.817

Heating Value of Wet Product Gas at $60^{\circ} \mathrm{F}=104 \mathrm{BTU} / \mathrm{scf}$ Heating Value of Dry Product Gas at $60^{\circ} \mathrm{F}=134 \mathrm{BTU} / \mathrm{dscf}$ 


\section{E. EQUIPMENT ARRANGEMENT}

The main components of the Vortex Gasifier system have been designed from the preceeding information and the general arrangement and main dimensions of the equipment is shown in Figures 2.23, 2.24 and 2.25.

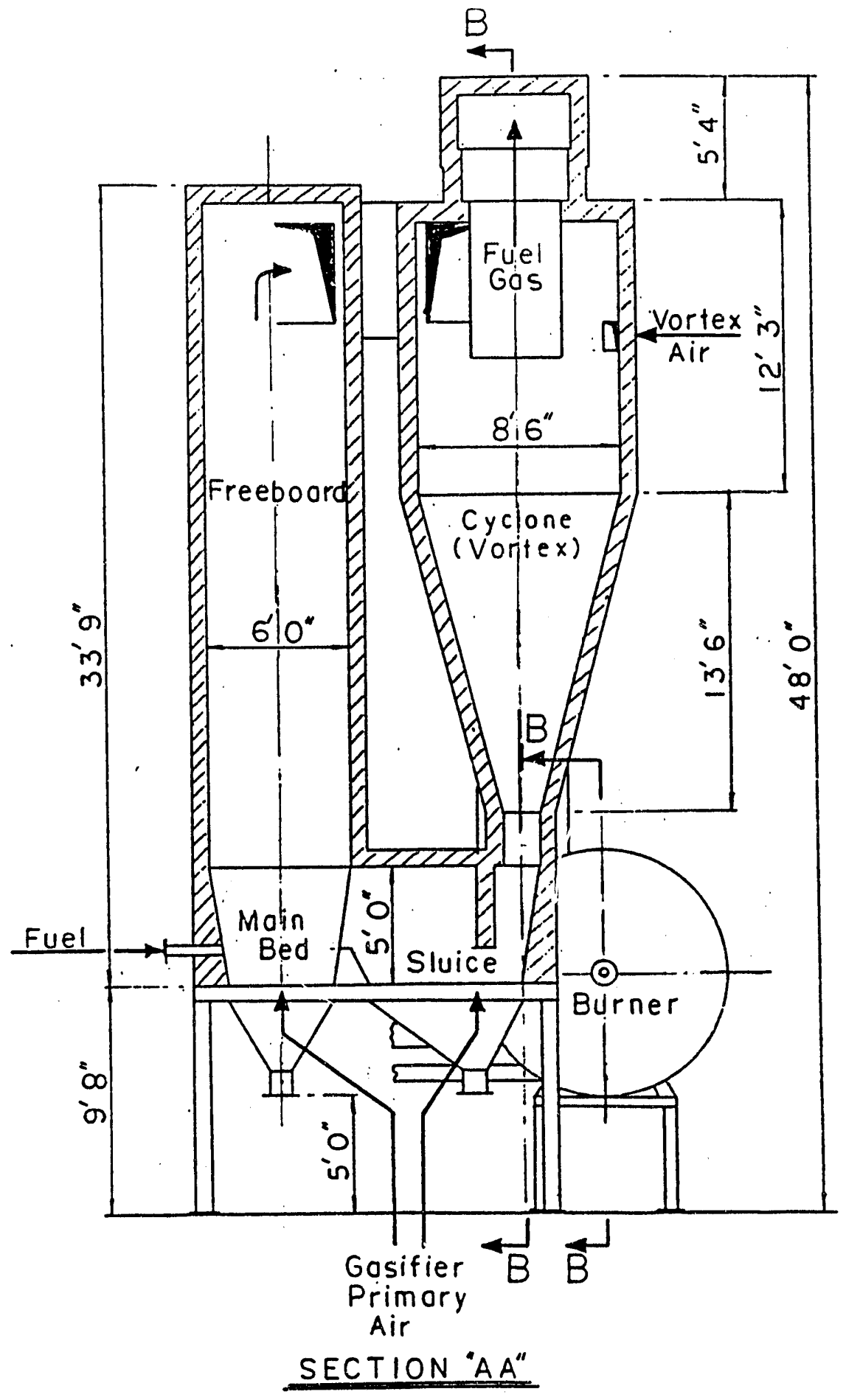

Figure 2.23. Equipment Arrangement - End View 


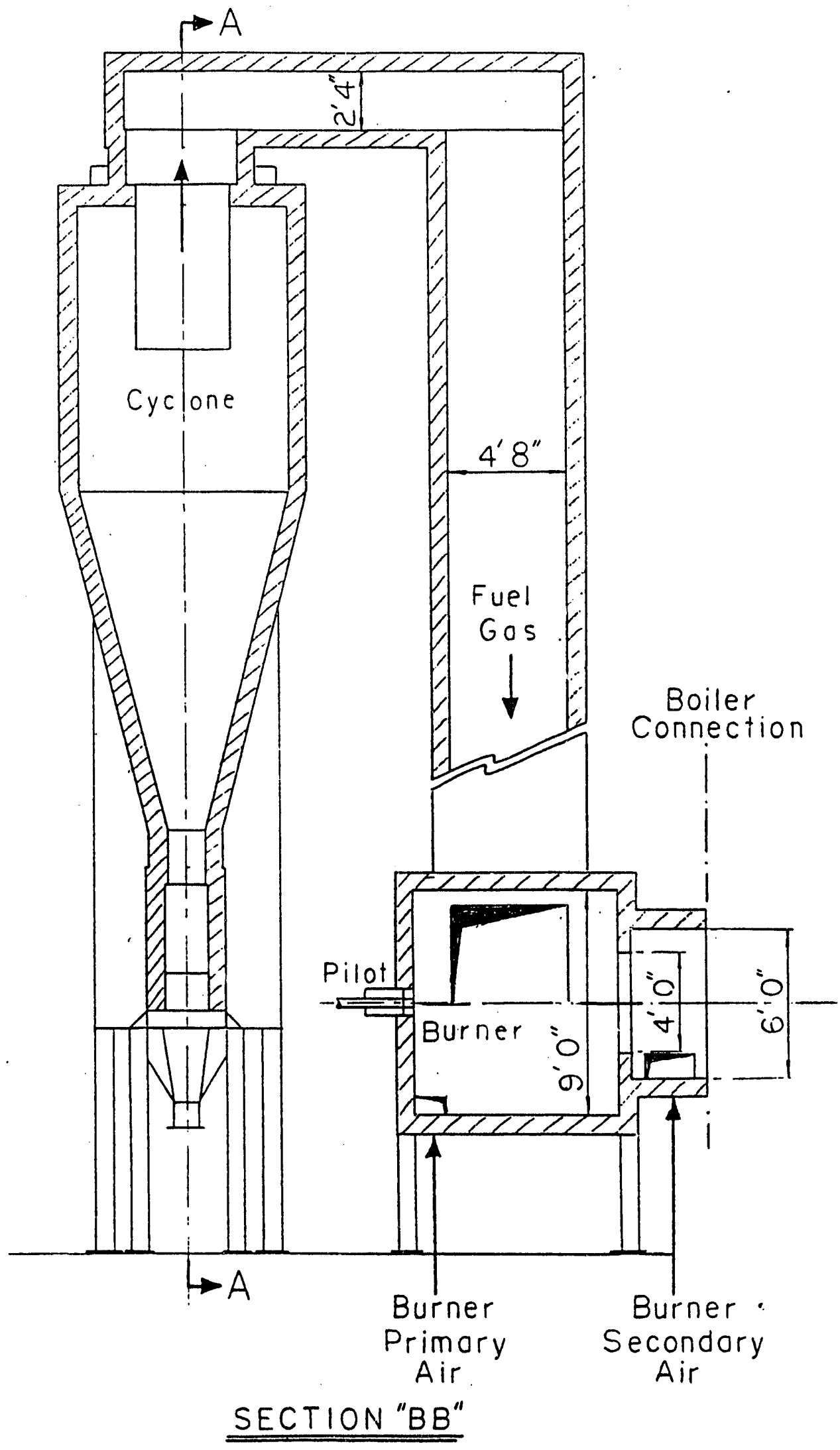

Figure 2.24. Equipment Arrangement - Side View 


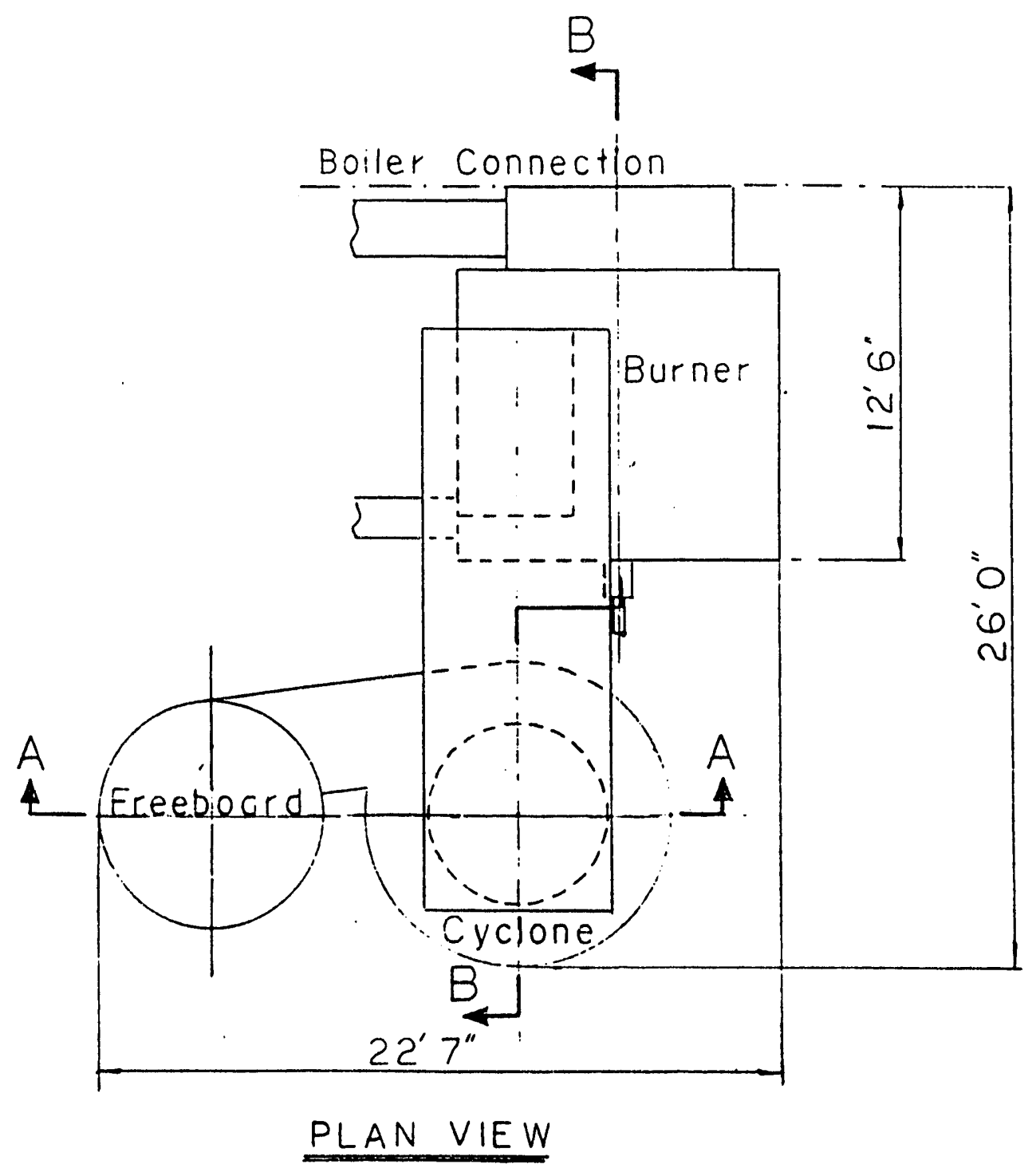

Figure 2.25. Equipment Arrangement - Plan View 


\section{F. PROJECT CAPITAL COSTS}

An estimate of equipment costs for a 100,000 lb/h steam Vortex gasifier retrofit is tabulated below. Estimates of engineering, design, drafting and start-up labor and installation costs have also been made and are included in the table to provide the predicted required capital investment. Using cost scaling indices, the capital investment requirements for $60,000 \mathrm{lb} / \mathrm{h}$ steam and $20,000 \mathrm{lb} / \mathrm{h}$ steam boiler retrofits have also been estimated.

$\begin{array}{lrrr} & 100,000 \mathbf{l b} / \mathbf{h} & \mathbf{6 0 , 0 0 0} \mathbf{l b} / \mathbf{h} & \mathbf{2 0 , 0 0 0} \mathbf{l b} / \mathbf{h} \\ \text { Gasifier, transfer duct and burner } & \$ 107,000 & \$ 79,000 & \$ 35,000 \\ \text { Refractory lining (installed) } & 210,000 & 155,000 & 68,000 \\ \text { Pilot burner } & 6,000 & 6,000 & 6,000 \\ \text { Fans } & 24,000 & 18,000 & 8,000 \\ \text { Air Ducts } & 14,000 & 10,000 & 5,000 \\ \text { Valves and Dampers } & 19,000 & 14,000 & 6,000 \\ \text { Instruments and Controls } & 114,000 & 114,000 & 114,000 \\ \text { Coal/limestone handling and feeding } & 200,000 & 155,000 & 89,000 \\ \text { Solids removal system } & 40,000 & 31,000 & 18,000 \\ \text { Steelwork } & 10,000 & 7,000 & 3,000 \\ \text { Electrical Equipment } & 40,000 & 29,000 & 13,000 \\ \text { Baghouse } & \mathbf{2 2 0 , 0 0 0} & 162,000 & 71,000 \\ \text { Ash handling } & \underline{\mathbf{2 0 0 , 0 0 0}} & \underline{155,000} & \underline{89,000} \\ \text { TOTAL EQUIPMENT } & 1,204,000 & 935,000 & 525,000 \\ \text { Engineering labor, etc. } & 126,000 & 126,000 & 126,000 \\ \text { Installation costs } & 270,000 & 219,000 & 149,000 \\ \text { Delivery, contingency \& mark-up } & \underline{400,000} & \underline{320,000} & \underline{200,000} \\ \text { CAPITAL INVESTMENT } & \$ 2,000,000 & \$ 1,600,000 & \$ 1,000,000 \\ & & & \end{array}$


It should be noted that for the above estimates it has been assumed that:

- a building/enclosure will not be required,

- an inducted draft fan will not be required,

- the existing stack and flue gas ducts can be used,

- the boiler can be retrofitted without pressure part modifications. Flue gas velocities will be higher than for natural gas firing and may be a concern, and

- ash collection points can be readily installed on the boiler.

\section{G. PROJECT OPERATING COSTS}

Based on 8000 hours per year operation (i.e., 0.913 load factor) the yearly operating costs are predicted as follows:

Coal supply*

Limestone supply

Solids disposal**

Added repair and maintenance

Added power cunsumption

TOTAL OPERATING COST

Avoided Natural Gas Cost

Net Yearly "Income"
$14,180 \mathrm{lb} / \mathrm{h} @ \$ 38$ per ton

$4,280 \mathrm{lb} / \mathrm{h} @ \$ 20$ per ton

$4,750 \mathrm{lb} / \mathrm{h} @ \$ 20$ per ton

$1.33 \%$ equipment costs

$85 \mathrm{KW} @ .65 \&$ per kWh

$5,270 \mathrm{lb} / \mathrm{h} @ \$ 4.5$ per $10^{6} \mathrm{BTU}$
$\$ 2,155,000$

342,000

380,000

16,000

$\underline{44,000}$

$\$ 2,937,000$

$\$ 4,396,000$

$\$ 1,459,000$

It is assumed that the Net Yearly "Income" fort the other retrofit sizes can be prorated directly from steam output.

* The coal unburned carbon loss of about 5\% is high and should be reduced if possible. However, it can be seen that it does not detract too greatly from the project economics.

* This assumes that the ash can be landfilled as a residual waste for disposal. (i.e., It is not classified as a special waste possibly due to its CaS content). 


\section{H. ECONGIMIC ANALYSIS AND "PAYBACK"}

Using the results of Sections $F$ and G, a 15 year life cycle economic analysis has been carried out. The basis for this analysis is as follows:

- An $8 \%$ yearly interest rate is used to calculate the value of the capital, at the end of each year, had it been invested.

- The Net Yearly "Income" or Saving is escalated at 4\% per year to account for inflation. Thus, the yearly saving can be calculated.

- A yearly cumulative saving is calculated at the end of each year.

- The value of capital investment is subtracted from the cumulative saving, to give a net cumulative income at the end of each year.

- The net cumulative income is brought back to a present day value using the $8 \%$ yearly interest rate.

The results of the economic analysis for retrofit steam outputs of $100,000 \mathrm{pph}, 60,000$ pph and 20,000 pph are shown on Figure 2.26. A negative value on this graph indicates a cumulative loss. The starting point on each curve is the original capital investment. Where the curves cross the Time axis indicates the "Payback", i.e., when the money lost by capital investment has been recovered by the net income (savings). It can be seen that the payback times for the $10 \mathrm{C}, 000 \mathrm{pph}, 60,000 \mathrm{pph}$ and $20,000 \mathrm{pph}$ examples are 1.55 years, 2.1 years and 4.5 years, respectively.

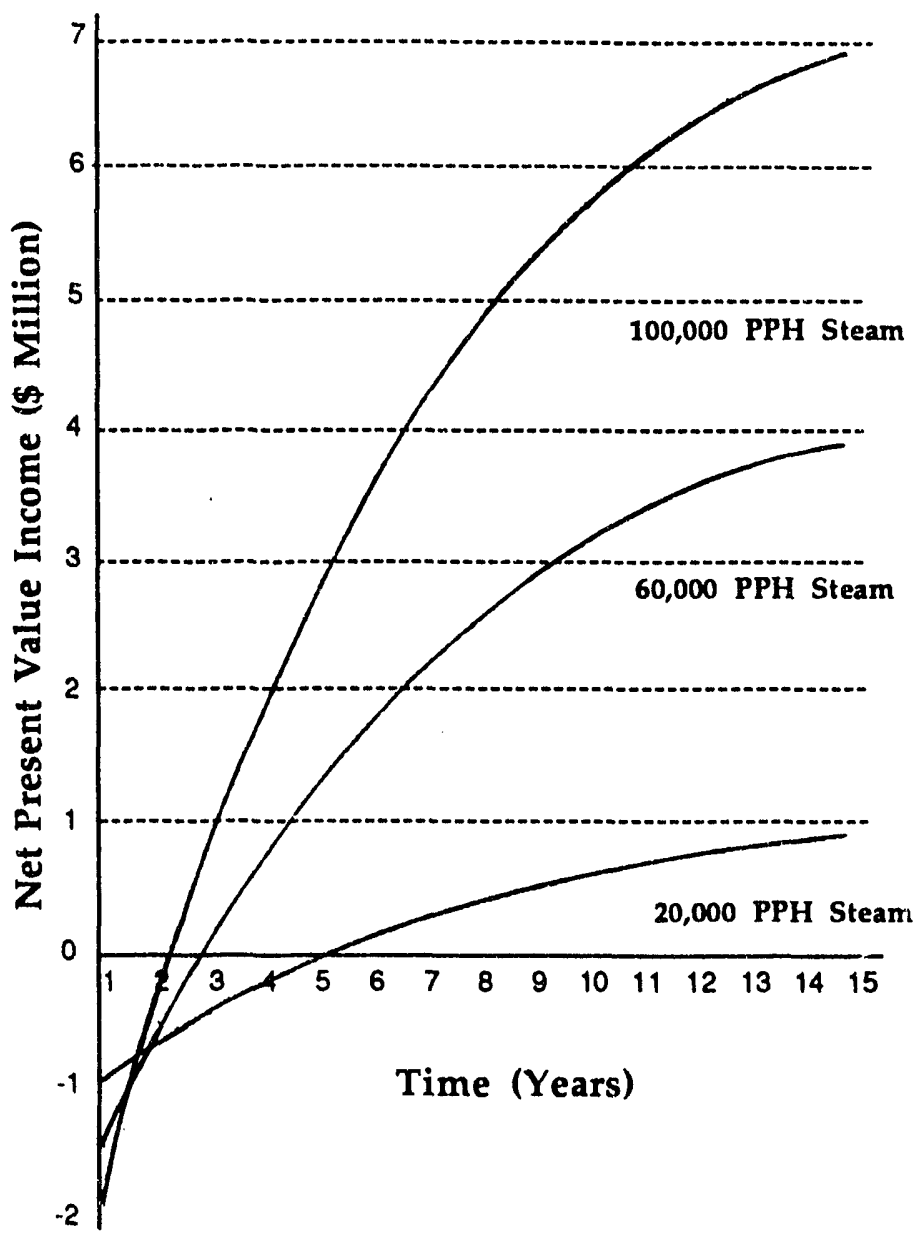

Figure 2.26. Economic Analysis for Retrofit Steam Outputs $(100,000 \mathrm{pph} ; 60,000 \mathrm{pph}$ and 20,000 pph) 
A positive value on the graph indicates a net cumulative income. For example, after 15 years the total return on investment, in present day dollars, for the three boiler options is $\$ 7.2$ million, $\$ 3.92$ million and $\$ 0.84$ million, respectively.

A second graph, Figure 2.27, shows the relationship between retrofit boiler steam output, and "payback" time, i.e., the time to achieve return on capital investment.

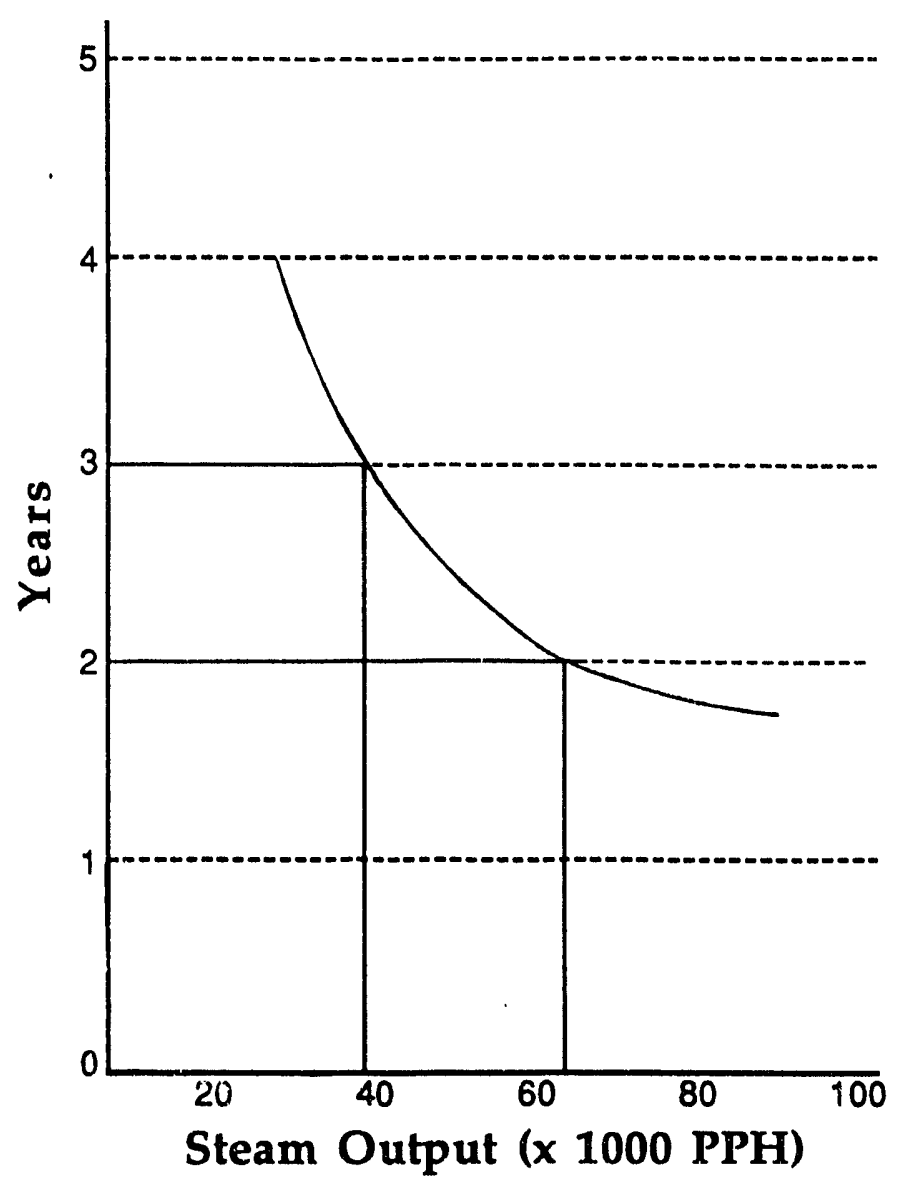

Fig are 2.27. Payback Time

\section{DISCUSSION AND CONCLUSIONS}

Based on the assumptions made, it can be seen that a 100,000 pph steam, natural gas fired, boiler retrofit appears to be very viable with a payback in about 1.5 years and a net present value income of more than $\$ 7$ million after 15 years. The two main areas of concern in this analysis are:

- mainly due to the complexity of a retrofit, the capital cost may be significantly higher than that estimated; and

- the yearly savings may be significantly lower. For example, limitations imposed by the retrofitted equipment may result in the necessity for down-rating boiler output.

However, a payback time of 2 years is typically considered to be very acceptable. Thus, if the predicted yearly savings are correct, then the capital cost would have to increase by more than $28 \%$ before ine 2 year payback is exceeded. If the capital cost estimate is correct, the yearly savings would have to decrease by more than $22 \%$ before the 2 year payback is exceeded. 
From Figure 2.27 it can be seen that, based on the assumptions made, a 2 year payback can be achieved on a retrofit boiler with an output of about $65,000 \mathrm{pph}$ steam. It can be concluded therefore, that the economics of retrofitting an oil/gas fired boiler with a steam output of $100,000 \mathrm{pph}$, or greater, are very attractive. Also, there is a very good chance that steam outputs in the 60,000 to $100,000 \mathrm{pph}$ range will also give an acceptable return on investment. Thus the need to confirm the performanre of the Vortex gasifier is demonstrated.

If 3 years is taken as the highest acceptable payback time, it can be seen in Figure 2.27 that steam outputs of less than about $40,000 \mathrm{pph}$ will give unattractive economics. It can be concluded that a technology with a lower capital cost is needed for retrofitting boilers with a steam output of prohably less than $60,000 \mathrm{pph}$, and certainly less than $40,000 \mathrm{pph}$. 
APPENDIX A

\section{VORTEX $^{\mathrm{TM}}$ (VFBC) PILOT PLANT FACILITY DRAWINGS}




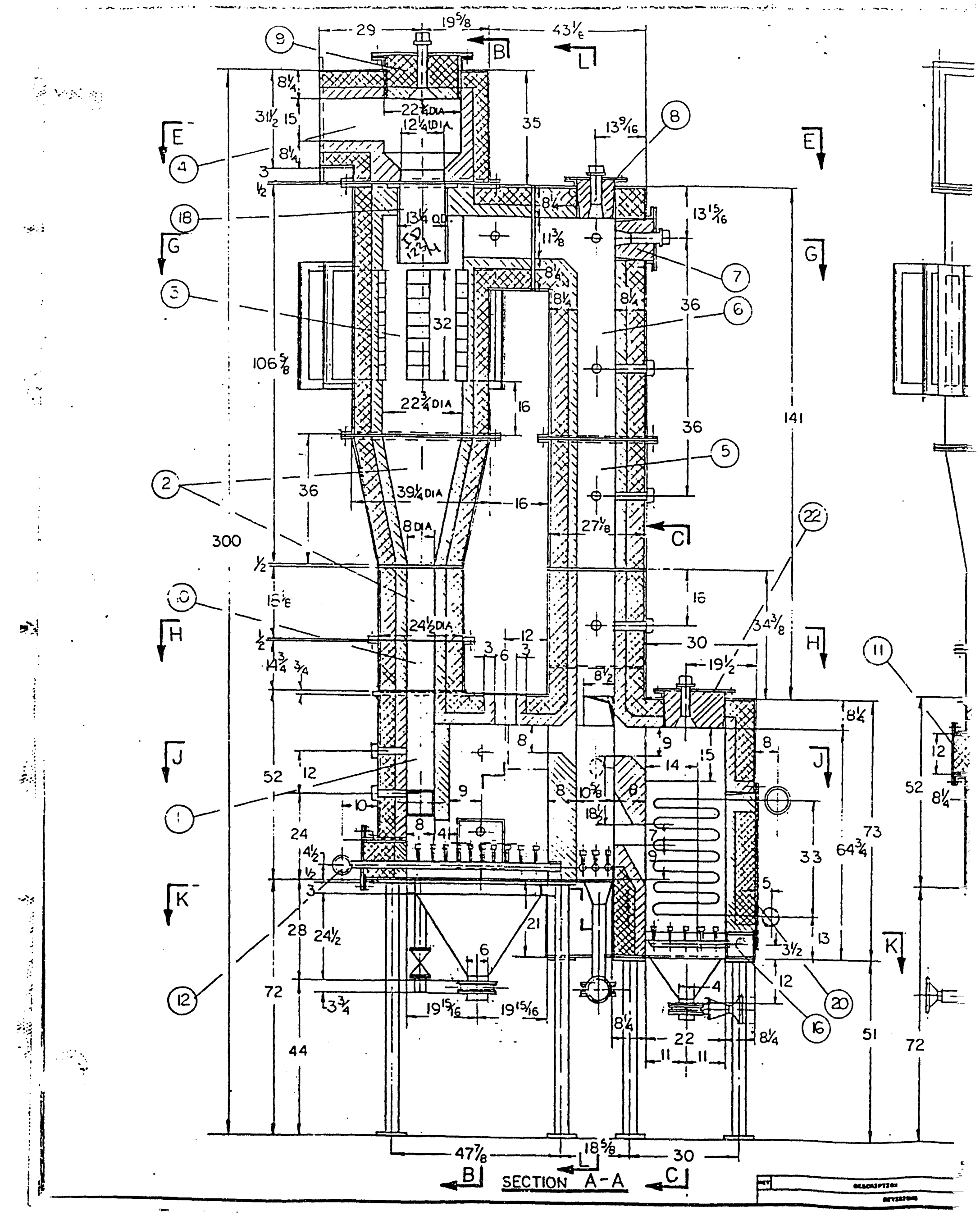




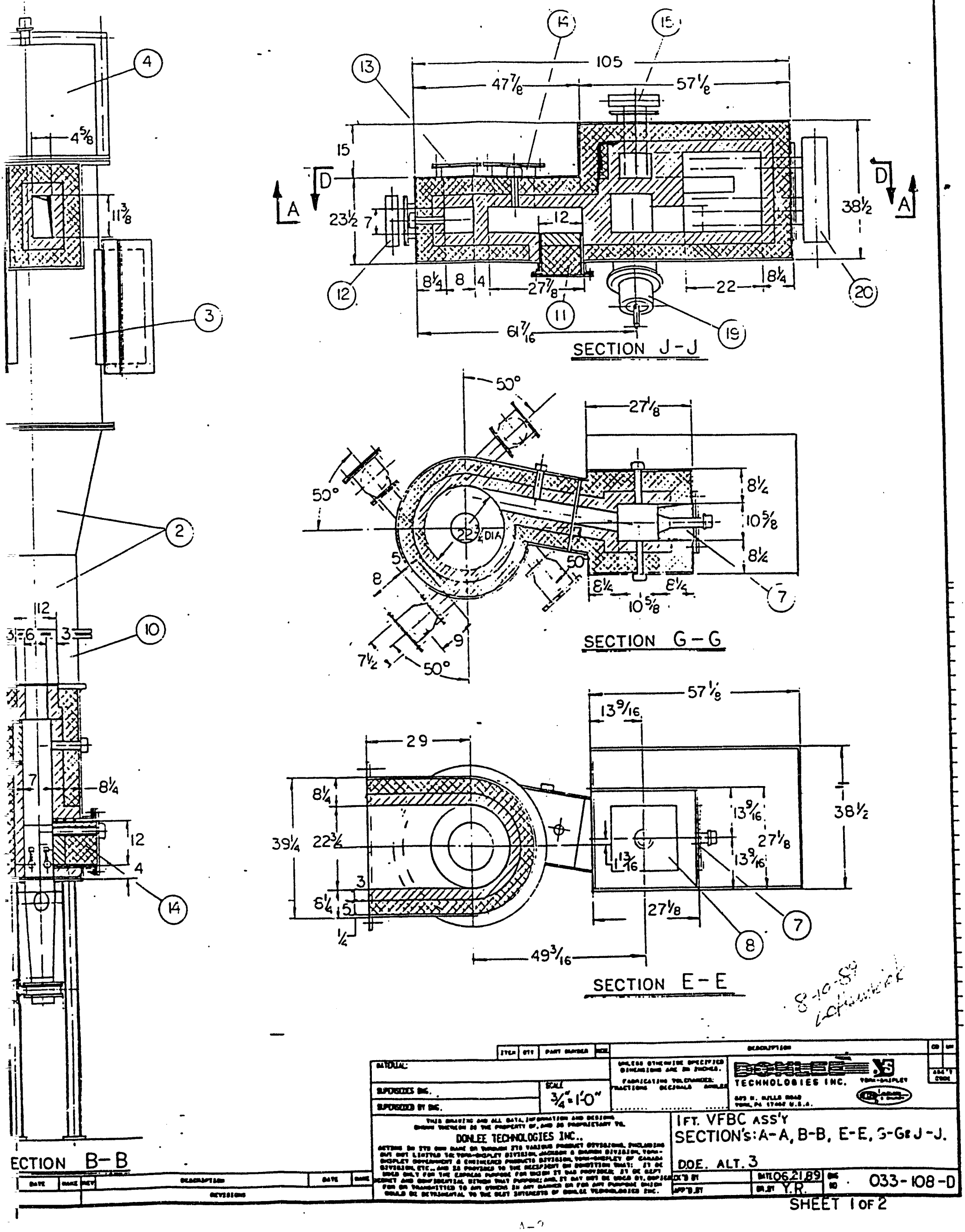




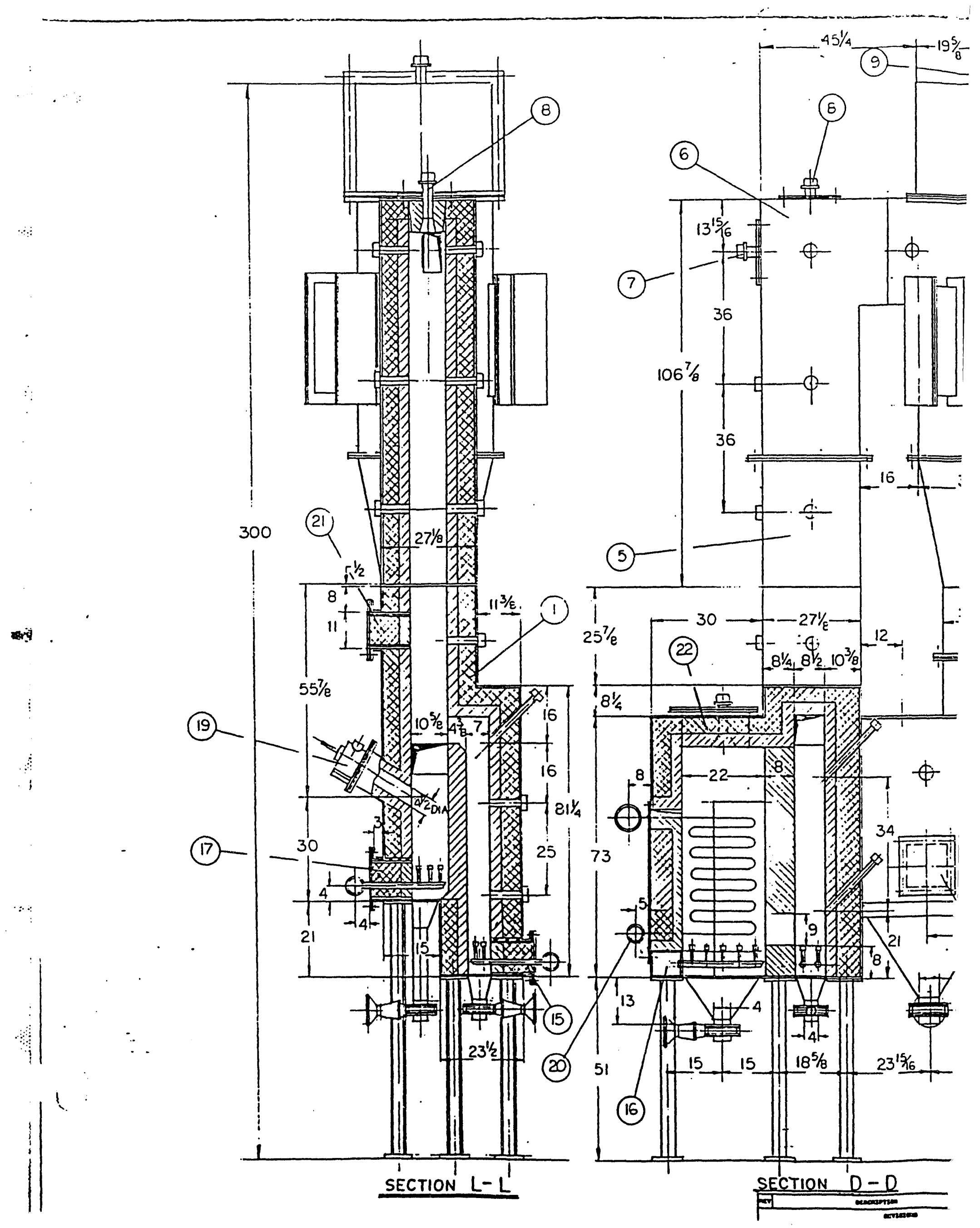




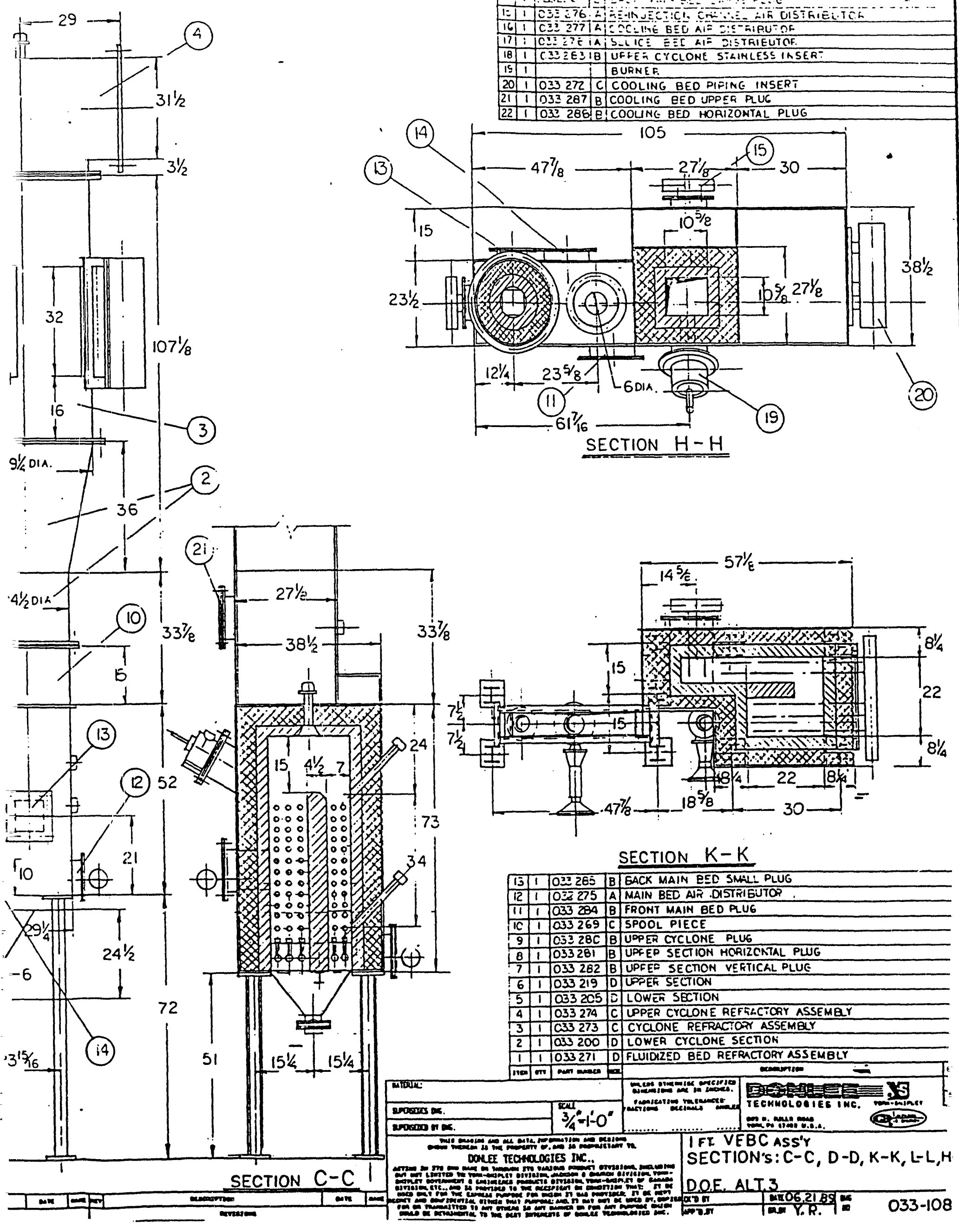




\section{APPENDIX B}

\section{VORTEX $^{\mathrm{TM}}$ TESTING TRENDS}

B-1 
Iigure B-1. Gas Emissions at the Boiler Outlet from the VFBC Test Facility November 7, 1991

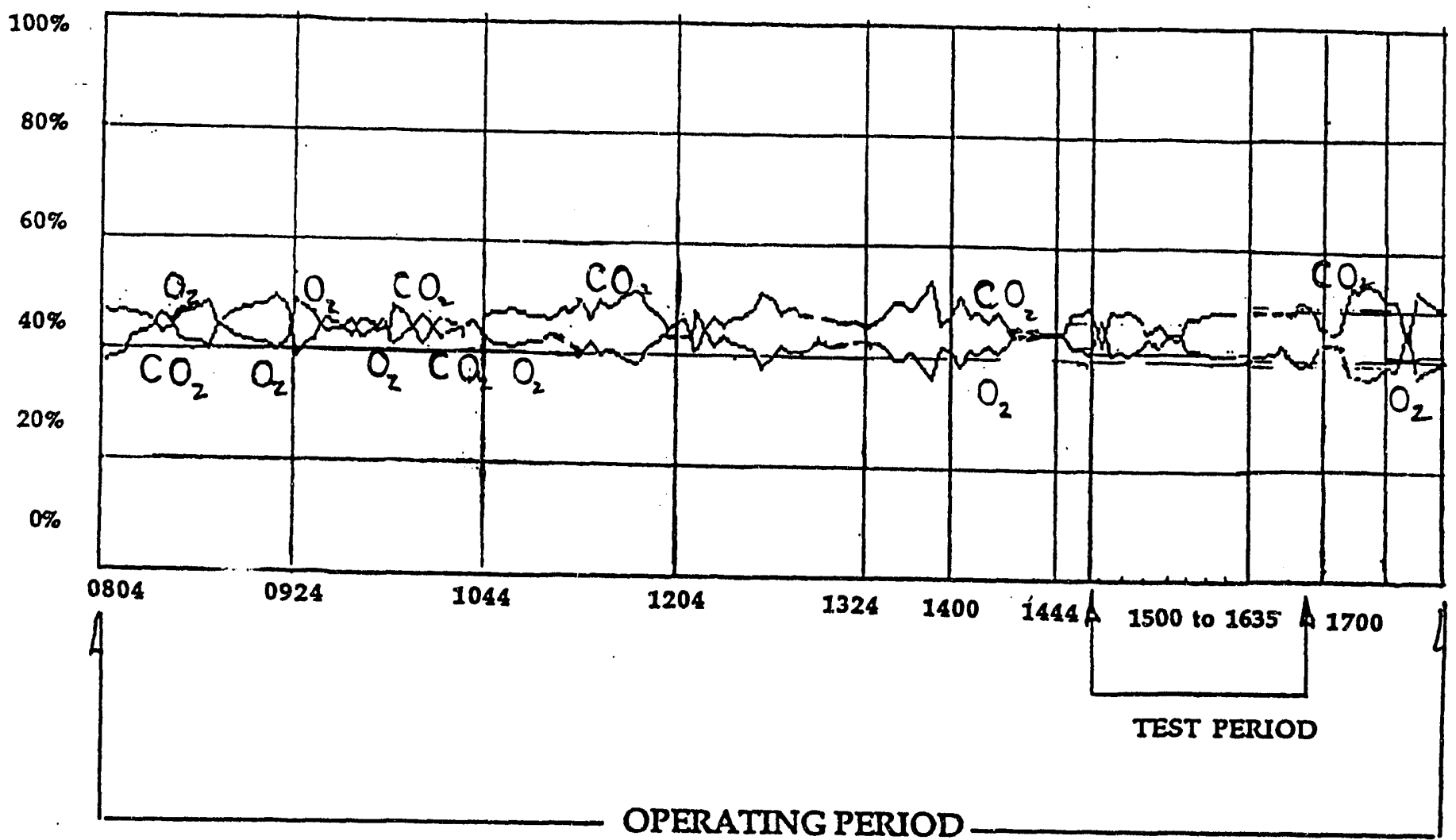

November 7, 1991

$100 \%$ Equals
$\mathrm{O}_{2}=25.00 \%$
$\mathrm{CO}_{2}=20.00 \%$


Figure B-2. Gas Emissions at the Boiler Outlet from the VFBC Test Facility November 7, 1991

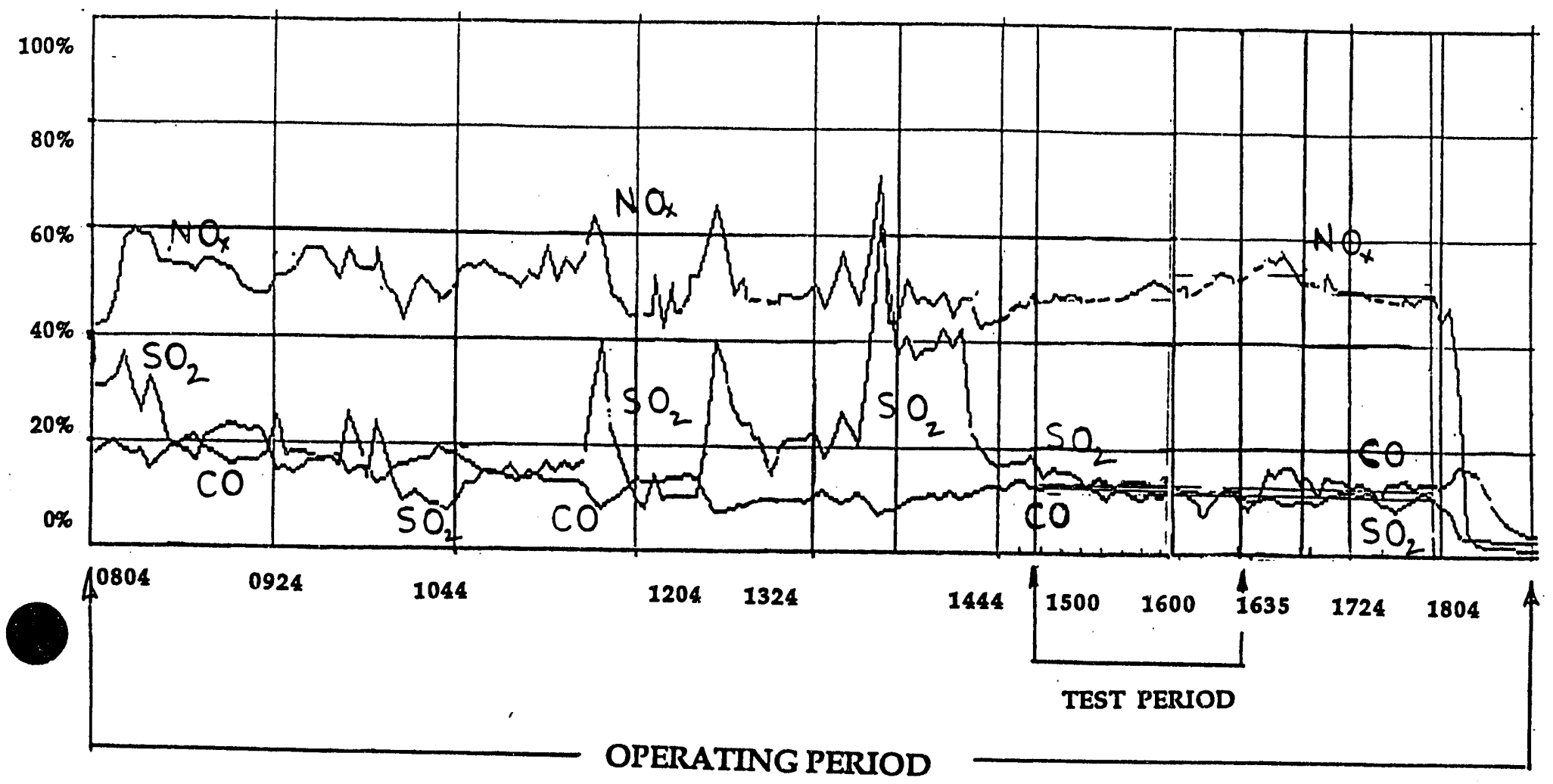

November 7, 1991

\section{$100 \%$ Equals}

$\mathrm{SO}_{2}=2000.00 \mathrm{ppm}$

$\mathrm{NO}_{\mathrm{x}}=250.00 \mathrm{ppm}$

$\mathrm{CO}=1000.00 \mathrm{ppm}$ 
Figure B-3. Gas Emissions at the Boiler Outlet from the VFBC Test Facility November 8, 1991

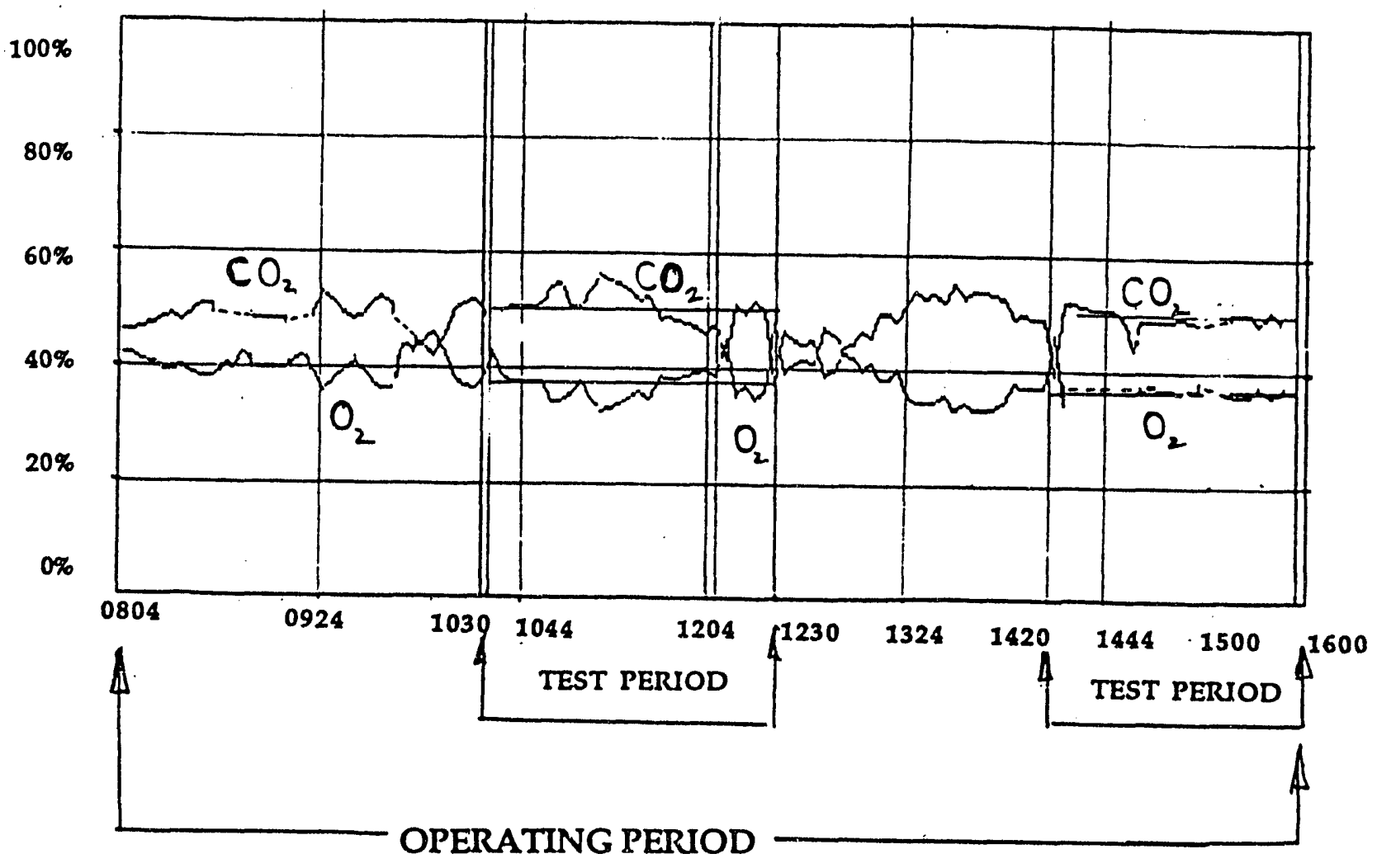

November 8, 1991

$$
\begin{aligned}
& 100 \% \text { Equals } \\
& \mathrm{O}_{2}=25.00 \% \\
& \mathrm{CO}_{2}=20.00 \%
\end{aligned}
$$


Figure B-4. Gas Emissions at the Boiler Outlet from the VFBC Test Facility November 8, 1991

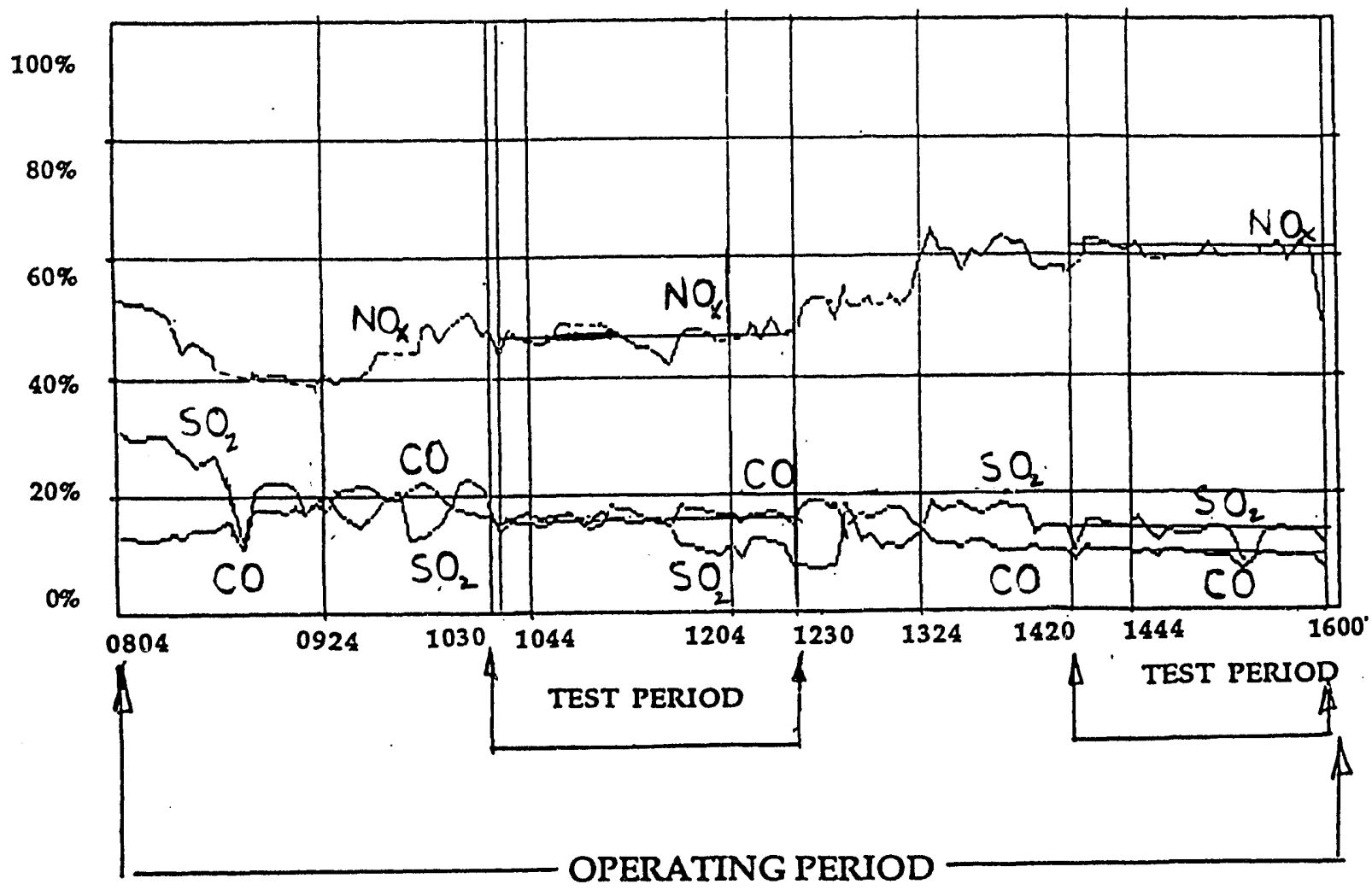

November 8, 1991

$100 \%$ Equals

$\begin{array}{lll}\mathrm{SO}_{2} & =2000.00 & \mathrm{ppm} \\ \mathrm{NO}_{\mathrm{X}} & =250.00 & \mathrm{ppm} \\ \mathrm{CO} & =1000.00 & \mathrm{ppm}\end{array}$ 
Figure B-5. Gas Emissions at the Boiler Outlet from the VFBC Test Facility November 15, 1991

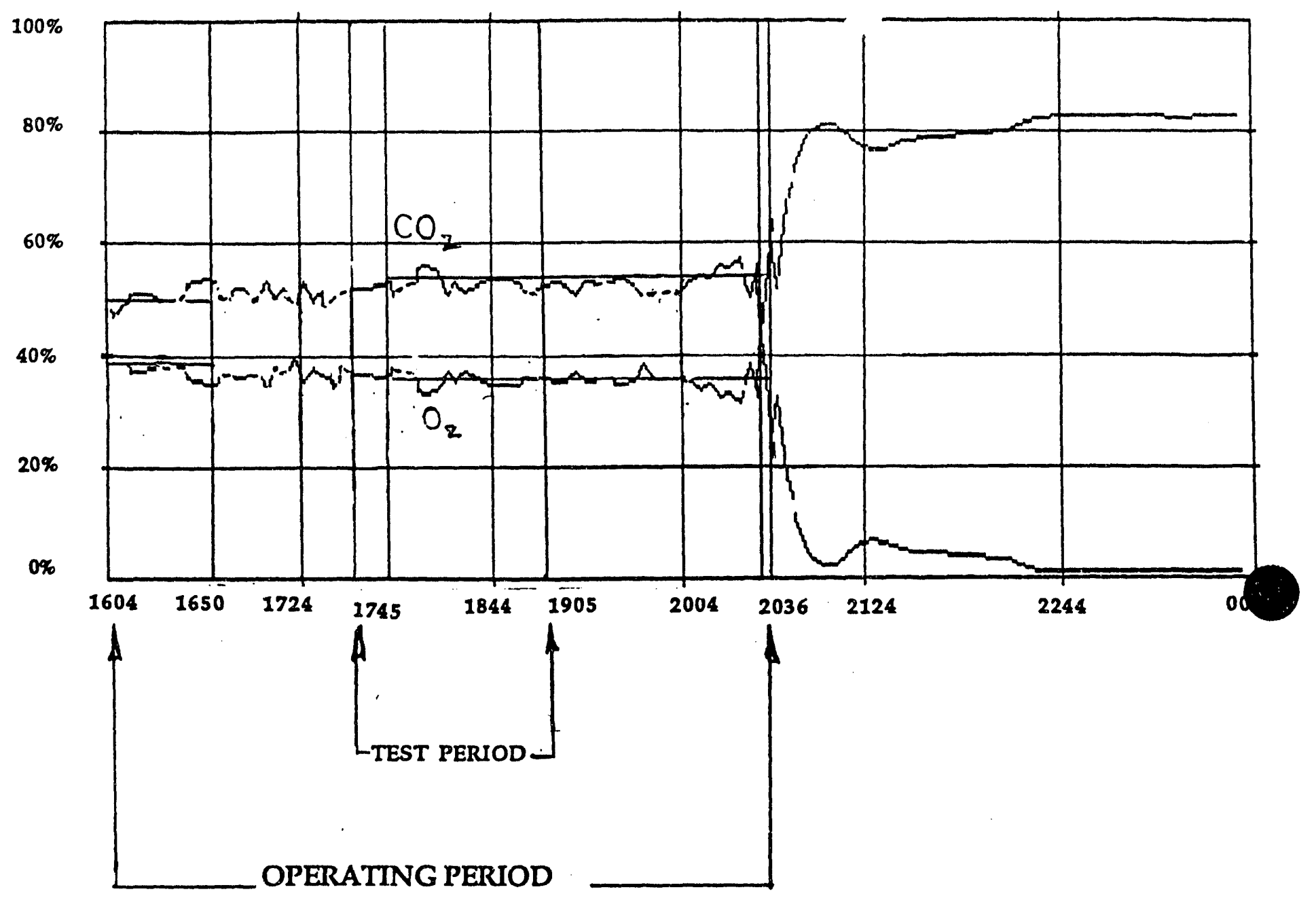

November 15, 1991

\section{$100 \%$ Equals}

$\mathrm{O}_{2}=25.00 \%$
$\mathrm{CO}_{2}=20.00 \%$ 
Figure B-6. Gas Emissions at the Boiler Outlet from the VFBC Test Facility November 15, 1991

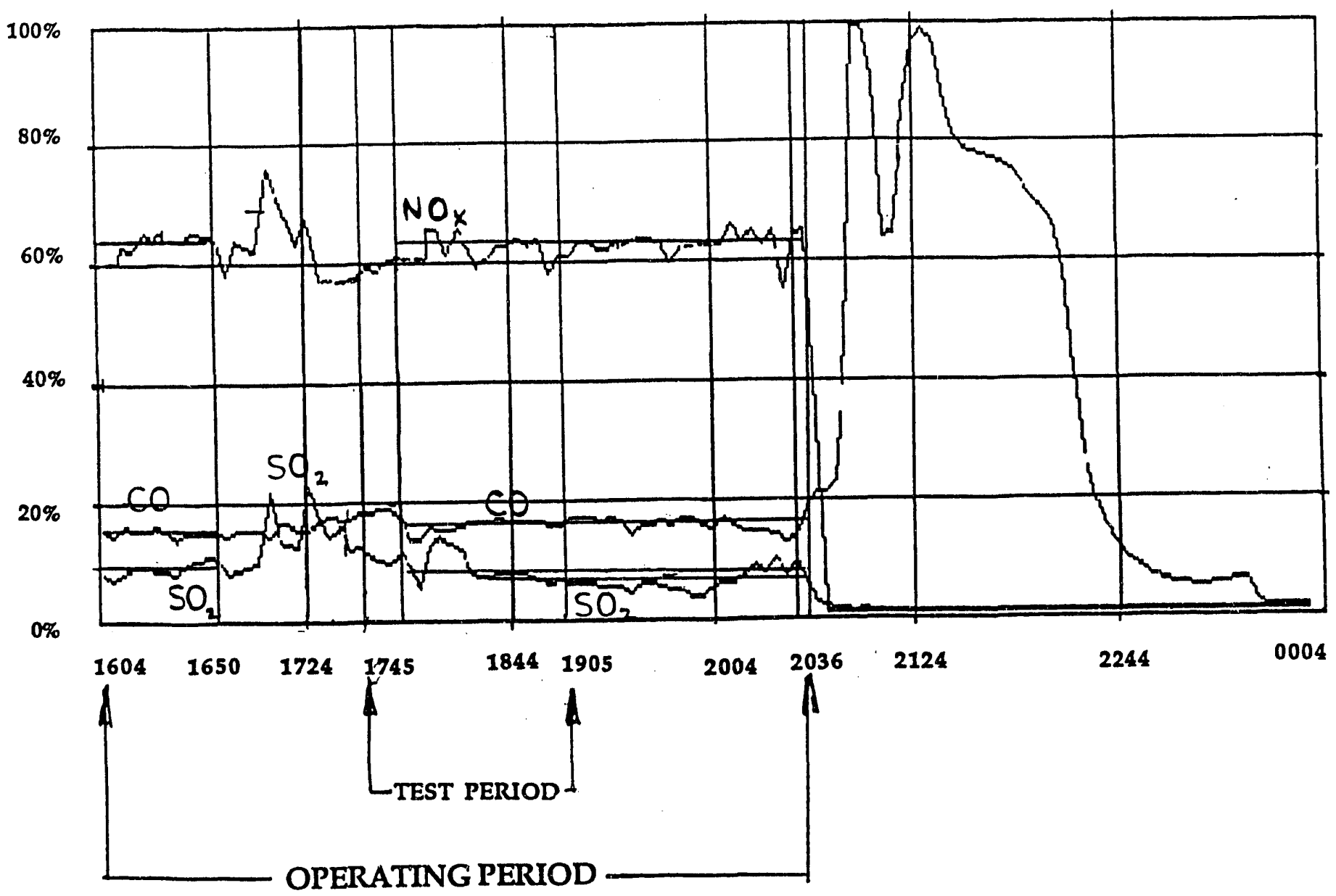

November 15, 1991

\section{$100 \%$ Equals}

$\mathrm{SO}_{2}=2000.00 \mathrm{ppm}$

$\mathrm{NO}_{\mathrm{x}}=250.00 \mathrm{ppm}$

$\mathrm{CO}^{\mathrm{X}}=\mathbf{1 0 0 0 . 0 0 \mathrm { ppm }}$ 
Figure B-7. Gas Emissions at the Boiler Outlet from the VFBC Test Facility November 7, 1991

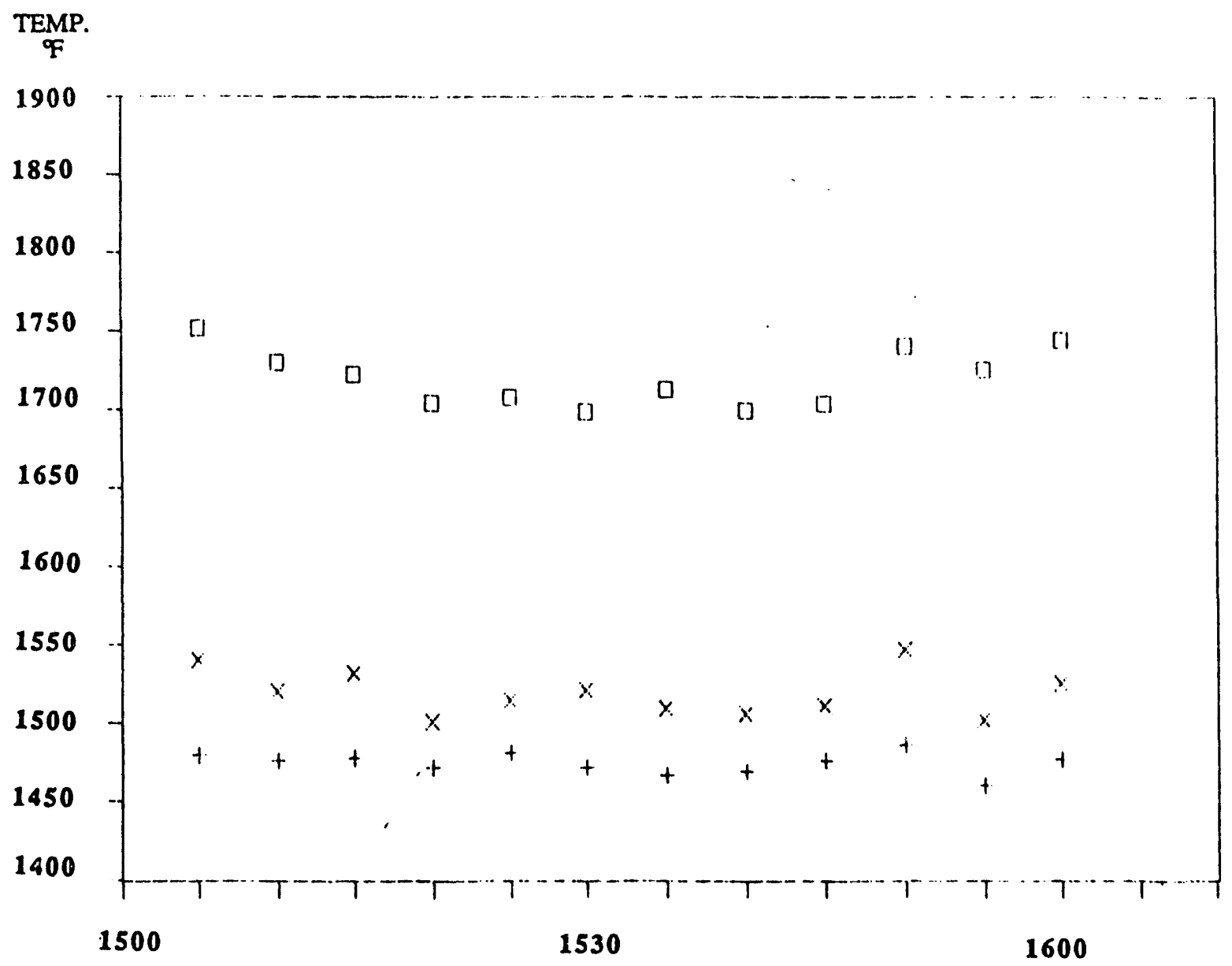

TIME DURING TEST

$\frac{\text { LEGEND }}{+}$ MAIN BED
X TOP FREEBOARD
$\square$ CYLONE OUTLET


Figure B-8. Gas Emissions at the Boiler Outlet from the VFBC Test Facility November 8, 1991

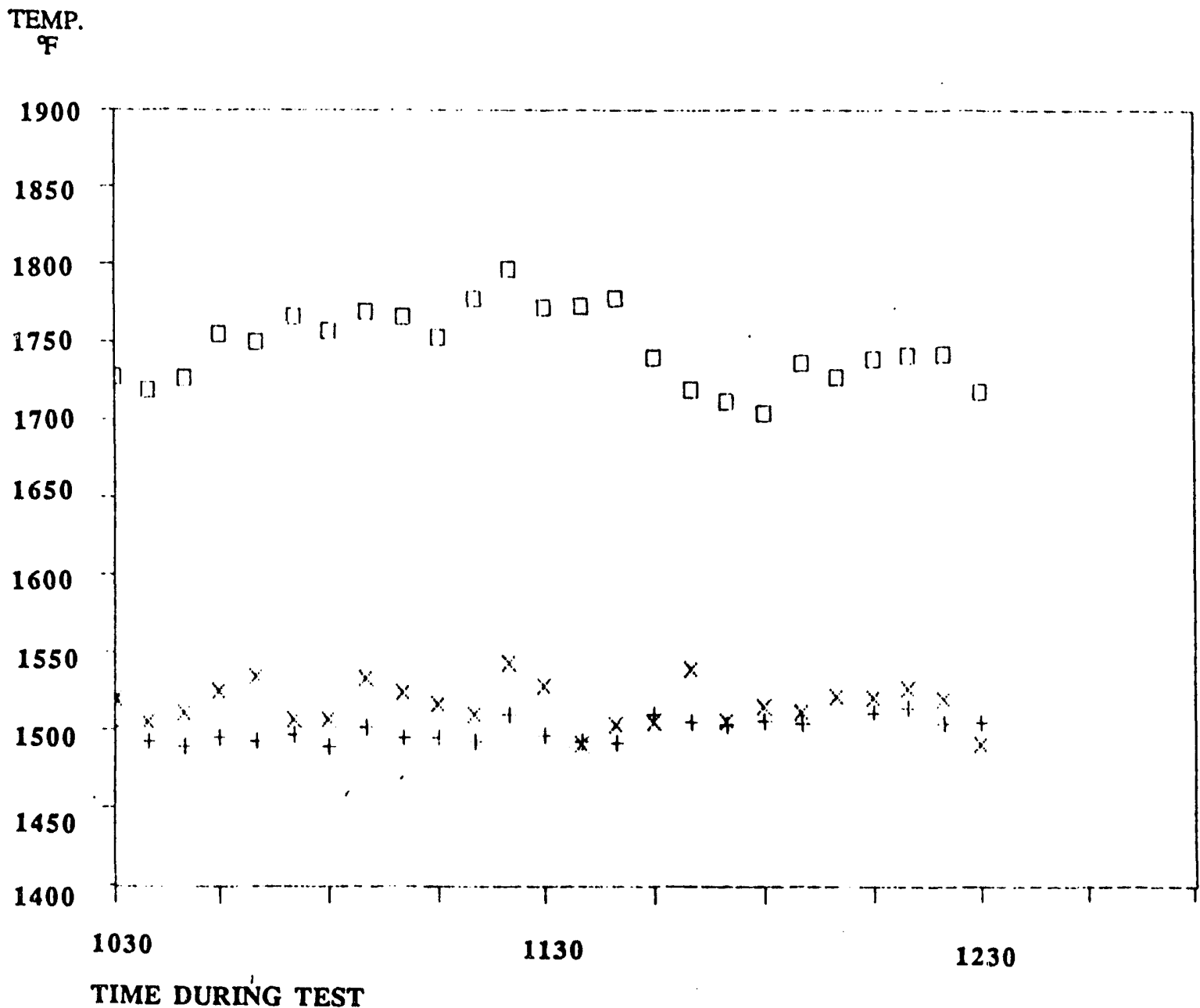

\section{LEGEND}

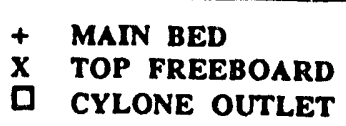


Figure B-9. Gas Emissions at the Boiler Outlet from the VFBC Test Facility November 8, 1991

TEMP.

F

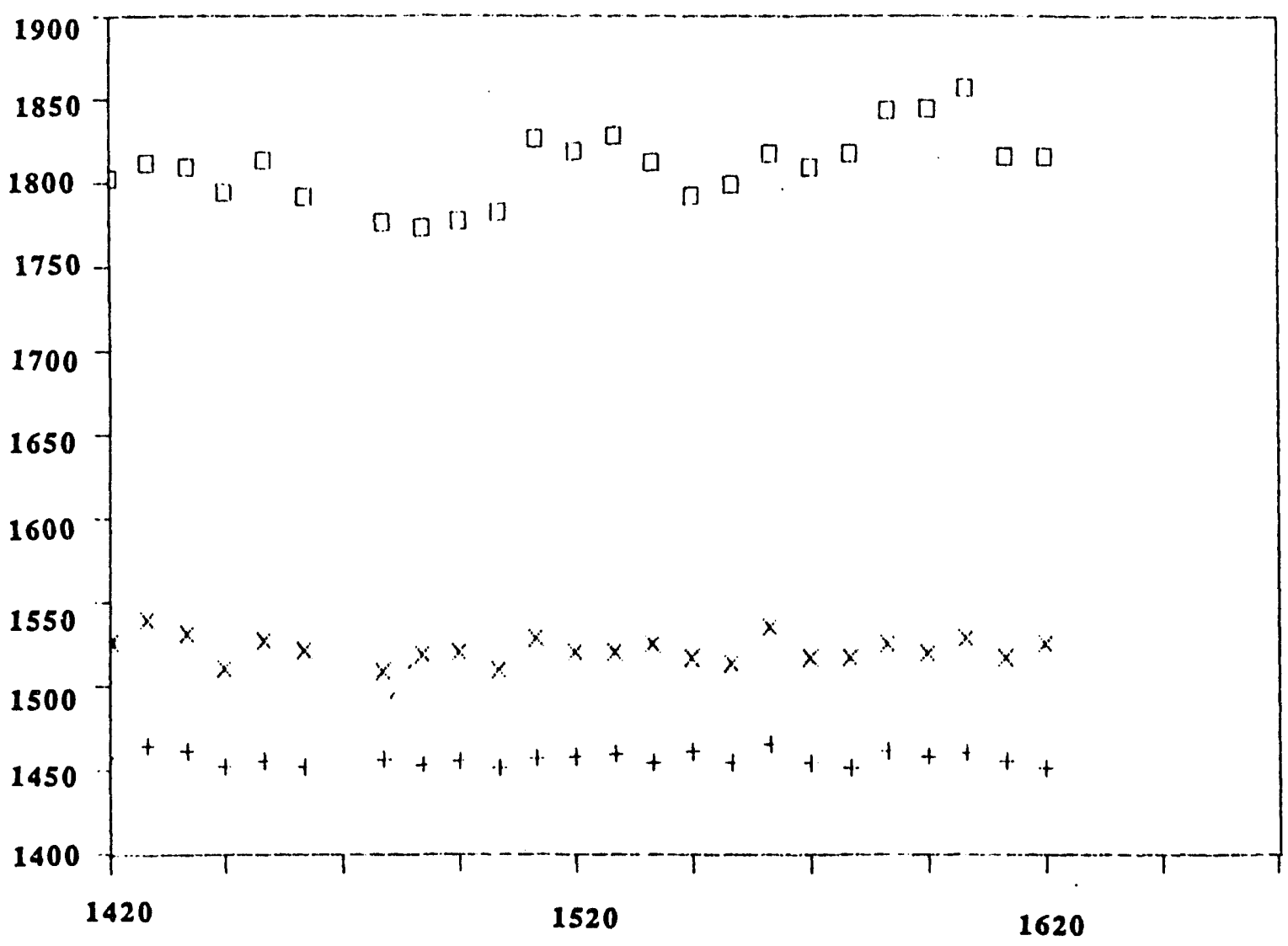

TIME DURING TEST

\section{LEGEND}

\begin{tabular}{ll}
\hline+ & MAIN BED \\
$\mathbf{X}$ & TOP FREEBOARD \\
$\square$ & CYLONE OUTLET
\end{tabular}


Figure B-10. Gas Emissions at the Boiler Outlet from the VFBC Test Facility November 15, 1991

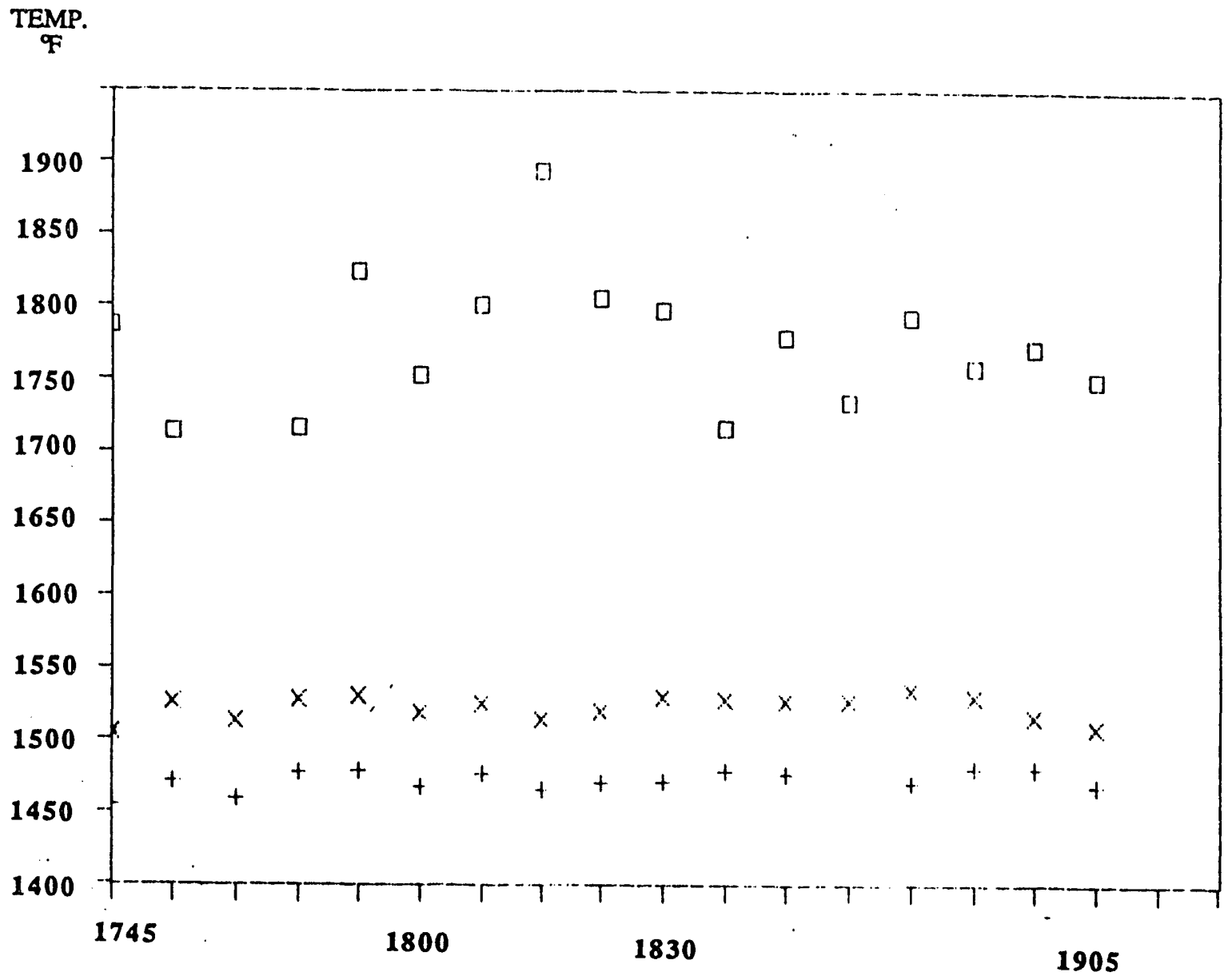

TIME DURING TEST

\section{LEGEND}

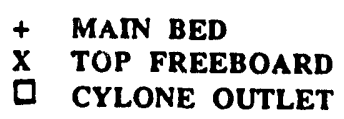




\section{APPENDIX C}

\section{ECONOMIC EVALUATION \\ OF THE VORTEX ${ }^{\mathrm{TM}}$ (VFBC) PROOF-OF-CONCEPT FACILITY}




\section{ECONOMIC EVALUATION \\ OF THE VORTEXTM (VFBC) \\ PROOF-OF-CONCEPT FACILLITY}

An economic analysis was completed as part of the Level I effort of this project. This previous analysis is updated to reflect the impact of performance demonstrated during the testing phase of Level III.

\section{DESIGN BASIS}

The prototype facility size was selected to be $60,000 \mathrm{lb} / \mathrm{hr}$ of saturated 200 psig steam generating capacity. Performance criteria for which the prototype was designed include maintaining emissions to within regulated limits, providing automated solids handling systems capable of dust free operation, and providing a turndown capability of at least 4:1. Specific component design criteria and operating conditions are discussed separately.

An Illinois No. 6 coal was selected as the base fuel for the prototype. The analyses of the coal and limestone used in the economic analysis are:

COAL

\begin{tabular}{lc} 
Constituent & Wt \% \\
\hline $\mathrm{C}$ & 63.23 \\
$\mathrm{H}$ & 4.70 \\
$\mathrm{O}$ & 8.43 \\
$\mathrm{~S}$ & 2.70 \\
$\mathrm{~N}$ & 1.24 \\
Moisture & 9.70 \\
Ash & 10.00 \\
Size & $3 / 4 \times 0$
\end{tabular}

\section{LIMESTONE}

\begin{tabular}{lc} 
Constituent & Wt \% \\
\hline Calcium Carbonate & 94.1 \\
Magnesium Carbonate & 3.3 \\
Silica & 0.6 \\
Inerts & 1.8 \\
Moisture & 0.2 \\
Size & $1 / 8 \times 0$
\end{tabular}

To simplify the updating of the economic analysis, these feed materials were also used in the revised analysis reported here. 


\section{A. ASSUMPTIONS}

The assumptions used in preparing the original design and the ones used in the revised analysis are:

Combustion Efficiency

Sulfur Capture Efficiency

$\mathrm{Ca} / \mathrm{S}$ Molar Ratio

Excess Air

Vortex/Primary Air Ratio

VFBC Temperature, ${ }^{\circ} \mathrm{F}$

Boiler Exit Temperature, ${ }^{\circ} \mathrm{F}$

Economizer Exit Temperature, ${ }^{\circ} \mathrm{F}$

Boiler Blowdown (\% of capacity)

Radiation Heat Loss, \% Coal HHV

\begin{tabular}{cc} 
Level I & Level II \\
\cline { 2 - 2 } $98.5 \%$ & $98.0 \%$ \\
$90 \%$ & $80 \%$ \\
2.5 & 2.5 \\
$20 \%$ & $40 \%$ \\
$3: 1$ & $1.14: 1$ \\
1600 & 1600 \\
500 & 500 \\
320 & 320 \\
2 & 2 \\
0.75 & 0.75
\end{tabular}

The excess air and Vortex/Primary Air ratio used in the revised analysis is essentially the values projected by analyzing performance data based on ash analysis. These values are more optimistic than those obtained based on gas analysis as described in the previous section. The sulfur capture and the $\mathrm{Ca} / \mathrm{S}$ ratio values are achievable based on demons ated performance. 


\section{B. MASS AND ENERGY BALANCE}

Saturated steam at $200 \mathrm{psig}$ is generated at a rate of $60,000 \mathrm{lb} / \mathrm{hr}$. Assuming the steam is used as process steam, i.e., no condensate is returned, and water enters the system at the ambient temperature of $77^{\circ} \mathrm{F}$, the heat required to generate the steam is $69,274,200 \mathrm{Btu} / \mathrm{hr}$. An additional $380,304 \mathrm{Btu} / \mathrm{hr}$ is required to provide the $2 \%$ boiler blowdown, so the total steam generation heat load is $69,654,504 \mathrm{Btu} / \mathrm{hr}$. The heat input, i.e., the higher heating value of the coal is $81,792,513 \mathrm{Btu} / \mathrm{hr}$. The overall thermal efficiency of the system is nearly $85.2 \%$ as detailed below.

The heat absorption pattern in the system is as follows:

\begin{tabular}{lcc} 
Component & Heat Extracted, Btu/hr & Percent of Heat Input \\
\cline { 2 - 3 } Cooling Bed & $36,068,691$ & 44.34 \\
Ash Cooler & 349,737 & 0.43 \\
Boiler & $28,914,844$ & 35.55 \\
Economizer & $4,321,231$ & 5.31 \\
$\quad$ TOTAL & $69,654,503$ & 85.63
\end{tabular}

Blowdown Loss

380,304

0.47

Net Heat Absorbed

$69,274,199$

85.16

Heat Loads \& Losses

Calcination \& Sulfation

Vaporization of Water Unburned Carbon Loss

Radiation Loss

Stack Gas Sensible Heat

Ash Sensible Heat

TOTAL
144,195

$3,834,426$

$1,289,535$

610,090

$5,645,735$

167,599

$11,691,580$
0.18

4.71

1.59

0.75

6.94

0.21

$\underline{14.38}$

OVERALL TOTAL HEAT ABSORBED OR LOST $\quad 99.54 \%$ (roundoff) 


\section{MAJOR COMPONENTS AND SUBSYSTEMS}

This section describes the design criteria and detailed operating conditions of the major c aponents and subsystems in the prototype facility.

\section{A. COAL RECEIVING, STORAGE, AND FEEDING}

The specifications of this subsystem include:

- Facilities to receive and unload truck deliveries of minus $3 / 4^{\prime \prime}$ coal while eliminating fugitive dust emissions,

- Storage for 3 days of full load operation, and

- Controlled, reliable, and dust free feeding of coal from the storage silo to the VFBC.

The specific design of this subsystem is described below.

The coal receiving station includes an in-ground receiving hopper $\left(15^{\prime} \times 15^{\prime} \times 12^{\prime}\right.$ deep) with sloped sides to facilitate discharge onto a bucket elevator. The receiving hopper is enclosed in a shed to prevent dust emissions during coal discharge from the truck. The bucket elevator conveys coal from the receiving hopper to the storage silo in an enclosure.

The storage silo is a 19 feet diameter steel vessel of bolted fabrication. The overall height is 50 feet. The upper 35 feet is cylindrical; the next 10 feet is a cone with a 2 foot diameter discharge opening at the bottom. The discharge is 5 feet above the ground. The vessel is supported on steel beams. A bin filter is mounted on the top.

Coal feed to the VFBC is accomplished using a variable speed 8 inch rotary type coal feeder through a 3 inch pneumatic transfer pipe. The coal is transported at a velocity of $70 \mathrm{ft} / \mathrm{sec}$ to minimize the potential for saltation and plugging. A fan with a $15 \mathrm{HP}$ motor supplies the required 289 CFM of air. 


\section{B. LIMESTONE RECEIVING, STORAGE, AND FEEDING}

This system is similar to the coal handling system; the only difference in design is the truck unloading station. Since limestone is especially susceptible to dusting, deliveries will be in enclosed trucks from which the sorbent will be transferred pneumatically into the storage silo.

The limestone storage silo is a $10^{\prime}$ diameter, $28^{\prime}$ tall rolled steel fabricated vessel. The bottom discharge cone is 55 degrees slope.

A variable speed metering feeder moves limestone through a 6 inch rotary airlock into a 2 inch pneumatic transport pipe. The stone is transported at a velocity of $\mathbf{8 2 . 5}$ $\mathrm{ft} / \mathrm{sec}$. A fan with a 7-1/2 HP motor supplies air at the required rate of $156 \mathrm{CFM}$.

\section{ASH HANDLING SYSTEM}

Fly ash is collected in ash hoppers at the boiler, economizer, and baghouse. Each hopper is equipped with a 2 " rotary valve that discharges the ash into a 3 " diameter pneumatic transport pipe that conveys it to a storage hopper or reinjects it into the combustor. A fan with a $10 \mathrm{HP}$ motor delivers air at a rate of $291 \mathrm{CFM}$ to convey the ash.

Bed ash is withdrawn at a temperature of $1500^{\circ} \mathrm{F}$, cooled in a Holo-Flite conveyor to $500^{\circ} \mathrm{F}$, discharged into a $3^{\prime \prime}$ diameter pneumatic transport system, and conveyed to the storage silo. The solids are cooled to $500^{\circ} \mathrm{F}$ by boiler feedwater flowing at a rate of 32 GPM. The heated feedwater leaves the cooling conveyor at a temperature of about $100^{\circ} \mathrm{F}$ and flows to the deaerator.

The ash storage silo is a $14^{\prime}$ diameter, $35^{\prime}$ tall steel vessel capable of storing 3 days of solid waste prior to discharge into trucks. The ash storage is elevated so that the discharge is $16^{\prime}$ above the ground; ash is discharged directly into trucks for transport to a land fill. 


\section{VORTEX FLUIDIZED BED COMBUSTOR}

The VFBC consists of a main bed, freeboard, two adjacent cooling beds, a cyclone combustor, a sluice for returning solids from the cyclone to the main bed, and reinjection channels to return solids from the cooling beds to the main bed. Each section of the VFBC system is described below.

\section{Main Bed}

The main bed is a circulating fluidized bed located immediately below the freeboard in the center of the bottom section of the combustor. Coal and limestone are fed into this section of the combustor. The bed is fluidized with the main portion of the primary combustion air.

The coal will devolatilize and partially burn in this section. Hot solids from the cyclone combustor enter the main bed via the sluice, providing heat to the main bed and maintaining its solids inventory. Solids are also withdrawn from the main bed, cooled in the adjacent bubbling beds, and returned. The heat inputs are balanced by the solids returning from the cooling beds to maintain a bed temperature of $1500^{\circ} \mathrm{F}$.

The main bed dimensions are 4.5' $\times 3$ '; the plan area is $13.5 \mathrm{ft}^{2}$. The total air flow to the main bed is 6400 SCFM. The velocity in the main bed is about $30 \mathrm{ft} / \mathrm{sec}$.

\section{Sluice}

The sluice is an integral part of the main bed; it is a rectangular section connecting the bottom of the cyclone discharge to the main bed. Its plan area is $2 \mathrm{ft}^{2}$.

Hot solids enter the sluice from the cyclone at a temperature of $1600^{\circ} \mathrm{F}$. The sluice is fluidized at a velocity of $4 \mathrm{ft} / \mathrm{sec}$ to provide movement of the solids into the main bed. 


\section{Freeboard}

The freeboard is a refractory lined vessel with the same dimensions as the main bed immediately below it. Air entering the freeboard from the sluice, cooling beds, and lift channels increased the gas velocity through the freeboard to $40 \mathrm{ft} / \mathrm{sec}$. The height of the freeboard, determined by the height of the cyclone to which it is attached, is 32 feet.

\section{Cooling Beds}

The prototype facility contains two cooling beds. A total in-bed heat transfer area of $565 \mathrm{ft}^{2}$ is required to absorb the 36 million Btu/hr at the design full load condition. Although this amount of surface could be installed in a single cooling bed, we elected to use two to extend the turndown capabilities of the system.

The operating temperature of the cooling beds is $1450^{\circ} \mathrm{F}$ at the design load. Each cooling bed is 4.5' $\times 4^{\prime}$; the plan area of each is $18 \mathrm{ft}^{2}$. The gas velocity is $2 \mathrm{ft} / \mathrm{sec}$ through the cooling beds.

Water cooled heat exchangers are installed in each cooling bed. Water flows through the tubes by natural circulation.

Solids from the main bed enter each cooling bed at a temperature of $1500^{\circ} \mathrm{F}$ and leave at $1450^{\circ} \mathrm{F}$. Air used to fluidize the cooling beds passes into the freeboard immediately above the operating level of the main bed.

\section{Reinjection Channels}

The circulating solids are returned from each cooling bed to the main hed by a dense phase lift. The reinjection channels are rectangular with a plan arei of $1.125 \mathrm{ft}^{2}$. The superficial gas velocity through each lift is $20 \mathrm{ft} / \mathrm{sec}$ at full load conditions. 


\section{Cyclone Combustor}

This component performs two functions: particles entrained in the gas from the freeboard are captured for recycle to the bed, and combustion is completed.

The cyclone size was determined using typical relative dimensions and an inlet gas velocity of $70 \mathrm{ft} / \mathrm{sec}$. The actual gas flow from the freeboard is $555 \mathrm{ft} 3 / \mathrm{sec}$. The inlet area, then is $7.93 \mathrm{ft}^{2}$. The cyclone diameter is $8 \mathrm{ft}$. The barrel length and the cone length are each $16 \mathrm{ft}$.

This cyclone is significantly larger than that designed for the prototype in Level I. The cyclone is based on an inlet velocity of $70 \mathrm{ft} / \mathrm{sec}$. The difference is due to two factors: in the original design, the total excess air value was $20 \%$ rather than the value of $40 \%$ used in this revision, and the original design was based on having one-fourth the total air flow through the freeboard and nearly one-half is used in this revision. The impact of these changes is a significant increase in cyclone diameter and cyclone height since the height is typically determined as a value relative to diameter.

Even though the cyclone is larger than the one previously specified, it is still smaller than one for a conventional circulating fluidized bed operating with 20 percent excess air. Such a system would require a cyclone with a diameter of $11.5 \mathrm{ft}$. The overall height of the barrel and cone would be 46 feet.

\section{Waste Heat Boiler}

The waste heat boiler reduces the temperature of the flue gas from $1600^{\circ} \mathrm{F}$ to $500^{\circ} \mathrm{F}$. A total heat transfer surface area of $7240 \mathrm{ft}^{2}$ is required. The boiler in the Level I analysis had a surface area of $5375 \mathrm{ft}^{2}$.

\section{Economizer}

The economizer reduces the temperature of the flue gases from $500^{\circ} \mathrm{F}$ to the final stack temperature of $320^{\circ} \mathrm{F}$. A total surface area of $2372 \mathrm{ft}^{2}$ is required. The economizer in the Level I report had a surface area of $1757 \mathrm{ft}^{2}$. 


\section{Baghouse}

A baghouse is used for final particulate control. The baghouse originally selected for the Level I prototype design contained 540 bags and provided an air-to-cloth ratio of 2.66:1. Although the revised flow rate is higher, the same baghouse will suffice; the air-to-cloth ratio at the revised flue gas flow rate is 3.6:1, still well within accepted values.

\section{Balance of Plant}

The boiler feedwater facilities and air fans originally selected had sufficient excess capacity to accommodate the revised flows in this analysis. A complete description is included in the Level I Topical Report. 


\section{E. COMPARISON OF CAPITAL AND OPERATING COSTS}

A comparison with conventional gas and oil fired packaged boilers was completed to assess the economic potential. The capital cost of the packaged boiler systems is based on the current cost of conventional York-Shipley boilers. York-Shipley does not manufacture a boiler with the steam generating capacity of the prototype facility; two gas-fired boilers are required to generate $60,000 \mathrm{lb} / \mathrm{hr}$ of steam.

The cost estimates in the Level I Topical Report included a 20\% contingency for the cost of the VFBC system as well as a $20 \%$ overall installation contingency. The larger VFBC specified in this analysis is approximately $50 \%$ more expensive than that specified earlier. The boiler and economizer are approximately $20 \%$ more expensive than those previously costed based on a six-tenths rule for cost estimation. These revisions would increase the capital cost of the facility to $\$ 1,039,279$ versus $\$ 901,074$ in the Level I Topical Report. The Total Capital Investment would be $\$ 3,793,709$ verses $\$ 3,289,217$ in the Level I economic evaluation.

The assumptions and costs used in completing the operating cost estimates and for the comparison with gas and oil fired packaged boilers are:

Plant Life

Operating

Limestone Cost

Coal Cost

Ash Disposal Cost

Electricity Cost

Water Cost

VFBC Operating Labor

Gas-Fired Boiler Operating Labor

Interest Rate

Oil or Gas Cost

Gas Boiler Installed Cost.

Maintenance for VFBC

Maintenance for Gas-Fired Boiler
20 Years

330 Days/Year

$\$ 15,20$ \& 25/Ton

$\$ 30,40$ \& $50 /$ Ton

$\$ 27,36$ \& 45/Ton

$\$ 0.05 / \mathrm{Kwh}$

$\$ 0.5 / 1000 \mathrm{gal}$

$\$ 150,000$ Year

$\$ 75,000$ Year

$10 \%$

$\$ 4,5 \& 6 / \mathrm{MMBTU}$

$\$ 347,988$

$\$ 140,000$ Year

$\$ 50,000$ Year 
Cost estimates of this type are very sensitive to the assumptions used. The most important assumptions are the costs of coal, limestone, ash disposal and oil/gas. Current prices for coal range between $\$ 30 /$ ton to $\$ 40 /$ ton; limestone costs are about $\$ 18$ to $\$ 20 /$ ton; ash disposal costs are roughly $\$ 30-\$ 40 /$ ton; and oil/gas current costs are $\$ 5.00 / \mathrm{MMBTU}$ for industrial users. Future costs are almost impossible to predict. Therefore, economic projections based on increasing or decreasing fuel costs should be used only to indicate what might happen.

Three cases were examined to determine the range of paybacks possible. They are as follows:

\section{Case I Case II $\quad \underline{\text { Case III }}$}

Coal Cost, $\$$ Ton

Linestone Cost, $\$ /$ Ton

Ash Disposal, \$/Ton

Oil/Gas Cost, \$/MMBTU
30

15

27

6
40

20

36

5
50

25

45

4

The paybacks for Case I, Case II and Case III, respectively, are 1.78, 3.20 and 16.04 years.

The assumptions used in the above economic analysis are somewhat different from those in the Level I economic evaluation. However, the assumptions used here best represent the current economic conditions and good economic methods of evaluation. 


\section{SUMMARY AND CONCLUSIONS}

The economic analysis indicates that the VFBC is very attractive. Payback periods for the large capital investment required relative to the oil/gas-fired boilers are quite attractiv t at today's fuel and ash disposal costs. The Case III payback of 16.04 years is high. However, keep in mind that the coal, limestone and ash disposal costs are all much higher than current costs and the oil/gas costs are much lower than current costs. Thus, this is the worst case situation. Nevertheless, this case is still more economical than the oil/gas case for the time period considered. 


\section{APPENDIX D}

\section{PENN STATE 2VFBC GASIFIER SELECTED NON-VORTEX RAW OPERATING DATA}




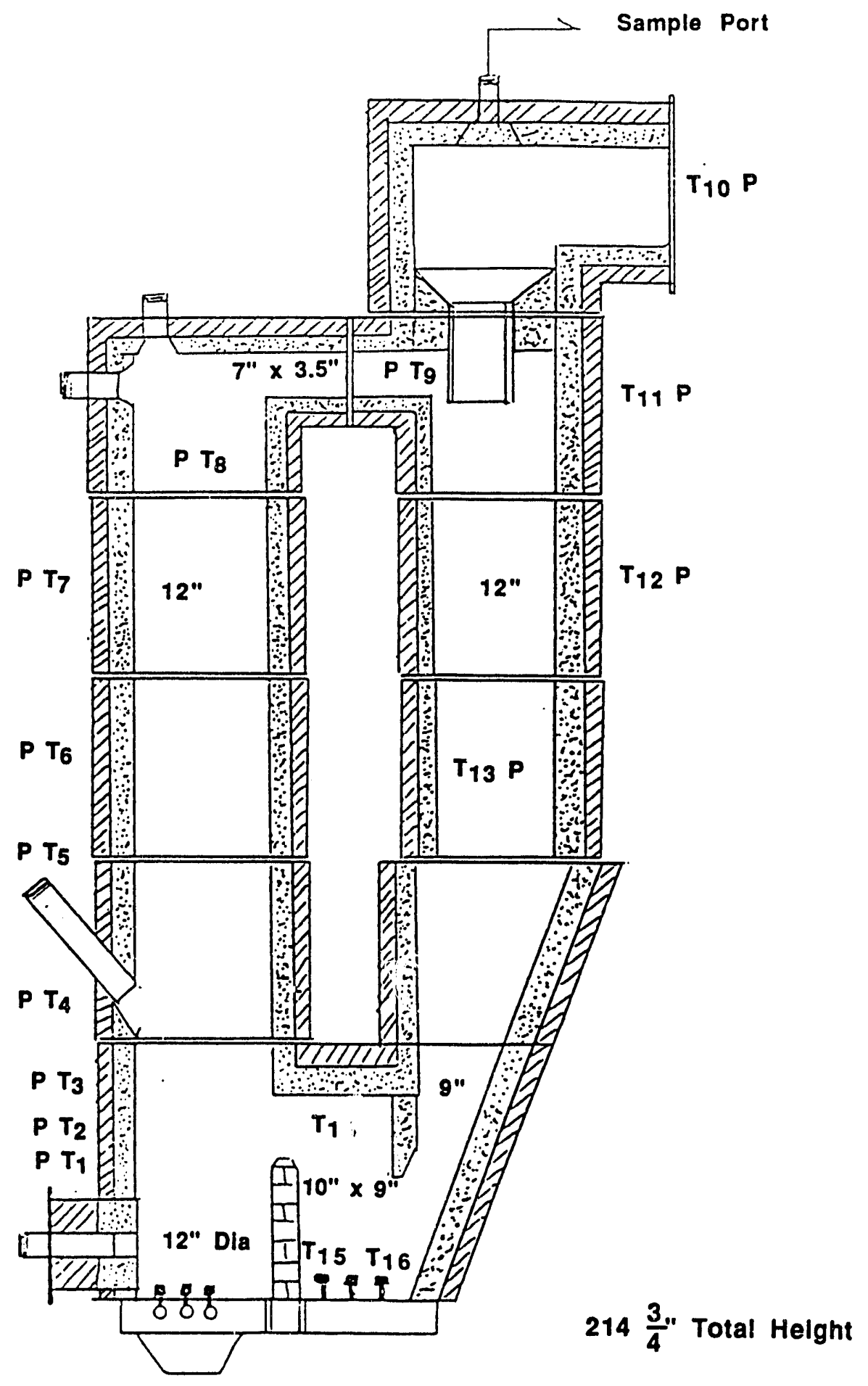

Penn State Gasifier

LEGEND

$T=$ Temperature of Alr or Gas

$P=$ Pressure of Alr or Gas 


\section{PENN STATE NON-VORTEX MATRIX}

\begin{tabular}{|c|c|c|c|c|c|}
\hline $\begin{array}{c}\text { BST } \\
\#\end{array}$ & $\begin{array}{c}\text { TEMMP } \\
\left({ }^{\circ} \mathrm{F}\right)\end{array}$ & $\begin{array}{c}\text { INPUT } \\
(\mathrm{BTU} / \mathrm{H})\end{array}$ & $\begin{array}{c}\text { Ca to S } \\
\text { RATIO }\end{array}$ & $\begin{array}{c}\text { VORTEX } \\
\text { AIR }\end{array}$ & $\begin{array}{c}\text { FREEBOARD } \\
\text { AIR (SCFM) }\end{array}$ \\
\hline 1 & 1700 & $2 \mathrm{EE}^{6}$ & BASELINE & 0 & 127.34 \\
\hline 2 & 1650 & $2 \mathrm{EE}^{6}$ & 2.5 to 1 & 0 & 138.34 \\
\hline 3 & 1750 & $2 \mathrm{EE}^{6}$ & 2.5 to 1 & 0 & 162.16 \\
\hline 4 & 1850 & $2 \mathrm{EE}^{6}$ & 2.5 to 1 & 0 & 169.60 \\
\hline 5 & 1650 & $2 \mathrm{EE}^{6}$ & 1.5 to 1 & 0 & 132.29 \\
\hline 6 & 1650 & $2 \mathrm{EE}^{6}$ & 2.5 to 1 & 0 & 130.28 \\
\hline 7 & 1650 & $2 \mathrm{EE}^{6}$ & 3.5 to 1 & 0 & 149.39 \\
\hline
\end{tabular}



$12: 00$

TEMPERATURES:

\begin{tabular}{|c|c|c|c|}
\hline T1: _ & .00 & T9: & .00 \\
\hline T2: & 1662.00 & T10: & 1246.00 \\
\hline T3: & 1667.00 & T11: & 1664.00 \\
\hline T4: & 1664.00 & T12: & 1630.00 \\
\hline TS: & 1645.00 & T13: & 1215.00 \\
\hline T6: & 1516.00 & T14: & 1663.00 \\
\hline T7: & 1645.00 & T15: & 1672.00 \\
\hline T8: & 1678.00 & T16: & 162.00 \\
\hline
\end{tabular}

BED TEMP AVERAGE: 1667.00

PRESSURES:

ANALYSIS

(IN H2O)

MAIN BED \#1 PRES:_ $\quad 12.50$

BLOWER PRESSURE :

DRAFT PRESSURE: - +.4

MAIN BED DELTA P:SLURRY LINE AIR: - $\quad .00$

BURNER PURGE AIR:- $\quad .25$

GAS FLOW BURNER: - $\quad .00$

TOTAL AIR DELTA :- $\quad 4.20$

MAIN BED \#3 PRES. - $\quad 6.10$

MAIN BED H4 PRES. - $\quad 7.50$

SLUICE \#14 PRESS. - $\quad 6.00$

SLUICE \#15 PRESS. - 5.00

AIR FLOWS: (SCFM)

SLUICE AIR FLOW: _ $\quad 87.00$

MN BED AIR FLOW: - 109.04

F.BOARD AIR FLOW: 196.04
(\%)

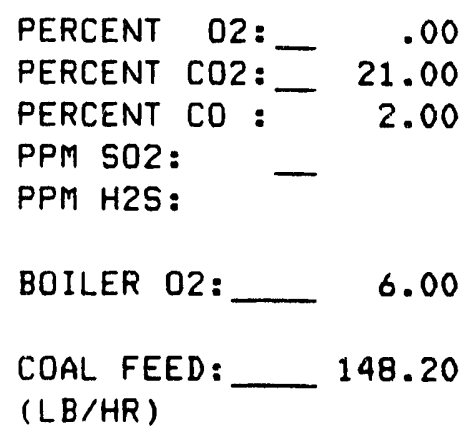

AIR FLOWS: (ACFM)

$\begin{array}{ll}\text { SLUICE AIR FLOW: } & 349.15 \\ \text { MN BED AIR FLOW:- } & 437.60 \\ \text { F.BOARD AIR FLOW: } & 786.75\end{array}$

VELOCITIES: (FT/SEC)

MAIN BED VELOCITY:

SLUICE VELOCITY: FREEBOARD VELOCITY:

CYCLONE INLET VEL.:

CYCLONE OUTLET VEL:
9.29

6.21

16.70

77.13

106.61
FIRING RATE :

2000700.00

NOTES: $\quad 3.5$ TO 1 RATIO OF LIMESTONE TO SULFUR

SLURRY MIX SHOWN ON TEST CURVE

GC RUN AT 12:20

D-3 
DATE : MAY 16,91

TIME : $12: 30$

TEMPERATURES:

\begin{tabular}{|c|c|c|c|}
\hline T1: & .00 & T9: & .00 \\
\hline T2: & 1669.00 & T10: & 1246.00 \\
\hline T3: & 1673.00 & T11: & 1662.00 \\
\hline T4: & 1670.00 & T12: & 1637.00 \\
\hline T5: & 1653.00 & T13: & 1240.00 \\
\hline T6: & 1543.00 & T14: & 1672.00 \\
\hline$T 7:$ & 1654.00 & T15: & 1682.00 \\
\hline TB: & 1683.00 & T16: & 162.00 \\
\hline
\end{tabular}

PRESSURES :

ANALYSIS

(IN H2O)

(\%)

$\begin{array}{lr}\text { MAIN BED H1 PRES: } & 12.00 \\ \text { BLOWER PRESSURE:- } & \\ \text { DRAFT PRESSURE: - } & +.4 \\ \text { MAIN BED DELTA P:- } & \\ \text { SLURRY LINE AIR: - } & .00 \\ \text { BURNER PURGE AIR:- } & .23 \\ \text { GAS FLOW BURNER: - } & .00 \\ \text { TOTAL AIR DELTA :- } & 4.00 \\ \text { MAIN BED H3 PRES.- } & 6.30 \\ \text { MAIN BED H4 PRES.- } & 8.50 \\ \text { SLUICE \#14 PRESS.- } & 7.50 \\ \text { SLUICE \#15 PRESS.- } & 6.00 \\ & \\ \text { AIR FLOWS: (SCFM) } & \\ & \\ \text { SLUICE AIR FLOW:- } & 84.00 \\ \text { MN BED AIR FLOW:- } & 106.42 \\ \text { F. BOARD AIR FLOW: } & 190.42\end{array}$

PERCENT 02: $-\quad .00$

PERCENT CO2: - 20.50

PERCENT CO : 2.40

PPM SO2:

PPM H2S:

BOILER 02: _ $\quad 1.70$

COAL FEED: 148.20

(LB/HR)

AIR FLOWS: (ACFM)

VELOCITIES: (FT/SEC)

MAIN BED VELOCITY:

SLUICE VELOCITY:

FREEBOARD VELOCITY:

CYCLONE INLET VEL.:

CYCLONE OUTLET VEL:
9.10

6.02

16.28

75.22

103.96
338.46

428.79

767.25
SLUICE AIR FLOW:

F.BOARD AIR FLOW: 
DATE : MAY 16,91

TIME : $1: 00$

TEMPERATURES:

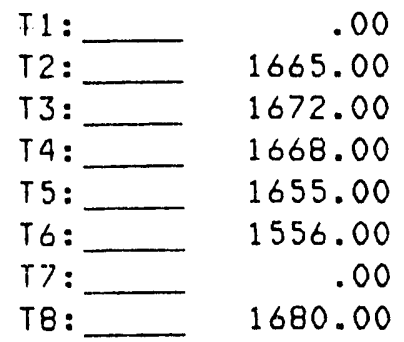

$$
\begin{aligned}
& \text { T9: } \quad 1644.00 \\
& \text { T10: } \quad 1253.00 \\
& \text { T11: } \quad 1660.00 \\
& \text { T12: } \quad 1637.00 \\
& \text { T13:- } \quad 1258.00 \\
& \text { T14: } \quad 1671.00 \\
& \text { T15: } \quad 1682.00 \\
& \text { T16: } \quad 164.00
\end{aligned}
$$

BED TEMP AVERAGE: 1673.50

PRESSURES :

( IN H2O)

MAIN BED \#1 PRES: BLOWER PRESSURE:

DRAFT PRESSURE: MAIN BED DELTA P: SLURRY LINE AIR: BURNER PURGE AIR:GAS FLOW BURNER: TOTAL AIR DELTA :MAIN BED $\# 3$ PRES. MAIN BED H4 PRES. SLUICE \#14 PRESS. SLUICE \#1S PRESS. -

13.00 $+.4$ .00 .23 .00

3.50 8.00 7.50

7.00

5.50

AIR FLOWS: (SCFM)

SLUICE AIR FLOW: $\quad 83.00$ MN BED AIR FLOW: — 99.50 F.BOARD AIR FLOW: $\quad 182.50$

VELOCITIES: (FT/SEC)

MAIN BED VELOCITY:

SLUICE VELOCITY:

FREEBOARD VELOCITY:

CYCLONE INLET VEL.:

CYCLONE OUTLET VEL:

8.50

5.94

15.59

72.02

99.55
ANALYSIS

(\%)

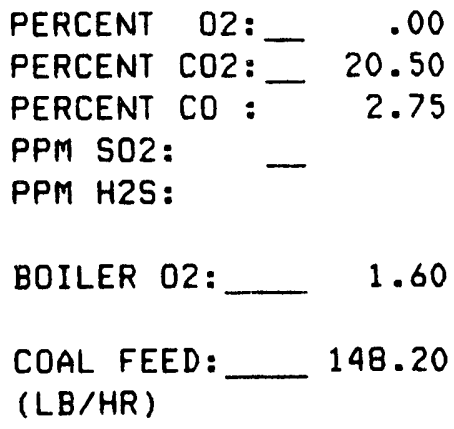

AIR FLOWS: (ACFM)

SLUICE AIR FLOW:

334.11 MN BED AIR FLOW:

400.53 F.BOARD AIR FLOW:

NOTES: $\quad 3.5$ TO 1 LIMESTONE TO SULFUR RATIO GC \# 133 START

SLURRY MIX SHOWN ON TEST CURVE D-5 
DATE: MAY 16,91

TIME : $1: 30$

TEMPERATURES:

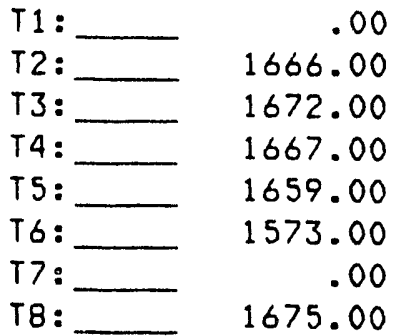

BED TEMP AVERAGE:

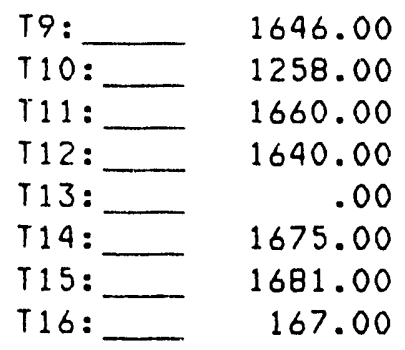

1673.50

PRESSURES :

(IN H2O)

MAIN BED H 1 PRES: BLOWER PRESSURE: DRAFT PRESSURE: MAIN BED DELTA P: SLURRY LINE AIR: BURNER PURGE AIR:GAS FLOW BURNER: TOTAL AIR DELTA :MAIN BED H3 PRES. MAIN BED \#4 PRES. SLUICE H14 PRESS. SLUICE HIS PRESS.

AIR FLOWS: (SCFM)

SLUICE AIR FLOW: MN BED AIR FLOW:

F.BOARD AIR FLOW:
13.00

$+.35$

.00

.23

.00

3.00

7.00

8.70

7.00

6.00
ANALYSIS

(\%)

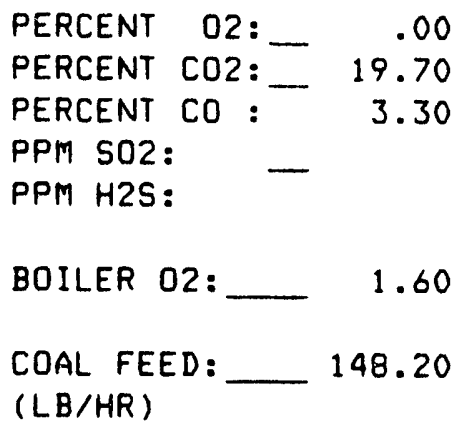

VELOCITIES: (FT/SEC)

MAIN BED VELOCITY:

SLUICE VELOCITY:

FREEBOARD VELOCITY:

CYCLONE INLET VEL.:

CYCLONE OUTLET VEL:
7.87

5.87

14.88

68.73

95.00
FIRING RATE:

2000700.00 
DATE : MAY 16,91

TIME: __ 2:00

TEMPERATURES:

\begin{tabular}{|c|c|c|c|}
\hline T1: & .00 & T9: & 1652.00 \\
\hline T2: & 1669.00 & T10: & 1271.00 \\
\hline T3: & 1672.00 & T11: & 1665.00 \\
\hline T4: & 1671.00 & T12: & 1646.00 \\
\hline T5: & 1660.00 & T13: & .00 \\
\hline T6: & 1577.00 & T14: & 1682.00 \\
\hline T7: & .00 & T15: & 1689.00 \\
\hline T8: & .00 & T16: & 168.00 \\
\hline
\end{tabular}

BED TEMP AVERAGE: 1679.00

PRESSURES :

(IN H2O)

MAIN BED \#1 PRES: -

BLOWER PRESSURE:

DRAFT PRESSURE:

MAIN BED DELTA P:

SLURRY LINE AIR:

BURNER PURGE AIR:-

GAS FLOW BURNER: -

TOTAL AIR DELTA :-

MAIN BED \#3 PRES. -

MAIN BED H4 PRES. -

SLUICE H14 PRESS. -

SLUICE. \#15 PRESS. -

AIR FLOWS: (SCFM)

SLUICE AIR FLOW:

MN BED AIR FLOW: -

84.00

92.16

F.BOARD AIR FLOW:

176.16
ANALYSIS

(\%)

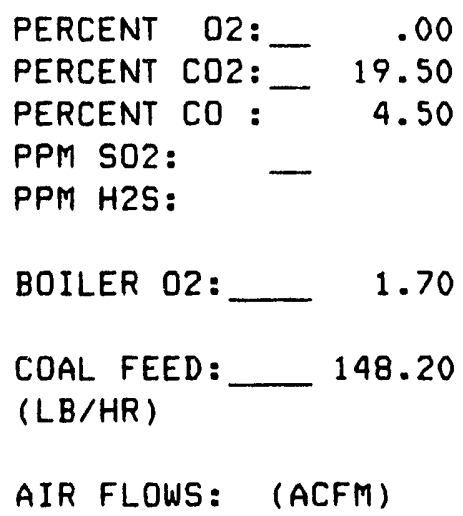

SLUICE AIR FLOW:

339.01

MN BED AIR FLOW:

371.94

F.BOARD AIR FLOW: _ $\quad 710.96$

VELOCITIES: (FT/SEC)

MAIN BED VELOCITY:

7.89

6.03

SLUICE VELOCITY:

15.09

FIRING RATE:

2000700.00

FREEBOARD VELOCITY:

69.70

CYCLONE INLET VEL.:

96.34

NOTES: $\quad 3.5$ TO 1 LIMESTONE TO SULFUR RATIO SLURRY MIX SHOWN ON TEST CURVE 
DATE: MAY 16.91

TIME : $2: 30$

TEMPERATURES:
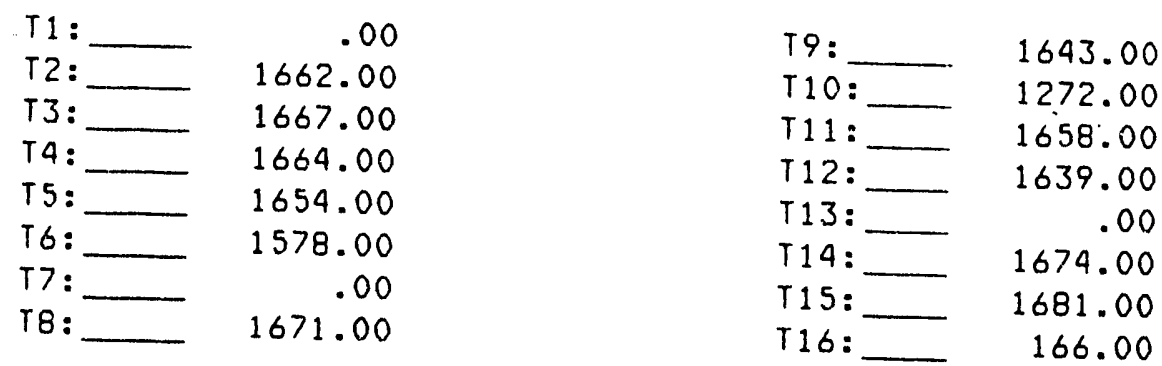

BED TEMP AVERAGE: 1671.50

PRESSURES:

(IN H2O)

ANALYSIS

(\%)

$\begin{array}{lr}\text { MAIN BED \#1 PRES:- } & 14.00 \\ \text { BLOWER PRESSURE:- } & \\ \text { DRAFT PRESSURE: - } & +.1 \\ \text { MAIN BED DELTA P:- } & \\ \text { SLURRY LINF AIR: - } & .00 \\ \text { BURNER PURGE AIR:- } & .23 \\ \text { GAS FLOW BURNER: - } & .00 \\ \text { TOTAL AIR DELTA :- } & 2.40 \\ \text { MAIN BED \#3 PRES.- } & 8.00 \\ \text { MAIN BED \#4 PRES.- } & 7.80 \\ \text { SLUICE \#14 PRESS.- } & 7.75 \\ \text { SLUICE \#1S PRESS.- } & 6.00 \\ & \\ \text { AIR FLOWS: (SCFM) } & \\ \text { SLUICE AIR FLOW: - } & 84.00 \\ \text { MN BED AIR FLOW: - } & 82.43 \\ \text { F. BOARD AIR FLOW: - } & 166.43\end{array}$

PERCENT 02: $\quad .00$

PERCENT CO2:- 19.25

PERCENT CO :- 5.10

PPM S02:

PPM H2S:

BOILER 02: $\_\quad 1.70$

COAL FEED: 148.20

( $L B / H R$ )

AIR FLOWS: (ACFM)

SLUICE AIR FLOW:

337.82

MN BED AIR FLOW:

331.51

F.BOARD AIR FLOW:

669.33

VELOCITIES: (FT/SEC)

MAIN BED VELOCITY:

SLUICE VELOCITY:

FREEBOARD VELOCITY:

CYCLONE INLET VEL.:

CYCLONE OUTLET VEL:
7.03

6.01

14.20

65.62

90.70
FIRING RATE:

2000700.00 
DATE: MAY 16,91

TIME : $3: 00$

TEMPERATURES:

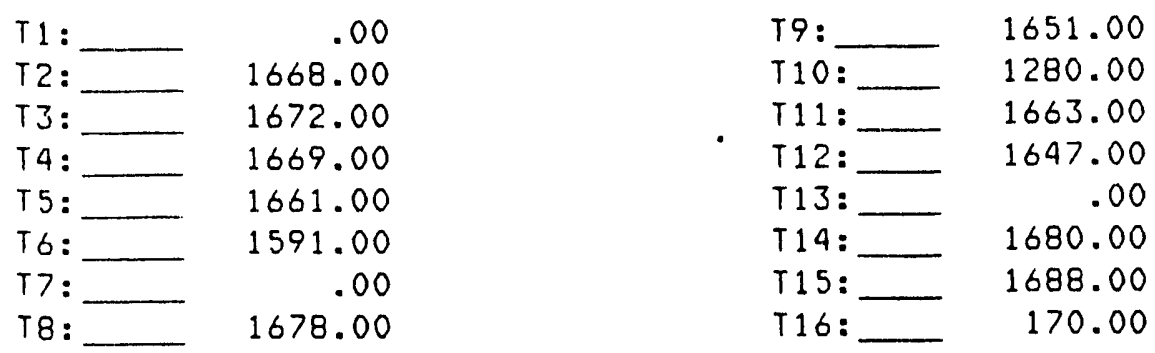

BED TEMP AVERAGE: 1678.00

PRESSURES:

( IN H2O)

MAIN BED \#1 PRES: $\quad 14.00$

BLOWER PRESSURE:

DRAFT PRESSURE:

MAIN BED DELTA P:-

SLURRY LINE AIR: - $\quad .00$

BURNER PURGE AIR: - $\quad .23$

TOTAL AIR DELTA :- 2.50

MAIN BED H3 PRES. - 8.20

MAIN BED \#4 PRES. - 8.75

SLUICE \#14 PRESS. - 6.50

SLUICE \#15 PRESS. - 8.20

AIR FLOWS: (SCFM)

SLUICE AIR FLOW: __ $\quad 83.00$

MN BED AIR FLOW: - $\quad 84.13$

F.BOARD AIR FLOW: 167.13
GAS FLOW BURNER: - $\quad .00$

ANALYSIS

(\%)

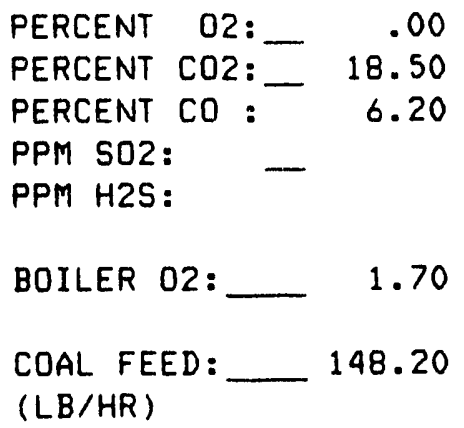

VELOCITIES: (FT/SEC)

MAIN BED VELOCITY: SLUICE VELOCITY: 
DATE: MAY 16.91

TIME: $3: 30$

TEMPERATURES:

\begin{tabular}{|c|c|c|c|}
\hline T1: & .00 & 19: & 1651.00 \\
\hline T2: & 1667.00 & T10: & 1283.00 \\
\hline T3: & 1672.00 & T11: & 1664.00 \\
\hline T4: & 1668.00 & T12: & 1649.00 \\
\hline T5: & 1661.00 & T13: & .00 \\
\hline T6: & 1598.00 & T14: & 1680.00 \\
\hline T7: & .00 & T15: & 1687.00 \\
\hline T8: & .00 & T16: & 170.00 \\
\hline
\end{tabular}

BED TEMP AVERAGE: $\quad 1677.00$

PRESSURES:

(IN H2O)

MAIN BED H1 PRES:_ $\quad 16.50$

BLOWER PRESSURE:

DRAFT PRESSURE:

MAIN BED DELTA P:SLURRY LINE AIR: BURNER PURGE AIR: GAS FLOW BURNER: TOTAL AIR DELTA :MAIN BED \#3 PRES. MAIN BED H4 PRES. SLUICE \#14 PRESS. SLUICE \#15 PRESS.

AIR FLOWS: (SCFM)

SLUICE AIR FLOW: $\quad 83.00$ MN BED AIR FLOW: - $\quad 78.92$ F.BOARD AIR FLOW: - 161.92
ANALYSIS

(\%)

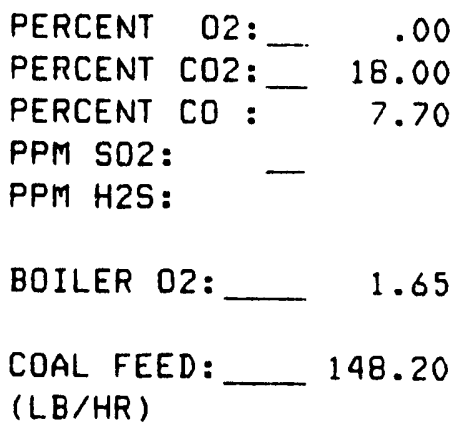

AIR FLOWS: (ACFM)

SLUICE AIR FLOW: MN BED AIR FLOW: 334.66 318.21 F.BOARD AIR FLOW: - $\quad 652.87$

VELOCITIES: (FT/SEC)

MAIN BED VELOCITY: SLUICE VELOCITY:

FREEBOARD VELOCITY:

CYCL IE INLET VEL.:

CYCL: JE OUTLET VEL:
6.75

5.95

13.85

64.01

88.47

FIRING RATE: 2000700.00 
DATE : MAY 16.91

TIME: $4: 00$

TEMPERATURES:

\begin{tabular}{|c|c|c|c|}
\hline T1: & .00 & T9: & 1655.00 \\
\hline T2: & 1668.00 & T10: & 1285.0 \\
\hline T3: & 1675.00 & T11: & 1668.0 \\
\hline T4: & $1675.00^{\circ}$ & T12: & 1652.0 \\
\hline TS: & 1665.00 & T13: & 1319.0 \\
\hline T6: & 1593.00 & T14: & 1696.0 \\
\hline$T 7:$ & .00 & T15: & 1701.00 \\
\hline T8: & .00 & T16: & 170.00 \\
\hline
\end{tabular}

BED TEMP AVERAGE: 1684.50

PRESSURES:

(IN H2O)

MAIN BED \#1 PRES:

BLOWER PRESSURE:

DRAFT PRESSURE:

MAIN BED DELTA P: SLURRY LINE AIR: BURNER PURGE AIR: GAS FLOW BURNER: TOTAL AIR DELTA :MAIN BED H3 PRES. MAIN BED \#4 PRES. SLUICE H14 PRESS. SLUICE \#15 PRESS. -

AIR. FLOWS: (SCFM)

SLUICE AIR FLOW: MN BED AIR FLOW:

F.BOARD AIR FLOW:
ANALYSIS

(\%)

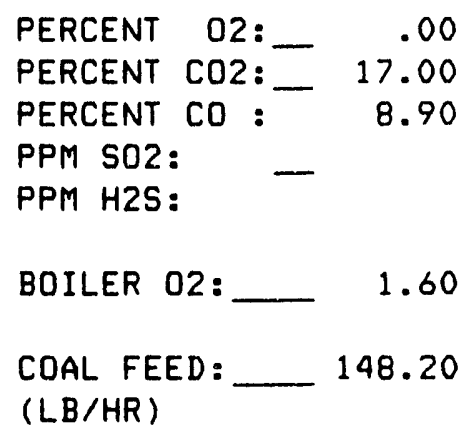

AIR FLOWS: (ACFM)

$\begin{array}{ll}\text { SLUICE AIR FLOW: } & 335.84 \\ \text { MN BED AIR FLOW:- } & 304.48 \\ \text { F.BOARD AIR FLOW: } & 640.32\end{array}$

VELOCITIES: (FT/SEC)

MAIN BED VELOCITY:

SLUICE VELOCITY: FREEBOARD VELOCITY:

CYCLONE INLET VEL.:

CYCLONE OUTLET VEL:
6.46

5.97

13.59

62.78

86.76

FIRING RATE:

2000700.00 
DATE : MAY 16,91

TIME : $4: 30$

TEMPERATURES:

$\begin{array}{rr}T 1:- & .00 \\ T 2:- & 1666.00 \\ T 3:- & 1670.00 \\ T 4:- & 1672.00 \\ T 5:- & 1665.00 \\ T 6:- & 1588 \quad 00 \\ T 7:- & .00 \\ T 8:- & 1677.00\end{array}$

BED TEMP AVERAGE: 1679.50

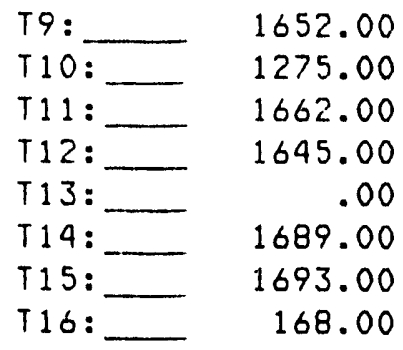

ANAL YSIS

(\%)

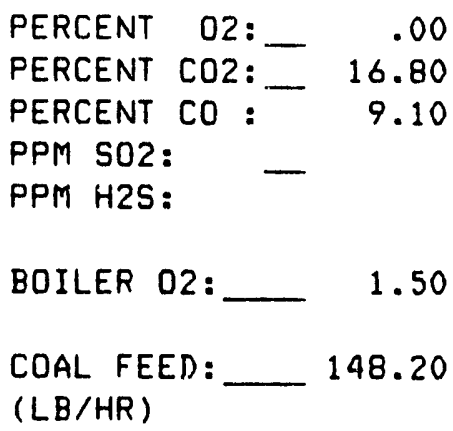

AIR FLOWS: (ACFM)

SLUICE AIR FLOW:

314.87

288.19

603.06

VELOCITIES: (FT/SEC)

MAIN BED VELOCITY:

SLUICE VELOCITY:

FREEBOARD VELOCITY:

CYCLONE INLET VEL.:

CYCLONE OUTLET VEL:
78.00

71.39

149.39
.23

1.80

6.30

6.00

5.00
6.12

5.60

12.80

59.12

81.71

FIRING RATE:

2000700.00

NOTES: $\quad 3.5$ TO 1 LIMESTONE TO SULFUR RATIO

FINAL SLUICE SAMPLE 


\section{APPENDIX E}

\section{PENN STATE 2VFBC GASIFIER SELECTED VORTEX RAW OPERATING DATA}




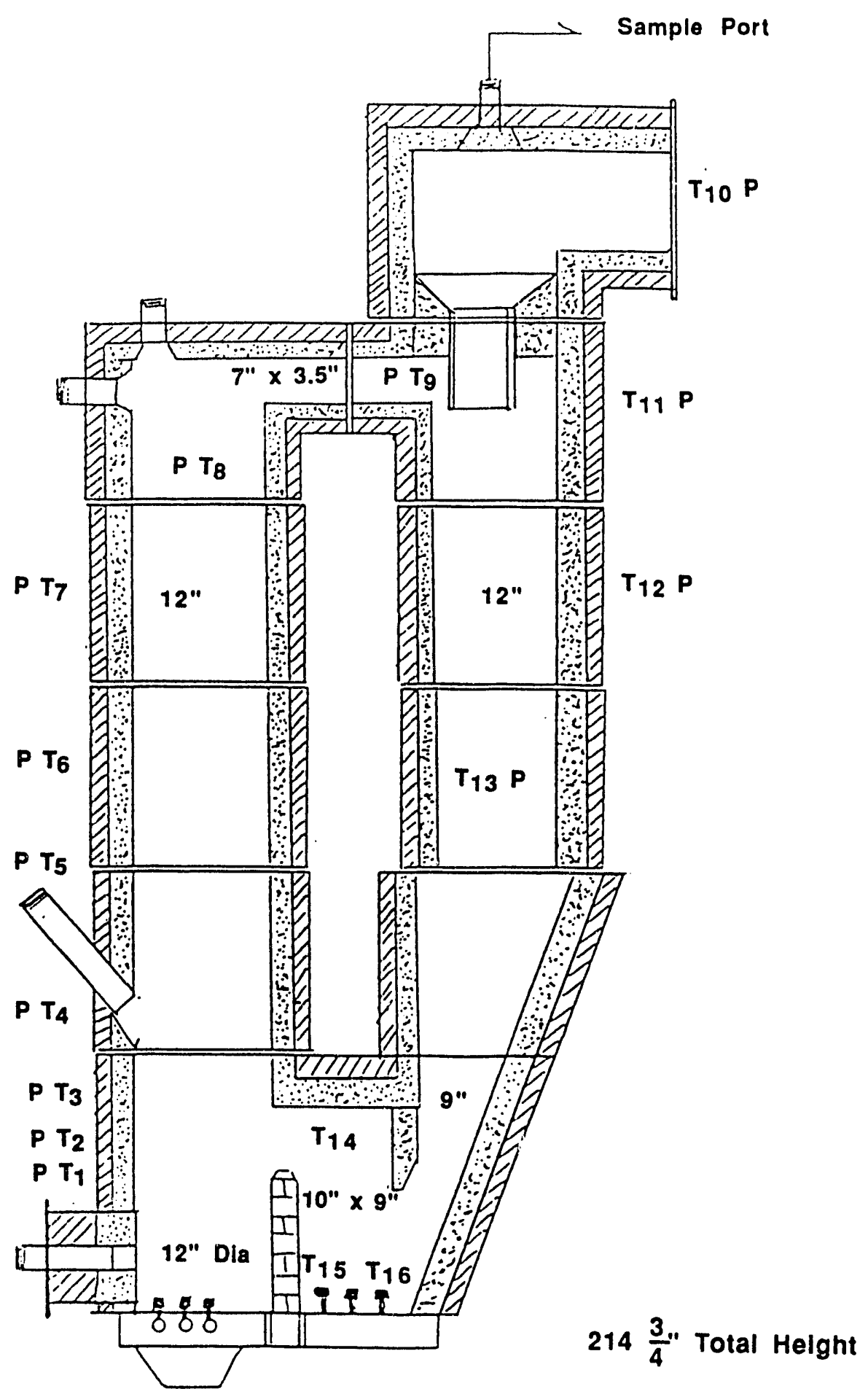

\section{Penn State Gasifier}

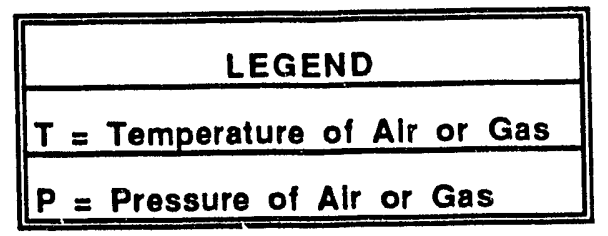

E-1 


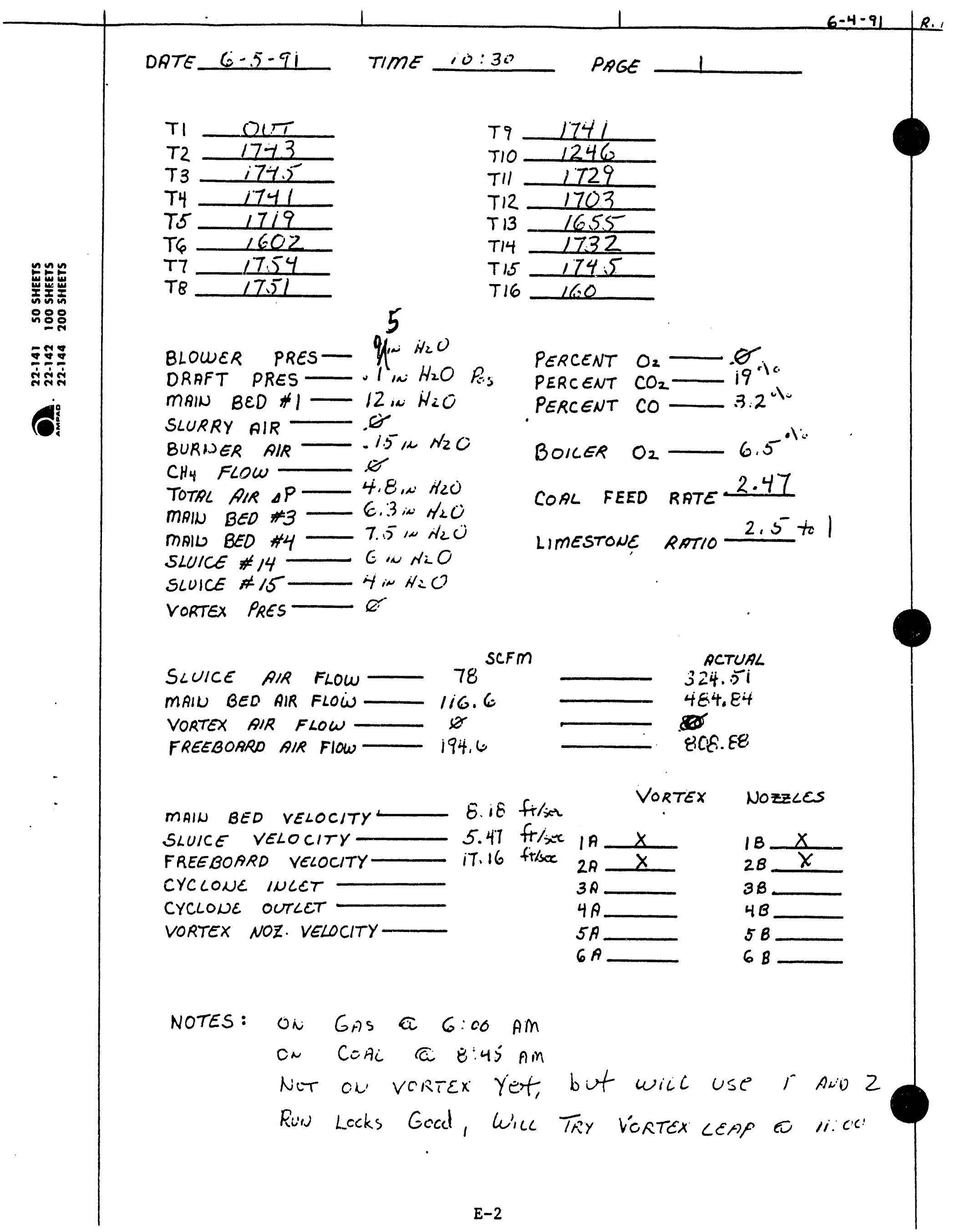




T1 $\frac{\text { OUT }}{1745}$
T2
T3 $\frac{1749}{1745}$
$T 4 \frac{1727}{1595}$
$T 5 \frac{1756}{\text { T6 }}$
T7
T8

$T 9 \frac{1745}{1246}$
$T 10 \frac{1730}{1109}$
$T 11 \frac{1709}{\frac{1664}{1742}}$
$T 13$
$T 14 \frac{1754}{157}$
$T 15$
BLOWER PRES- $95 \mathrm{iN} \mathrm{H}_{2} \mathrm{O}$
DRAFT PRES- $1 \mathrm{WH} \mathrm{H}_{2} \mathrm{O}$ POS MAIN BED \#I SLURRY AIR BURNER AIR 12 in $\mathrm{H}_{2} \mathrm{O}$

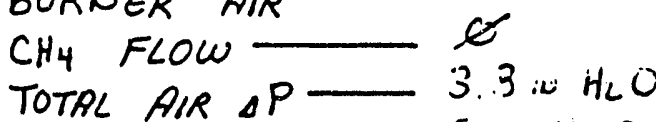
MAIN BED $\# 3-6 \mathrm{in} \mathrm{H}_{2} \mathrm{O}$ MAIU BED \#4- 7 in iV 20 SLUICE $\# 14 \longrightarrow 5.5 \mathrm{~m} \mathrm{HCO}$ SLUICE \#15-4ir HLO VORTEX PRES

PERCENT O2 PERCENT $\left.\mathrm{CO}_{2}-18.5^{\circ}\right)$ PERCENT CO-3.6" BOILER O2 6.5 COAL FEED RATE $2 \mathrm{~m} / \mathrm{c}$ LIMESTONE RATIO- 2.5 to

SLUICE AIR FLOW $20^{\text {SCFM }}-33 \%$ ACTUAL MAIN BED AIR FLOW -96.7 VORTEX AIR FLOW
FREEBOARD AIR FIOW $1 T 6.7$

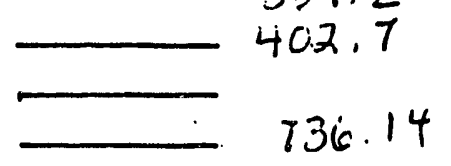

MAIN BED VELOCITY $\$ .55 \mathrm{ft} / \mathrm{sec}$

VORTEX NOZZLES

SLUICE VELOCITY $.5 .6 \mathrm{fi} / \mathrm{zeC}$

FREEBOARD VELOCITY- $15.6 \mathrm{ft} / \mathrm{STC}$
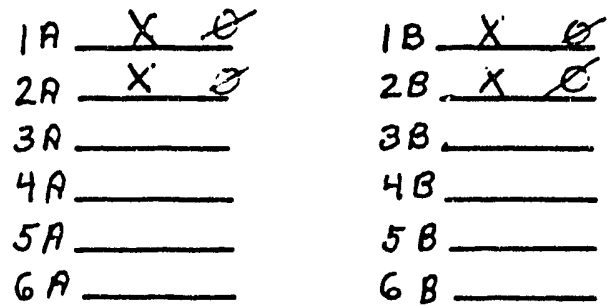
CYCLONE INLET

CYCLONE OUTLET

VORTEX NOZ. VELOCITY

$6 A$

$6 B$

NOTES: PREVORTEX 
DATE G-5.\% TIME 11:30 PAGE 3

T1 $\frac{0 . T}{1756}$
T2
T3 $\frac{1757}{1752}$
T4
T5 $\frac{1735}{041}$
T6 $\frac{1765}{1758}$
T7

\begin{tabular}{|c|c|}
\hline T9. & 17.54 \\
\hline T10. & 1254 \\
\hline TII & 1738 \\
\hline$T 12$ & 1719 \\
\hline$T 13$ & 1678 \\
\hline$T / 4$ & 17.51 \\
\hline T15 & 1763 \\
\hline$T 16$ & $\quad i 57$ \\
\hline
\end{tabular}

BLOWER PRES - $95^{\circ} \mathrm{N} \mathrm{N}_{2} \mathrm{O}$ PERCENT O2 $\mathrm{O}^{\circ}$. DRAFT PRES-.05, $\mathrm{N2} \mathrm{H}+$ PERCENT $\mathrm{CO}_{2}-18 \%$ MAIN BED $\# 1-12 \approx \mathrm{H}_{2} \mathrm{O}$ PERCENT CO- $4.4 \%$ SLURRY AIR — $\varnothing$ BURNER AIR $-16 \mathrm{NN} \mathrm{N}_{2} \mathrm{O}$ BOILER O2 $6.5^{\circ}$ $\mathrm{CH}_{4}$ FLOW
TOTAL AIR $\triangle \mathrm{P}=33 \mathrm{in} \mathrm{H} \mathrm{HO}$
O.4 MAIN BED \#3- 0.4 in $\mathrm{H}^{\circ} \mathrm{O}$ MAIU BED $\# 4-7.21 \mathrm{NHCO}$ SLUICE $\# 14 \longrightarrow C$ in $H_{L} O$ COAL FEED RATE 2 mIC SLUICE \#15- 4 in HCO VORTEX PRES

LIMESTONE RATIO- $2.5 \mathrm{ti}$

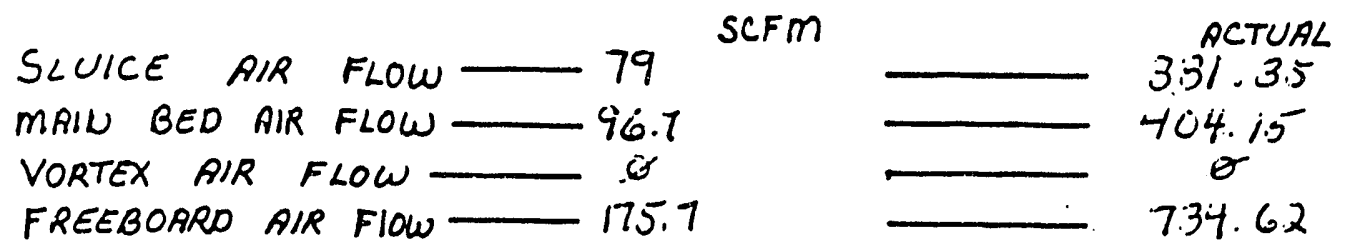

MAIN BED VELOCITY $8.57 \mathrm{ft} / \mathrm{seC}$ VORTEX NOZZLES SLUICE VELOCITY $5.59 \mathrm{Ht} / \mathrm{sec}$ FREEBOARD VELOCITY- $15.0 \mathrm{H}$ /SEC CYCLONE INLET CYCLONE OUTLET VORTEX NOZ. VELOCITY
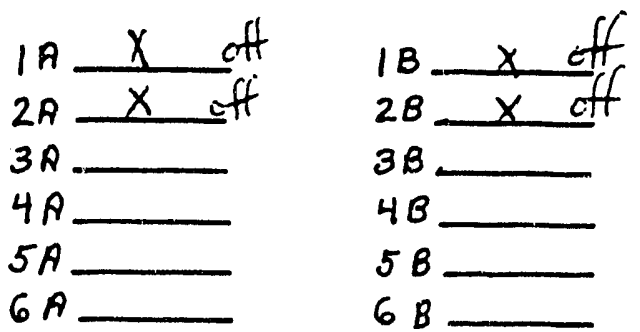

NOTES: WILL GO ON VORTEX IN fPRROX 20 mILITES 
DATE $[-15-91$ TIME

PAGE 4

TI

T2 $\frac{1758}{1754}$

T3 1754

T4 1753

$75 \quad 1741$

T6 $\frac{14}{176.5}$

T8 -1763

BLOWER PRES $\frac{95}{0}$

DRAFT PRES -

MBIN $B E D \# 1 \frac{11}{0}$

SLURRY AIR $\frac{1}{15}$
BURNER AIR

$\mathrm{CH}_{4}$ FLOW $\frac{0}{2.8}$

TOTAL AIR SP $\frac{2.8}{9.2}$

MAIN BED \#3 $\frac{0.2}{7.1}$

MAIL BED \#4 $\frac{7.1}{5.5}$

SLUICE \#15 $\frac{4.0}{0}$

VORTEX PRES 0

$T 9 \frac{1748}{1263}$
$T 10 \frac{1740}{1725}$
$T 11 \frac{1040}{T_{12}}$
$T 13 \frac{1759}{1768}$
$T 14 \frac{157}{T 15}$
$T 16 \frac{15}{}$

PERCENT $0.2 \frac{0}{18 . E}$

PERCENT $\mathrm{CO}_{2} \frac{18 . E}{6.5}$

PERCENT CO 6.5

BOILER $\mathrm{O}_{2} \mathrm{i.5}$

COAL FEED RATE $2 M \mu$

LIMESTONE RATIO 2.5: 1
SLUICE AIR FLOW $\frac{75}{89.04}$
MAIU BED AIR FLOW
VORTEX AIR FLOW $\frac{e^{\prime}}{104 . C 4}$
FREEBORRD AIR FIOW

MAIN BED VELOCITY

SLUICE VELOCITY

FREEBOARD VELOCITY

CYCLONE INLET

CYCLONE OUTLET

VORTEX NOZ. VELOCITY
SCFM

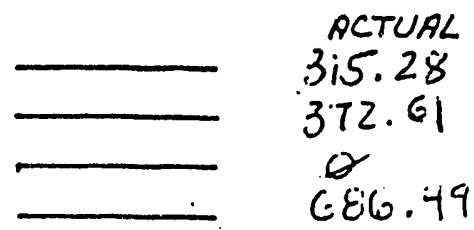

VORTEX NOZZLES

7.90

$5: 32$

14.57

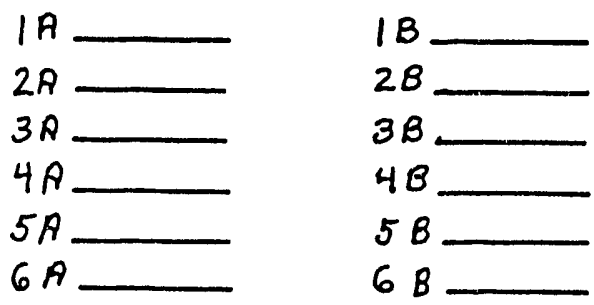

NOTES: Boisjomple taken 12:48. Duta taken alter anilyzers WERE RECALIBRATED.

G.L. RUN STARTCD 


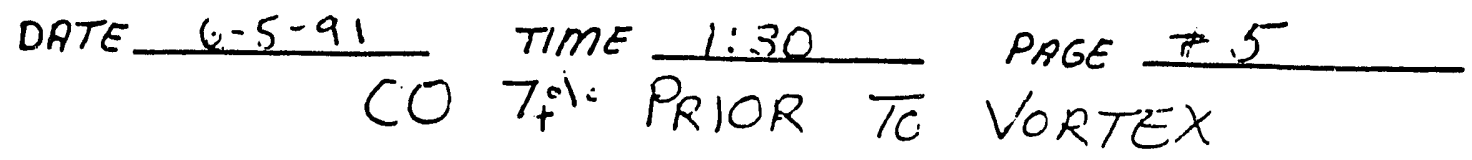

T1 $\frac{00 T}{1760}$
T2
T3 $\frac{1764}{1757}$
T4
T5 $\frac{1745}{10.5}$
T6
T7 $\frac{176.5}{176.5}$
T8

BLOWER PRES - $95 \mathrm{NH}=\mathrm{C}$ DRAFT PRES - 1 i $\mathrm{H}_{2} \mathrm{O}$ MAIN BED $\# 1-12$ i $H: O$ SLURRY AIR D

BURNER AIR - .16 in HLO $\mathrm{CH}_{4}$ FLOW

TOTAL AIR $\triangle P \longrightarrow 2.5 \sim \mathrm{H}_{2} \mathrm{O}$ MAIN BED $\# 3-7$ iN $\mathrm{H}_{2} \mathrm{O}$ MAIU BED $\# 4-9.6 \approx \mathrm{N}_{2} \mathrm{O}$ SLUICE \#14-7in $\mathrm{HLO}$ SLUICE \#15-5. 15120 VORTEX PRES

* T10 $\frac{17.51}{13.50}$
$T 11 \frac{1776}{18.17}$
$T 12 \frac{1746}{1771}$
$T 14 \frac{1777}{161}$
$T 15 \frac{16}{T 16}$

SLUICE AIR FLOW 75 MAIN BED AIR FLOW VORTEX AIR FLOW FREEBOARD AIR FIOW
SCFm 84.1 30

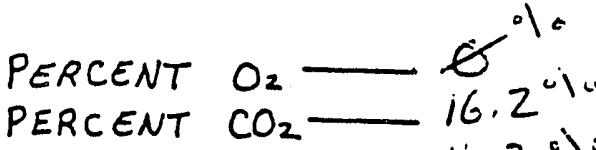

PERCENT CO

BOILER $\mathrm{O}_{2}$

SETINE 4.1
COAL FEED RATE $2.312 \mathrm{mmBTTH}$ LIMESTONE RATIO $2 \cdot 5$ to 1

MAIN BED VELOCITY $7.4 \mathrm{fr} / \mathrm{sec}$

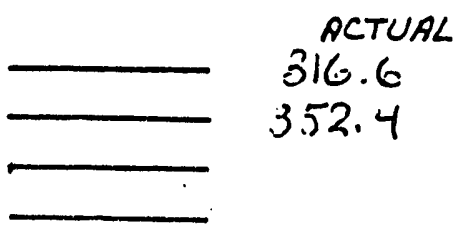

SLUICE VELOCITY

FREEBOARD VELOCITY

CYCLONE INLET

CYCLONE OUTLET

VORTEX NOZ. VELOCITY $5.34 \mathrm{fr} / \mathrm{sec}$

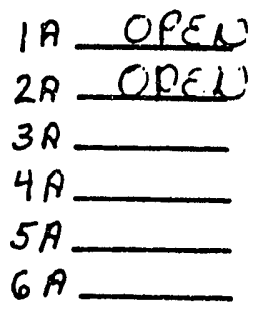

NOzzLES

IB OPEN $2 B$ OFEN $3 B$ $4 B$ $5 B$ $6 B$

NOTES: VURTEX ON O 30 SCFM - CO CP-CO DOW Running well Moved VORTEX To HC SCFM a $1: 35$ E. C. \#3. 
DATE $\quad$-5-91 TIME 2:00 PAGE \#C

T1 $\frac{00 T}{1751}$
T2
T3 $\frac{1757}{1751}$
T4
T5 $\frac{1741}{1704}$
T6
T7 $\frac{1761}{17.58}$

BLOWER PRES - $90 . \mathrm{H} 2 \mathrm{C}$

DRAFT PRES $\varnothing_{\text {iN }} \mathrm{H}_{2} \mathrm{O}$

MAIN BED $\# 1-11.5 \mathrm{NH} \mathrm{H} O$

SLURRY AIR $\varnothing$

BURNER AIR - . 16 iN $\mathrm{H}_{2} \mathrm{O}$

$\mathrm{CH}_{4}$ FLOW OO

TOTAL AIR $\triangle \mathrm{P}-2.5 \mathrm{in} \mathrm{H} \mathrm{HO}$

MAIN BED \#3- 7 in 120

MAIU BEO \#4- E.5 in itLO

SLUICE \#14-7 7 in $\mathrm{HLO}_{2} \mathrm{O}$

SLUICE $\# 15-5 \mathrm{~N} \mathrm{HCO}$

VORTEX PRES ?

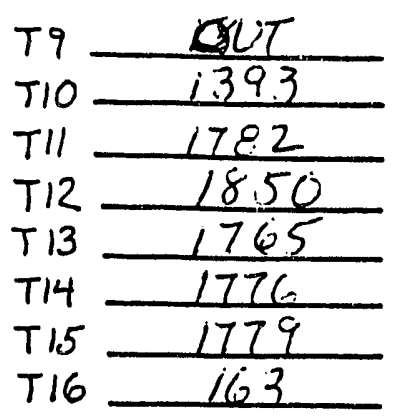

PERCENT O2 $\mathrm{O}_{2} \mathrm{Cl}$

PERCENT $\mathrm{CO}_{2} \longrightarrow 13.5 \mathrm{~T} .1 \mathrm{c}$

PERCENT CO 14

BOILER $\mathrm{O}_{2}$ $6^{\circ 10}$

SOANG 4.5 FEED RATE 2.6 milcION

LIMESTONE RATIO 2.5 to i

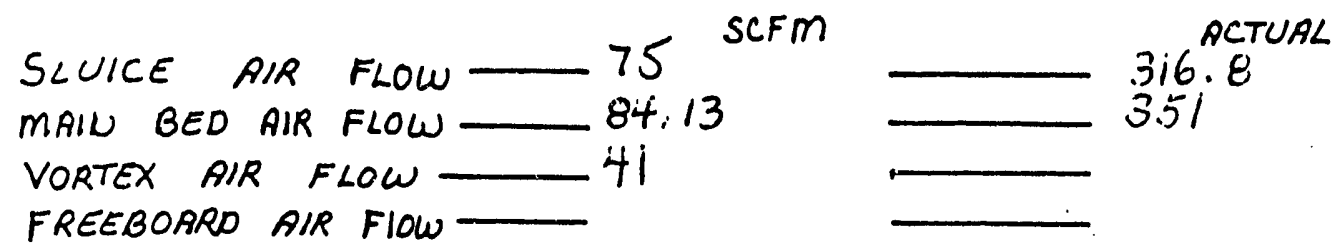

MAIN BED VELOCITY $7.4 .5 \mathrm{ft} / \mathrm{sec}$

VORTEX NOZZLES

SLUICE VELOCITY

FREEBOARD VELOCITY-

CYCLONE INLET

CYCLONE OUTLET

VORTEX NOZ. VELOCITY -
5. $35 \mathrm{ft} / \mathrm{sec}$ /A OPEN

$2 R$ OPE.N

$3 A$

$4 A$

$5 A$

$6 A$
$1 B$ OPEN

$2 B O P E N$

$3 B$

$4 B$

$5 B$

$6 B$

NOTES: Ruw Looks Good

$$
2.6 \text { Million }
$$


DATE TIME $2:-5.40$ PAGE

T1
T2 $\frac{\text { CiT }}{1756} \frac{17.5}{1753}$
T3
T4
T5 $\frac{1740}{\frac{17 \pi}{1761}}$
T6
T7
T8

BLOWER PRES - $8.5 \mathrm{NH} \mathrm{HZO}$ DRAFT PRES - $1.5 \mathrm{~W} \mathrm{H}_{2} \mathrm{O} T$ MAIN BED \#1- $12,2 \mathrm{NLO}$ SLURRY AIR $\sigma$ BURNER AIR - iV IN N. $\mathrm{CH}_{4}$ FLOW $\mathscr{C}$

TOTAL AIR IP $2.5 \mathrm{~N} \mathrm{H} \mathrm{H}$ MAIN BED $\# 3-7.1$ i $\mathrm{N}_{2} \mathrm{C}$ MAIU BED \#4 9 in $\mathrm{H}_{2} \mathrm{O}$ SLUICE \#14 T.W $\mathrm{H}_{2} \mathrm{O}$ SLUICE $\# 15-5$ in HiO VORTEX PRES

\begin{tabular}{|c|c|}
\hline T9 & $0<\pi$ \\
\hline TIO & 1.52 \\
\hline TII & 93 \\
\hline$T / 2$ & $j 87.3$ \\
\hline$T 13$ & 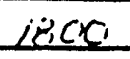 \\
\hline$T 14$ & 1789 \\
\hline$T 15$ & $17 \overline{155}$ \\
\hline TI6 & 10.5 \\
\hline
\end{tabular}

PERCENT $\mathrm{O}_{2} \longrightarrow \mathrm{e}^{-\%}$ PERCENT $\mathrm{CO}_{2}-i .3 .5 \%$ PERCENT CO— if Uil BOILER O2 $\mathrm{O}_{2}-6.5^{\circ} \mathrm{C}$ COAL FEED RATE $2.82 \mathrm{mILICA}$ LIMESTONE RATIO 2.5 to i

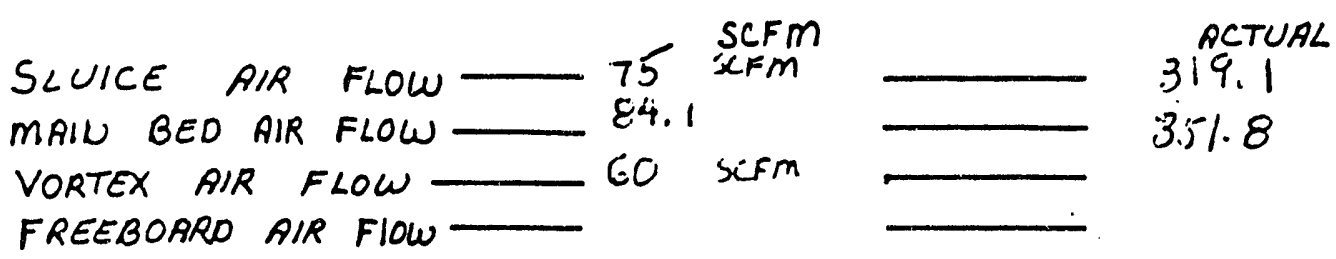

MAIU BED VELOCITY $7.46 \mathrm{tt} / \mathrm{T}$ C

VORTEX NOZZLES

SLUICE VELOCITY $5.39 \mathrm{ft} / \mathrm{sec}$

$\begin{array}{ll}1 A-O P E N & 1 B \text { OPEN } \\ 2 A-O P E N & 2 B \text { OPEA } \\ 3 A- & 3 B \\ 4 A- & 4 B \\ 5 A- & 5 B \\ 6 A- & B B\end{array}$

NOTES: $2: 12$ Bag SAMPCE \# 2 TAKEN

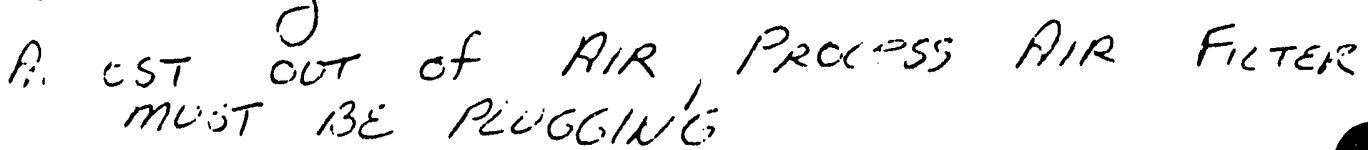

C. LONE EUTCT Gl unic. Rod 


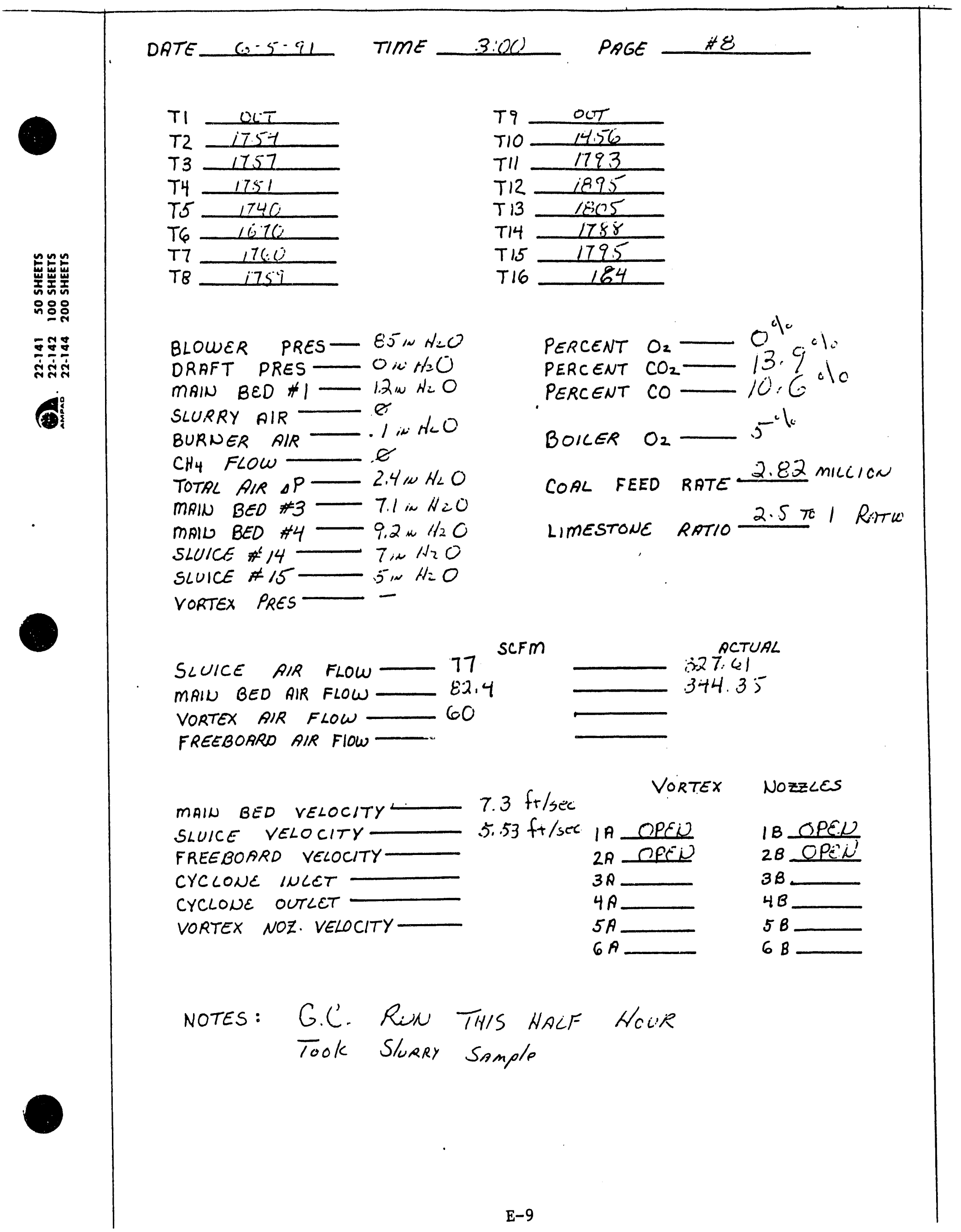


DATEE-OS-91 TIME 3:30PM PAGE

9

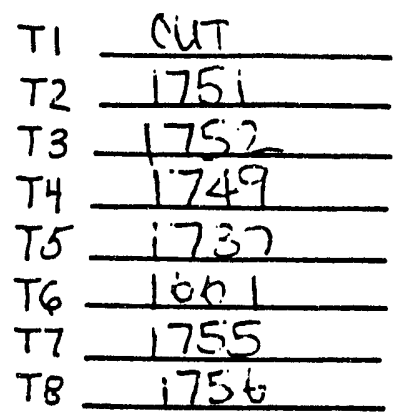

BLOWER PRES $95: 3 H: 0$

DRAFT PRES - 2 : $: \mathrm{H}_{2} \mathrm{O}$

MAIN BED \#1 $\frac{i z \text { in }}{\partial}=\circ$ SLURRY AIR $\frac{0}{\frac{1.1 .}{1}} \mathrm{H}_{2} \mathrm{O}$

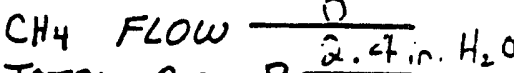
TOTAL AIR AP $\frac{2.4}{7.4}$. $\mathrm{H}_{2} \mathrm{O}$

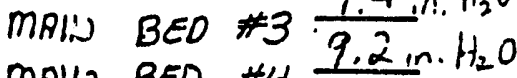

MAIU BED \#4 $\frac{9.25 \text { in. } H_{2} O}{7.25}$

SLUICE $\# 14-S_{\text {iC }} H_{2} \mathrm{O}$

VORTEX PRES ?.

SLUICE AIR FLOW 733 MAIU BED AIR FLOW $\frac{35.71}{\text { OU. }}$ FREEBOARD AIR FIOW

MAIN BED VELOCITY SLUICE VELOCITY CYCLONE INLET CYCLONE OUTLET VORTEX NOZ. VELOCITY-

NOTES: Air flow maxed.

T9 $\frac{\text { OUT }}{1459}$
T10
T11 $\frac{1791}{1896}$
T13
T14 $\frac{1807}{\frac{1782}{1787}}$
$T_{116}^{\frac{104}{104}}$

PERCENT O2 $\frac{0}{154}$

PERCENT $\mathrm{CO}_{2} \frac{13.4}{25}$

PERCENT CO 9.5

BOILER $\mathrm{O}_{2}$ 5\%

COAL FEED RATE $\frac{2.3_{\text {million }}}{2.1 / 1}$

LIMESTONE RATIO $=\frac{21 / 1}{1}$

SCFM

BCTUAL

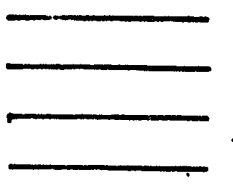

VORTEX NOZZLES
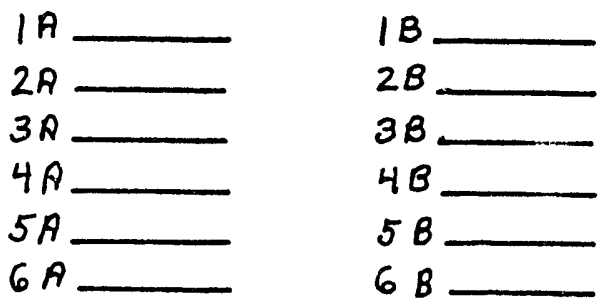
DATE_-5-21 TIME 4:30 PAGE

T1 $\frac{O U T}{1743}$
T2
T3 $\frac{1737}{1738}$
T4
T5 $\frac{1729}{1645}$
T6
T7 $\frac{1748}{1750}$

BLOWER PRES - $85: \mathrm{H}_{2} \mathrm{O}$ DRAFT PRES - . $210 \mathrm{H}_{2} \mathrm{O}+$ MAIN BED $\# 1-i \mathrm{O}$ in $\mathrm{H}_{2} \mathrm{O}$ SLURRY AIR : 12 in $\mathrm{H}_{2} \mathrm{O}$ BURNER AIR $\mathrm{CH}_{4}$ FLOW $2.5 \mathrm{~N} \mathrm{H}=\mathrm{O}$ TOTAL AIR $\triangle P=6.4 \mathrm{in} \mathrm{H}_{2} \mathrm{O}$ MAIN BED $\# 3-8.5$ in $\mathrm{H}_{2} \mathrm{O}$ MAID BED $\# 4-6.5 \% \mathrm{H}_{2} \mathrm{O}$ SLUICE \#14 SLUICE \#15 $5 \approx \mathrm{H}_{2} \mathrm{O}$

T9 $\frac{00 T}{1470}$
$T 10 \frac{1779}{T 11}$
$T 12 \frac{1903}{T 13} \frac{1811}{1805}$
$T 14 \frac{1813}{166}$
$T 16 \frac{166}{T}$

PERCENT O2 $\varnothing$ PERCENT $\mathrm{CO}_{2}-16.1$ PERCENT CO-\$. 25

BOILER $\mathrm{O}_{2}$

COAL FEED RATE 3mICUCN LIMESTONE RATIO- 2.5 TO $i$

VORTEX PRES

SLUICE AIR FLOW

77 SCFM RCTUAL MAIU BED AIR FLOW 84.1

VORTEX AIR FLOW 60 FREEBOARD AIR FIOW

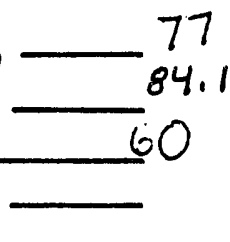

MAIN BED VELOCITYL

SLUICE VELOCITY-

FREEBOARD VELOCITY-

CYCLONE INLET

CYCLONE OUTLET

VORTEX NOZ. VELOCITY-

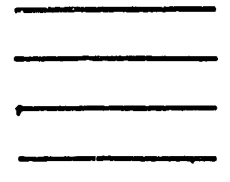

VORTEX NOZZLES
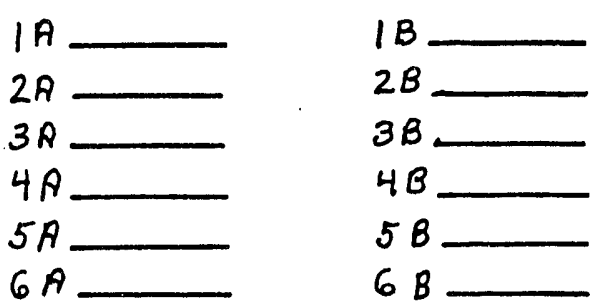

NOTES: laST Bay SAMPLE TrMeCN bus G.C.

Lot Sluice ShmpeE 


\section{APPENDIX F}

\section{VFBC GAS CHROMATOGRAPHY DATA FROM OUTSIDE LABORATORY}




\section{LABORATORY ANALYSIS REPORT}

TRI/Environmental, Inc. 9063 Bee Caves Road

Austin, TX 78733

Donlee Technologies Inc.

PO No: 41185

James Stuart

693 North Hills Rd.

York, PA 17402

Log No: $1005-18-7$

Analyte: THC,CO,CO2

$\mathrm{CH} 4, \mathrm{O} 2, \mathrm{~N} 2$

Method: GC

Date In: 4-3-91

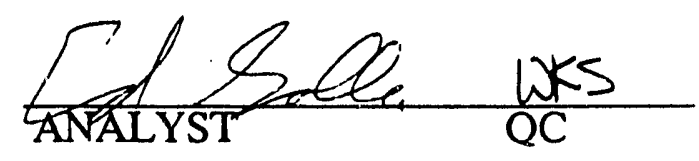

$\frac{4-5-91}{\text { Date of Analysis }}$

\begin{tabular}{|c|c|c|c|c|c|}
\hline $\begin{array}{c}\text { Sample } \\
\text { Identification }\end{array}$ & $\begin{array}{l}\mathrm{CO} \\
(\%)\end{array}$ & $\begin{array}{l}\mathrm{CH} 4 \\
(\%)\end{array}$ & $\begin{array}{l}\mathrm{CO} 2 \\
(\%)\end{array}$ & $\begin{array}{l}\mathrm{O} 2 \\
(\%)\end{array}$ & $\begin{array}{l}\mathrm{N} 2 \\
(\%)\end{array}$ \\
\hline$\# 12: 30 \mathrm{pm} \quad 3-28-91$ & 3.5 & 1.4 & 13.1 & 2.8 & 73.4 \\
\hline$\# 23: 00 \mathrm{pm}$ & 4.2 & 1.5 & 12.2 & 2.9 & 71.1 \\
\hline \#3 3:30 pm & 4.6 & 1.5 & 11.3 & 2.2 & 71.6 \\
\hline
\end{tabular}

* Corrected for blanks where applicable QC Quality Control Check

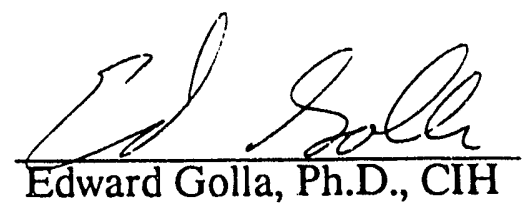

Lab Director 


\section{LABORATORY ANALYSIS REPORT}

TRI/Environmental, Inc.

9063 Bee Caves Road

Austin, TX 78733

Donlee Technologies Inc.

James Stuart

693 North Hills Rd.

York, PA 17402
PO No: 41185

Log No: $1005-18-7$

Analyte: THC,CO,CO2

$\mathrm{CH} 4, \mathrm{O} 2, \mathrm{~N} 2$

Method: GC

Date In: 4-3-91

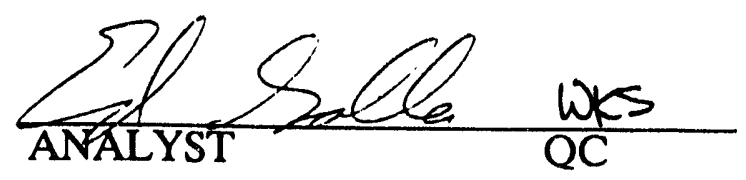

4-5-91

Date of Analysis

Sample Sulfur Hydrogen Ethene Propane Hydrogen

\begin{tabular}{ccccccc} 
Identification & Dioxide (ppm) & Sulfide (\%) & $(\%)$ & $(\%)$ & $(\%)$ \\
\hline & & & & & & \\
\#1 2:30 pm & $3.28-9 i$ & $<2$ & 0.07 & 0.14 & $<0.007$ & 3.7 \\
\#2 3:00 prn & $<2$ & 0.07 & 0.14 & $<0.007$ & 5.4 \\
\#3 3:30 pm & $<2$ & 0.07 & 0.11 & $<0.007$ & 5.5
\end{tabular}

* Corrected for blanks where applicable QC Quality Control Check

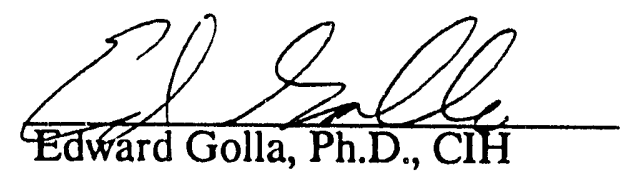

Lab Director 


\section{LABORATORY ANALYSIS REPORT}

TRI/Environmental, Inc.

9063 Bee Caves Road

Austin, TX 78733

Donlee Technologies, Inc.

Mr. James Stuart

693 North Hills Road

York, PA 17402
PO No: 41185

Log No: $1005-21-10$

Analyte: $\mathrm{CO}, \mathrm{CO} 2, \mathrm{H} 2$ $\mathrm{CH} 4, \mathrm{O} 2, \mathrm{~N} 2$

Method: GC

Date In: 4-12-91

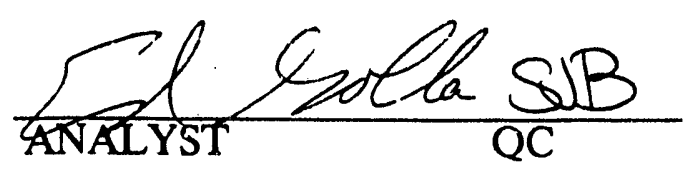

4-12-91

Date of Analysis

\begin{tabular}{ccccccc}
$\begin{array}{c}\text { Sample } \\
\text { Identification }\end{array}$ & $\begin{array}{c}\mathrm{CO} \\
(\%)\end{array}$ & $\begin{array}{c}\mathrm{CH} 4 \\
(\%)\end{array}$ & $\begin{array}{c}\mathrm{CO} 2 \\
(\%)\end{array}$ & $\begin{array}{c}\mathrm{O} 2 \\
(\%)\end{array}$ & $\begin{array}{c}\mathrm{N} 2 \\
(\%)\end{array}$ & $\begin{array}{c}\mathrm{H} 2 \\
(\%)\end{array}$ \\
\hline & & & & & & \\
4-5-91 2:42 pm \#1 & 3.9 & 0.59 & 17.5 & 0.8 & 70.9 & 3.7 \\
4-5-91 4:00 pm \#2 & 5.6 & 0.75 & 16.1 & 0.5 & 68.9 & 5.1 \\
4-5-91 4:00 pm \#2 & 5.7 & 0.73 & 16.1 & 0.5 & 68.4 & 5.1
\end{tabular}

* Corrected for blanks where applicable QC Quality Control Check

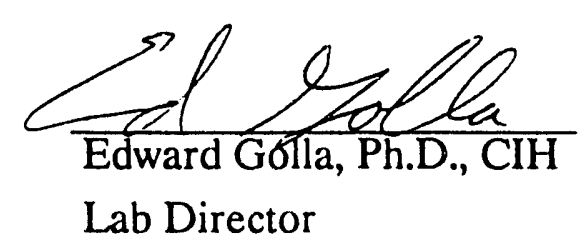




\section{LABORATORY ANALYSIS REPORT}

TRI/Environmental, Inc.

9063 Bee Caves Road

sustin, TX 78733

Donlee Technologies, Inc.

Mr. James Stuart

693 North Hills Road

York, PA 17402
PO No: 41185

Log No: $1005-21-10$

Analyte: $\mathrm{H} 2 \mathrm{~S}, \mathrm{SO} 2, \mathrm{C} 2 \mathrm{H} 4$

$\mathrm{C} 3 \mathrm{H} 8$

Method: GC

Date In: 4-12-91

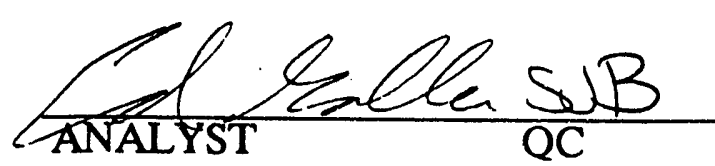

4-12-91

Date of Analysis

\begin{tabular}{ccccc}
$\begin{array}{c}\text { Sample } \\
\text { Identification }\end{array}$ & $\begin{array}{c}\mathrm{H} 2 \mathrm{~S} \\
(\mathrm{ppm})\end{array}$ & $\begin{array}{c}\mathrm{SO} 2 \\
(\mathrm{ppm})\end{array}$ & $\begin{array}{c}\mathrm{C} 2 \mathrm{H} 4 \\
(\mathrm{ppm})\end{array}$ & $\begin{array}{c}\mathrm{C} 3 \mathrm{H} 8 \\
(\mathrm{ppm})\end{array}$ \\
\hline & & & & \\
$4-5-912: 42 \mathrm{pm} \# 1$ & $4 / 2$ & $<4$ & 480 & $<30$ \\
$4-5-914: 00 \mathrm{pm} \# 2$ & 580 & $<4$ & 523 & $<30$ \\
4-5-91 4:00 pm \#2 & 593 & $<4$ & 528 & $<30$
\end{tabular}

* Corrected for blanks where applicable QC Quality Control Check

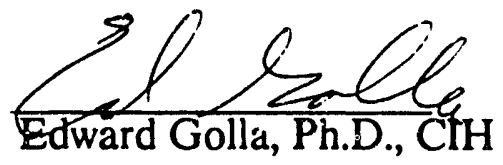

Lab Director 


\section{LABORATORY ANALYSIS REPORT}

TRI/Environmental, Inc. 9063 Bee Caves Road

Austin, TX 78733

Donlee Technologies, Inc.

Mr. James Stuart

693 North Hills Road

York, PA 17402
PO No: N/A

Log No: $1005-21-7$

Analyte: $\mathrm{CO}, \mathrm{CH} 4, \mathrm{CO} 2$ $\mathrm{O} 2, \mathrm{~N} 2, \mathrm{H} 2$

Method: GC

Date In: 4-16-91

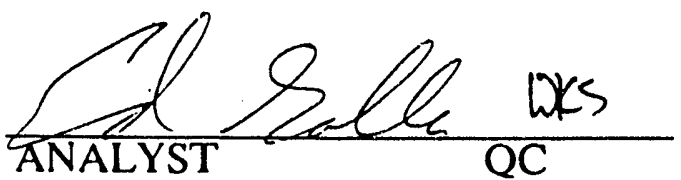

4-16-91

Date of Analysis

\begin{tabular}{ccccccc}
$\begin{array}{c}\text { Sample } \\
\text { Identification }\end{array}$ & $\begin{array}{c}\mathrm{CO} \\
(\%)\end{array}$ & $\begin{array}{c}\mathrm{CH} 4 \\
(\%)\end{array}$ & $\begin{array}{c}\mathrm{CO} 2 \\
(\%)\end{array}$ & $\begin{array}{c}\mathrm{O} 2 \\
(\%)\end{array}$ & $\begin{array}{c}\text { N2 } \\
(\%)\end{array}$ & $\begin{array}{c}\text { Hydrogen } \\
(\%)\end{array}$ \\
\hline & & & & & & \\
\#1 4-11-91 2:00 & 4.9 & 1.2 & 16.1 & 1.0 & 70.1 & 5.5 \\
\#2 4-11-91 3:30 & 5.6 & 1.3 & 15.4 & 1.0 & 69.3 & 6.0 \\
\#3 4-11-91 4:20 & 5.7 & 1.2 & 15.0 & 1.4 & 69.7 & 5.7
\end{tabular}

* Corrected for blanks where applicable QC Qua'ity Control Check

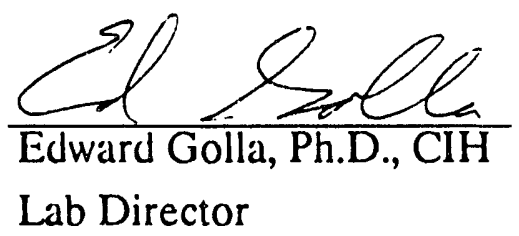




\section{LABORATORY ANALYSIS REPORT}

TRI/Environmental, Inc.

PO No: N/A

9063 Bee Caves Road

Log No: $1005-21-7$

Austin, TX 78733

Analyte: Sulfur Dioxide, Hydrogen Sulfide Ethane, Propane

Donlee Technologies, Inc. Ethylene

Mr. James Stuart

Method: GC

693 North Hills Road

Date In: 4-16-91

York, PA 17402

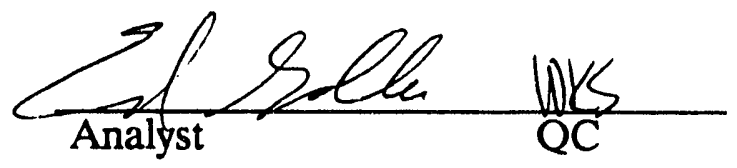

4-16-91

Date of Analysis

Sulfur Hydrogen

Sample Dioxide Sulfide Ethane Propane Ethylene

Identification $\quad(\mathrm{ppm}) \quad(\mathrm{ppm}) \quad(\mathrm{ppm}) \quad(\mathrm{ppm}) \quad(\mathrm{ppm})$

$\begin{array}{llllll}\# 14-11-912: 00 & <2 & 590 & <50 & <40 & 1190 \\ \# 24-11-913: 30 & <2 & 660 & <50 & <40 & 1180 \\ \# 34-11-914: 20 & <2 & 630 & <50 & <40 & 1250\end{array}$

* Corrected for blanks where applicable QC Quality Control Check

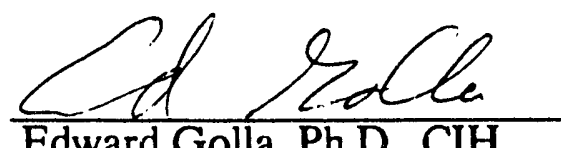

Edward Golla, Ph.D., CIH

Lab Director 
TRI/Environmental, Inc.

9063 Bee Caves Road

Austin, TX 78733

Donlee Technologies, Inc.

Mr. James Stuart

693 North Hills Road

York, PA 17402
PO No: N/A

Log No: $1005-29-4$

Analyte: $\mathrm{CO}, \mathrm{CH} 4, \mathrm{CO} 2$

$\mathrm{O} 2, \mathrm{~N} 2, \mathrm{H} 2$

Method: GC

Date In: 5-13-91

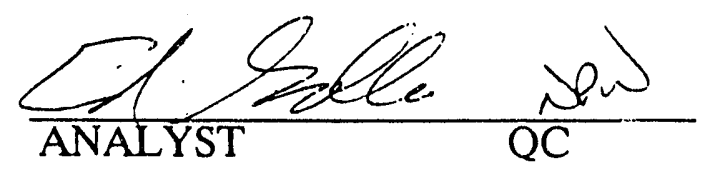

5-13-91

Date of Analysis

\begin{tabular}{ccccccc}
$\begin{array}{c}\text { Sample } \\
\text { Identification }\end{array}$ & $\begin{array}{c}\mathrm{CO} \\
(\%)\end{array}$ & $\begin{array}{c}\mathrm{CH} 4 \\
(\%)\end{array}$ & $\begin{array}{c}\mathrm{CO} 2 \\
(\%)\end{array}$ & $\begin{array}{c}\mathrm{O} 2 \\
(\%)\end{array}$ & $\begin{array}{c}\mathrm{N} 2 \\
(\%)\end{array}$ & $\begin{array}{c}\text { Hydrogen } \\
(\%)\end{array}$ \\
\hline & & & & &. & \\
\#1 5-9-91 1:30 & 4.8 & 1.3 & 17.3 & 0.9 & 70.0. & 6.3 \\
$\# 25-8-912: 00$ & 5.6 & 0.67 & 16.8 & 1.5 & 72.1 & 4.0 \\
$\# 35-8-914: 20$ & 7.2 & 0.74 & 16.5 & 1.0 & 69.8 & 5.2
\end{tabular}

* Corrected for blanks where applicable QC Quality Control Check

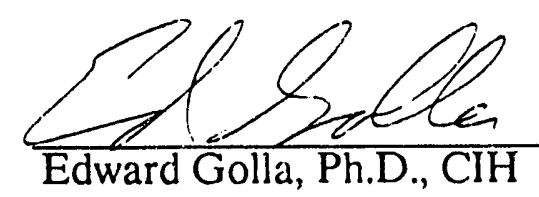

Lab Director 


\section{LABORATORY ANALYSIS REPORT}

TRI/Environmental, Inc.

9063 Bee Caves Road

Austin, TX 78733

PO No: N/A

Log No: $1005-29-4$

Analyte: Sulfur Dioxide, Hydrogen Sulfide Ethane, Propane

Donlee Technologies, Inc.

Ethylene

Mr. James Stuart

Method: GC

693 North Hills Road

Date In: 5-13-91

York, PA 17402

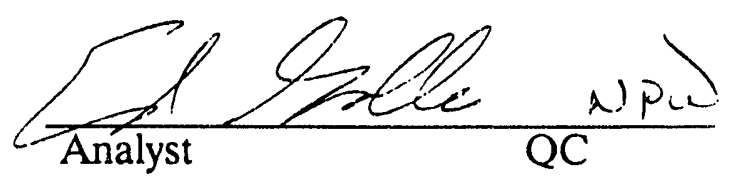

5-13-91

Date of Analysis

\begin{tabular}{ccccc}
$\begin{array}{c}\text { Sample } \\
\text { Identification }\end{array}$ & $\begin{array}{c}\text { Sulfur } \\
\text { Dioxide } \\
(\mathrm{ppm})\end{array}$ & $\begin{array}{c}\text { Hydrogen } \\
\text { Sulfide } \\
(\mathrm{ppm})\end{array}$ & $\begin{array}{c}\text { Propane } \\
(\mathrm{ppm})\end{array}$ & $\begin{array}{c}\text { Ethylene } \\
(\mathrm{ppm})\end{array}$ \\
\hline & & & & \\
$\# 15-9-911: 30$ & $<2$ & 673 & $<20$ & 1240 \\
$\# 25-8-912: 10$ & $<2$ & 822 & $<20$ & 245 \\
$\# 35-8-914: 20$ & $<2$ & 992 & $<20$ & 218
\end{tabular}

* Corrected for blanks where applicable QC Quality Control Check

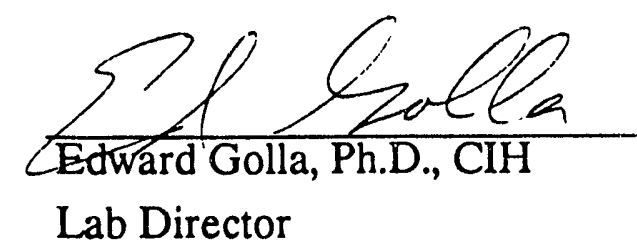




\section{LABORATORY ANALYSIS REPORT}

TRI/Environmental, Inc.

9063 Bee Caves Road

Austin, TX 78733

Donlee Technologies, Inc.

Mr. James Stuart

693 North Hills Road

York, PA 17402
PO No: N/A

Log No: $1005-29-9$

Analyte: $\mathrm{CO}, \mathrm{CH} 4, \mathrm{CO} 2$ $\mathrm{O} 2, \mathrm{~N} 2, \mathrm{H} 2$

Method: GC

Date In: 5-22-91

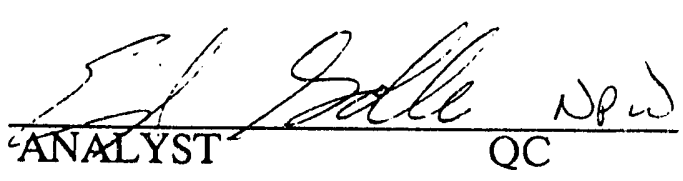

5-22-91

Date of Analysis

\begin{tabular}{ccccccc}
$\begin{array}{c}\text { Sample } \\
\text { Identification }\end{array}$ & $\begin{array}{c}\mathrm{CO} \\
(\%)\end{array}$ & $\begin{array}{c}\mathrm{CH} 4 \\
(\%)\end{array}$ & $\begin{array}{c}\mathrm{CO} 2 \\
(\%)\end{array}$ & $\begin{array}{c}\mathrm{O} 2 \\
(\%)\end{array}$ & $\begin{array}{c}\mathrm{N} 2 \\
(\%)\end{array}$ & $\begin{array}{c}\text { Hydrogen } \\
(\%)\end{array}$ \\
\hline \#1 5-14-91 2:20pm & 4.6 & 1.2 & 16.5 & 1.9 & 69.7 & 5.7 \\
\#2 5-14-91 3:30pm & 4.5 & 1.0 & 13.0 & 3.0 & 73.1 & 5.0 \\
$\# 15-16-912: 20 \mathrm{pm}$ & 6.2 & 0.9 & 17.4 & 1.5 & 67.7 & 6.3 \\
\#2 5-16-91 3:30pm & 9.5 & 0.9 & 16.1 & 1.3 & 63.7 & 9.8
\end{tabular}

* Corrected for blanks where applicable QC Quality Control Check

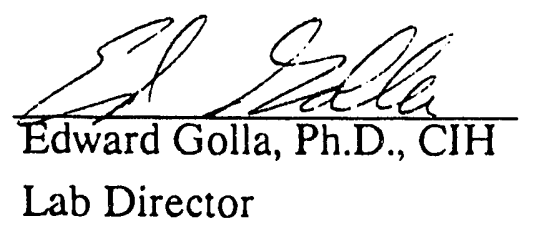




\section{LABORATORY ANALYSIS REPORT}

TRI/Environmental, Inc. 9063 Bee Caves Road Austin, TX 78733

Donlee Technologies, Inc. Mr. James Stuart 693 North Hills Road York, PA 17402
PO No: N/A

Log No: $1005-29-9$

Analyte: Sulfur Dioxide, Hydrogen Sulfide Ethane, Propane Ethylene

Method: GC

Date In: 5-22-91

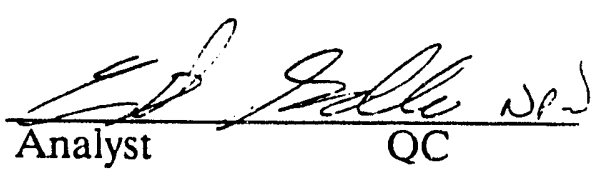

5-22-91

Date of Analysis

Sulfur Hydrogen

\begin{tabular}{ccccc}
$\begin{array}{c}\text { Sample } \\
\text { Identification }\end{array}$ & $\begin{array}{c}\text { Dioxide } \\
\text { (ppm) }\end{array}$ & $\begin{array}{c}\text { Sulfide } \\
\text { (ppm) }\end{array}$ & $\begin{array}{c}\text { Propane } \\
\text { (ppm) }\end{array}$ & $\begin{array}{c}\text { Ethylene } \\
\text { (ppm) }\end{array}$ \\
\hline \#1 5-14-91 2:20pm & $<2$ & 150 & $<20$ & 1162 \\
$\# 25-14-913: 30 \mathrm{pm}$ & $<2$ & 11.5 & $<20$ & 677 \\
$\# 15-16-912: 20 \mathrm{pm}$ & $<2$ & 331 & $<20$ & 724 \\
$\# 25-16-913: 30 \mathrm{pm}$ & $<2$ & 247 & $<20$ & 640
\end{tabular}

* Corrected for blanks where applicable QC Quality Control Check

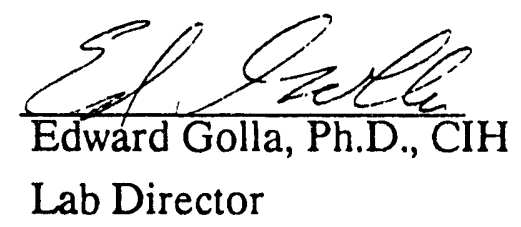




\section{LABORATORY ANALYSIS REPORT}

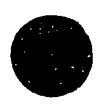

TRI/Environmental, Inc.

9063 Bee Caves Road

Austin, TX 78733

Donlee Technologies, Inc.

Mr. James Stuart

693 North Hills Road

York, PA 17402
PO No: N/A

Log No: $1005-33-8$

Analyte: Sulfur Dioxide,

Hydrogen Sulfide

Ethane, Propane

Ethylene

Method: GC

Date In: 6-11-91

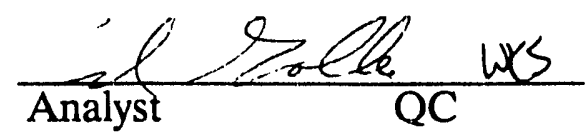

6-11-91

Date of Analysis

Sulfur Hydrogen

\begin{tabular}{ccccc}
$\begin{array}{c}\text { Sample } \\
\text { Identification }\end{array}$ & $\begin{array}{c}\text { Dioxide } \\
(\mathrm{ppm})\end{array}$ & $\begin{array}{c}\text { Sulfide } \\
(\mathrm{ppm})\end{array}$ & $\begin{array}{c}\text { Propane } \\
(\mathrm{ppm})\end{array}$ & $\begin{array}{c}\text { Ethylene } \\
(\mathrm{ppm})\end{array}$ \\
\hline \#1 6-5-91 12:48pm & $<2$ & 391 & $<20$ & 454 \\
\#2 6-5-91 2:12pm & $<2$ & 409 & $<20$ & 182 \\
\#3 6-5-91 4:30pm & $<2$ & 610 & $<20$ & 265
\end{tabular}

* Corrected for blanks where applicable QC Quality Control Check

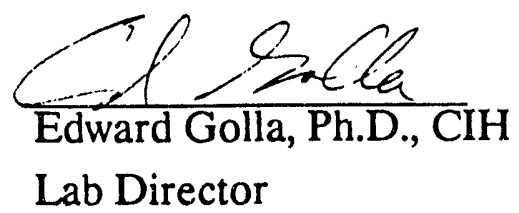




\section{LABORATORY ANALYSIS REPORT}

TRI/Environmental, Inc.

9063 Bee Caves Road

Austin, TX 78733

Donlee Technologies, Inc.

Mr. James Stuart

693 North Hills Road

York, PA 17402
PO No: N/A

Log No: $1005-33-8$

Analyte: $\mathrm{CO}, \mathrm{CH} 4, \mathrm{CO} 2$ $\mathrm{O} 2, \mathrm{~N} 2, \mathrm{H} 2$

Method: GC

Date In: 6-11-91

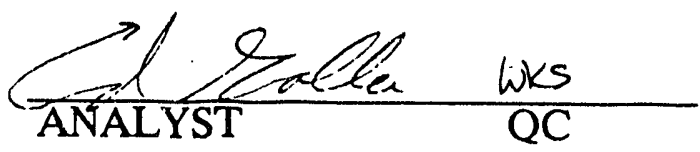

6-11-91

Date of Analysis

\begin{tabular}{ccccccc} 
Identification & $(\%)$ & $(\%)$ & $(\%)$ & $(\%)$ & $(\%)$ & $(\%)$ \\
\hline \#1 6-5-91 12:48pm & 7.1 & 1.0 & 16.1 & 1.8 & 67.6 & 6.1 \\
\#2 6-5-91 2:12pm & 14.4 & 0.6 & 12.6 & 1.2 & 61.6 & 10.0 \\
\#3 6-5-91 4:30pm & 7.9 & 0.7 & 16.6 & 2.0 & 68.1 & 6.4
\end{tabular}

* Corrected for blanks where applicable QC Quality Control Check

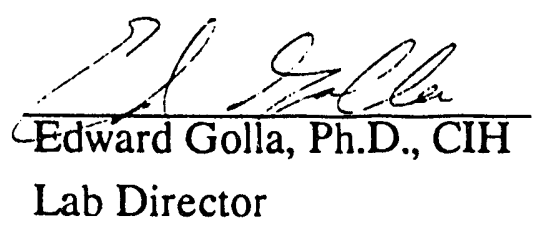




\section{LABORATORY ANALYSIS REPORT}

TRI/Environmental, Inc.

9063 Bee Caves Road

Austin, TX 78733

Donlee Technologies

Mr. James Stuart

693 North Hills Road

York, PA 17402

Comments:
PO No: N/A

Log No: $1005-36-10$

Analyte: See Below

Method: GC

Date In: 7-1-91

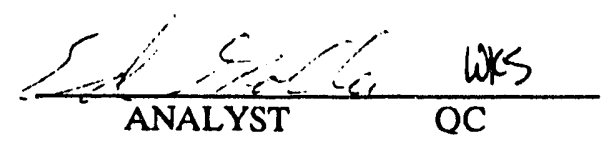

7-1-91

Date of Analysis
\#1 \#2 \#1 \#2 6-18-91 2:00pm 6-18-91 3:50pm 6-25-91 2:00pm 6-25-91 3:30pm

Test Parameters

11.1

7.5

12.3

Carbon Monoxide (\%)

Methane (\%)

6.3

0.8

Carbon Dioxide (\%)

15.9

Oxygen (\%)

Nitrogen (\%)

Hydrogen (\%)

Sulfur Dioxide (ppm)

Hydrogen Sulfide (ppm)

Propane (ppm)

Ethylene (ppm)

3.2

69.8

4.4

$<2$

718

$<20$

512
0.3

13.7

2.6

66.8

5.8

$<2$

614

$<20$

91
0.9

15.2

1.8

67.5

6.5

$<2$

607

$<20$

348
0.3

12.7

1.4

65.2

8.4

$<2$

888

$<20$

47

QC Quality Control Check

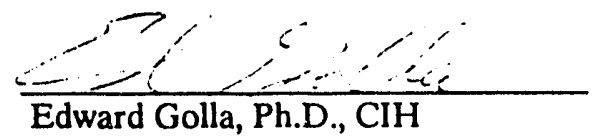

Lab Director 


\section{APPENDIX G}

\section{VFBC GAS CHROMATOGRAPHY ANALYSES AND ANALYSIS OF ACCURACIES}




\section{APPENDIX G \\ FLUE GAS ANALYSIS BY PENN STATE AND TRI}

The flue gas exiting from the cyclone was sampled so that the composition of the gas could be determined. Samples of flue gas were passed through the gas chromatograph (GC) for analysis. This GC is capable of analyzing the following gaseous components:

- Nitrogen $\left(\mathrm{N}_{2}\right)$;

- Carbon Dioxide $\left(\mathrm{CO}_{2}\right)$;

- Carbon Monoxide (CO);

- Sulfur Dioxide $\left(\mathrm{SO}_{2}\right)$;

- Hydrogen Sulfide $\left(\mathrm{H}_{2} \mathrm{~S}\right)$;

- Oxygen $\left(\mathrm{O}_{2}\right)$;

- Methane $\left(\mathrm{CH}_{4}\right)$;

- Ethane $\left(\mathrm{C}_{2} \mathrm{H}_{6}\right)$;

- Ethene or Ethylene $\left(\mathrm{C}_{2} \mathrm{H}_{4}\right)$;

- Acetylene $\left(\mathrm{C}_{2} \mathrm{H}_{2}\right)$;

- Propane $\left(\mathrm{C}_{3} \mathrm{H}_{8}\right)$;

- Hydrogen $\left(\mathrm{H}_{2}\right)$; and

- Water $\left(\mathrm{H}_{2} \mathrm{O}\right)$.

The detection limits for sulfur dioxide and hydrogen sulfide were 1000 and $500 \mathrm{ppm}$, respectively, much too high for determining the level of these two gases during the testing.

An outside laboratory (Texas Research Institute) was contacted, primarily to obtain sulfur compound $\left(\mathrm{SO}_{2}\right.$ and $\left.\mathrm{H}_{2} \mathrm{~S}\right)$ analyses. Complete flue gas analyses from the outside laboratory were also obtained to provide a check on the Penn State GC analyses.

In the analyses no acetylene was detected. This is as should be expected in our gasifier system. Ethene and propane were only detected (by TRI) at these gases' detection limits. Water could not be quantified by either GC. The water content in the flue gas was determined from the dry gas analyses and the nitrogen and hydrogen balances.

The detection limits for the gaseous components in the flue gas are presented in Table 1 along with the accuracies achievable. Apparently, the accuracies for the Penn State gas components of $\mathrm{N}_{2}$, $\mathrm{CO}_{2}, \mathrm{CO}, \mathrm{O}_{2} \mathrm{C}_{2} \mathrm{H}_{4}$ and $\mathrm{H}_{2}$ are much tighter than for TRI. Likewise, $\mathrm{SO}_{2}, \mathrm{H}_{2} \mathrm{~S}, \mathrm{C}_{2} \mathrm{H}_{6}$ and $\mathrm{C}_{3} \mathrm{H}_{8}$

$$
\text { G - } 1
$$


are more accurate for TRI analyses. Note, however, instrumented error (roughly $0.1 \%$ of value of gas), sample handling errors and column changes with time were not accounted for Penn State data in Table 1. The actual Penn $S:$ te accuracies may be somewhat worse than those in Table 1.

Penn State detection limits are lower for $\mathrm{NO}_{2}, \mathrm{CO}_{2}, \mathrm{CO}, \mathrm{O} 2$ and $\mathrm{H}_{2}$. However, in all of these cases, the actual concentrations of these gases detected, were much higher than even the TRI detection limits. In the cases of the components of $\mathrm{SO}_{2}, \mathrm{H}_{2} \mathrm{~S}, \mathrm{CH}_{4}, \mathrm{C}_{2} \mathrm{H}_{6}, \mathrm{C}_{3} \mathrm{H}_{8}$ and $\mathrm{C}_{2} \mathrm{H}_{4}$, the TRI detection limits are significantly lower. These are lower concentration components that require low detection limits to achieve accurate determinations. The detection limits for TRI are, thus more effective than those for Penn State.

Table 1. Gas Chromatography Accuracies and Detection Limits (1)

\begin{tabular}{|c|c|c|c|c|}
\hline GASEOUS COMPOUND & Penn State & $\begin{array}{l}\text { ICIES ---- } \\
\text { TRI (2) }\end{array}$ & $\begin{array}{l}--\mathrm{DET} \\
\text { Penn State }\end{array}$ & $\begin{array}{c}\text { PTION LIMITS -- } \\
\text { TRI }\end{array}$ \\
\hline Nitrogen $\left(\mathrm{N}_{2}\right)$ & $\pm 0.2 \%$ of value & $\pm 2 \%$ of value & $200 \mathrm{ppm}$ & $0.5 \%$ (or $5000 \mathrm{ppm})$ \\
\hline Carbon Dioxide $\left(\mathrm{CO}_{2}\right)$ & $\pm 0.08 \%$ of value & $\begin{array}{l} \pm 4 \% \text { of value or } \\
\pm 0.5 \% \mathrm{CO}_{2}\end{array}$ & $200 \mathrm{ppm}$ & $0.5 \%$ (or $5000 \mathrm{ppm}$ ) \\
\hline Carbon Monoxide (CO) & $\pm 1 \%$ of value & $\begin{array}{l} \pm 4 \% \text { of value or } \\
0.5 \% \mathrm{CO}\end{array}$ & $350 \mathrm{ppm}$ & $0.5 \%$ (or $5000 \mathrm{ppm}$ ) \\
\hline Sulfur Dioxide $\left(\mathrm{SO}_{2}\right)$ & $\cdots$ & $\pm 2 \mathrm{ppm}$ & $1000 \mathrm{ppm}$ & $2 \mathrm{ppm}$ \\
\hline Hydrogen Sulfide $\left(\mathrm{H}_{2} \mathrm{~S}\right)$ & $-\cdots$ & $\begin{array}{l} \pm 2 \text { ppm or } \\
5 \% \text { of value }\end{array}$ & $500 \mathrm{ppm}$ & $2 \mathrm{ppm}$ \\
\hline $\operatorname{ygen}\left(O_{2}\right)$ & $\pm 0.01 \%$ of value & $\pm 0.5 \%$ of value & $200 \mathrm{ppm}$ & $0.10 \%$ (or $1000 \mathrm{ppm}$ ) \\
\hline ivethane $\left(\mathrm{CH}_{4}\right)$ & $\pm 4 \%$ of value & $\begin{array}{l} \pm 4 \% \text { of value or } \\
0.5 \% \text { of } \mathrm{CH}_{4}\end{array}$ & $200 \mathrm{ppm}$ & 30 or $50 \mathrm{ppm}$ \\
\hline Ethane $\left(\mathrm{C}_{2} \mathrm{H}_{6}\right)$ & $-\cdots$ & $\pm 30 \mathrm{ppm} \mathrm{C} \mathrm{C}_{2} \mathrm{H}_{6}$ & $500 \mathrm{ppm}$ & 30 or $50 \mathrm{ppm}$ \\
\hline Propane $\left(\mathrm{C}_{3} \mathrm{H}_{8}\right)$ & ---- & \pm 30 ppm $\mathrm{C}_{3} \mathrm{H}_{8}$ & $500 \mathrm{ppm}$ & 30 or $50 \mathrm{ppm}$ \\
\hline Ethene or Ethylene $\left(\mathrm{C}_{2} \mathrm{H}_{4}\right)$ & $\pm 0.02 \%$ of value & $\begin{array}{l} \pm 5 \% \text { of value or } \\
\pm 50 \text { ppm } \mathrm{C}_{2} \mathrm{H}_{4}\end{array}$ & $200 \mathrm{ppm}$ & 10 to $100 \mathrm{ppm}$ \\
\hline Hydrogen $\left(\mathrm{H}_{2}\right)$ & $\pm 0.03 \%$ of value & $\begin{array}{l} \pm 4 \% \text { of value or } \\
\pm 0.5 \% \text { of } \mathrm{H}_{2}\end{array}$ & $1000 \mathrm{ppm}$ & $\pm 0.2 \%$ (or $2000 \mathrm{ppm})$ \\
\hline Water $\left(\mathrm{H}_{2} \mathrm{O}\right)$ & --.-- & --- & $\ldots$ & $-\cdots$ \\
\hline
\end{tabular}

(1) Calibration gases for the Penn State analyzers $\left(\mathrm{CO}_{2}, \mathrm{CO}, \mathrm{O}_{2}\right)$ and the $\mathrm{GC}$ are accurate to $\pm 2 \%$. The accuracy of the $\mathrm{O}_{2}, \mathrm{CO}_{2}$ and $\mathrm{CO}$ analyzers is $\pm 1 \%$ of range or $0.10 \% \mathrm{CO}$, and $\pm 0.30 \% \mathrm{CO}_{2}$, typically.

(2) For values of such as " $\pm 4 \%$ of value or $\pm 0.5 \% \mathrm{CO}_{2}$ " use the larger value for the accuracy. In this example if $\mathrm{CO}_{2}$ is less than $12.5 \%, 0.5 \%$ of $\mathrm{CO}_{2}$ is larger. If $\mathrm{CO}_{2}$ is larger than $12.5 \%$, then $4 \%$ of the value is the larger value, and at $12.5 \% \mathrm{CO}_{2}$, both values are the same.

(3) Water values are calculated values determined from nitrogen and hydrogen balances. 


\begin{abstract}
APPENDIX H
2VFBC SOLIDS ANALYSES OF SLUICE DRAIN AND BAGHOUSE DRAIN
\end{abstract}




\section{APPENDIX H}

\section{SOLIDS ANALYSES OF \\ SLUICE DRAIN AND BAGHOUSE DRAIN}

Designation of the samples is by sample name (sluice ash or baghouse fly ash) and date of test. Reference to the test number is made on some of the sample analysis sheets.

No samples were taken from Test No. 1 on $3 / 28 / 91$. Only two fly ash samples could be positively identified since these samples were collected after all testing was complete. Most fly ash samples had been combined with other ash samples or had not been labeled originally. 


\section{ANALYTICAL REPORT}

CLIENT: Jim Stuart

Donlee Technologies, Inc.

693 N. Hills Road

York PA 17402

$\begin{array}{ll}\text { SAMPLE: } & 1017104 \\ \text { PROJECT: } & 104416 \\ \text { PO NO: } & 33682 \\ \text { REPORTED: } & 03-J U N-91 \\ \text { RECEIVED: } & 11-A P R-91 \\ \text { WORK ORDER: } & \end{array}$

PROJECT DESCRIPTION: Ash Drained From The Sluice

CLIENT SAMPLE IRENTIFICATION: TEST

SAMPLING DATE: 05-APR-91 TIME: 14:50 BY: client

Loss on Ignition
Acid Insolubles
Calcium
Magnesium
Sulfur
Sulfate sulfur
Carbon
Carbon Dioxide
Reactivity - Sulfide
Organic Carbon
pH

Loss on Ignition

Acid Insolubles

Magnesium

sulfur

Sulfate sulfur

Carbon

Reactivity - Sulfide

$\mathrm{pH}$

$$
\begin{gathered}
\text { RESULT } \\
1.05 \\
83.2 \\
2.10 \\
0.09 \\
0.14 \\
0.14 \\
1.07 \\
0.09 \\
<50 \\
1.05 \\
12.50
\end{gathered}
$$

\footnotetext{
Respectfully submitted,

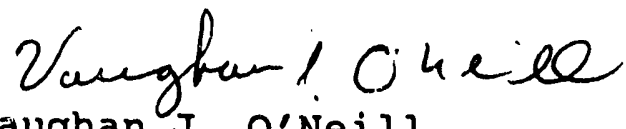

Vaughan J. O'Neill,

Group Leader, Physical Testing
} 


\section{ANALYTICAL REPORT}

CLIENT: Jim stuart

Donlee Technologies, Inc.

693 N. Hills Road

York PA 17402

SAMPLING DATE: 11-APR-91

TIME: $15: 00$

BY: Client

\section{Siluice}

SAMPLE: 1017386

\# 1 Ash

Loss on Ignition

Acid Insolubles

Calcium

Magnesium

Sulfur

Sulfate Sulfur

Carbon

Carbon Dioxide

Organic Carbon

Reactivity - Sulfide

$\mathrm{pH}$

UNITS

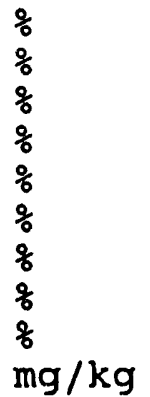

SAMPLE : 1017387

\#2. Ash

Loss on Ignition

Acid Insolubles

Calcium

Magnesium

Sulfur

Sulfate sulfur

Carbon

Carbon Dioxide

Organic Carbon

Reactivity - Sulfide

$\mathrm{pH}$

$\begin{array}{ll}\text { PROJECT: } & 104494 \\ \text { PO NO: } & 41220 \\ \text { REPORTED: } & 03-J U N-91 \\ \text { RECEIVED: } & 16-A P R-91 \\ \text { WORK ORDER: } & \end{array}$

RESULT

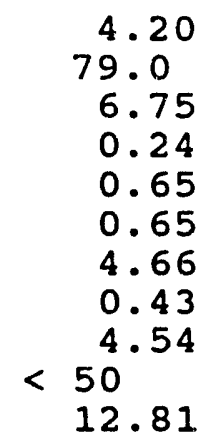

12.3

67.3

7.16

0.28

1.08

1.04

11.1

0.57

10.9

889

12.84

Respectfully submitted,

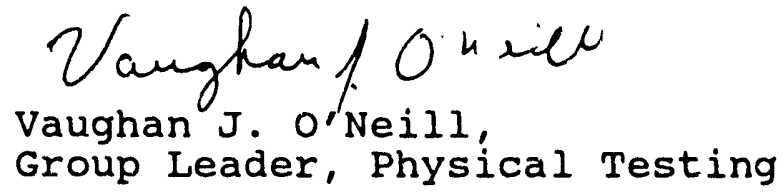




\section{ANALYTICAL REPORT}

CLIENT: Jim stuart

Donlee Technologies, Inc.

693 N. Hills Road

York PA 17402

CLIENT SAMPLE IDENTIFICATION: SAMPLE \#3 Sinice

SAMPLE DESCRIPTION: End of Test P.M. $1800+F$

SAMPLING DATE: 08-MAY-91 BY: Client

Moisture

Loss on Ignition

Acid Insolubles

Calcium

Magnesium

Sulfur

Sulfate sulfur

CHN Analysis

Carbon

Carbon Dioxide

Organic Carbon

sulfide (as $s$ )

$\mathrm{pH}$

\section{UNITS}

\%

$\%$

8

\%

8

$\%$

8

$q$

\%

$\mathrm{mg} / \mathrm{kg}$
SAMPLE: $\quad 1019818$

PROJECT: 105086

PO NO: $\quad 41259$

REPORTED: 03-JUN-91

RECEIVED :

WORK ORDER:
RESULT

$$
\begin{gathered}
1.50 \\
69.4 \\
12.2 \\
0.41 \\
1.25 \\
1.22 \\
1.64 \\
0.95 \\
1.38 \\
138 \\
12.64
\end{gathered}
$$

Respectfully submitted,

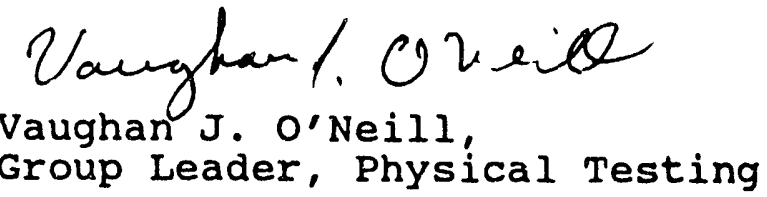




\section{ANALYTICAL REPORT}

CLIENT: Jim Stuart

Donlee Technologies, Inc. 693 N. Hills Road

York PA 17402

$\begin{array}{ll}\text { SAMPLE: } & 1019819 \\ \text { PROJECT: } & 105086 \\ \text { PO NO: } & 41259 \\ \text { REPORTED: } & 03-J U N-91 \\ \text { RECEIVED: } & 13-\mathrm{MAY}-91 \\ \text { WORK ORDER: } & \end{array}$

CLIENT SAMPLE IDENTIFICATION: SAMPLE \#2 Sinice

SAMPLE DESCRIPTION: $1650 \mathrm{~F}$

SAMPLING DATE: $0 \%$ MAY-91 BY: client

Moisture

UNITS

Loss on Ignition

Acid Insolubles

Calcium

Magnesium

sulfur

Sulfate sulfur

CHN Analysis

Carbon

Carbon Dioxide

Organic Carbon

Sulfide (as $s$ )

$\mathrm{pH}$
RESULT

12.9

65.8

8.13

0.28

1.49

1.45

12.1

3.37

11.2

395

12.83

Respectfully submitted,

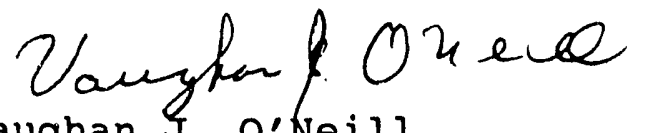

Vaughan S. O'Neill,

Group Leader, Physical Testing 


\section{ANALYTICAL REPORT}

CLIENT: Jim stuart

Donlee Technologies, Inc. 693 N. Hills Road

York PA 17402

CLIENT SAMPLE IDENTIFICATION: $1650-1.5$ TO 1 SAMPLE DESCRIPTION: Test \# 5 Siuice SAMPLING DATE: 14-MAY-91 BY: client

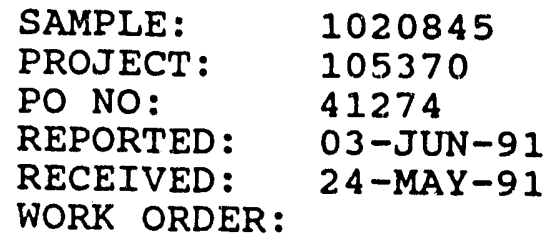

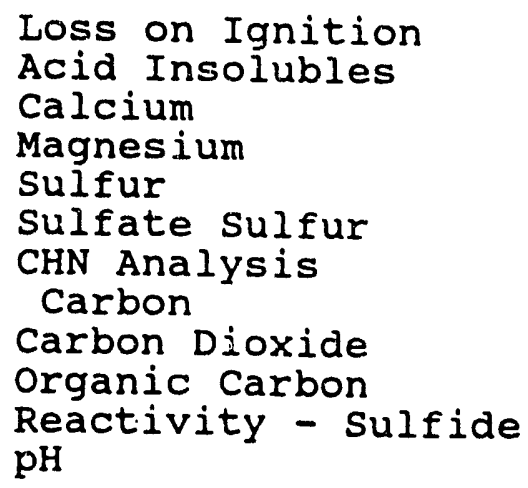

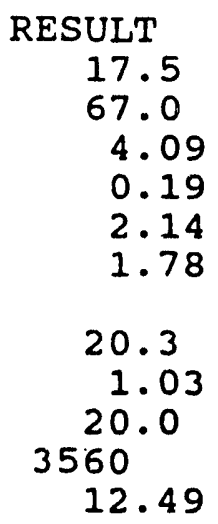

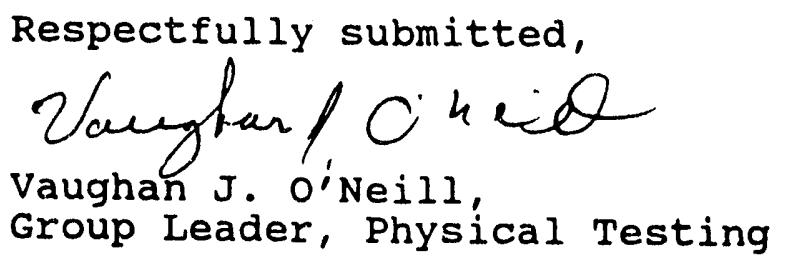




\section{ANALYTICAL REPORT}

CLIENT: Jim Stuart

Donlee Technologies, Inc.

693 N. Hills Road

York PA 17402

$\begin{array}{ll}\text { SAMPLE: } & 1020846 \\ \text { PROTECT: } & 105370 \\ \text { PO NO: } & 41274 \\ \text { REPORTED: } & 03-J U N-91 \\ \text { RECEIVED: } & 24 \text {-MAY-91 } \\ \text { WORK ORDER: } & \end{array}$

CLIENT SAMPLE IDENTIFICATION: $1650-3.5$ TO 1

SAMPLE DESCRIPTION: End Run Sample Sluice

SAMPLING DATE: 16-MAY-91 BY: Client

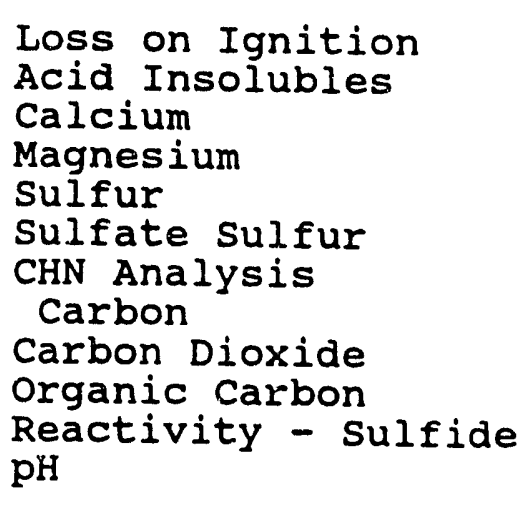

Loss on Ignition

Acid Insolubles

Magnesium

Sulfur

Sulfate sulfur

CHN Analysis

Carbon

Carbon Dioxide

Organic Carbon

$\mathrm{pH}$
RESULT

$$
\begin{gathered}
9.66 \\
60.9 \\
13.2 \\
0.49 \\
1.23 \\
1.02 \\
11.5 \\
0.90 \\
11.2 \\
227 \\
12.86
\end{gathered}
$$

227

\footnotetext{
Respectfully submitted,

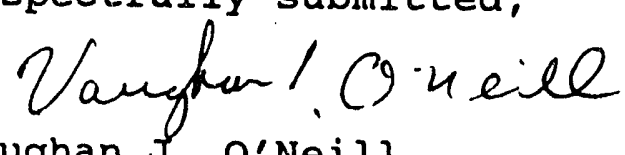

Vaughan J. O'Neill,

Group Leader, Physical Testing
}

345 North Wyomissing Blid. P.O. Box 6307 - Reading, PA 19610-0307 a 215/376.6581 - Fax: 215/376-6050) Other offices in Baltimore, Lehigh Valley and Trenton. 


\section{ANALYTICAL REPORT}

CLIENT: Jim stuart
Donlee Technologies, Inc.
693 N. Hills Road
York PA 17402

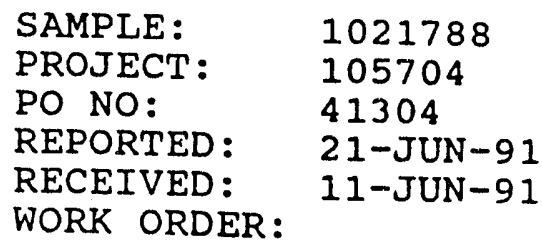

CLIENT SAMPLE IDENTIFICATION: \#1 1750 DEGREES F SAMPLE DESCRIPTION: $\quad 1 A-1 B \quad 2 A-2 B$ sincle

SAMPLING DATE: 05-JUN-91 BY: Client

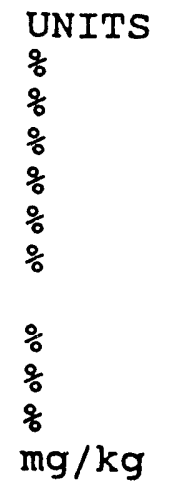

Loss on Ignition

Acid Insolubles

Calcium

Magnesium

Sulfur

Sulfate sulfur

CHN Analysis

Carbon

Carbon Dioxide

Organic Carbon

Reactivity - Sulfide

$\mathrm{pH}$

Results are reported on the as received basis.

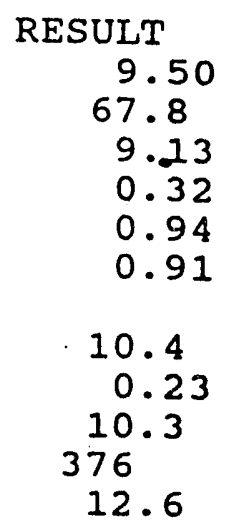

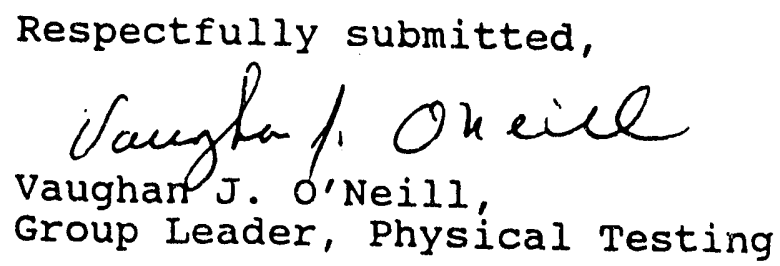




\section{ANALYTICAL REPORT}

CLIENT: Jim stuart

Donlee Technologies, Inc. 693 N. Hills Road

York PA 17402

$\begin{array}{ll}\text { SAMPLE: } & 1021789 \\ \text { PROJECT: } & 105704 \\ \text { PO NO: } & 41304 \\ \text { REPORTED: } & 21-J U N-91 \\ \text { RECEIVED: } & 11-J U N-91 \\ \text { WORK ORDER: } & \end{array}$

CLIENT SAMPLE IDENTIFICATION: FINAL 1750 DEGREES F

SAMPLE DESCRIPTION: $1 \mathrm{~A}-2 \mathrm{~A} \quad 1 \mathrm{~B}-2 \mathrm{~B}$ Sluice

SAMPLING DATE: 05-JUN-91 BY: Client

Loss on Ignition

Acid Insolubles

Calcium

Magnesium

sulfur

Sulfate sulfur

CHN Analysis

Carbon

Carbon Dioxide

Organic Carbon

Reactivity - Sulfide

$\mathrm{pH}$

Results are reported on the as received basis.

UNITS
$q$
$q$
$q$
$q$
$q$
$q$
$q$
$q$
$q$
$q$
$q$
$\mathrm{mg} / \mathrm{kg}$

RESULT

9.89

61.6

13.1

0.41

0.98

0.96

10.7

1.48

10.3

463

12.6

Respectfully submitted,
Uaugho $/ 0$ hed
Vaughan J. o'Neill,
Group Leader, Physical Testing

30 Noble Street $-\mathrm{P}$.O. B()X 6527 - Realding, PA 19611-0527 -215/376-4595 or 215/376-6581 - Fax: 215/376-8522 Engineering Offices in Baltimore, Lehigh Valley, Reading and Trenton. 


\section{ANALYTICAL REPORT}

CLIENT: Jim Stuart

Donlee Technologies, Inc. 693 N. Hills Road

York PA 17402

CLIENT SAMPLE IDENTIFICATION: \#9

SAMPLE DESCRIPTION: Ash Drained From sluice

SAMPLING DATE: 18-JUN-91 BY: Client

$\begin{array}{ll}\text { SAMPLE: } & 1023516 \\ \text { PROJECT: } & 106188 \\ \text { PO NO: } & 34026 \\ \text { REPORTED: } & 09-J U L-91 \\ \text { RECEIVED: } & 28-J U N-91 \\ \text { WORK ORDER: } & \end{array}$

SAMPLE: $\quad 1023516$

PO NO: 106188

REPORTED: 09-JUL,-91

WORK ORDER:

\section{Loss on Ignition \\ Acid Insolubles \\ Calcium \\ Magnesium \\ Sulfate sulfur \\ sulfur \\ CHN Analysis \\ Carbon \\ Carbon Dioxide \\ Organic Carbon \\ Reactivity - Sulfide \\ $\mathrm{pH}$}

Results are reported on the as received basis.
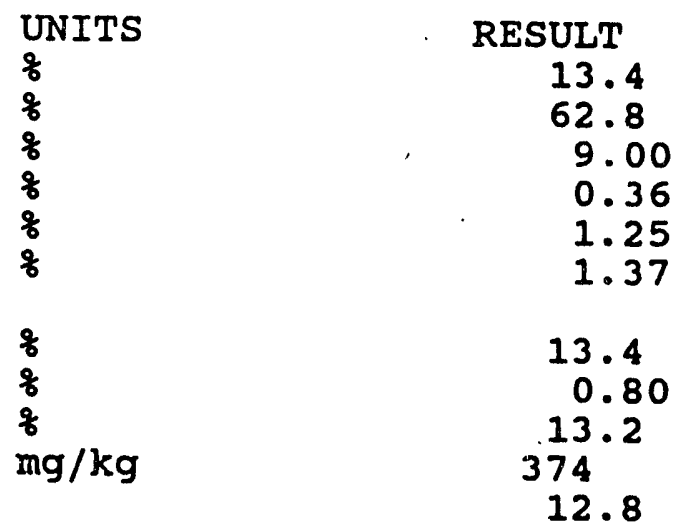

Respectfully submitted,

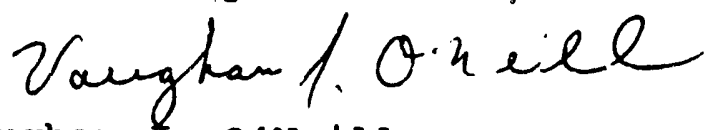

Vaughan J. O'Neill,

Group Leader, Physical Testing 


\section{ANALYTICAL REPORT}

CLIENT: Jim Stuart

Donlee Technologies, Inc. 693 N. Hills Road

York PA 17402

$\begin{array}{ll}\text { SAMPLE: } & 1023517 \\ \text { PROJECT: } & 106188 \\ \text { PO NO: } & 34026 \\ \text { REPORTED: } & 09-J U L-91 \\ \text { RECEIVED: } & 28-J U N-91 \\ \text { WORK ORDER: } & \end{array}$

CLIENT SAMPLE IDENTIFICATION: \#10

SAMPLE DESCRIPTION: Ash Drained From sluice

SAMPLING DATE: 25-JUN-91 TIME: 16:00 BY: Client

Loss on Ignition

Acid Insolubles

Calcium

Magnesium

Sulfate sulfur

Sulfur

CHN Analysis

Carbon

Carbon Dioxide

Organic Carbon

Reactivity - Sulfide

$\mathrm{pH}$

Results are reported on the as received basis.

UNITS
$\frac{q}{6}$
$\frac{q}{6}$
$\frac{q}{8}$
$\frac{q}{8}$
$\frac{q}{8}$
$q$

$\frac{q}{6}$
$\frac{q}{6}$
$\frac{q}{6}$
$\mathrm{mg} / \mathrm{kg}$

RESULT
10.3
65.9
8.66
0.36
1.11
1.18
10.2
0.77
9.99
690
12.8

Respectfully submitted,

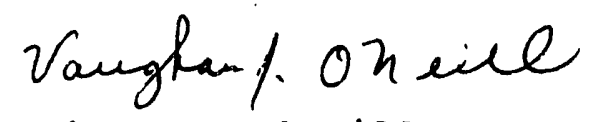

Vaughan J. O'Neill, Group Leader, Physical Testing 


\section{ANALYTICAL REPORT}

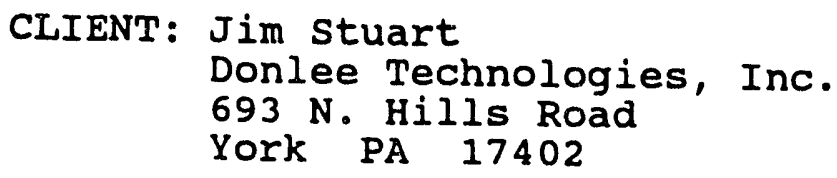

CLIENT: Jim stuart

Donlee Technologies, Inc. 693 N. Hills Road

York PA 17402

$\begin{array}{ll}\text { SAMPLE: } & 1029643 \\ \text { PROJECT: } & 107598 \\ \text { PO NO: } & 41377 \\ \text { REPORTED: } & 04-\text { SEP-91 } \\ \text { RECEIVED: } & 23 \text {-AUG-91 } \\ \text { WORK ORDER: } & \end{array}$

CLIENT SAMPLE IDENTIFICATION: TEST \#7

SAMPLE DESCRIPTION: Fly Ash Drained From Baghouse

SAMPLING DATE: 16-MAY-91 BY: client

\author{
Loss on Ignition \\ Acid Insolubles \\ Calcium \\ Magnesium \\ Sulfur \\ Sulfate sulfur \\ CHN Analysis \\ Carbon \\ Carbon Dioxide \\ Organic Carbon \\ Reactivity - sulfide \\ $\mathrm{pH}$
}

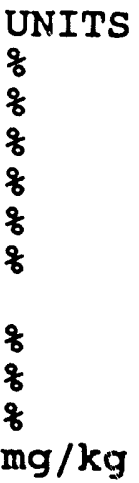

Results are reported on the as received basis.

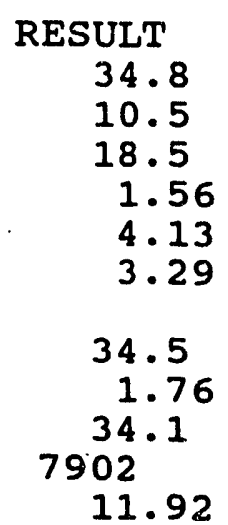

Respectfully submitted,

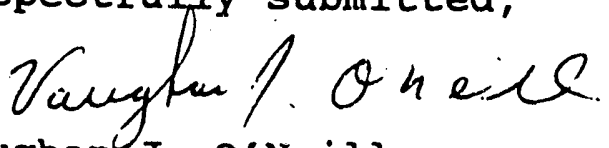

Vaughan J. O'Neill,

Group Leader, Physical Testing 


\section{ANALYTICAL REPORT}

CLIENT: Jim Stuart

Donlee Technologies, Inc. 693 N. Hills Road

York PA 17402

$\begin{array}{ll}\text { SAMPLE: } & 1029644 \\ \text { PROJECT: } & 107598 \\ \text { PO NO: } & 41377 \\ \text { REPORTED: } & 04-\text { SEP-91 } \\ \text { RECEIVED: } & 23-A U G-91 \\ \text { WORK ORDER: } & \end{array}$

SAMPLE: $\quad 1029644$

PROJECI: 107598

REPORTED: 04-SEP-91

WORK ORDER:

\section{$\mathrm{pH}$}

CLIENT SAMPLE IDENTIFICATION: TEST \#8

SAMPLE DESCRIPTION: Fly Ash Drained From Baghouse

SAMPLING DATE: 05-JUN-91 BY: client

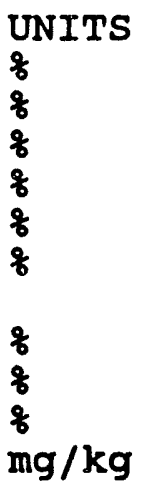

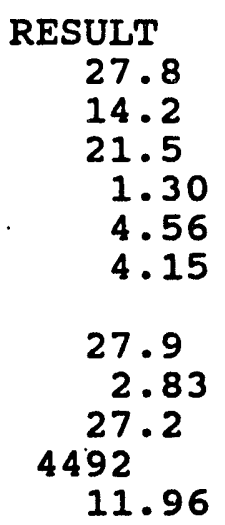

Results are reported on the as received basis.

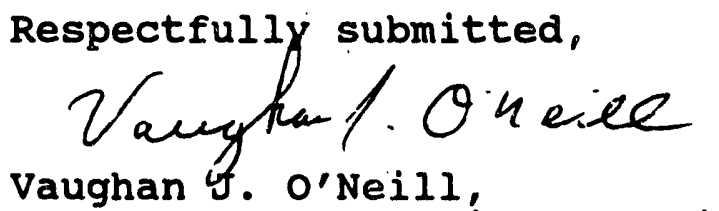

Vaughan 'f. O'Neill, Group Leader, Physical Testing 

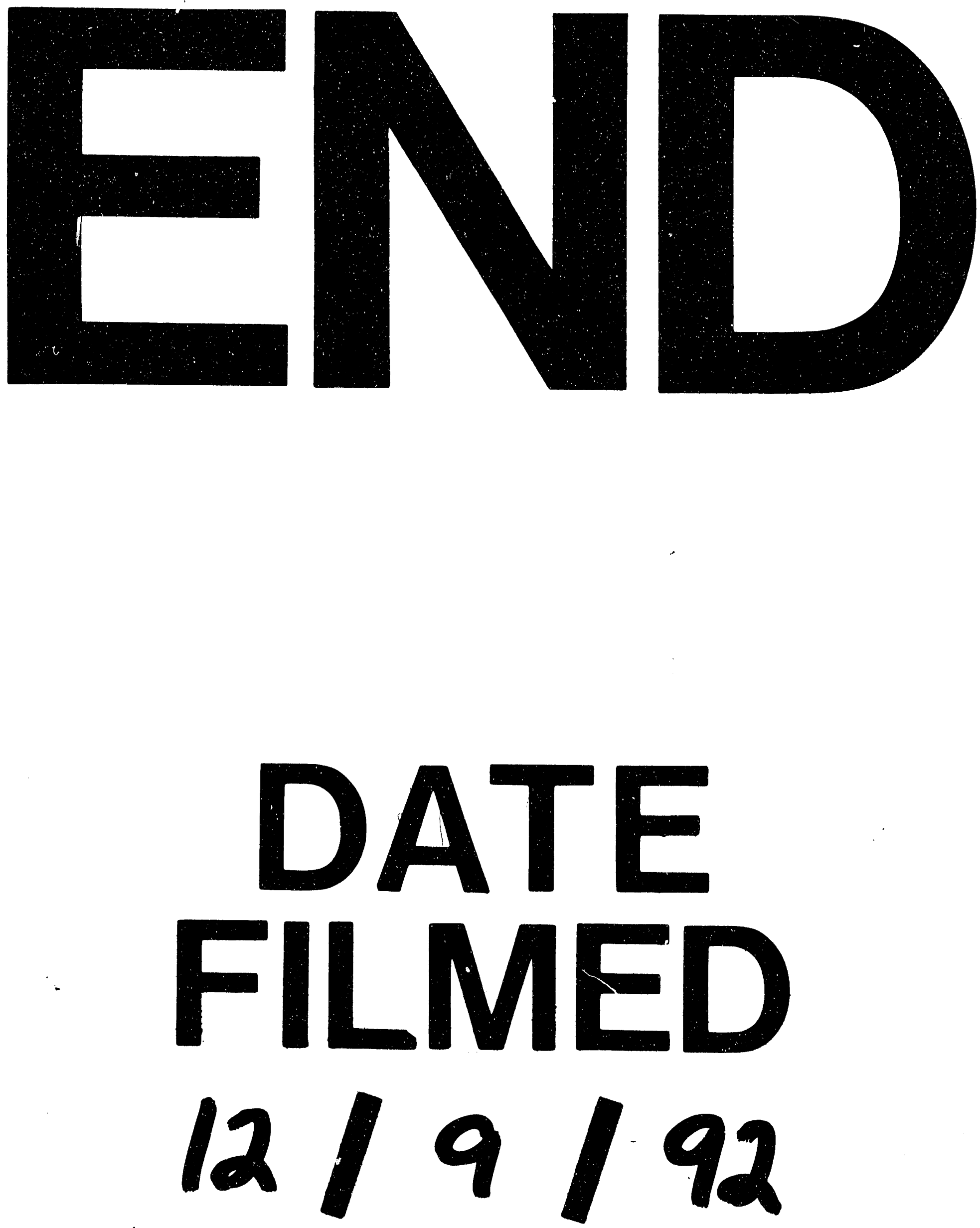
. 